UNIVERSIDAD NACIONAL DE LA PLATA

FACULTAD DE HUMANIDADES Y CIENCIAS DE LA EDUCACIÓN

MAESTRÍA EN ESCRITURA Y ALFABETIZACIÓN

\title{
ESCRIBIR, LEER y HABLAR PARA APRENDER BIOLOGÍA CELULAR
}

Diseño e implementación de una secuencia didáctica en formación docente inicial

Tesis presentada para obtener el grado de Magíster en Escritura y Alfabetización

Presenta: Patricia Iglesia

Especialista en Docencia Universitaria

Licenciada y Profesora en Ciencias Biológicas

Directora: Silvina Cordero

Doctora en Ciencias de la Educación

Co-directora: Adriana Mengascini

Especialista en Didáctica de las Ciencias Experimentales

Licenciada en Biología

Octubre 2018 


\section{A Silvina Cordero y Adriana Mengascini}

Por recibirme con calidez y comprensión cuando llegué con alguito de esta tesis a cuestas.

Por respetar mis tiempos, contener y comprender la ansiedad y angustia que me generó este proceso de escritura.

Por las tantísimas reuniones de trabajo para esta tesis, compartidas en estos años, primero en la casa de 55, después en la nueva sede del GDC de la calle 45, y en este último año cuando el tiempo apremiaba, por Skype. Gracias por leer(me) con infinita paciencia y esperarme sin perder la sonrisa, aun cuando me desesperaba por no poder avanzar lo suficiente.

A Sara Steven (la docente S) amiga, colega, compañera. Gracias por compartir sueños, aceptar el desafío de pensar, discutir y diseñar secuencias de enseñanza y permitirme "invadir" una de tus aulas del Vera.

A las y los estudiantes que fueron parte y sustancia de esta investigación, las y los verdaderas/os Abigail, Alba, Brenda, Camilo, Cristóbal, Noelia, Oscar, Vanesa y Yanina

A Mónica Astudillo, mi muy querida amiga, quien también cargó con su hermosa tesis muchos años.

Por alentarme siempre, escribiendo palabras bonitas, tanto que después de cada una de sus lecturas sentía que iba a poder terminarla y que valía la pena hacerlo. Gracias también por prestarme el ovillo de Saramago con el que empieza esta historia.

A Ana De Micheli, con quien empecé a investigar sobre el aula universitaria, hace más de veinte años.

Gracias por ser lectora estos últimos meses, por las devoluciones incisivas, que valoro y agradezco enormemente, porque me permitieron enriquecer la mirada acerca de aquello que decía o dejaba de decir en relación con la enseñanza de la Biología.

A Caro Roni, compañera de esta maestría y de la vida, con quien compartimos, intercambiamos, reflexionamos, nos alentamos y sufrimos nuestras tesis.

A Laura Colombo, Viole, que como parte de su oficio, me ayudó a encarar este año la escritura de un par de capítulos, que sentía difusos y nubosos, para así superar una de las últimas "crisis de escritura".

A quienes fueron y son parte

de la Maestría en Escritura y Alfabetización, de la Universidad Nacional de La Plata. Un espacio de formación que valoro haber encontrado y del que fui parte en la segunda cohorte. Del que me siento orgullosa, por haber aprendido en él, conviviendo con compañeras y compañeros de diferentes disciplinas y lugares. En especial, gracias por diferentes razones a Mirta Castedo, Inés Sancha, María Regina Usandizaga, Gabriela Hoz, Eugenia Heredia.

Y por último va mi agradecimiento más importante, a mis afectos más cercanos e íntimos, que son quienes me sostienen. Y hace tantísimos años vienen escuchando acerca de "la tesis", aunque no quede muy claro de qué se trata y porqué está conmigo hace tanto tiempo.

A Alfre, mi compañero, que estos últimos años convivió con mi lucha con "ella". A Mati, Mariela, Nico, Juli, Guido, Pato, Ceci y Pablo, que sé que están ahí para lo que sea. Y a los más peques, Franco, Dante, Milo y Julia, que llegaron en los últimos años y mantuvieron vigente todo el tiempo (a pesar de la tesis) mis ganas de contar cuentos, jugar, cantar y bailar. 
Índice

INTRODUCCION

CAPÍTULO 1 - Acerca de los referentes teóricos y antecedentes que fundamentan este estudio 8

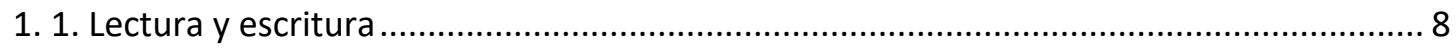

1.1.1. Leer y escribir en el nivel superior como prácticas sociales situadas .......................... 8

1.1.2. Investigaciones que abordan leer y escribir para aprender en Argentina .................. 16

1.1.3. Leer y escribir para aprender Biología como práctica propia de docencia e

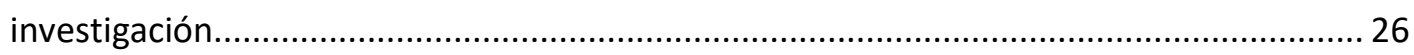

1.2. La Biología como una Ciencia Natural, y su enseñanza .................................................. 29

1.2.1. El contenido disciplinar desde una perspectiva sistémica y compleja...................... 29

1.2.2. Enseñar y aprender Biología a través del leer y escribir .......................................... 32

1.2.3. Investigaciones basadas en diseño e implementación de secuencias didácticas en la

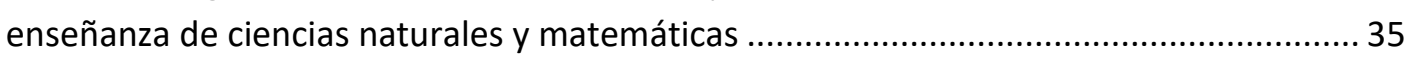

1.3. Análisis de las prácticas didácticas. Teoría de la acción didáctica conjunta ..................... 40

1.4. Enseñar y aprender contenidos situados y complejos, a través del leer y escribir en un aula de formación docente inicial

CAPÍTULO 2 - Acerca de decisiones metodológicas durante el proceso de investigación: configurando el problema, los interrogantes y las estrategias

2.1. Algunos supuestos y decisiones preliminares. Acerca del diseño didáctico, su implementación y el trabajo colaborativo

2.1.1. Acerca de la perspectiva metodológica 53

2.2. Definición del problema, ajuste de preguntas y objetivos de investigación 55

2. 3. Contexto de intervención didáctica. Decisiones metodológicas acerca de dónde y cuándo situar el problema

2.3.1. El devenir del contexto de intervención. Decisiones para reajustar dónde y cuándo situar el problema

2.4. Decisiones metodológicas en torno a la secuencia didáctica seleccionada 62

2.5. Decisiones para enfocar el análisis del desarrollo de la secuencia didáctica 63

2.6. Estrategias de recolección y organización de datos para el análisis................................ 65

2.6.1. Observación, registro y transcripción de clases ......................................................... 65

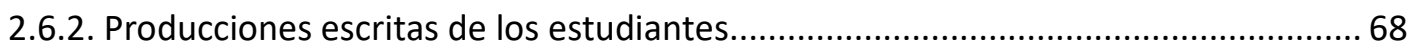

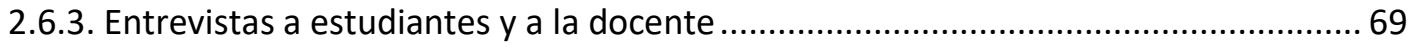

2.7. Estrategias utilizadas para el análisis de datos ................................................................ 70

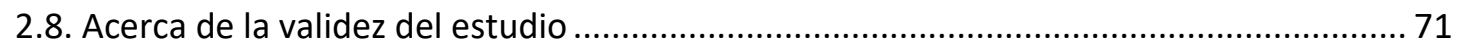

CAPÍTULO 3 - Acerca de la secuencia didáctica sobre ciclo celular: situaciones de enseñanza e intervenciones docentes 
3.1. Presentación de la secuencia de enseñanza implementada 72

3.2. Desarrollo de la secuencia didáctica en el aula.................................................. 73

3.3. Las situaciones de escritura en la secuencia didáctica implementada ........................ 88

3.4. Las situaciones de lectura en la secuencia didáctica implementada ........................... 91

3.5. Las situaciones de diálogo en la secuencia didáctica implementada .......................... 93

3.6. El lugar de las intervenciones docentes en el diseño didáctico .................................. 95

3.7. La propuesta de enseñanza desde la perspectiva de los estudiantes ........................... 96

CAPÍTULO 4 - Escribir y leer para reflexionar sobre el ciclo celular ....................................... 101

4.1. Propuesta inicial de escritura y contexto de producción.......................................... 103

4.1.1. ¿Qué dicen los escritos? Análisis de las producciones....................................... 106

4.2. Propuesta de lectura en pequeño grupo ......................................................... 112

4.3. Interacción en el aula en torno a las tareas de escritura y lectura. Intervención docente y constitución del medio didáctico ................................................................ 114

4.3.1. ¿Qué sucedió durante la tarea de escritura inicial? .......................................... 115

4.3.2. ¿Qué sucedió durante la tarea de lectura? Interacción en el pequeño grupo: Vanesa, Abigail y Alba 120

4.3.3. ¿Qué sucedió al hablar acerca de lo que se leyó? Interacción en el grupo clase con coordinación docente

4.3.4. Las intervenciones orales de la profesora: categorías elaboradas en este estudio 140

4.4. Las situaciones de escritura desde la perspectiva de los estudiantes ......................... 154

4.5. Recapitulación y relación con preguntas de investigación ........................................ 158

CAPÍTULO 5 - Escribir y revisar cooperativamente lo escrito........................................... 163

5.1. Propuesta de escritura en clase y contexto de producción ...................................... 165

5.1 .1 ¿Qué dicen los escritos? Análisis de las producciones...................................... 167

5.2. Propuesta de revisión cooperativa de lo escrito .................................................. 170

5.3. Interacciones en el aula en torno a la tarea de escritura y lectura. Intervenciones docentes y constitución del medio didáctico.......................................................... 173

5.3.1 Comentar acerca de lo escrito ................................................................... 173

5.3.2. Leer y revisar lo escrito en plenario ......................................................... 177

5.4. La situación de enseñanza desde la perspectiva de estudiantes y docente ................ 211

5.4.1. ¿Qué dijeron los estudiantes? ............................................................. 211

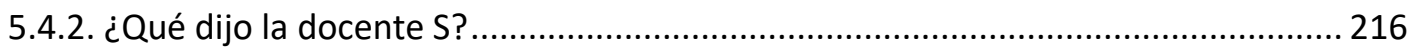

5.5. Recapitulación y relación con preguntas de investigación ...................................... 217



6.1. Acerca de las prácticas de enseñanza como prácticas sociales, cooperativas .............. 222 
6.2. Acerca de la recapitulación de resultados.

6.3. Acerca de tensiones, aportes y nuevas preguntas......................................................... 230

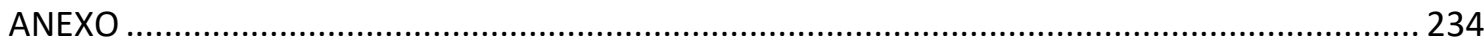

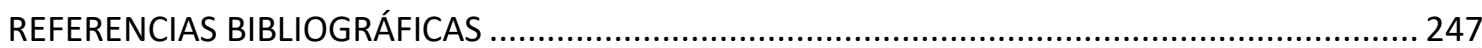




\section{INTRODUCCION}

Empezar por el principio, como si ese principio fuese la punta siempre visible de un hilo mal enrollado del que basta tirar y seguir tirando para llegar a la otra punta, la del final, y como si, entre la primera y la segunda, hubiésemos tenido en las manos un hilo liso y continuo del que no ha sido preciso deshacer nudos ni desenredar marañas, cosa imposible en la vida de los ovillos

$$
\text { José Saramago (La caverna) }
$$

Ese principio al que alude Saramago, para este trabajo de investigación, fue pensar cómo abordar el análisis de prácticas de lectura y escritura puestas en relación con la enseñanza de contenidos disciplinares. El hilo del que tiramos, nunca fue liso y muchas veces se ocultó a nuestra mirada, algunas lentes nos permitieron descubrirlo al trasluz, enfocarlo un poco más, por momentos atraparlo y sostenerlo, para seguir tirando y mantenerlo fuera de la maraña que intentaba ser ovillo. En esas ocasiones creímos que pronto llegaríamos a la otra punta del hilo, a ese final. Sin embargo, al seguir avanzando surgieron nuevos nudos que tuvimos que desenrollar y aun a veces, cortar el hilo para recuperarlo (y recuperarnos) y poder continuar. $Y$ para que a través del proceso de desenrollar/desarrollar fuéramos entendiendo algo más acerca de lo que sucedía en esa maraña que constituye la esencia de la vida de los ovillos.

Aun cuando la introducción se presenta al inicio de este trabajo, fue escrita al finalizar la investigación con el propósito de contar a las y los lectores ${ }^{1}$ de qué trata esta tesis. $Y$ quizás por ello compartir la metáfora del hilo y el ovillo nos permite poner esta parte del escrito en clave de rememoración.

En consonancia con la reflexión inicial que mencionamos, el trabajo de investigación encarado para esta tesis se centró en el diseño y desarrollo de una secuencia didáctica que integró diversas prácticas de lectura, escritura y oralidad a la enseñanza de ciertos contenidos de Biología celular en un aula de formación inicial de profesores.

Al abordar ese objeto de análisis nos preguntamos por las características que adquirieron en ese marco las situaciones de escritura, lectura y oralidad que constituían esa secuencia. A la vez, nos interesó relevar las intervenciones docentes durante esas situaciones para comprender aquello que se generaba durante la interacción en relación al conocimiento en juego. Esa puesta en foco de la interacción didáctica entre docente, estudiantes y conocimiento en juego durante las situaciones, nos permitió identificar algunas condiciones de enseñanza que potenciaron procesos de aprendizaje. Al mismo tiempo ese foco permitió que emergieran algunos indicios que dieron cuenta de

\footnotetext{
${ }^{1}$ En este escrito hemos optado por el uso genérico del masculino, sólo de manera tal de evitar redundancias al reiterar femenino y masculino para referir al colectivo integrado por personas de distintos géneros. Esta decisión es al único efecto de no interferir en la lectura y no connota preferencias de uso.
} 
desafíos, resistencias y logros en relación con el trabajo desarrollado durante la implementación de la secuencia de enseñanza.

La organización de la clase que propusimos y que llevó adelante la docente alternó diferentes modalidades de trabajo, distribuyendo los roles para que los estudiantes tomaran la responsabilidad como lectores y escritores promoviendo gradualmente la autonomía. Este proceso fue una condición didáctica que nos propusimos atender al diseñar las secuencias, ya que consideramos que la tensión entre la relevancia dada al trabajo colectivo y el individual favorecería "articular el aprendizaje cooperativo y el trabajo personal de cada alumno, como condiciones que hacen posible coordinar la construcción social del conocimiento y la responsabilidad individual' (Lerner, 2002: 5).

Habiendo enunciado los principales aspectos del problema abordado en esta tesis explicitamos ahora la manera en que hemos organizado la presentación de nuestro trabajo, estructurado en seis capítulos.

En el primer capítulo desplegamos los referentes teóricos y antecedentes que enmarcan y contextualizan nuestra indagación. Comenzamos presentando la perspectiva teórica y epistemológica en la que nos inscribimos al concebir la lectura y la escritura como prácticas sociales situadas. Para después retomar aportes de la Didáctica de la Biología y delinear cómo concebimos el objeto de enseñanza, dado que será en el marco de constituir ciertos objetos disciplinares que adquirirán relevancia determinadas prácticas de lectura y escritura. Finalmente referimos a las investigaciones acerca del diseño de secuencias didácticas y vinculamos nuestro trabajo con algunos aspectos de esas líneas de investigación, así como establecimos diferencias en otros. En la tercera parte de este capítulo nos dedicamos a presentar aquellos componentes de la Teoría de la acción didáctica conjunta (Sensevy, 2012) cuyos aportes fueron fundamentales para el análisis de las prácticas de enseñanza en nuestro trabajo de investigación. Para finalizar situamos la indagación en la formación inicial de profesores, con la intención de delinear algunos de los matices que adquieren las prácticas de enseñanza en ese contexto.

En el segundo capítulo describimos y fundamentamos las decisiones metodológicas que asumimos durante el proceso, así como las estrategias empleadas para recoger información, analizar e interpretar los datos. En él presentamos el problema, las preguntas y objetivos de investigación, así como damos cuenta del contexto en el que se ubica el estudio y los recortes y ajustes sucesivos que realizamos.

El tercer capítulo está dedicado a la descripción de la secuencia didáctica efectivamente implementada, en él relatamos y pusimos en contexto los sucesos de cada clase. Para 
después caracterizar la diversidad de tareas de escritura, de lectura e instancias de diálogo que constituyeron la secuencia creada e implementada en nuestra investigación En los capítulos cuatro y cinco presentamos los principales resultados de este estudio, donde profundizamos el análisis de dos series de situaciones de escritura, lectura y diálogo que sucedieron en instancias claves de la secuencia. En ellos analizamos la interacción didáctica en el aula, así como sistematizamos y categorizamos las intervenciones de la docente durante esa interacción. Describimos minuciosamente las secuencias de interacción para dar cuenta de la dualidad entre reticencia y expresión docente, así como el vínculo entre certezas/incertezas de los estudiantes. En cada uno de estos capítulos incluimos aportes desde la perspectiva de los estudiantes y en el último, también de la docente. Los cerramos con una recapitulación y presentación de discusión y conclusiones parciales, al poner en relación las preguntas de investigación con el análisis realizado en cada uno de ellos.

En el último capítulo, el seis, recogemos las principales conclusiones de nuestro estudio y puntualizamos aquellos aportes que consideramos más destacables, en el marco de las potencialidades y limitaciones de los resultados obtenidos. Finalmente, en el Anexo, los lectores encontrarán las consignas escritas de todas las actividades de la secuencia didáctica que entregamos a los estudiantes en papel y la guía que se envió por mail para acompañar la lectura de bibliografía.

Al cerrar esta introducción dejamos tendidas algunas puntas del ovillo para invitar a quienes quieran elegir alguna de ellas y seguir ese hilo, ya como lectores de la trama del texto ${ }^{2}$. De este texto/tejido que finalmente escribimos/tejimos a partir del ovillo que surgió de la maraña de hilos.

\footnotetext{
2 Texo, texui, textum: tejer. "Es esclarecedor que el concepto texto tenga el mismo origen que el griego techné y el sánscrito Taksati: un tejido rico y ordenado con sentido." W.Klein (1992) "Einleitung zur Zeitschrift für Literaturwissenschaft und Linguistik 86 - Textlinguistik (Introducción a Revista de Literatura y Linguística 86 - Linguística del texto)
} 


\section{CAPÍTULO 1}

Acerca de los referentes teóricos y antecedentes que fundamentan este estudio

\section{Introducción}

En este capítulo inicial damos cuenta de referentes teóricos y antecedentes que provienen de distintos campos disciplinares y enmarcan esta investigación. Nuestro objeto de estudio refiere al desarrollo de una secuencia didáctica que incluye situaciones de enseñanza que integran escribir y leer para aprender Biología Celular en un aula de formación docente inicial. Es por ello que los referentes teóricos que retomamos aquí provienen de diferentes vertientes, interactúan, conviven y en parte se amalgaman en esta tesis de maestría.

En primer lugar (en 1.1) presentamos referentes vinculados con la lectura y escritura, poniendo énfasis en su definición como prácticas sociales situadas. Nos detuvimos así en investigaciones desarrolladas en el nivel superior de enseñanza para compartir diagnósticos que aportaron información como insumo para nuestro trabajo. Pusimos en foco trabajos que desarrollaron otros grupos de investigación de nuestro país para vincularlos así con la investigación que llevamos a cabo para esta tesis. A la vez, retomamos indagaciones previas propias en el contexto de nivel superior para presentar la trama de sentido que dio lugar al trabajo de investigación desarrollado para esta tesis.

En el apartado 1.2, incluimos referentes del campo de la didáctica de la Biología, que también constituye un espacio amplio y diverso. Enfocamos nuestra presentación en aquellos aspectos que tuvieron relevancia para el diseño e implementación de la secuencia. Uno de ellos es la perspectiva asumida respecto del contenido disciplinar en tanto objeto de enseñanza, para vincular esa perspectiva con la escritura y lectura, dado que es en relación con ciertos objetos de enseñanza que ciertas prácticas son pertinentes. Por último, en este apartado describimos investigaciones de diseño e implementación de secuencias didácticas, para contrastar diferentes enfoques y compartir aquello que retomamos de esta línea de investigación didáctica.

En tercer término, en 1.3, presentamos la perspectiva teórica desde la que analizamos el desarrollo de la secuencia didáctica, enunciando los supuestos y potencialidades de la Teoría de acción didáctica conjunta (JATD). En el último apartado (1.4), situamos los referentes previos en el contexto de la formación docente inicial.

\section{1. Lectura y escritura}

\subsubsection{Leer y escribir en el nivel superior como prácticas sociales situadas}


Desde la perspectiva teórica asumida, leer y escribir son prácticas sociales situadas, constituyen así modos de actuar delineados por la cultura que difieren de un contexto a otro (Ivanic, 1998, Street, 1995). Es en ese sentido que presentan particularidades al interior de una disciplina y componen ese espacio conceptual, retórico y discursivo (Bogel y Hjortshoj, 1984).

Asumir la lectura y la escritura en tanto prácticas implica considerar que no se aprenden de manera declarativa, sólo indicando pautas y pasos a seguir, sino que es necesario que los estudiantes las puedan ejercer para lograr autonomía al leer y escribir. Para aprender las materias -concebidas como espacios para la enseñanza de una disciplinase requiere poder comprender y producir los discursos que las caracterizan y para ello resulta necesario que los estudiantes tengan oportunidades de realizar actividades de producción escrita y lectura de bibliografía propias de cada asignatura, con orientación de los docentes (Carlino, 2005, 2013). Para constituir en objeto de enseñanza esas prácticas será imprescindible concederles un lugar relevante en las clases, de manera tal de enseñar quehaceres de lector y escritor en términos de Delia Lerner (2001).

Los quehaceres de lector a los que referimos en esta investigación implicaron interacciones con otros lectores (pares y docente) acerca de qué expresaban los textos y cómo lo hacían. En términos de constituirse en lectores los estudiantes contrastaron interpretaciones, argumentaron para sostener la propia y/o ajustarla al confrontar con las versiones de los compañeros.

En cuanto a los quehaceres de escritor, para Lerner (2001) resulta central que la escritura no se reduzca a ser objeto de evaluación a lo largo de la escolaridad, sino que pueda constituirse en un objeto de enseñanza. En este mismo sentido, Carlino (2005) se ha referido a las prácticas de escritura de nivel superior promoviendo su utilización como instrumento de reflexión y organización del pensamiento, dado que al escribir se concentra la atención en ciertas ideas y ello estimula una revisión crítica del propio saber. El uso de la escritura en el aprendizaje se vincula con el contexto en el cual se realiza la producción escrita; esto significa que las concepciones de escritura y aprendizaje y los factores asociados a ese contexto son relevantes, dado que configuran el enfoque con que los estudiantes abordan las tareas de escritura y las estrategias que despliegan para elaborar el texto escrito (Vázquez y Jakob, 2007). Así, no es posible concebir la escritura, en tanto instrumento de elaboración y construcción de ideas, de manera independiente del tipo de prácticas que se plantean. En nuestra investigación asumimos estas premisas al proponer a los estudiantes ciertas tareas de escritura, con la intención de promover una ida y vuelta recursiva y reflexiva entre escritura y pensamiento. La escritura presupone un otro como destinatario, por ello implica una 
objetivación y será esa externalidad lo que tiene la posibilidad de estructurar el pensamiento y devolverlo modificado. Será en esas instancias que la escritura puede adquirir función epistémica (Bazerman, 2009; Bazerman, Little, Bethel, Chavkin, Fouquette y Garufis, 2005; 2016; Carter, Miller y Penrose, 1998; Langer y Applebee, 1987).

Entender la lectura y la escritura como prácticas sociales situadas también supone poner énfasis en los propósitos que las orientan en las distintas situaciones (Bazerman y Prior, 2004). Al reconocer las relaciones que lectores y escritores establecen respecto a los textos y asumir que no siempre se lee y escribe de la misma forma, lo situado adquiere relevancia. Esas prácticas no son transferibles directamente desde un dominio de conocimiento a otro, y más allá de algunos aspectos generalizables, como por ejemplo ortografía y gramática, es necesario enseñarlas en cada contexto disciplinar para poder aprender su especificidad (Gottschalk y Hjortshoj, 2004). Es por ello que las maneras de leer y escribir pertinentes para un determinado ámbito precisan ser reconstruidas a través de un nuevo aprendizaje para que puedan ser utilizadas en cada entorno disciplinar específico (Tynjala, Mason y Lonka, 2001).

De acuerdo con esta línea conceptual, nuestro trabajo se centró en el leer y escribir en una asignatura específica. El foco de esta investigación fue comprender cómo, a través de la lectura y la escritura se podía enseñar contenidos de una disciplina, en este caso Biología Celular. Para aprender esos contenidos era necesario conocer y relacionar estructuras y procesos biológicos, así como también comprender las formas de mirar y actuar sobre el mundo natural propias de esa disciplina (Sanmartí, 2001). Al trabajar con futuros docentes de Biología nos interesó que los estudiantes pudieran transformarse en integrantes de una comunidad disciplinar, y que así pudieran apropiarse de su manera particular de mirar el mundo. En este sentido, consideramos que era necesario favorecer la comprensión de los discursos que caracterizan a la disciplina y a los textos que circulan entre lectores que comparten una determinada manera de leer y entender un corpus de textos, una comunidad textual en términos de Olson, (1998). La noción de comunidad textual es potente para entender que existen diferentes modos de leer y comprender los escritos, modos que forman parte de diversas culturas lectoras. La asignatura Biología Celular, en la que desarrollamos la secuencia didáctica objeto de esta tesis, es un espacio de formación en una institución de nivel superior de enseñanza, y al inscribirse como parte de una carrera de formación de profesores de Biología para enseñanza en el nivel medio, configuraría una comunidad textual particular.

Nos interesó centrar nuestro estudio en las prácticas de lectura y escritura del nivel superior, por ser el nivel de enseñanza en el que siempre hemos trabajado e 
investigado. Leer y escribir en ese nivel contribuye al aprendizaje de una materia, pero a la vez pueden surgir obstáculos al abordar esas prácticas. Esas dificultades que habitualmente encuentran los estudiantes al enfrentar prácticas de lectura y escritura académicas han sido relevadas a través de investigaciones realizadas en diversos contextos, tanto internacionales (Chanock, 2001; 2004; Lillis 1999; Russell, 2013; Solé y Castells, 2004; Thaiss y Porter, 2010; entre otros trabajos que abordan la cuestión), como nacionales (Arnoux, Alvarado, Balmayor, Di Stefano, Pereira, y Silvestri, 1996; Arnoux,, Silvestri, y Nogueira, 2002; Carlino, 2005, 2008; Di Stéfano y Pereira, 2004; García Romano, Padilla y Valeiras, 2012; Jakob, Bono, Vélez, Boatto, Luján y Rainero, 2014; Padilla, 2004, 2008; Pereira y Di Stéfano, 2003, entre otros).

En este nivel educativo es frecuente exigirles a los estudiantes que afronten de manera autónoma la lectura de bibliografía y que produzcan escritos teniendo en cuenta ciertas convenciones que corresponden a cada campo disciplinar específico. Esas convenciones habitualmente están naturalizadas en las instituciones de nivel superior, por ello permanecen implícitas y no suelen enseñarse, transformándose en lo que Lillis (1999) denominó práctica institucional del misterio. La autora refiere así a ciertos saberes prácticos que se constituyen en algo de sentido común para aquellos integrantes del campo académico, pero que resultan inaccesibles y misteriosos para los estudiantes menos familiarizados con esas prácticas. La capacidad de usar de manera pertinente el lenguaje en este nivel educativo se suele asumir como algo generalizable, transparente y que depende de las aptitudes o la dedicación individual del estudiante. En este mismo sentido, la escritura es concebida como una tarea individual, aprendida (o no) en niveles educativos previos, o en cursos específicos de composición por fuera de una matriz disciplinar (Russell, 1990).

El movimiento escribir a través del currículum (Writing across the curriculum WAC), cuyo comienzo se remonta a la década de los 70 , aboga por un sostén institucional además de un apoyo sistemático para incrementar la cantidad y calidad de la escritura que se realiza en las clases de diferentes materias, en especial de nivel universitario (Bazerman et al, 2005, 2016; Russell, 1994; Russell, Lea, Parker, Street y Donahue, 2009). Un aspecto esencial de esta corriente es considerar el escribir como una manera de aprender y así la escritura puede ser una tarea abordada por todos los docentes en vez de estar sólo a cargo de profesores de Lengua (Russell, 1990). Es por ello que se organizan espacios institucionales en los que se acompaña la escritura que se lleva a cabo en asignaturas específicas.

Desde este enfoque se han desarrollado numerosas intervenciones que implicaron un trabajo sistemático acompañando la lectura y escritura de los estudiantes en asignaturas 
específicas. Una serie de estudios atendió a la experiencia y desempeño de los alumnos involucrados en situaciones de escritura en las asignaturas. Como por ejemplo, la investigación realizada por Haas (1994), que siguió durante cuatro años de estudios hasta su graduación a una alumna de biología. Haas documentó que la estudiante desarrolló formas de leer más complejas y sofisticadas a medida que se iba familiarizando con el campo disciplinar, esta manera de leer influyó a la vez en su forma de escribir y le permitió no sólo aprender contenidos disciplinares sino entender con mayor facilidad la Biología al considerar los aspectos retóricos de los textos, comprendiendo cómo los autores argumentan su posición desde contextos históricos e intertextuales. Así también, desde esta corriente se realizaron investigaciones en las que se analizaron los cambios y compromisos que asumieron los docentes que incorporaron la escritura a la enseñanza de sus asignaturas dentro de estos ambientes institucionales (Bazerman et al, 2005; 2016).

Por su parte, la corriente escribir para aprender (Writing to learn, WTL) estrechamente relacionada con escribir a través del currículum, se basa en la consideración de que las maneras de pensar y comprender de los estudiantes pueden clarificarse y potenciarse a través de ciertas tareas de escritura. De acuerdo con ese principio se desarrollaron propuestas que pusieron foco en el proceso de escritura como una herramienta para favorecer el pensamiento y el aprendizaje en diversos dominios de conocimiento (Applebee, 1984; Emig 1977; Nelson, 2001; Newell 1984). Dentro de esta línea, Langer y Applebee (1987) analizaron el efecto de diferentes tareas de escritura en distintas actividades de aprendizaje y concluyeron que las situaciones en las que se escribían las respuestas a una actividad promovieron un mejor desempeño de los alumnos en las tareas de aprendizaje, que aquéllas en las que sólo se leía. Sin embargo, esos beneficios no eran generalizables a otros contextos o actividades. Así también, encontraron que las distintas tareas de escritura promovieron diferente tipo de aprendizaje. En este mismo sentido, diversas investigaciones han mostrado que las actividades que demandaban escritura favorecieron aprender contenidos en dominios específicos, por ejemplo Ciencias Naturales (Tynjala, Mason y Lonka, 2001).

Bazerman (2009) retomó algunos estudios que vinculaban escritura y aprendizaje, los describió y analizó, y a partir de ellos propuso que el trabajo cognitivo realizado durante la escritura estaba estrechamente vinculado con las situaciones en las que se desarrollaba, como así también con los géneros y sistemas de actividad en los que la escritura estaba teniendo lugar. En el trabajo mencionado Bazerman propuso que los géneros podían ser pensados como herramientas cognitivas en términos de Vygotski y así podrían influir en el aprendizaje. Por ello consideró que era relevante explicitar las 
convenciones de los géneros al orientar a los estudiantes durante experiencias de aprendizaje en las que se incluyera el trabajo con el leer y escribir. Así, la enseñanza que hiciera consciente las características de la lectura y la escritura que se demandaba en cada espacio disciplinar podría ayudar a los estudiantes a otorgar sentido a las formas científicas de pensar acerca del mundo. A su vez, en otro trabajo, Nelson (2001) sostuvo que, cuando propusieron tareas de escritura para ser realizadas a partir de la lectura de textos disciplinares, los estudiantes ganaron autonomía sobre esos textos y aumentaron su conocimiento. De esta manera pudieron hacer sus propias contribuciones durante los intercambios en clase acerca de lo leído. Esto también fue posible porque cuando solicitaron esas tareas de escritura los docentes autorizaron a los alumnos a hacer sus propias aseveraciones sobre el tema y eso dio oportunidades, no sólo para escribir, sino también para hablar con los pares acerca de lo escrito.

Por su parte, Kelly y Bazerman (2003) desarrollaron un trabajo de investigación con estudiantes universitarios de una asignatura de Ciencias Naturales (Oceanografía). Estos alumnos trabajaron en clase con argumentación científica y se les solicitó que escribieran un artículo utilizando diversos datos provenientes de diferentes fuentes. Se analizaron las producciones y en particular cómo los estudiantes relacionaron datos para construir evidencias que fundamentaran aspectos teóricos de cierto problema. Los resultados de esta investigación demostraron la necesidad de explicitar las convenciones que demandan los géneros (en este caso la argumentación científica), para así enseñarlos en el contexto de las materias, y favorecer que los estudiantes se apropiaran de las maneras científicas de pensar acerca del mundo y asignar sentido a los hechos. Kelly, Regev y Prothero (2008) realizaron una investigación en la que diseñaron situaciones de enseñanza que proporcionaban oportunidades para el desarrollo y la práctica de argumentación en temas sociocientíficos. En el trabajo, realizado de manera conjunta entre el investigador y el profesor a cargo de una asignatura del primer año de la carrera de Oceanografía, se documentaron las estrategias retóricas y epistémicas que los estudiantes pudieron utilizar satisfactoriamente para desarrollar argumentos basados en evidencias. Los resultados indicaron la importancia que adquirió el diseño de tareas que integraban la enseñanza de la argumentación escrita, que así se constituyó en una práctica que permitió que los estudiantes se aproximaran a determinadas maneras científicas de relacionar datos y evidencias, un aspecto relevante en la enseñanza de las Ciencias Naturales.

La corriente escribir en las disciplinas (Writing in the disciplines: WID) establece cómo las diversas disciplinas construyen conocimiento a través de sus diferentes formas textuales (Bazerman, 1988). Así como también cuáles son los tipos de desafíos que 
encuentran los estudiantes que ingresan a estos espacios disciplinares y deben aprender a escribir de la manera requerida en ese campo (Bazerman et al 2005; 2016). Aun cuando en esta investigación no nos centramos en las maneras particulares en las que los científicos escriben, consideramos pertinente incluir esta corriente dado que en las secuencias didácticas diseñadas ${ }^{3}$ incorporamos textos que refieren a situaciones y escritos propios del campo disciplinar.

En esta línea Dysthe (1996) investigó en aulas de escuelas de Noruega y Estados Unidos cómo la interacción entre escritura y oralidad influyó sobre el aprendizaje. La autora describió dos modalidades de prácticas docentes, la enseñanza monológica y dialógica, y proporcionó ejemplos de cómo la interacción acerca de lo escrito a partir de preguntas abiertas, sin respuestas prefijadas, pudo promover la participación de los estudiantes al incluir en el diálogo múltiples voces. Los resultados del estudio dieron muestras de que la enseñanza dialógica proporcionó mayores oportunidades para el aprendizaje que sólo hablar o escribir de manera individual. En este sentido, valorizó a los estudiantes como pensadores y a sus producciones como verdaderos dispositivos que promovieron el pensamiento al propiciar la interacción múltiple entre discurso oral y escrito.

En otro estudio realizado con estudiantes de nivel superior, Dysthe (2000) mostró cómo el trabajo sistemático con la escritura que realizó una profesora logró establecer una comunidad de aprendizaje cooperativo en la que se potenció el aprendizaje de todos los estudiantes del curso y no sólo de aquellos que eran mejores escritores y discutidores. Las secuencias de enseñanza incluyeron situaciones en las que los estudiantes leyeron para escribir y esa escritura funcionó como soporte para después hablar acerca de lo escrito. Así hubo instancias de trabajo de escritura individual y otras en las que esos escritos se ponían en común en pequeños grupos de discusión para finalmente interactuar en grupo clase a través de lo que se había leído y escrito. La autora refirió que la noción bakhtiniana de "cómo la comprensión y el significado se crean a través del diálogo" proporcionó una base teórica para desarrollar aulas con multivocidad (Dysthe, 1996, 2000), en las que escribir y hablar de los contenidos de la asignatura resultaron elementos claves.

La multivocidad a la que refiere Dysthe (1996) es otro aspecto de la dialogicidad que pone énfasis en la contribución de diferentes voces -su coexistencia y no una mera yuxtaposición- al tópico que se está tratando. No implica que cada estudiante diga qué

\footnotetext{
${ }^{3}$ Nos referimos tanto a la secuencia didáctica implementada en 2012 y analizada en profundidad como a las dos secuencias diseñadas e implementadas el año 2011 y que fueron consideradas como parte del contexto previo que enmarca el presente trabajo.
} 
sería lo que quiso decir, sino que es la tensión que surge entre las diferentes voces, puntos de vista y perspectivas, aquello que aporta a pensar en nuevos significados, en otras ideas y a comprender de manera diferente (Dysthe, 2000). El discurso no se transforma en dialógico porque los estudiantes intervengan en diferentes turnos de habla, será dialógico si cada intervención depende de las otras y la tensión entre las voces crea nuevos significados (Dysthe, 1996). Aprender en este contexto no se reduce a recibir aquello que se transmite, sino que se aprende a través de un proceso de interacción incorporando las palabras y los discursos, haciéndolos propios.

En los casos analizados por Dysthe (2000) la clase funcionó como una comunidad de prácticas (Lave y Wenger, 1991), donde los alumnos ganaron en experiencia construyendo una comunidad de escritores a través de grupos de lectura y revisión con reglas claras establecidas por la docente; esas reglas se flexibilizaron una vez que el grupo se las apropió. Así la autora concluyó que las tareas cortas de escritura que la docente propuso antes de las discusiones orales, fueron muy efectivas para aumentar la participación de los estudiantes y enriqueció la calidad de la discusión. En este sentido, la escritura individual de un resumen que los estudiantes realizaron en su casa antes de cada clase y de la discusión en grupos, aseguró que todos conocieran el texto que tuvieron que discutir. A la vez, al escribir el comentario personal en clase se aseguraba que, antes del intercambio y la discusión, cada alumno ya hubiera constituido una perspectiva personal, de manera tal de tener una voz propia que les permitiera participar en el debate posterior. Otra condición clave en este proceso de aprendizaje fue la activa participación de la docente: como un par en la discusión, ella desafió los puntos de vista de los alumnos y creó tensión entre sus voces con sus intervenciones. Las preguntas abiertas, que no tenían una única respuesta, realizadas de forma escrita $\mathrm{u}$ oral, promovieron que los estudiantes explicitaran sus propias ideas y argumentos, y así resultaron un elemento muy importante en estas clases con multivocidad analizadas por Dysthe (1996, 2000).

En una investigación posterior Dysthe (2012) presentó situaciones de escritura académica en el contexto de una asignatura, y analizó el feedback electrónico realizado por escrito en formato digital, que efectuaron estudiantes de la carrera de Leyes del primer año de la universidad a sus pares. Se categorizaron los comentarios en tres tipos diferentes: confirmatorios, evaluativos y desafiantes. Del análisis surgió que los comentarios de tipo confirmatorio y evaluativo fueron útiles porque promovieron la motivación, la reformulación de las propias ideas o de las maneras de escribir, al proponer ejemplos de otras formas de decir. Pero los comentarios más productivos en términos de aprendizaje fueron los denominados desafiantes porque a través de ellos 
se presentó una voz crítica y contrastante que resultó productiva en el sentido de interpelar al estudiante a nuevas maneras de pensar y escribir.

Estos trabajos se constituyen en casos de aulas concretas en las que ciertas tareas de escritura ofrecieron a los estudiantes oportunidades para promover aprendizaje. Sin embargo, con la escritura no alcanzó, sino que resultaron centrales las intervenciones docentes mediando el trabajo con la lectura y la escritura, promoviendo la interacción dialógica y por lo tanto la multivocidad (Dysthe, 2000, 2012). Es por ambos aspectos que consideramos pertinente incluir como parte de nuestro marco teórico las investigaciones coordinadas por Olga Dysthe.

Así también, las experiencias de trabajo con escritura y habla en situaciones de enseñanza en museos de arte, que se describen en el libro Enseñanza basada en el diálogo de Dysthe, Bernhardt y Esbjorn (2013), nos aportan herramientas y reflexiones interesantes para pensar las prácticas analizadas en esta tesis. Estas experiencias refieren a diversas situaciones en las que se incluyó escritura individual (por ejemplo, de las primeras impresiones ante una obra de arte o de palabras clave que pudieran resumir aquello que provocaba esa obra), para posteriormente realizar una reflexión en pequeño grupo acerca de lo escrito y pensado y a continuación una conversación con toda la clase. Las autoras dan cuenta de que en grupos grandes siempre había alumnos que adoptaban una actitud más pasiva pero que al darles la oportunidad de formular en pequeño grupo lo escrito o pensado participaban de manera diferente, mucho más activa aun cuando en la conversación general no intervinieran directamente. Las autoras también comentan que se dio el caso de alumnos muy reticentes a escribir o con dificultades para hacerlo, en esos casos el trabajo con escrituras breves de ideas 0 palabras que servían como anclaje para el diálogo posterior podía ser una manera fructífera de trabajar esa instancia inicial (Dysthe, Bernhardt y Esbjorn, 2013).

\subsubsection{Investigaciones que abordan leer y escribir para aprender en Argentina}

En nuestro país, desde hace más de diez años, el equipo coordinado por Delia Lerner, Beatriz Aisenberg y Ana Espinoza viene desarrollando investigaciones que incluyeron diseño, implementación y análisis de situaciones de lectura y escritura integradas en secuencias didácticas. Se han desarrollado tanto en el área de Ciencias Sociales (Aisenberg, 2005, 2010, 2012, 2014; Aisenberg y Lerner, 2008; Torres, 2008) como en Ciencias Naturales (Espinoza, Casamajor y Pitton, 2009; Lerner, Aisenberg y Espinoza, 2009) con el propósito de aprender contenidos disciplinares en la escolaridad primaria. Además del trabajo sobre el contenido disciplinar, las prácticas del lenguaje que se 
utilizaron en estos contextos de estudio se constituyeron también en objeto de enseñanza durante la implementación de las secuencias didácticas.

En particular, desarrollaron diferentes secuencias para el aprendizaje de contenidos de Historia en aulas de $4^{\circ}$ a $9^{\circ}$ año de escolaridad (Aisenberg, 2010, 2014). En ellas se trabajó articulando dos cuestiones centrales: las situaciones de lectura se enmarcaron en el estudio de un determinado tema de Historia, siendo el propósito de lectura instalar algún aspecto de ese tema. La otra cuestión clave de estos diseños fue que se privilegió la actividad de lectura, al leer con frecuencia y releer articulando momentos de lectura individual, grupal y colectiva del mismo texto. Así se realizó una intensa actividad de lectura compartida y se trabajó sobre las interpretaciones que los alumnos realizaban de lo que fueron leyendo, de manera tal de propiciar que el leer con los pares y comentar enriqueciera el aporte del texto. Como parte de esta investigación Aisenberg (2010) presentó los resultados del desarrollo de una secuencia didáctica sobre migraciones internas en Argentina entre 1930 y 1970, en cuatro escuelas de Buenos Aires, en dos $6^{\circ}$ y dos $7^{\circ}$ grados. Una de las actividades que fue incluida en la secuencia fue la lectura de testimonios de migrantes, la secuencia propuso el planteo de consignas abiertas para favorecer que los alumnos se involucraran en la lectura. Inicialmente los alumnos tomaron el testimonio de cada migrante por separado, teniendo en cuenta este hecho se promovió que establecieran relaciones entre esos testimonios a partir de una consigna de lectura global “¿Qué hay en común y de diferente entre las distintas historias?" que se trabajó en parejas de estudiantes. Las producciones posteriores indicaron que pudieron establecer regularidades entre los testimonios. En una nueva situación de implementación se cambió la consigna mencionada y se solicitó a los alumnos que completaran un cuadro comparativo para la búsqueda de regularidades. Aunque se intentó preservar el propósito inicial, ante esta nueva consigna los estudiantes se centraron en completar cada casillero sin relacionar los testimonios, quedando una mirada atomizada sobre ese contenido.

A partir de estos datos se concluyó que aun cuando la actividad propuesta no determinó la clase de trabajo intelectual de los estudiantes, las consignas planteadas influyeron en el sentido de los contenidos finalmente aprendidos (Aisenberg, 2010). Fue a través del trabajo con la lectura de textos históricos, la relectura y las explicaciones del docente que adquirieron un lugar relevante en las sucesivas instancias de trabajo acerca del tema- que los alumnos pudieron movilizar conocimientos previos, pero a la vez, tal como refiere la autora: "conceptualizaciones, representaciones sociales, y marcas de la disciplina escolar" (Aisenberg, 2014). 
El mismo equipo ha realizado una investigación cuyo objetivo fue "identificar condiciones didácticas para las situaciones de lectura que favorecen una buena aproximación al conocimiento disciplinar y al aprendizaje de la lectura de textos del área." (Espinoza et al, 2009: 21). En este caso se centraron en analizar qué aportaba el trabajo recurrente con la lectura para aprender un contenido disciplinar de Ciencias Naturales (la estructura de la materia), a la vez que se propusieron indagar acerca de qué se requiere para enseñar a leer textos en clases de Ciencias Naturales. Esta investigación implicó el diseño y puesta en funcionamiento de una secuencia de enseñanza desarrollada con alumnos de 12 y 13 años; en ella se realizó un seguimiento con observación de las clases, registro de audio y análisis tanto de las producciones de los estudiantes como de los registros de observación. Los resultados mostraron la importancia que tuvo que los estudiantes se apropiaran de un propósito de lectura de manera tal que pudieran llegar a la lectura del texto con preguntas genuinas. Las autoras sostuvieron que, aun cuando instalar ese propósito podría sesgar la interpretación del texto, fue necesario hacerlo dado que leer para aprender Ciencias Naturales ya conlleva un sesgo de acuerdo a las prácticas sociales de referencia en esa área de conocimiento (Espinoza et al, 2010).

En otros trabajos, integrantes del mismo equipo de investigación presentaron el diseño y puesta en aula de situaciones de escritura centradas en la reconstrucción de explicaciones ante un suceso histórico. Estas situaciones se inscribieron en una secuencia extensa que incluyó reiteradas actividades de lectura en las que se leyó y discutió sobre las diferentes explicaciones a ese hecho; a partir de estas lecturas a lo largo de varias clases se trabajó con la escritura de explicaciones a sucesos históricos en pequeños grupos de alumnos. Esta tarea implicó también releer los textos ya trabajados para escribir y reescribir el propio a partir de sucesivas devoluciones, tanto colectivas como individuales que realizó el docente (Torres y Larramendy, 2010).

Estas investigaciones, que incluyeron el desarrollo y la puesta en aula de secuencias didácticas para enseñar un contenido de Historia o Ciencias Naturales a través del trabajo sostenido con la lectura, pusieron de relieve la relación que existe entre: a) el tipo de propuesta para abordar las lecturas y la producción escrita, b) el trabajo intelectual que se propicia, y c) el contenido a enseñar. En las propuestas del equipo mencionado se jerarquizó no sólo la tarea que se planteó a los alumnos, sino que a la vez el trabajo del docente adquirió un rol relevante. En este sentido, fueron las intervenciones docentes las que regularon la posibilidad de los alumnos de controlar y ajustar la interpretación que realizaron de lo que leyeron (Aisenberg, 2014). Así, a través de estas intervenciones aquellas ideas que resultaban invisibles en un texto pudieron 
tornarse en observables, al contrastar diferentes interpretaciones que se hicieron explícitas en las instancias compartidas de lectura.

Por estas razones que mencionamos es que consideramos que resultan antecedentes de nuestro trabajo, dado que ponen el acento no sólo en qué clase de materiales de lectura incluir según el propósito didáctico, sino en cómo hacerlo, a través de qué tipo de consignas es posible trabajar con ellos, mostrando cómo las maneras de abordar la lectura (o la escritura) impactan en aquello que realmente se enseña. Y cómo esa manera de trabajar con los textos adquiere sentido si se quieren enseñar objetos disciplinares complejos, y se jerarquiza la regulación que pueden realizar los docentes.

Otros equipos de investigación en Argentina han indagado qué sucede en aulas de nivel superior de enseñanza con la lectura y escritura académica. En este sentido, Carlino (2005) propuso una definición de la noción "alfabetización académica" que fue desarrollada a partir del concepto "literacy" utilizado en el ámbito anglosajón y tuvo amplia difusión en los últimos diez años. La autora considera que alfabetización académica:

Señala el conjunto de nociones y estrategias necesarias para participar en la cultura discursiva de las disciplinas así como en las actividades de producción y análisis de textos requeridos para aprender en la universidad. Apunta, de esta manera, a las prácticas de lenguaje y pensamiento propias del ámbito académico superior. Designa también el proceso por el cual se llega a pertenecer a una comunidad científica y/o profesional, precisamente en virtud de haberse apropiado de sus formas de razonamiento instituidas a través de ciertas convenciones del discurso. (Carlino, 2005: 13,14)

En ocasiones se interpretó que la principal responsabilidad de la alfabetización académica estaba asignada a los estudiantes, quienes deberían obtener las estrategias necesarias para participar en las prácticas de lenguaje del nivel universitario; en esta concepción quedaba desdibujado el rol de los profesores en ese proceso. Fue por ello que Carlino (2013) actualizó la definición de la noción incorporando de manera explícita el rol activo de los docentes y las instituciones del nivel superior, proponiendo:

Sugerir "alfabetización académica" al proceso de enseñanza que puede (o no) ponerse en marcha para favorecer el acceso de los estudiantes a las diferentes culturas escritas de las disciplinas. Es el intento denodado por incluirlos en sus prácticas letradas, las acciones que han de realizar los profesores, con apoyo institucional, para que los universitarios aprendan a exponer, argumentar, resumir, buscar información, jerarquizarla, ponerla en relación, valorar razonamientos, debatir, etc., según los modos típicos de hacerlo en cada materia. Conlleva dos objetivos que, si bien relacionados, conviene distinguir: enseñar a participar en los géneros propios de un campo del saber y enseñar las prácticas de estudio adecuadas para aprender en él. En el primer caso, se trata de formar para escribir y leer como lo hacen los especialistas; en el segundo caso, de enseñar a leer y a escribir para apropiarse del conocimiento producido por ellos (Carlino, 2013: 270, 271).

Consideramos pertinente referirnos a esta modificación de la noción de alfabetización académica porque coincidimos en que, en este proceso de inclusión a la cultura escrita 
disciplinar, los profesores y las instituciones adquieren un rol relevante. Las secuencias didácticas diseñadas para la indagación que realizamos tuvieron entre otros objetivos "enseñar las prácticas de estudio adecuadas para aprender en él" (en este caso, el campo disciplinar de la Biología Celular). Y fue por ello que el trabajo sostenido durante las clases con diversas prácticas de lectura y escritura se inscribe en esta perspectiva, que define la alfabetización académica como un proceso a llevar a cabo a lo largo de la formación inicial y no sólo al inicio de los estudios superiores.

El equipo coordinado por Carlino ha desarrollado diferentes proyectos de investigación en los que se indagó qué se hace con el leer y escribir hacia el interior de asignaturas del nivel superior y medio de enseñanza. Los trabajos iniciales se enfocaron en indagar acerca de concepciones y prácticas de docentes y estudiantes, con relación a la lectura y escritura en la universidad (Carlino y Estienne, 2007; Di Benedetto y Carlino, 2007; Diment y Carlino, 2006; Fernández y Carlino, 2006, 2008, entre otros). En la investigación realizada por Diment y Carlino (2006) se da cuenta de que tanto alumnos como docentes de los primeros años de la Universidad de Buenos Aires consideraban que las prácticas de escritura no debían ser objeto de enseñanza en la universidad. Pero a la vez surge de la indagación el hecho de que algunos docentes que sí se ocupaban de orientar el trabajo escrito que realizaban sus alumnos, que además era valorado por ellos, consideraban que las acciones que llevaban a cabo no implicaban enseñar a escribir en sus materias. Por su parte, la indagación que desarrollaron Fernández y Carlino (2006) se centró en primera instancia en relevar cuáles eran las ideas de estudiantes y docentes de dos Facultades de la Universidad Nacional del Centro de la Provincia de Buenos Aires acerca de las similitudes y diferencias entre las prácticas de lectura y escritura en la escuela media y la universidad. Para después caracterizar estas últimas desde la perspectiva de estudiantes y docentes de las carreras de Ciencias Humanas y Veterinarias de la misma universidad (Fernández y Carlino, 2008).

Con relación al ámbito de educación superior no universitaria, Carlino coordinó un estudio nacional denominado: Leer y escribir para aprender en las diversas carreras $y$ asignaturas de los IFD que forman a profesores de enseñanza media, que fue desarrollado en el marco del Instituto Nacional de Formación Docente (INFD) durante los años 2009-2013. En esta investigación se propuso conocer "cómo los profesores de diversas asignaturas y carreras de los Institutos de Formación Docente (IFD) que forman a futuros educadores para el nivel secundario conciben las relaciones entre lectura, escritura, enseñanza y aprendizaje de los contenidos de sus materias. Asimismo, describe lo que dicen que se hace en sus clases e instituciones para apoyar el trabajo de sus alumnos en las tareas de producción y comprensión de textos que se proponen 
en los diversos espacios curriculares." (Carlino, Iglesia, Bottinelli, Cartolari, Laxalt, y Marucco, 2013:1) Este estudio, en el que esta tesista participó como investigadora, recuperó y sistematizó declaraciones de más de 500 docentes de todo el país en relación con lo que sucedía durante las clases con el leer, escribir y hablar, así como los argumentos que sostenían las decisiones didácticas que los profesores que respondieron la encuesta enunciaban con relación a esas prácticas.

Los principales resultados de este estudio vinculados con nuestra investigación son aquellos que refieren al trabajo en cada espacio curricular. La mayor parte de los docentes declaró ocuparse del leer y escribir en sus asignaturas, sin embargo al analizar lo enunciado respecto de la forma de trabajar con estas prácticas la incorporación del leer y escribir a la enseñanza era llevado a cabo de diversas maneras, que fueron categorizadas en dos modalidades: a) intervenir sólo en los extremos de la situación que demanda leer y/o escribir, o b) intervenir durante la práctica de escritura. En el primer caso (que fue la categoría que se presentó con mayor frecuencia), los profesores propusieron tareas que demandaban leer y/o escribir acerca de los temas de la asignatura, pero sólo intervenían al inicio de la tarea o al final. Al comienzo, dando pautas acerca de cómo escribir, por ejemplo exponiendo las características del género textual pedido y las condiciones generales que esa producción debía cumplir. $O$ al finalizar la lectura y/o la escritura, cuando se corregía la producción del estudiante, pero no estaba previsto volver sobre ese escrito o sobre la interpretación de lo leído, para retomar aquello sobre lo que hay que seguir trabajando. En estas modalidades de trabajo se solicitaba a los estudiantes que leyeran y/o escribieran, pero el proceso quedaba sólo a cargo de ellos; esta categoría de trabajo en los extremos se realizaría en los márgenes de las situaciones de clase (Carlino, Iglesia, Laxalt, 2012; 2013).

La segunda modalidad de trabajo, que fue categorizada como intervención durante las prácticas de lectura o escritura, correspondió a aquellos casos en los que los profesores realizaban trabajo recursivo con borradores o mediante el diseño de secuencias que promovían la revisión a partir de las sugerencias y orientaciones del docente y los pares. En este caso no sólo se proponía leer y escribir sino que los profesores intervenían durante el proceso. De esa manera, las situaciones didácticas podrían funcionar como oportunidades para poner en primer plano aquello que se estaba aprendiendo, para dotarlo de visibilidad y así transformarlo en un objeto de reflexión (Carlino, Iglesia, Laxalt, 2012, 2013).

La investigación que desarrollamos en esta tesis se complementa con los resultados del informe mencionado que fue realizado a partir de una encuesta masiva. En nuestro trabajo, a partir de observaciones y entrevistas, analizamos qué sucedió en un aula de 
formación docente a lo largo de una secuencia diseñada para trabajar con prácticas de lectura y escritura durante la enseñanza de contenidos disciplinares de Biología Celular. Como parte de las investigaciones realizadas por el mismo equipo, Manuela Cartolari (2015) presentó los resultados de su tesis doctoral. En este estudio de tipo naturalista se exploró y analizó aquello que sucedía con relación al leer, escribir (y hablar acerca de lo leído y escrito) en tres asignaturas de una institución de formación docente en Historia de la ciudad de Buenos Aires. Se concluyó como resultado de la investigación que las formas particulares de leer y escribir en Historia se hallaban entramadas en relación con los supuestos ontológicos y epistemológicos acerca de la disciplina, que daban cuenta de cómo se conoce y piensa en ese campo. Es así que para apropiarse de esas maneras particulares de pensar la Historia los futuros docentes tenían que poder aprender a construir significado y producir escritos con las reglas del juego de la comunidad de referencia.

Cartolari (2015) describió dos modalidades de interacción (dialógico-interpretativo y monológico) acerca del discurso escrito en las aulas de las materias observadas, y vinculó esas formas de enseñar con la manera en que los estudiantes hacían uso de la lectura y escritura para aprender (Cartolari y Molina, 2015). Durante las clases dialógicas los estudiantes tuvieron mayor participación y así pudieron dar a conocer qué significados habían construido a partir de los textos. Esta participación les permitió explicitar dificultades de comprensión que pudieron ser retomadas por la docente. A la vez, durante estos intercambios se potenció la interacción entre pares que se interpelaban y argumentaban.

Cuando los alumnos discutieron la interpretación de un texto, la docente (que tenía a cargo una de las asignaturas) no anticipó su propia interpretación experta, sino que promovió que surgieran nuevos aportes para discutir y profundizar las diversas interpretaciones. Para contrastar las diferentes perspectivas que surgían, los estudiantes retomaban los textos, releían y anclaban su fundamentación en lo escrito para poner en tensión la interpretación de sus pares o acordar con ellos (Cartolari, 2014). Estas condiciones que Cartolari describió se pueden vincular con lo que surgió del análisis de las intervenciones didácticas de la docente en algunas de las clases analizadas para nuestra investigación.

María Elena Molina, quien forma parte del mismo equipo, realizó una investigación acerca de los usos de la argumentación oral y escrita en dos materias (Biología y Letras) del primer año de carreras de dos universidades públicas (Universidad de Buenos Aires y Universidad Nacional de Tucumán). Como parte de las conclusiones de este trabajo 
se estableció que fueron las acciones dialógicas aquellas que hicieron posible que escribir y argumentar tuvieran funciones didácticas. Durante esas acciones se plantearon instancias de debate y conversación sobre lo escrito y leído, que hicieron posible la ampliación del tiempo didáctico (Molina, 2015). Así también, describe y categoriza ciertas condiciones didácticas que fueron relevantes para aprender desde la perspectiva de los alumnos que entrevistó. Una de las condiciones que los estudiantes mencionaron como relevante para aprender (14/15 en el caso de Biología), fue el tipo de tareas de escritura que se les solicitó. Otra de las condiciones muy mencionada por los estudiantes (14/15 en el caso de Biología) fueron las explicaciones dadas por los docentes con relación a la tarea, integrando otros recursos a las tareas escritas (imágenes, en el caso de Biología). Todos los estudiantes de ambas materias que fueron entrevistados (25/25), refirieron y destacaron como condición relevante que las devoluciones escritas que realizaron las docentes a sus producciones, fueron efectuadas a tiempo y eso les permitió aprender y volver sobre aquello que habían trabajado durante la escritura inicial (Molina y Carlino, 2013; Molina y Padilla, 2013) Ambas cuestiones: el tipo de tarea y las intervenciones docentes también fueron analizadas en detalle en nuestro caso, por lo tanto podremos establecer relaciones con la investigación realizada por Molina.

En otro de los trabajos de investigación del mismo equipo, en este caso, la investigación llevada a cabo por Carolina Roni, se desarrolló una intervención didáctica, para la que se diseñaron e implementaron secuencias para enseñar Biología en el nivel medio en dos escuelas, de manera conjunta con los profesores a cargo de las materias. Como parte de los resultados de la investigación se concluyó que sólo cuando el docente postergó la institucionalización (Brousseau, 2007) del conocimiento disciplinar los estudiantes recurrieron a la lectura de la bibliografía. Y cuando se reguló y enseñó cómo y para qué utilizarla, los alumnos ganaron en autonomía para la interpretación de la bibliografía y así pudieron recurrir a ella aún en ausencia del docente (Roni, Alfie y Borches, 2012). En cambio, si esa institucionalización se anticipaba, obturaba la posibilidad de que los estudiantes recurrieran a la bibliografía con preguntas propias (Roni y Borches, 2013). Este caso se vincula con nuestra investigación dado que, a pesar de que se desarrolló en nivel medio de enseñanza, coincidió en elaborar de manera cooperativa entre la investigadora y los docentes, un diseño didáctico integrando el trabajo con el leer y escribir para aprender contenidos de Biología Celular. Con relación al trabajo con la lectura y la escritura en aulas de nivel superior, en este caso el aula universitaria, queremos destacar los aportes realizados por investigadores de la Universidad Nacional de Río Cuarto. En numerosos trabajos se han ocupado de 
indagar y analizar qué les sucede a los estudiantes cuando abordan prácticas de lectura y escritura al iniciar el nivel superior. Vázquez y Jakob (2007) analizaron protocolos de pensamiento explicitados en voz alta por estudiantes universitarios que estaban realizando un informe escrito en parejas utilizando diversas fuentes. Las autoras consideraron que esta investigación les permitió matizar la dicotomía del enfoque superficial versus enfoque profundo. A partir de lo analizado construyeron nuevas categorías de análisis basadas en la combinación de tres dimensiones: presencia/ausencia de estrategias de planeamiento, reproducción /reestructuración de la información, y tratamiento superficial/profundo de la información.

Para caracterizar los procesos de pensamiento asociados a la escritura de los estudiantes utilizaron las tres categorías construidas a partir de las dimensiones que mencionamos: a) improvisado-reproductivo, b) anticipativo débil-elaborativo superficial, y c) anticipativo fuerte-elaborativo profundo (Vázquez, Jakob, 2007: 27). Esa caracterización da cuenta de diversas maneras en las que los alumnos pueden encarar la planificación y textualización. En los casos categorizados como (a), durante el proceso de planificación los estudiantes recorrieron los textos fuente y de manera prácticamente azarosa eligieron fragmentos y los reprodujeron casi sin cambios cuando textualizaban. En el segundo enfoque (b) hubo indicios de planificación pero esos planes fueron poco precisos, al textualizar se incluyó el parafraseo y se puso de manifiesto en los protocolos orales la intención de establecer relaciones entre las diferentes partes de la producción escrita, pero se evidenciaron ciertas confusiones conceptuales. Por su parte, aquellos del tercer enfoque (c) dieron cuenta de la elaboración de planes más complejos debido a que pudieron establecer mayor número de relaciones conceptuales. Esos planes funcionaron para los alumnos como instrumento de control durante todo el proceso de escritura, al textualizar, parafrasearon y estuvieron atentos a producir un texto integrado (Vázquez y Jakob, 2007).

Con la intención de ofrecer oportunidades para reflexionar acerca de los procesos de pensamiento asociados a la escritura académica en los diversos proyectos de investigación que han encarado, participantes del mismo equipo diseñaron y llevaron a cabo una serie de experiencias pedagógicas en las que integraron la lectura y la escritura como elementos centrales para el aprendizaje de contenidos disciplinares en diversas asignaturas. Una de las experiencias se realizó con estudiantes que cursaron las materias Didáctica I y Didáctica II (área de Lengua), correspondiente al tercer año de Licenciatura en Psicopedagogía y del Profesorado y Licenciatura en Educación Especial, respectivamente (Vázquez, Rosales, Jakob y Astudillo, 2005). Durante la secuencia didáctica diseñada y analizada los estudiantes debían escribir dos informes 
académicos y entre esas dos tareas de escritura hubo una serie de actividades para desarrollar estrategias para producir este tipo de escrito; ese trabajo estaba íntimamente relacionado con los contenidos conceptuales de la asignatura y fue acompañado de forma sistemática por los docentes de la asignatura. Como parte de sus conclusiones los autores sostienen que no ocurren cambios repentinos ni transformaciones drásticas, sino que las mejoras en los textos y en los procesos de escritura son graduales (Vázquez y Jakob, 2007). Consideran que un resultado relevante de sus propias investigaciones, fue comprobar que a través de ciertas intervenciones didácticas que permitieron regular el trabajo de los estudiantes durante el curso fue posible mejorar las producciones de aquellos alumnos que se encontraban en condiciones más desfavorables al inicio del proceso de trabajo. Es así que las acciones didácticas tales como las secuencias de tareas propuestas y el acompañamiento durante esas tareas tuvieron un rol fundamental para sostener que es posible enseñar a escribir dentro de las disciplinas universitarias, y que ello redunda en beneficios para quienes más necesitan mejorar la producción de textos (Vázquez, Jakob, Pelizza y Rosales, 2009).

En un artículo posterior dieron cuenta del trabajo de diseño e investigación integrando de manera protagónica el leer y escribir a secuencias didácticas implementadas en diversas materias del primer año de la universidad. Destacaron la relevancia que adquirió realizar un trabajo sistemático y sostenido a lo largo de la cursada, centrado en las prácticas de enseñanza que se desarrollaban en el aula (Jakob, Bono, Vélez, Boatto, Luján y Rainero, 2014). Y es en este sentido que coincide plenamente con la propuesta de trabajo que hemos diseñado, implementado y analizado en esta investigación.

Estas propuestas funcionaron como dispositivos didácticos que involucraban a docentes y alumnos universitarios en la enseñanza de prácticas de lectura y escritura propias del nivel. Sin embargo, no constituyen las propuestas habituales en las aulas universitarias. Leticia García Romano durante el desarrollo de su tesis doctoral ha indagado acerca de las representaciones sobre la lectura y la escritura en estudiantes y profesores de las carreras de Biología de la Universidad Nacional de Córdoba. Los resultados obtenidos están en consonancia con otras investigaciones vinculadas a las concepciones sobre la lectura y la escritura en nivel superior que ya hemos mencionado, dado que para los docentes la lectura y la escritura no aparecieron como objetos de enseñanza propios de la universidad (García Romano, Padilla y Valeiras, 2016).

La visión predominante en el discurso de estudiantes y profesores que participaron de la investigación es la que refiere al lenguaje como sistema de transmisión de la información. Aun cuando en el contexto científico efectivamente sea utilizado para transmitir información, resultan relevantes otras funciones tales como su uso para 
interpretar y dar sentido a la experiencia (y no sólo para comunicarla) así como resulta una herramienta indispensable para participar en las comunidades disciplinares (García Romano, Padilla y Valeiras, 2016).

En el mismo sentido se inscribe el rol de la escritura sólo como herramienta de registro que fue planteada por los alumnos de los primeros años de universidad y que es semejante a lo descripto para estudiantes en la etapa de finalización de la escuela secundaria. Los estudiantes entrevistados reconocieron la diferencia entre aquello que se demanda en nivel medio y universidad con relación a las prácticas de lectura y escritura. A la vez manifestaron las dificultades para comprender los artículos científicos que se presentaban como bibliografía en las asignaturas (García Romano, Padilla y Valeiras, 2012; García Romano, Valeiras y Masullo, 2013). En sus resultados han encontrado que los alumnos complejizaban sus concepciones a medida que avanzaban en la carrera, los estudiantes de los últimos años incluían en su discurso aspectos específicos de la lectura y escritura de artículos. Consideraron que este aspecto se vincula con las prácticas de lectura y escritura que se desarrollaban en las asignaturas de los últimos años, en las que se incorporaba la discusión de resultados de investigaciones y la escritura de informes y artículos por parte de los estudiantes (García Romano, Padilla y Valeiras, 2016).

En este apartado hemos relevado investigaciones que aportaron elementos sustanciales a la hora del diseño, implementación y análisis porque dan cuenta de las representaciones y prácticas habituales de poblaciones de alumnos y docentes con relación al leer y escribir y a cómo se conciben y se enseñan y aprenden estas prácticas. A la vez, hemos dado cuenta de investigaciones que desarrollan propuestas de intervención que funcionaron como dispositivos de enseñanza que integraron el leer y escribir a la enseñanza de contenidos disciplinares. En el siguiente apartado presentamos la experiencia de docencia e investigación propia que ha tenido un rol relevante como antecedente de investigación para el trabajo desarrollado en esta tesis.

\subsubsection{Leer y escribir para aprender Biología como práctica propia de docencia e investigación}

Incluimos en esta sección algunos resultados del trabajo de investigación que se desarrolló en la cátedra de Biología 08 de la sede Regional Norte, del Ciclo Básico Común ( $\mathrm{CBC}$ ), primer año de la Universidad de Buenos Aires, cátedra de la que formo parte desde hace casi 25 años. En el marco de una innovación curricular y didáctica, se incorporó el trabajo sistemático con la escritura como recurso para la enseñanza de la asignatura; con el propósito de favorecer que los estudiantes aprendieran a pensar los 
seres vivos desde una concepción más integrada y compleja. Se jerarquizó que establecieran relaciones multicausales involucrando diferentes niveles de organización (molecular, celular, organismo). Se pretendía que pudieran articular los contenidos del currículum para explicar situaciones biológicas particulares, de manera tal de establecer relaciones entre el conocimiento general acerca de un tema y el caso particular. Por ello, continuamente se les propuso ir y venir de la teoría a la práctica, estableciendo una relación dialéctica entre ambas. Ese recorrido de lo teórico general a lo particular del caso a trabajar, se constituyó en un desafío importante para los estudiantes.

Esa mirada sistémica acerca de los objetos disciplinares a enseñar también impregnó el trabajo durante el diseño de la secuencia didáctica objeto de esta tesis, ya que incorporamos elementos que provenían del material utilizado en la cátedra al diseño de algunas de las situaciones de enseñanza. Se incluyeron algunas consignas del mismo estilo que las trabajadas en la cátedra, por ejemplo actividades que demandaban establecer diversas clases de relaciones.

A través de encuestas implementadas en diferentes comisiones de la misma cohorte y en cohortes sucesivas, se les preguntó a los alumnos qué sucedía cuando tenían que escribir textos relacionando conceptos disciplinares en un contexto particular (por ejemplo cierto tipo de célula en la que se está llevando a cabo algún proceso). En sus respuestas mencionaron el desafío que implicaba este tipo de producción, y algunos estudiantes manifestaron no saber cómo encarar el escrito. Nos preocupó en especial que las respuestas más frecuentes eran del tipo no sé redactar y no sé relacionar (Iglesia, De Micheli, Donato y Otero, 2005). Estas respuestas permiten pensar que los alumnos asumen como propio el problema, y parecen considerar que deberían haber aprendido, en alguna otra materia y momento, a escribir esa clase de textos relacionando conceptos de Biología, tal como solicitamos. Estos resultados nos permitían inferir que era probable que los estudiantes que participaban de la investigación para esta tesis también tuvieran esa concepción acerca de la propia escritura.

Una conclusión que planteamos después de más de 15 años de trabajo incorporando la escritura a la enseñanza de la Biología y a la investigación sobre la propia práctica en la cátedra, es que para que los estudiantes pudieran escribir en los exámenes aquello requerido era importante que escribieran de forma sistemática durante las clases. A la vez, que escribieran de manera recurrente favoreció que, en muchos casos, pudieran aprender de manera más profunda e integrada los contenidos de la asignatura. Esto implicó establecer una relación dual, de ida y vuelta entre aprender a escribir Biología, y escribir para aprender Biología (Iglesia y De Micheli, 2008). La manera en que los 
docentes de la cátedra intervenimos cuando recibimos las producciones de los alumnos, las leemos y "corregimos", está mediada por la escritura. La intención durante esa devolución es establecer un diálogo escrito, de manera tal que las sugerencias y preguntas que incluimos orienten la revisión de aquello que se está aprendiendo. Concebimos el escribir como una acción recursiva que puede profundizar el conocimiento sobre el tema y a la vez permite pensar cómo escribir acerca de lo que se está conociendo. Esa corrección-devolución que realiza el docente no se centra en marcar el error y calificar; en cambio prioriza que el alumno pueda seguir trabajando con ese escrito, lo reconozca como un texto provisorio, perfectible, como una manera de estudiar ese contenido y ponerlo en relación con otros. Los docentes escribimos diferentes clases de comentarios, algunos puntuales y otros más generales, así como sugerencias por fuera del texto del alumno, sin invadirlo, con la intención de orientar los nuevos escritos. El docente se ubica como lector del texto que produjo el estudiante, primero lo lee y puede así tener una mirada general y no parcializada por la sumatoria de correcciones. Serán los alumnos como escritores quienes volverán sobre el propio texto a partir de las sugerencias y orientaciones, quienes tienen la posibilidad de volver sobre su propio texto y corregirlo (Gottschalk y Hjostshoj, 2004). De la misma manera trabajamos al realizar las devoluciones de los escritos durante la secuencia didáctica analizada para esta tesis.

La experiencia previa del trabajo en la cátedra y los resultados obtenidos, así como su análisis e interpretación, influyeron a la hora de decidir instancias de trabajo semanal con situaciones de escritura para la secuencia diseñada en esta investigación. Así también la experiencia previa de docencia e investigación fue un soporte para insistir en la necesidad de volver una y otra vez sobre el propio escrito para reelaborarlo.

Escribir durante el curso textos semejantes a los que se solicitaban en las evaluaciones resultó en el caso de cátedra de Biología una tarea potencialmente útil para aprender Biología y, eventualmente, aprobar los exámenes (Iglesia, 2014). Consideramos que la escritura que los estudiantes realizan en respuesta a determinadas tareas propuestas durante el curso era un recurso potente para aprender la materia (De Micheli e Iglesia, 2012). En parte, porque esas tareas de escritura hacían visible la trama de relaciones biológicas que los estudiantes establecían, a la vez que permitía enriquecerla, dado que promovía pensar acerca de ella. Pero no era sólo la tarea propuesta, sino que las acciones docentes que acompañaban y orientaban, a la vez que promovían pensar y aprender a través del escribir, adquirieron especial relevancia (De Micheli e Iglesia, 2012, 2017; Iglesia, 2014). 
Todos estos aspectos trabajados, analizados y evaluados a través de investigaciones realizadas en y por la cátedra mencionada, que ponían en foco el dispositivo didáctico diseñado, fueron antecedentes relevantes a tener en cuenta durante el diseño y la implementación de la secuencia analizada en esta tesis.

\subsection{La Biología como una Ciencia Natural, y su enseñanza}

En esta segunda parte del capítulo nos centramos en la disciplina de referencia. Presentamos nuestra toma de posición en relación con el conocimiento biológico a enseñar, así como las referencias que dan cuenta y fundamentan la manera en que integramos lectura, escritura y oralidad a la enseñanza de esos contenidos disciplinares. A la vez, incluimos un tercer apartado que fundamenta el trabajo con el diseño e investigación de secuencias didácticas en la enseñanza de las Ciencias Naturales, estableciendo relaciones con las diseñadas para esta investigación.

\subsubsection{El contenido disciplinar desde una perspectiva sistémica y compleja}

En este apartado describimos la perspectiva de Didáctica de las Ciencias Naturales en la que nos posicionamos. En primera instancia definimos cuáles son los objetos a enseñar y cómo se delimitan y articulan los contenidos específicos que implican esos objetos de enseñanza. Consideramos imprescindible hacerlo porque es en ciertos contextos de enseñanza que adquirió sentido trabajar con modos particulares de leer y escribir.

Si pensamos que los contenidos de las Ciencias Naturales no están en un libro sino en los hechos que suceden en el mundo, las maneras de enseñarlos no se reducen a lo que se enuncia en los libros y las maneras de aprender no se limitan a solicitar que los alumnos repitan esos contenidos. Enseñar Ciencias Naturales consistiría en entablar un diálogo sobre el mundo, pensar acerca de él a través de teorías, considerando que la ciencia justamente propone una forma rigurosa de mirar los sucesos, de explicar y predecir, pero que existen también otras maneras de pensar acerca de ellos (Izquierdo y Sanmartí, 2001).

Un aspecto central a tener en cuenta al elaborar un diseño didáctico es qué ciencia enseñar, y es desde esa decisión didáctica que se cargarán de sentido los objetos a enseñar (Izquierdo, 2005). La mirada que tengamos con relación a la naturaleza de la ciencia condiciona los modos y propósitos que los profesores asumimos para enseñarla. Asumir una perspectiva más crítica acerca de su naturaleza, que la conciba como controversial y colectiva (no neutral, ni objetiva ni reducida a un único método universal) podría "favorecer la apropiación de los contenidos desde una perspectiva que incluya 
los condicionamientos históricos, las tensiones y controversias, y la provisionalidad e incertidumbre asociadas a sus resultados" (Massarini y Schneck, 2015: 111).

En cuanto a la mirada sobre los objetos disciplinares asumimos que concebir a los seres vivos desde una perspectiva sistémica, implica complejizar y superar el enfoque reduccionista. Este enfoque presupone que los sucesos biológicos que acontecen en los organismos podrían ser explicados por la sumatoria de fenómenos que ocurren en los niveles de organización inferiores (Mayr, 2005). El conocimiento exhaustivo de componentes de los menores niveles de organización permitiría, desde un enfoque reduccionista, la reconstrucción y comprensión de los hechos que suceden en los niveles de mayor complejidad. En contrapartida, la perspectiva sistémica u holística entiende a los sistemas vivos como estructuras auto-eco organizadas y multicausales (Maturana y Varela, 1984; Morin, 1990), caracterizadas por ciertas propiedades emergentes que no se encuentran presentes en los niveles de menor grado de organización (Lewontin, 2001; Lewontin, Rose y Kamin, 1987; Mayr, 2006; Rose, 2001).

Según Meyer (1979) los organismos vivos deberían concebirse con una doble mirada epistemológica. Una de ellas piensa a lo vivo como una totalidad identificable que tiene dimensión histórica e interacciona a través de su comportamiento con el ambiente del que es también subsidiario; pero al mismo tiempo se lo entiende como el resultado de un gran número de procesos metabólicos y fisiológicos.

Para integrar ambas miradas y que los futuros profesores pudieran construir una perspectiva sistémica de los seres vivos, nos propusimos superar el conocimiento atomizado que en general los alumnos han construido durante su escolaridad, de manera tal de favorecer una comprensión multicausal, compleja y más integrada de lo vivo. El contenido a enseñar en esta secuencia deriva de la noción de célula, un objeto central desde la mirada hegemónica de la Biología, presente en los programas de enseñanza de diferentes niveles educativos y por lo tanto un contenido relevante desde la formación. El ciclo celular, que es el tema particular de la secuencia analizada, se pensó desde esta concepción sistémica, por ello en vez de enfatizar la adquisición de gran cantidad de información y terminología acerca de la biología celular, jerarquizamos el establecimiento de relaciones entre conceptos referidos a diferentes niveles de organización (organismos, células, moléculas), utilizándolos para explicar situaciones biológicas concretas, estableciendo una relación dialéctica entre la teoría y la práctica. La interpretación de qué se aprende, cómo se aprende, por quién y bajo qué condiciones implica decidir un posicionamiento epistemológico al enseñar. Para delimitar qué se aprende se definieron cuáles eran los objetos pertinentes, en nuestro caso nos 
centramos en cómo constituir las células y los procesos metabólicos que suceden en ellas de manera tal de concebirlas como objetos complejos y dinámicos. El sentido estuvo dado porque pretendimos que los futuros docentes pensaran en múltiples relaciones (espaciales, temporales, funcionales), a la vez que concibieran esa complejidad celular al establecer vínculos entre los diferentes niveles de organización (molecular, celular y del organismo). Al pensar el "cómo" se diseñaron secuencias didácticas que incluyeron diversas actividades que trabajaran con el leer, escribir y hablar acerca de las células, para así ir constituyendo los objetos a enseñar a través del trabajo con el lenguaje específico. Pero a la vez no perdimos de vista "quién aprende": en nuestro caso esas secuencias se implementaron en un contexto específico y estaban dirigidas a futuros profesores de Biología. Los destinatarios fueron estudiantes que se constituirían en profesionales que enseñarían un modelo de célula más o menos integrado y operativo, en parte de acuerdo a cuáles fueron los modelos que pudieron constituir durante su formación inicial.

Kelly (2012) caracteriza tres perspectivas epistemológicas que suponen diferentes maneras de pensar el conocimiento a enseñar, a) la perspectiva disciplinar, que considera las maneras en que la Historia y la Filosofía de las Ciencias han influido en el aprendizaje de las ciencias y el rol central que el conocimiento disciplinar adquiere en tanto objeto a enseñar; b) la perspectiva personal, que se centra en las maneras en que cada individuo como aprendiz conceptualiza el conocimiento y cómo esa mirada personal influye en su aprendizaje; c) la perspectiva epistemológica como práctica social, que determina qué se concibe como conocimiento en cada contexto.

En consonancia con esta última posición se realizaron investigaciones que provienen de las perspectivas socioculturales y etnográficas, y de los estudios pragmáticos que incluyeron hablar y actuar para aprender en clases de Ciencias Naturales. Nos referimos a estudios tales como los que desarrolló Lemke (1997), quien fue uno de los primeros autores que analizó el significado que tiene el habla en clases de Ciencias. En la perspectiva epistemológica como práctica social a la que referimos, son importantes aquellos estudios que ponen en relevancia tanto los dispositivos como el contexto comunicativo. Así, el conocimiento es visto como una acción competente en una situación, en vez de una correcta y estática representación del mundo. Para decidir en qué sentido la acción de los alumnos sería competente se requiere analizarla en una actividad que tenga algún "propósito humano", dado que la comunicación y la acción tienen sentido sólo si la práctica tiene un propósito (Kelly, 2012). Desde este enfoque Wickman y Ostman (2002) estudiaron cómo se pueden construir ciertos significados a través de la interacción discursiva en clases de Ciencias Naturales, así analizaron de 
qué manera los intercambios con el docente y entre los estudiantes, y los dispositivos previstos influyeron en la dirección que tomó el aprendizaje a través de hablar y actuar en una clase de Ciencias.

Con relación a este enfoque de las investigaciones, Dumrauf y Cordero (2004) analizaron las interacciones discursivas en clases de Física de nivel medio, en torno a la noción de calor. La perspectiva de análisis utilizada, que destaca la dinámica, complejidad y multidimensionalidad de la situación áulica a través de la reconstrucción de seis tipos de "in-estabilidades" (conceptual, focal, discursivo-simbólica, institucional, social y afectiva, tomadas de Leander y Brown, 1999), permitió al mismo tiempo recuperar la estructura de acción del docente. Dicha estructura, reconstruida a partir de;

\begin{abstract}
Una danza de (in)estabilidades, se basó en las siguientes estrategias: a) expresión de las ideas de los alumnos vinculadas a una noción determinada; b) recuperación de palabras utilizadas por los estudiantes (en este caso a través de su repetición verbal, acentuándolas desde la entonación y su registro en el pizarrón); c) contextualización de palabras propuestas por los estudiantes, aproximadas al conocimiento científico que se pretende (re)construir en el aula; d) discusión, hasta su exclusión, de palabras o ideas que difieren de la acepción científica de los conceptos trabajados; e) utilización de situaciones concretas para su análisis. Tales estrategias fueron utilizadas de manera reiterada a lo largo del episodio analizado, conformando ciclos de expresiónrecuperación-discusión-cierre provisorio que permitieron llegar a la noción científica a través de aproximaciones sucesivas. (Dumrauf y Cordero, 2004)
\end{abstract}

La tercera perspectiva mencionada por Kelly (2012) nos aportó elementos para jerarquizar el sentido que podían tener las diferentes actividades incluidas en el diseño y que formaron parte del dispositivo didáctico. Y a la vez nos interesó pensar en que la acción de los estudiantes será competente en una situación, es decir el conocimiento a construir es situado y adquiere sentido en contexto y ese contexto al que se refiere Kelly se constituye a través de la interacción durante las clases.

\title{
1.2.2. Enseñar y aprender Biología a través del leer y escribir
}

Las expresiones características de la Biología, disciplina configurada como una de las Ciencias Naturales, responden a una forma particular de ver el mundo a través de modelos o teorías que establecen relaciones entre fenómenos. Es por ello que el lenguaje resulta fundamental como instrumento para construir las ideas científicas y también como medio para comunicarlas. Aprender ciencias desde esta concepción implica apropiarse del lenguaje que constituye la cultura científica y que fue construido a lo largo de siglos y transmitido principalmente a través de textos escritos (Izquierdo y Sanmartí, 2000).

Los profesores de ciencias pueden usar el lenguaje como un sistema de etiquetado preestablecido para denotar estructuras y fenómenos, o pueden trabajar con el lenguaje de manera interpretativa. Usarlo de manera interpretativa implicará invitar a los 
estudiantes a no ser reproductores de hechos sino a poder interpretarlos (Sutton y Caamaño, 1997). En otro trabajo Sutton (2003) expone el rol que adquiere el lenguaje como herramienta interpretativa en situaciones nuevas y presenta la relación entre el surgimiento de nuevas nociones científicas y el uso metafórico del lenguaje. Este autor sugiere que los profesores pueden actuar como mediadores que orientan a los estudiantes a explorar estos sublenguajes de temas particulares que se han desarrollado al pensar nuevas ideas y constituirlas como nociones científicas.

Así, al enseñar a vincular hechos del mundo y modelos teóricos, al explicar, justificar, argumentar, los docentes acompañan a los estudiantes para que puedan poner en acción los modelos aprendidos (Adúriz Bravo, 2011). En ese caso las asignaturas se constituyen en espacios en los que se pretende enseñar no sólo ciertos objetos conceptuales, sino también las formas científicas de mirar y pensar acerca de ellos, como también las maneras particulares de leer, escribir y hablar acerca de estos saberes (Izquierdo y Sanmartí, 2000). De este modo, el trabajo con secuencias didácticas que incluyan leer, escribir y hablar ciencias, podría funcionar como una guía hacia nuevas formas de pensar acerca del mundo (Sutton, 2003).

Como resultado de sus trabajos de investigación, Anderberg, Svensson, Alvegard y Johansson (2008) plantearon que el uso del vocabulario científico por parte de los alumnos no implica necesariamente que hayan comprendido el significado de los conceptos disciplinares. Estos investigadores en Didáctica de las Ciencias Naturales sostuvieron que era frecuente que el empleo de una expresión por parte de los estudiantes fuera arbitrario y realizado por asociación. Así argumentaron que la relación entre las concepciones de los estudiantes, los significados que asignaban a ciertos términos específicos y las expresiones puntuales con que los denotaban era dinámica y ambigua. Por ello, afirmaron que era necesario diseñar situaciones para que los alumnos reflexionaran explícitamente sobre la adecuación de los vínculos que establecían entre aquello que intentaban expresar y las diversas maneras que utilizaban para referirlo. Los estudiantes necesitaron pensar acerca de cómo iban modificando lo que intentaban decir y cómo podían reconocer el mismo significado a través de diferentes contextos y expresiones que daban cuenta de cierto hecho. Como conclusión de su investigación, Anderberg et al (2008) plantearon que fueron los docentes, a través de un trabajo recursivo e intencional, quienes pudieron promover que los estudiantes atravesaran diferentes grados de comprensión del lenguaje y la bibliografía. En un inicio los alumnos reconocieron el significado de términos disciplinares aislados y establecieron relaciones superficiales entre ese significado y la forma de expresarlo. Pero fue a través del trabajo con el lenguaje específico, con intervenciones y tareas que 
permitieron situar esos términos en contextos variados, que fue posible abrirlos y que los estudiantes establecieran redes de conexiones más holísticas entre los conceptos, sus expresiones y los sucesos a los que referían.

Hand y Prain (2012) relevaron publicaciones de los últimos 30 años en las que se relacionó escritura y aprendizaje de contenidos disciplinares. A partir de este relevamiento los autores concluyeron que ese vínculo se estableció cuando se generaban las siguientes condiciones de enseñanza: a) si la situación de escritura demandaba que los estudiantes se centraran en comprender conceptos disciplinares y requería que justificaran aquello que habían comprendido del tema en cuestión, b) si el destinatario del escrito era significativo para los estudiantes, c) si los alumnos tenían orientación durante la escritura y d) si el trabajo con los textos involucraba a los estudiantes en un ir y venir sobre los sucesivos borradores. Fue en esos casos que ciertas tareas de escritura adquirieron función epistémica, dado que promovieron que los estudiantes reelaboraran y organizaran ideas acerca de conceptos y procesos claves en cada tema vinculando diversos tópicos. En este sentido, afirmaron que la escritura funcionó como un espacio metacognitivo para reflexionar acerca del propio aprendizaje y permitió a los estudiantes caracterizar los vínculos conceptuales que habían podido establecer entre diferentes modos de presentar el conocimiento científico (Hand y Prain, 2012).

Con relación a qué condiciones genera el tipo de tareas de escritura que se propone a los estudiantes, estos autores han investigado la implementación de secuencias didácticas vinculando escritura y aprendizaje de contenidos disciplinares (Hand y Prain, 2002, 2012; Hand, Prain y Yore, 2001). Las tareas de escritura que propusieron a los estudiantes les requirieron abordar nuevos contenidos, así como también cuestionar y aclarar sus ideas. $\mathrm{Y}$ para realizarlas los alumnos debieron argumentar acerca de aquellos significados que habían comprendido y no sólo demostrar qué era lo que sabían. Estas tareas funcionaron como promotoras de aprendizaje cuando motivaron y desafiaron a los estudiantes, y a la vez cuando hubo acompañamiento de los profesores que aportaron regulación experta, así como de los pares durante la realización de la tarea (Hand y Prain, 2002).

En otro trabajo Hand, Hohenshell y Prain (2006) analizaron qué sucedió con el aprendizaje de conceptos de Biología Celular y Molecular a través del diseño e implementación de secuencias didácticas que incluyeron diversas actividades de escritura. Los resultados dieron cuenta de que el empleo de tareas diversas de escritura no convencional tuvo beneficios significativos para el aprendizaje de conceptos de Biología Molecular. Sin embargo, los resultados que se obtuvieron en el caso de las 
secuencias diseñadas para aprender Biología Celular no fueron tan concluyentes, en esta secuencia las tareas de escritura marcaron diferencias en el aprendizaje sólo en los casos en que se abordaban contenidos novedosos para los estudiantes.

Los resultados de investigaciones que vinculan escritura y procesos de aprendizaje, nos aportan insumos para interpretar y poner en relación aquello que sucedió al desarrollar la secuencia didáctica durante la elaboración de esta tesis.

\subsubsection{Investigaciones basadas en diseño e implementación de secuencias didácticas en la enseñanza de ciencias naturales y matemáticas}

La investigación que realizamos se centra en el diseño y análisis de secuencias didácticas, es por ello que resulta pertinente detenernos en investigaciones sobre diseño y puesta en aula de secuencias de enseñanza que, como tales, articulan teoría y práctica, y así caracterizar el marco que orienta la producción de esas situaciones en contextos de disciplinas específicas.

Diversos estudios han analizado el proceso de diseño de secuencias didácticas y su puesta en aula como un problema de investigación. Comenzamos mencionando el artículo escrito por Ruthven, Laborde, Leach y Tiberghien (2009) porque en él se sintetizan y contrastan diferentes enfoques teóricos que los programas europeos de investigación en diseño de secuencias didácticas en Matemáticas y Ciencias Naturales desarrollaron. En el artículo se caracterizan y comparan tres perspectivas teniendo en cuenta las relaciones que cada una de ellas establece entre las grandes teorías que las sustentan, los marcos teóricos particulares de cada enfoque sobre diseño de secuencias de enseñanza y las herramientas didácticas que cada una define. Cada modelo teórico da cuenta de numerosas experiencias didácticas en las que pusieron en aula las secuencias de enseñanza, reajustando el diseño inicial a partir de implementaciones sucesivas.

A diferencia de los casos mencionados en esa publicación, nuestro trabajo con las secuencias implicó una única instancia de diseño e implementación para cada una de ellas. Sin embargo, la lectura de trabajos que abrevan en cada una de las perspectivas nos permitió reconocer y profundizar la relación entre el diseño teórico y la acción en el aula, así como algunas de las herramientas de diseño que definen los enfoques nos resultaron de utilidad para el análisis e interpretación de los datos. Los autores del artículo que mencionamos (Ruthven, Laborde, Leach y Tiberghien, 2009) concluyen que es valioso establecer un diálogo entre las diversas perspectivas dado que algunas de sus herramientas teóricas pueden complementarse en el diseño de nuevas situaciones 
de enseñanza. Por esto mismo, es que consideramos pertinente incluir como referencia para nuestro trabajo a los diferentes enfoques.

El primer modelo teórico mencionado en el artículo es la Teoría de las Situaciones Didácticas (Brousseau, 2007), sus herramientas asociadas son las situaciones adidácticas y las variables didácticas que se proponen para mediar en la construcción de nuevo conocimiento matemático a través de la resolución de problemas. Este enfoque ha sido moldeado a partir de la perspectiva piagetiana sobre desarrollo cognitivo y refinado a la luz de la noción de obstáculo epistemológico de Bachelard (2004).

El segundo enfoque caracterizado en el artículo de Ruthven et al (2009) es la Teoría de Dos Mundos, desarrollada para el diseño de secuencias didácticas de Física para la escuela secundaria. En esta perspectiva se considera la modelización como aspecto central a trabajar para comprender Ciencias Naturales. Las herramientas que el enfoque tiene previstas y orientan el diseño de actividades, son: a) la distancia entre conocimiento cotidiano y científico y b) las relaciones entre los modelos cotidiano y científico (Buty, Tiberghien y Le Marechal, 2004). El diseño también propone el trabajo en clase con pequeños grupos de estudiantes que puedan interactuar construyendo su propio punto de vista, para después contrastarlo en el grupo completo de clase mediante una revisión crítica. En esta instancia se propone que el docente guíe hacia la institucionalización del conocimiento científico.

Desde esta perspectiva se presenta el resultado de más de diez años de investigación en diseño y análisis de secuencias didácticas, mediante un trabajo realizado por el equipo de investigación en colaboración con profesores de Ciencias Naturales de los últimos años de la escuela secundaria y que fue desarrollado para la enseñanza de diversos contenidos de Física y Química. Este grupo de investigación (grupo Lyon) ha diseñado y puesto en práctica diversas secuencias didácticas que han sido evaluadas en términos de aprendizaje de los estudiantes; para ello compararon cursos en los que se desarrolló la secuencia (10 cursos) con otros similares en los que no se implementó (9 cursos). Los estudiantes de los cursos en los que se desarrolló la secuencia pudieron responder más y mejor en términos cuantitativos a una batería de preguntas. $Y$ esos estudiantes pudieron establecer más relaciones entre conceptos de Física y situaciones del mundo material, así como vincular el lenguaje cotidiano con el científico (Buty, Tiberghien y Le Marechal, 2004).

Es en este sentido que nos interesa citar este enfoque, dado que muestra cómo el trabajo con situaciones que promueven hablar y escribir en pequeños grupos y en grupo 
clase permite explicitar los modelos que subyacen al mundo cotidiano y científico, de manera tal de favorecer la vinculación de ambos lenguajes. Buty, Tiberghien y Le Marechal coinciden con Lijnse (2000) en basar el diseño en hipótesis claramente definidas acerca del conocimiento, el aprendizaje y la enseñanza. Sin embargo, a diferencia de Lijnse, otorgan relevancia al análisis del conocimiento inicial de los alumnos y consideran sucesivas implementaciones de las secuencias para refinar su diseño.

Nos detenemos en particular en la tercera perspectiva que aborda el artículo mencionado, la Social Constructivista en Enseñanza de las Ciencias, desarrollada por el grupo de investigación con sede en la universidad de Leeds (Leach y Scott, 2003; Leach, Ameitler y Scott, 2009); este enfoque se basa en la perspectiva sociocultural del aprendizaje propuesta por Vygotski (2007) quien da relevancia al lenguaje, en tanto medio semiótico que otorga significado a los conceptos acerca de los cuales se habla, sean estos conceptos científicos o aquéllos utilizados en la comunicación cotidiana. Se plantea que el conocimiento científico se desarrolla como resultado de interacciones sociales entre científicos que trabajan de manera conjunta para construir explicaciones acerca del mundo físico (Leach, Ameiller y Scott, 2009). También las concepciones cotidianas acerca del mundo se desarrollan a través de interacciones sociales mediadas por el lenguaje.

Es el lenguaje el que proporciona las herramientas a través de las cuales el pensamiento puede ser resignificado en el plano social para después ser internalizado y utilizado por cada individuo. En particular el lenguaje científico, que implica usos particulares de ciertos términos y que se establece y consensua en comunidad, es considerado por estos autores como un lenguaje social en términos de Bahktin.

[Los lenguajes sociales] son puntos de vista específicos sobre el mundo, formas de conceptualizar el mundo en palabras, maneras específicas de mirar el mundo, cada una caracterizada por sus propios objetos, significados y valores. Así es que todo ello está yuxtapuesto entre sí, se complementa mutuamente y coexiste en la conciencia de cada persona. (Bakhtin, 1934/1981, p. 292, citado por Leach, Ameitler y Scott, 2009).

El lenguaje social de las Ciencias Naturales se desarrolla al interior de cada comunidad científica e implica el uso de ciertos conceptos para explicar fenómenos del mundo natural a través del desarrollo de modelos que proporcionan razones para esa explicación. Además de los discursos, las representaciones matemáticas y visuales son centrales en el lenguaje social de las Ciencias. Aprender Ciencias Naturales no implica sólo nuevas formas de hablar o de usar el lenguaje, sino que demanda que los estudiantes puedan reconstruir el sentido de esos discursos. Esa reconstrucción requiere aprender a hablar de una nueva manera y esas nuevas formas son 
extremadamente difíciles de abordar, utilizar y comprender para algunos estudiantes (Lemke, 1997). Para comprender esa manera particular de usar el lenguaje de las Ciencias, resulta necesario que cada estudiante pueda otorgar sentido a lo que se habla a su alrededor, relacionando ese discurso con sus propias ideas y formas de pensar. Así, para aprender es necesario que los estudiantes reorganicen y reconstruyan los discursos hablados, escritos y leídos que circulan en el aula en un plano social. La noción de internalización que define el enfoque sociocultural refiere a esa reconstrucción que incluye como primer escalón una interpretación personal de las ideas propuestas en el plano social (Ameitler, Leach y Scott, 2009).

La perspectiva socio constructivista incluye como partes del proceso de aprendizaje tanto a la interacción social, como a la manera personal de dar sentido al conocimiento e identifica al lenguaje como un recurso central en ambos planos. Al diseñar e implementar secuencias didácticas desde este marco se le otorga un rol clave al docente, dado que es quien pone en escena el contenido científico al presentarlo a una audiencia. Se promueve que no sólo lo actúe, sino que esa acción de enseñanza funcione como soporte y orientación a los estudiantes durante el proceso de internalización de esos contenidos, propuestos inicialmente en el plano social del aula. Para ello tendría que reconocer las dificultades que los estudiantes encuentran al abordar ese contenido y mediar a través de una secuencia de intervenciones para que los alumnos puedan afrontarlas. A la vez, esa enseñanza debería proporcionar oportunidades para que se apropien de esas nuevas ideas y las utilicen (Leach, Ameitler y Scott, 2009).

Desde este enfoque se han desarrollado diversas secuencias didácticas para enseñar contenidos específicos de Ciencias Naturales para estudiantes de nivel secundario. A lo largo de cada secuencia diseñada se previó alternar el uso del discurso dialógico, abierto a diferentes puntos de vista, con momentos en que se utilizaba un discurso que los autores denominan "autoritario" porque está centrado en un único punto de vista, es escuchada una única voz (la del docente) y no se exploran nuevas ideas (Scott, Mortimer y Aguiar, 2005; Buty y Mortimer, 2008).

En las situaciones de planteo de hipótesis inicial a partir de la presentación de un problema, se consideró el empleo tanto del lenguaje cotidiano como del científico, en una interacción con discurso dialógico. En otros momentos del diseño se previeron instancias de uso de un discurso en el que el docente controlaba la dirección de la conversación para enfocarla en un punto de vista, en general el científico (Mortimer y Scott, 2003). Esas secuencias diseñadas se evaluaron en términos de aprendizaje de los estudiantes, utilizando pre y pos test. Una de las secuencias fue diseñada para 
enseñar circuitos eléctricos en nivel medio, se implementó en 15 cursos y en otros 15 se enseñó el tema de manera habitual; después se analizó cómo los estudiantes construyeron explicaciones escritas. En todos los casos los alumnos que participaron del desarrollo de la secuencia pudieron generar mejores explicaciones (Leach, Hind, Lewis y Scott, 2006).

Leach y Scott (2000) cuestionan ciertos resultados de gran parte de las investigaciones en diseño e implementación de secuencias didácticas, en las que se atribuyen los avances en el conocimiento de los estudiantes sólo a la secuencia de tareas diseñada. Aunque no dejan de mencionar que seguramente cierta organización de actividades de enseñanza tiene mayor sentido lógico que otra, estos investigadores consideran que se suele otorgar poca atención al docente y a cómo presenta y media a través del lenguaje el trabajo de los estudiantes con las actividades de enseñanza. Por ello es que desde esta perspectiva se jerarquiza el hecho de que los docentes comprendan y se apropien del sentido de las tareas de enseñanza, dado que ello influye en su actuación durante el desarrollo de la secuencia y a su vez impacta en el aprendizaje de los estudiantes (Leach y Scott, 2002).

Acordamos con este grupo de investigación en la necesidad de preservar el rol protagónico del docente en el diseño y desarrollo de las situaciones de enseñanza; por ello el diseño y la implementación de la secuencia que se analiza en esta Tesis fueron realizados en equipo con la profesora a cargo de los cursos. En la etapa de diseño se decide qué, cómo y para qué se van a enseñar ciertos contenidos y por ello resulta necesario consensuar criterios entre investigadora y docente para la toma de decisiones didácticas (Sanmartí, 2005). En esa toma de decisiones influyen los objetivos de enseñanza y aprendizaje que se planteen. Pero a la vez esos objetivos dependen de varios factores, tales como cuál es la perspectiva epistemológica sobre la disciplina, cómo se concibe que los estudiantes aprenden y por lo tanto cómo se considera que se debería enseñar en ese contexto. Por ello, fue importante trabajar durante la instancia de diseño de manera cooperativa con la docente que tuvo a cargo la puesta en aula de la secuencia, y así tuvimos oportunidad de reflexionar, discutir y consensuar criterios y perspectivas comunes.

Desde la perspectiva socio constructivista se propone, como primer paso para el diseño de una secuencia, redefinir el conocimiento disciplinar de base en función del contexto de enseñanza para identificar cuál es el conocimiento científico a enseñar (Leach y Scott, 2003). En segunda instancia consideran necesario conocer cómo esa área de la ciencia se conceptualiza en el lenguaje cotidiano de los estudiantes, comparar ambos lenguajes sociales para poder identificar cuál sería la demanda de aprendizaje y tenerla 
en cuenta durante el trabajo con la secuencia. Esta herramienta, tal como ellos la conciben, ayudaría a identificar los propósitos de enseñanza de ese contenido científico en el contexto particular. Al comparar ambos lenguajes sociales, se podrían contrastar, en términos ontológicos y epistemológicos, los patrones de razonamiento en los que se basan las explicaciones dadas por los estudiantes con relación a ciertos fenómenos naturales. A la vez, la ciencia a enseñar en las escuelas se suele centrar en determinados conceptos, así como ciertas maneras de pensar acerca de ellos. Por ello podemos considerar que esa "ciencia a enseñar" constituye en sí misma un lenguaje social diferente al empleado en la disciplina de referencia (Leach y Scott 2000). Así el concepto demanda de aprendizaje posibilita poner en foco los desafíos intelectuales que los estudiantes enfrentan cuando abordan cierto contenido en particular, para poder diseñar la enseñanza en función de esos desafíos.

Leach y Scott $(2000,2002)$ definen algunos aspectos de la noción demanda de aprendizaje. En primer lugar, la consideran específica de un contenido en particular, da cuenta de los desafíos que surgen al abordarlo. En nuestro caso la noción de célula en tanto escenario dinámico, en el que se suceden y coexisten diferentes procesos en el transcurso de su vida, constituyó la noción científica a enseñar. En segundo lugar la demanda de aprendizaje puede ser identificada con relación a un grupo particular de estudiantes, dado que se asume que el grupo comparte ciertos usos sociales del lenguaje y los significados que les atribuyen. Por ello está basada más en las diferencias entre esos lenguajes sociales, que entre la estructura cognitiva o mental de cada alumno. Es en este sentido que el concepto es de naturaleza epistemológica más que psicológica.

Buty, Tiberghien y Le Marechal (2004) al referirse a "dos mundos" (cotidiano y científico) también proponen identificar el salto entre aquello que los alumnos conocen de su vida cotidiana y lo que se espera que aprendan. A la vez, coinciden con Leach y Scott (2002) en la relevancia asignada a las intervenciones docentes durante la puesta en aula de la secuencia, así como en la necesidad de actuar en equipo con los profesores encargados de las materias en las que se implementan las situaciones didácticas, para favorecer la comprensión y apropiación de los significados de las acciones que forman parte de la secuencia de enseñanza.

\subsection{Análisis de las prácticas didácticas. Teoría de la acción didáctica conjunta}

Para analizar la práctica didáctica tomamos parte de la caracterización que realiza Sensevy (2007) al proponer una teoría de la acción didáctica conjunta (JATD). Desde 
esta perspectiva, refiere a la acción didáctica como aquello que "los individuos hacen en lugares (instituciones) en los que se enseña y aprende" (Sensevy, 2007: 6).

En esta línea se caracteriza la acción didáctica considerándola como una práctica conjunta, entre profesor y alumnos, que se establece en comunicación a lo largo del tiempo, y que a la vez está enfocada alrededor del saber, en tanto objeto de enseñanza. Se conciben los procesos de enseñanza y aprendizaje como un sistema compuesto a la vez por tres subsistemas: el subsistema del docente, de los estudiantes y del conocimiento en juego. Es así que la acción didáctica implica la interacción entre ese saber, el docente y los alumnos. Y esta mirada implica tener en cuenta que no es posible dar cuenta del comportamiento didáctico del docente si no se comprenden al mismo tiempo las acciones de los estudiantes y la estructura y función del saber implicado dado que ese sistema didáctico es indivisible (Sensevy, 2012). La acción didáctica conjunta a la que hicimos referencia es considerada una acción cooperativa, dado que se constituye en un proceso comunicativo y, como tal, esa relación es esencialmente dialógica. La noción de acción conjunta reconoce que la relación educativa tiene un carácter colectivo y dialéctico, el profesor propone reglas, da indicios pero esta propuesta requiere que los alumnos jueguen con las reglas del juego, y puedan interpretar esos indicios para construir a partir de ellos (Rickenmann, 2007).

Sensevy propone que esas interacciones didácticas pueden ser consideradas como transacciones; esa manera de caracterizarlas requiere que quien analice un determinado hecho realizado por el profesor debe buscar la acción del alumno como complemento y, de la misma manera, cuando se analizan las acciones de los alumnos, se analiza la co-acción del docente. Considerarlas como transacciones implica mirar desde cierta perspectiva que pone foco en la interacción, buscar cómo actúan los actores implicados en ella y cuáles son los objetos transaccionales en juego, los saberes contenidos en esa relación. Pero a la vez, demanda analizar la situación de esa acción, caracterizar el marco en el que surge la transacción dado que no puede ser comprendida sin tener en cuenta cuál es su entorno (Sensevy, 2010). Es así que la JATD propone una unidad específica de análisis que denomina epistemic joint action, para abordarla resulta necesario describir al mismo tiempo la acción del docente, las acciones de los alumnos y la manera en que ambas representan un movimiento específico en relación con el conocimiento en juego. Ese conocimiento es entendido como la posibilidad de actuar en una situación específica, asumiendo que cuando se adquiere nuevo conocimiento es posible hacer algo que previamente no se podía hacer en ese contexto (Sensevy, Gruson y Forest, 2015). 
Esta acción didáctica conjunta que hemos descripto tiene anclaje en tres conceptos básicos, que también focalizan su significado en lo colaborativo (Sensevy, 2012, 2015). Ellos son:

- atención conjunta (joint attention) considera que compartir la atención sobre los mismos objetos al mismo tiempo por parte de los alumnos, resulta un aspecto clave de la acción didáctica.

- potencialidad conjunta (joint affordance) refiere a las posibilidades de acción que los alumnos de manera conjunta son conscientes de que pueden realizar sobre ciertos objetos de conocimiento (Gibson, 1979, citado en Sensevy, 2012).

- sustrato común (common ground) alude a la serie de concepciones compartidas que hace que la comunicación sea posible y efectiva entre los participantes de la acción conjunta. Se relaciona con la noción common background que propone Wittgenstein (1997) para referir a los significados compartidos, en este caso serían aquellos conceptos que forman parte del contexto común de referencia para la acción didáctica conjunta.

Sensevy (2012) propone considerar estos tres conceptos de manera conjunta formando parte de un mismo sistema. Compartir un bagaje común permite que diferentes personas puedan enfocar su atención en los mismos objetos y ser conscientes de sus posibilidades de acción con relación a ellos.

Al referirnos al contexto institucional en que se efectúan las acciones didácticas, será necesario tener en cuenta los contratos didácticos que las rigen. El concepto de contrato didáctico fue propuesto por Brousseau en su texto "El caso de Gael" publicado en francés en 1981 y posteriormente traducido al inglés por Virginia Warfield, coautora de la versión de la que extractamos el fragmento que presentamos más abajo. En ese artículo Brousseau describe de manera detallada lo que ocurre durante situaciones didácticas que tuvieron como objetivo enseñar a lo largo de una serie de sesiones clínicas cierto conocimiento a un alumno que afrontaba dificultades al intentar resolver problemas matemáticos. Como parte de las conclusiones de ese trabajo, Brousseau definió la noción de contrato didáctico de la siguiente manera:

En el transcurso de una sesión cuyo objetivo es enseñarle a un estudiante una pieza específica de conocimiento (una situación didáctica) el estudiante interpreta la situación que se le presenta, las preguntas que se le plantean, la información que se le da, y las restricciones que se le imponen como una función de lo que sea que el maestro reproduce, conscientemente o no, en una forma repetitiva en su práctica docente. Estamos particularmente interesados en lo que entre esos hábitos es específico para el conocimiento enseñado: le dimos el nombre de "contrato didáctico" al conjunto de comportamientos (específicos) del maestro que son esperados por el estudiante y al 
conjunto de comportamientos del estudiante que son esperados por el maestro. (Brousseau y Warfield, 1999).

Ese contrato, que regula de manera no explícita las acciones de docentes y estudiantes, está basado en la interpretación que el alumno realiza de la situación. Pone el centro en aquellos comportamientos repetitivos del docente, que pueden ser previsibles para los alumnos y por ello pueden dar lugar a anticipaciones a partir de la interpretación de esa situación didáctica. Así el contrato didáctico de una situación puede considerarse como un sistema de hábitos que da lugar a un sistema de expectativas y, por ser didáctico, está consignado a ser roto al progresar los saberes durante la transacción. Consideramos la noción de contrato esencial para describir las situaciones didácticas, dado que permite aportar un marco al estudio de cómo se constituyen esas normas en la clase y cómo deben ser redefinidas al incorporar lo novedoso en una relación dialéctica con lo ya conocido (Sensevy, 2007). Es el resultado de una negociación, no es explícito ni acordado libremente, sino que se mantiene implícito como una serie de obligaciones que las partes (alumnos, profesor y sistema escolar) consideran que deben cumplir. Los profesores no pueden comprometerse a que se produzca efectivamente un conocimiento, y por lo tanto no es posible pactar de manera formal un contrato, ni escribir las cláusulas, ni es posible predecir cómo se produce su ruptura. Sin embargo, tanto docentes como alumnos tienen idea de lo que el otro espera de él y esta manera de tener en cuenta al otro crea las posibilidades de intervención, de regulación de la situación didáctica (Brousseau, 2007).

En nuestra investigación nos interesó, para el análisis de las prácticas, reconocer las condiciones de enseñanza en las que el trabajo con la lectura y la escritura podía favorecer el aprendizaje de contenidos disciplinares, por ello la noción de contrato didáctico constituyó parte del marco para interpretar las interacciones que sucedieron. Al analizar las clases retomamos qué fue lo que los estudiantes explicitaron y qué de lo expresado pudimos vincular con ese contrato institucional implícito. Desde la perspectiva de la Teoría de las Situaciones Didácticas el aprendizaje se basa en la ruptura del contrato didáctico tradicional, dado que los conocimientos adquiridos reemplazan o modifican a los previos (Brousseau, 2007).

Aprender a actuar en un contexto social específico (como es un aula de un Profesorado) es aprender a jugar cierto juego ${ }^{4}$ en situaciones que están inmersas en una institución. Y para describir la gramática de las situaciones en tanto actividades humanas podemos concebirlas como si fueran juegos didácticos; para ello describimos de manera general esa caracterización tal como la presenta Sensevy (2007, 2010). Consideremos dos

\footnotetext{
${ }^{4}$ to play certain game.
} 
jugadores: $A$ y $B$; para ganar el juego, A necesita producir ciertas estrategias, pero aunque $B$ acompaña a $A$ durante el juego, no puede jugar por él, ni suministrarle las estrategias ganadoras. Si $A$ las produce, no sólo ganaría el juego sino que también ganaría $B$, por ello este juego es esencialmente cooperativo entre A y $B$. Ahora bien, aunque $B$ tiene la información para producir las estrategias ganadoras, no puede comunicarlas directamente a $\mathrm{A}$, dado que $\mathrm{A}$ las debe producir por su propia cuenta. $\mathrm{A}$ su vez, B es juez y parte en este juego del saber, debe favorecer que A pueda producir por sí mismo las estrategias ganadoras, a la vez que es él (B) quien las valida. Así es $B$ quien debe actuar de manera tal que $A$ asuma su responsabilidad en el juego y por ello tiene que realizar la devolución, para que $A$ se implique verdaderamente en ese juego. Este diálogo didáctico entre $A$ y $B$ requiere de la reticencia de $B$, dado que si $B$ muestra las estrategias ganadoras, A no podrá jugar y producir estas estrategias por su cuenta y B no sabría si A aprendió (Sensevy, 2007, 2010).

Pero es importante tener en cuenta que las intervenciones del docente (B) ejercen un efecto en las acciones del alumno (A). Los profesores no pueden producir esas estrategias ganadoras, ni describirlas para ser imitadas, dado que no son acciones a imitar por un aprendiz, sino que debe hablar, producir sistemas de signos, diseñar pistas para que los alumnos interpreten esos signos y puedan producir por sí mismos las estrategias ganadoras. El alumno sabe que encontrará en los enunciados del docente elementos para ganar el juego, y que para ello debe interpretar los comportamientos del profesor a pesar de las reglas de reticencia que el docente debe respetar. Es por ello que el juego didáctico es recíproco, y puede ser descripto como un juego en el que un jugador (la docente en este caso) sólo gana si los demás jugadores (alumnos) lo hacen. Pero no puede realizar los movimientos ganadores, es decir no puede aprender por sus alumnos. Todo lo que puede hacer es jugar de manera indirecta en pos de que los alumnos aprendan, es en este sentido que en los capítulos de resultados nos centraremos en las intervenciones orales de la docente durante ciertas situaciones didácticas, que consideramos que tuvieron ese rol (Sensevy, Gruson y Forest, 2015).

Un supuesto inicial es considerar que un juego didáctico, regido por cierto contrato didáctico, presupone un contexto cognoscitivo común entre $\mathrm{A}$ y $\mathrm{B}$, un sistema de significados compartidos que son indispensables para la producción de estrategias ganadoras en el juego; aun cuando ese sistema no sea suficiente, funcionará como un trasfondo en el cual tengan sentido las transacciones didácticas. Durante el juego didáctico los alumnos tienen que abordar problemas, considerando que un problema es aquello que no puede resolverse directamente a partir de ese contexto cognitivo común, resultado de lo que se ha enseñado previamente. Para enfrentarlo y otorgar sentido a lo 
que se va trabajando es imprescindible ese contexto común, pero también es evidente su insuficiencia para resolver el problema. $Y$ es justamente el rol docente lo que funciona como elemento clave en esta transacción. Es decisivo para identificar la experiencia que los alumnos tienen, y así poder conocer cuál es el contexto común para esa situación y, a la vez, sus intervenciones serán relevantes para transformar los conocimientos en un largo y continuo proceso (Sensevy, 2007).

En orden de asegurarse que los estudiantes realmente aprenden, la docente debe ser reticente con relación a sus propios saberes respecto al conocimiento en juego. Es central que los alumnos actúen motu proprio y que la docente no revele cuáles son las estrategias ganadoras, sino que promueva que sea el jugador A quien las produzca. Brousseau (2007) ha descripto, a través de referencias literarias, dos efectos posibles si el docente transgrede la cláusula motu proprio y no es reticente.

El "efecto Topaze" recuerda la primera escena del célebre Topaze, de Marcel Pagnol, en donde se ilustra un proceso fundamental: Topaze le toma dictado a un alumno. Como el docente no puede aceptar los errores que supone que el alumno cometería, ni tampoco puede decirle directamente cómo debe escribir las palabras del dictado, lo que realiza es remarcar las "s" que ciertas palabras en plural tienen al finalizar (les moutons). Aunque ese sonido en francés no se pronuncia, el alumno fue alertado por el docente de la presencia de la letra s final en esa palabra. Así, Topaze impide que su alumno produzca la estrategia ganadora y sólo da lugar para que escriba lo que él ha indicado. En el caso del "efecto Jourdain", Brousseau alude a la escena del Burgués gentilhombre de Molière en la que el maestro de Filosofía revela a Jourdain lo que son la prosa o las vocales. Así, el profesor, para evitar el debate del conocimiento con el alumno y eventualmente comprobar el fracaso, admite reconocer el indicio de conocimiento o en los comportamientos o en las respuestas del alumno, aunque en realidad sólo esté expresando algo de sentido común.

En el diálogo didáctico, el jugador B (docente) puede estar tentado a reconocer, en un comportamiento de A (alumno), una estrategia ganadora y dar por supuesto que ha ganado (efecto Jourdain). O puede estar tentado de darle directamente la información necesaria permitiendo la producción de comportamientos que imitan la estrategia ganadora sin que ésta sea objeto real de apropiación (efecto Topacio). Existen así dos maneras de que B (el profesor) "haga trampa en el juego": en el momento de la producción por parte de A, el alumno, de la estrategia ganadora (efecto Topacio) y en el momento de su "evaluación" (efecto Jourdain). En estos casos se transgrede una regla fundamental de la acción didáctica: la docente debe ser reticente de manera tal que los alumnos actúen motu proprio y puedan construir conocimiento por sí mismos. 
Desde esta perspectiva se asume que el significado se elabora mediante un proceso de inferencias producidas de manera situada, en un contexto que se constituye en el medio institucional. Así se considera el medio didáctico a través de dos descriptores: el primero es aquél que ya hemos referido como un bagaje, un trasfondo común que permite que tanto los alumnos como el docente tengan expectativas acerca de lo que se espera de él y puedan predecir intencionalidades que, como tales, conforman el contrato didáctico. Es decir, el medio didáctico conforma un sistema de significados compartidos que hace posible la acción conjunta. Sin embargo para aprender los estudiantes necesitan encontrarse con un medio antagonista (Brousseau, 2007) que provoque cierta resistencia a esa acción conjunta. Esa noción refiere al conocimiento que los alumnos no pueden asimilar directamente, la manera en que el medio provoca cierta resistencia puede ser prevista y diseñada por el docente y el investigador. Es importante tener en cuenta que para poder enfrentar a ese medio se requiere tomar consciencia de él, y así, al experimentar esa resistencia al medio, los estudiantes pueden encontrarse con aquello que no saben y darse cuenta que necesitan cierto conocimiento (Sensevy, 2010).

Uno de los casos que Brousseau describe para dar cuenta del medio como antagonista es la situación didáctica del rompecabezas (puzzle). El desafío que se presenta a los alumnos consistió en aumentar el tamaño de las piezas de un rompecabezas de manera tal que un segmento que medía $4 \mathrm{~cm}$ en el original pasara a medir $7 \mathrm{~cm}$ de longitud en la reproducción. Los estudiantes trabajaban en grupos para producir las nuevas piezas. En algunos casos resolvieron añadir $3 \mathrm{~cm}$ a cada segmento, no pudieron pensar el caso como un problema de proporcionalidad y en cambio lo pensaron como un problema de adición, tal como planteaban problemas previos que habían resuelto y en los que debían establecer relaciones entre números. Pero en este caso al sumar los $3 \mathrm{~cm}$ a cada segmento las piezas resultantes no encajaban, así fue el medio en tanto antagonista quien aportó un feedback específico al ser evidente la incompatibilidad entre las piezas. Los alumnos deben darse cuenta de su ignorancia para resolver el problema aplicando aquello que ya conocían. Deben estar convencidos en este caso que han medido bien y que no pueden resolver el problema con la adición como método matemático. Si eso sucede van a poder cuestionar el método utilizado. A lo largo de la situación la docente va asumiendo diferentes roles en la transacción, en principio acompaña el proceso de pensamiento $y$, a medida que transcurre el tiempo didáctico, progresivamente va asumiendo mayor responsabilidad en la transacción, aunque mantiene la reticencia (Sensevy, 2012). 
Para caracterizar la acción didáctica es importante identificar cómo los alumnos se orientan, al actuar a partir de los hábitos implícitos en el contrato didáctico o estableciendo relaciones epistémicas con el medio. A través de estudios empíricos, tal como el que encaramos, se podría conocer qué clase de relación dialéctica se construye entre las orientaciones ancladas en el contrato y aquéllas que propone el medio, de manera tal de comprender la acción didáctica conjunta y la forma en que los estudiantes se apropian del contenido disciplinar. La relación entre contrato y medio resultará central en esa caracterización (Sensevy, 2010). Para describir la manera en que la docente hace jugar el juego a sus alumnos desde esta perspectiva teórica se utilizan una serie de categorías, propuestas inicialmente por Brousseau y retomadas por Sensevy (2007), que se denominan: definir, devolver, regular e institucionalizar.

Al iniciar el juego es necesario definir, este descriptor refiere a cómo la docente instala las reglas del juego que permiten que los alumnos de motu proprio intervengan en él. Pero además de definir el juego, para que los estudiantes intervengan en ese juego de aprendizaje la docente debe actuar de manera reticente y devolver el juego. Esa reticencia implica dejar que los alumnos interactúen con el medio didáctico a pesar de la resistencia que éste pueda presentar. Pero ese dejar hacer no significa que la docente no se involucre sino que resulta imprescindible que pueda regular mediante intervenciones pertinentes las estrategias que producen sus alumnos. Así podrá influir para favorecer que los estudiantes puedan producir las estrategias ganadoras que den lugar a la construcción de conocimiento genuino. Esa regulación resultará clave para orientar a los alumnos a transitar a través de la relación dialéctica entre certezas/incertezas en relación con el conocimiento en juego (Sensevy, 2010, 2014). Al institucionalizar la docente reconoce aquellas maneras de actuar y pensar pertinentes en relación con cierto objeto de conocimiento. Esta acción es imprescindible para que los alumnos controlen su propio proceso de apropiación del conocimiento en juego. Estas cuatro categorías que hemos mencionado (definir, devolver, regular e institucionalizar) permiten describir los juegos de aprendizaje y así conocer cómo la interacción influye en los modos de construcción de conocimiento. En algunas de las escenas didácticas nos interesó utilizar estas categorías que dan cuenta de la gramática del juego, y aun cuando no las hayamos hecho explícitas en todas esas escenas, constituyeron herramientas para analizar en un nivel más estructural la acción didáctica.

Desde la Teoría de la Acción Conjunta (JATD) se proponen otra serie de categorías para dar cuenta de la dinámica de la co-construcción de significados en clase. Este triplete de categorías se denominan: mesogénesis, cronogénesis y topogénesis, y se 
utilizan para abordar el análisis de cómo la docente construye el juego de manera conjunta con sus alumnos (Sensevy, 2007; Rickenman, 2007).

La primera de ellas, mesogénesis, describe el proceso por el cual el docente organiza un medio con el que intenta que los alumnos interactúen para aprender. Aquello que constituye el contenido debe ser redefinido constantemente durante la transacción didáctica y por ello es que el trabajo conjunto de profesor y alumnos es de vital importancia durante la génesis del medio (Sensevy, 2007, 2010). Es a través de las tareas que los alumnos deben realizar interactuando con un medio didáctico, que podrán construir nuevos conocimientos al ir modificando ese medio (Rickenmann, 2006). Analizar las prácticas a partir de esta dimensión implicó estudiar la forma en que se produjo el contenido colectivamente entre la docente $S$ y los estudiantes.

Por su parte, la cronogénesis describe la evolución del conocimiento propuesto por el docente y estudiado por los alumnos, tal como se desarrolla durante la acción didáctica. Así esta dimensión refiere a la génesis del tiempo didáctico, dado que la enseñanza se concibe como una progresión. La cronogénesis y la mesogénesis están íntimamente ligadas, si se cambia una condición durante el desarrollo de la enseñanza, se reconfigura el medio y podremos analizar ese cambio mesogenético. Pero a la vez, si se analiza ese nuevo elemento en relación con lo previo, estamos considerando un valor cronogenético (Sensevy, 2007). El profesor gestiona el tiempo didáctico con la intención de avanzar en el programa, por ejemplo cuando un estudiante responde correctamente a una pregunta que realizó y decide no consultar a los demás alumnos y avanzar con otra cuestión (Rickenmann, 2006).

Por último, la topogénesis describe la manera en que se comparten las responsabilidades en las transacciones didácticas, el docente ocupa una posición en la relación y posibilita que los alumnos ocupen sus posiciones en el proceso didáctico (Sensevy, 2010). Así, en interacción con un medio, los estudiantes desarrollan acciones acordes con el proyecto didáctico, los comportamientos a través de los cuales encaran la tarea resultarían indicadores del tipo de relación con las actividades de aprendizaje que están construyendo. Diversos tipos de actividad podrían promover que los alumnos asuman distintas funciones en relación con ellos, es en este sentido, que podemos mencionar que:

Las investigaciones recientes han mostrado que cuando se varían los topos o tipos de actividad que se propone a los alumnos, los conocimientos que estos construyen sobre los objetos de enseñanza son más variados y complejos. (Rickenmann, 2006:5).

Analizar los procesos de topogénesis requiere poner en foco cuál es el rol que cada agente de la transacción asume en el marco del contrato didáctico como sistema de 
expectativas entre docente y alumnos, por lo tanto la categoría permitiría privilegiar la naturaleza conjunta de esa interacción (Sensevy, 2007). En nuestro caso, a través de esta dimensión analizamos cómo cambia la responsabilidad de la acción desde la docente a algunos alumnos que asumen una posición activa durante el intercambio, explicitando posiciones con relación al contenido epistémico en juego. La topogénesis corresponde a la pregunta ¿quién actúa? o ¿cómo interviene aquél que actúa?, manteniendo en trasfondo las otras dos dimensiones. Por su parte, la mesogénesis refiere a ¿qué?, es decir cuál es el contenido epistémico de la transacción y cómo se pone en juego ese contenido; y la cronogénesis corresponde a la pregunta ¿cuándo? a través de la cual se intenta identificar las razones y la clase de cambio de un contenido epistémico a otro (Sensevy, 2007).

Estas tres dimensiones íntimamente ligadas pueden ser utilizadas de manera conjunta para analizar los datos o es posible, como en nuestro análisis, seleccionar aquella que consideramos más representativa en cada momento para interpretar y comprender lo que sucedió durante la acción didáctica.

\subsection{Enseñar y aprender contenidos situados y complejos, a través del leer y escribir en un aula de formación docente inicial}

En los apartados previos nos hemos referido a la vinculación entre aprendizaje y escritura (y lectura). Y en especial al diseño e implementación de secuencias didácticas para enseñar contenidos disciplinares que incluyan actividades de lectura, escritura y oralidad en el nivel superior de enseñanza. A la vez, consideramos que enseñar ciertos objetos, en realidad enseñar cierta manera de concebir los objetos y constituirlos en situados y complejos, implicaría un trabajo recursivo a través de dispositivos didácticos que posibiliten que los estudiantes puedan establecer múltiples relaciones. Y es en este sentido que el leer y escribir son pertinentes. En este último apartado haremos referencia particular a cuál sería la especificidad que adquieren las prácticas de lectura y escritura para los futuros docentes.

En la formación del profesorado los enfoques mayoritarios oscilan entre dos posturas: aquellos que consideran a los profesores meros transmisores y por lo tanto reducen la profesionalidad, la autonomía y la capacidad de desarrollo, dado que presentan el saber disciplinar (de las disciplinas de referencia, así como de las Ciencias de la Educación) como un saber verdadero libre de influencias éticas e ideológicas. Y por otro lado una postura espontaneísta y activista basada en el principio de que a enseñar se aprende enseñando, que también limita el desarrollo profesional de los docentes al ubicar la experiencia didáctica cotidiana como referencia fundamental, sin considerar que esta 
práctica sin reflexividad se constituye en rutinaria y puede estar cargada de presupuestos que la orientan y cristalizan.

Peters (1987), desde la teoría de la actividad, da cuenta de la tensión que surge entre dos conceptos propios de la actividad: prácticas rutinarias (o habituales) e intencionalidad de esas prácticas. ¿Cómo se establecen esas rutinas? Son producto de prueba y error, como resultado de automatismos, o fueron asumidas como acciones cotidianas, pero que no pierden de vista las intencionalidades subyacentes en cada acción. En este último caso la reflexión es parte de la base de rutinas flexibles y adaptables de acuerdo a las intencionalidades (Edelstein, 2011). En este mismo sentido Porlán, del Pozo, Martín y Rivero (2001) sostienen que:

Una formación crítica del profesorado ha de basarse en una visión integradora de las relaciones entre conocimiento disciplinar, conocimiento experiencial e ideología subyacente, a través de principios como el respeto de la autonomía, el reconocimiento de la diversidad de significados y la negociación argumentada y crítica de los mismos. (Porlán, del Pozo, Martín y Rivero, 2001: 14).

Ahora bien, el contexto de nuestro trabajo es un aula de formación inicial de profesores ¿Qué particularidades tiene ese ámbito de formación de profesionales de la enseñanza? ¿Cómo se concibe la formación inicial de profesores de Biología? ¿Centrada sólo en los objetos biológicos en tanto entidades a transmitir, o será necesario a la vez que la formación dé cuenta de cómo se construye el conocimiento acerca de esos objetos particulares? Como parte del desarrollo de las secuencias nos propusimos favorecer la interacción en clase dado que consideramos que permite expresar diversos puntos de vista y argumentar el propio, a la vez que se negocian sentidos y significados y se ejerce vigilancia crítica acerca de lo que se enuncia. Así, habilitar y empoderar las voces de los estudiantes contribuye a constituirlos como futuros profesionales.

Con relación a las prácticas de lectura y escritura en esta instancia formativa haremos referencia a las situaciones de doble conceptualización que Lerner, Stella y Torres (2009) definen. Al referirse a ellas sostienen que:

La especificidad de esta estrategia formativa consiste en favorecer que los docentes ejerzan quehaceres propios de los lectores y los escritores, para poder luego conceptualizar tanto los quehaceres ejercidos como las características de la situación didáctica de la cual han participado. (Lerner, Stella y Torres, 2009)

Estas situaciones dan la posibilidad de compartir con pares la lectura y la escritura durante la formación y es por ello que favorecen la constitución de una comunidad de lectores y escritores. A la vez, el hecho de compartir estas prácticas posibilita conceptualizarlas, dado que al ejercerlas de manera comunitaria compartiendo interpretaciones, se transforman en observables diferentes elementos implícitos que no son evidentes en la lectura individual. Así, 
Se pone en evidencia que un texto puede ser entendido de diversas maneras, que leer es interactuar con el texto y que, en esta interacción, es fundamental el aporte del lector. (Lerner, Stella y Torres, 2009: 26).

Aunque las autoras refieren a esta instancia como parte de espacios de formación continua y a dispositivos que expresamente se proponen abordar esa doble conceptualización, nos permitimos tomar como referencia la noción dado que resulta pertinente para caracterizar instancias de formación inicial específica en las que el leer y escribir textos disciplinares haría posible visibilizar esas prácticas y ponerlas en juego como objetos de reflexión y revisión. 


\section{CAPÍTULO 2}

Acerca de decisiones metodológicas durante el proceso de investigación: configurando el problema, los interrogantes y las estrategias

\subsection{Algunos supuestos y decisiones preliminares. Acerca del diseño didáctico, su implementación y el trabajo colaborativo}

En este capítulo nos referimos al proceso metodológico de la investigación realizada para esta tesis, a través de la cual nos interesó conocer y comprender cómo trabajar de manera integrada escritura, lectura y oralidad para enseñar contenidos disciplinares específicos en la formación inicial de profesores de Biología.

Preguntarnos acerca de ese cómo supuso asumir que el escribir y leer son prácticas relevantes para aprender contenidos disciplinares en el nivel superior. A la vez, implicó sostener que docentes de las disciplinas (Biología en este caso) podían ocuparse del trabajo con la escritura y la lectura en sus asignaturas, tal como hemos argumentado en el capítulo previo de referentes. Y dado que la cuestión que nos ocupaba incluía cómo trabajar de manera integrada, asumimos que ese trabajo con prácticas de lectura y escritura podía estar entrelazado a la enseñanza de un contenido disciplinar; tan íntimamente asociado que no sería posible desgajarlo. Así, enseñar ese contenido desde esta postura, implicaría enseñar cómo lo atraviesa y configura el lenguaje disciplinar. Y para ello sería necesario trabajar con cómo escribir, leer y hablar acerca de ese contenido específico, a la vez que enseñar las maneras de representarlo (por ejemplo, al dibujar).

En este mismo sentido, consideramos que determinadas prácticas de escritura y lectura son pertinentes sólo en asociación con ciertas miradas sobre los objetos disciplinares. Asumimos que esas prácticas son situadas, y por lo tanto abordar el cómo requirió diseñar secuencias didácticas de acuerdo con nuestro marco referencial. Es decir, acordes con nuestra perspectiva acerca de cómo enseñar y aprender cierto objeto disciplinar, constituido en este caso desde una perspectiva sistémica. Pero a la vez, implicó seleccionar qué y para qué leer y escribir acerca de ese contenido, además de organizar el trabajo con los estudiantes durante esas prácticas.

Un aspecto central en este proceso metodológico fue la decisión de trabajar de manera colaborativa con la profesora. Es decir, no se aplicó una secuencia de enseñanza elaborada en otro contexto y sin participación docente, sino que se decidió diseñar e implementar de manera conjunta con la profesora a cargo secuencias que incluían diversas situaciones de enseñanza que entretejen escribir y leer para aprender contenidos biológicos. 
Asimismo conocer ese cómo requirió analizar qué ocurría en esas aulas de nivel superior durante el trabajo con las propuestas que diseñamos. Enfocamos el análisis en ciertas cuestiones centrales tales como las tareas que se incluían y las interacciones que ocurrieron durante el desarrollo de esas tareas. $Y$ de esa manera recortamos el problema que se aborda en esta tesis, y que puso foco en cómo se desarrolla una secuencia didáctica que integre escritura, lectura y oralidad a la enseñanza de un contenido disciplinar específico en el contexto de una asignatura del Profesorado de Biología.

\subsubsection{Acerca de la perspectiva metodológica}

Los diferentes modos de hacer ciencia de lo social no sólo implican distintas maneras de obtener y analizar la información empírica, sino que refieren principalmente a perspectivas diferentes para pensar y concebir las formas de llevar a cabo la investigación, no se reducen así a diferencias técnicas (Sirvent, 2010). Esos modos de hacer ciencia de lo social:

(...) tienen su anclaje y fundamentación en la trama de las dimensiones epistemológica, teórica, lógica y metodológica de cada una de las tradiciones paradigmáticas en ciencias sociales: la tradición positivista, hermenéutica y de la teoría social crítica. Es esta trama la que va a dar cuenta del perfil diferenciado de cada uno de los modos de hacer ciencia de lo social: un modo verificativo, un modo de generación conceptual y un modo participativo.(Sirvent, 2010:140)

De acuerdo a esta diferenciación que propone Sirvent, nuestro trabajo estuvo orientado por la lógica de generación conceptual. ${ }^{5}$ Nos reconocemos en esa lógica vinculada con los marcos cualitativos, que incluyen análisis descriptivos e interpretativos para poder abordar la densidad y complejidad de los procesos educativos investigados (Maxwell, 2005). Sin embargo, la implicación fue más allá de comprender las lógicas de generación conceptual dado que hubo intervención sobre la realidad analizada.

El problema delimitado no podía ser abordado mediante un estudio naturalista que analizara lo que sucedía en un contexto habitual de enseñanza, sino que requería una intervención didáctica de manera tal de poner en aula un diseño que pudiera generar ciertas condiciones de enseñanza. No obstante, ello no implica un enfoque experimental. Asumimos que las secuencias analizadas no pueden ser aisladas de su contexto y que deben ocurrir en el escenario natural de las entidades de estudio,

\footnotetext{
5 "La denominación de modo de generación conceptual tiene su anclaje en la noción y centralidad de los procedimientos de construcción de categorías que den cuenta de la descripción y comprensión holística del hecho social investigado. La naturaleza de los resultados buscados son conclusiones en términos de esquemas conceptuales que no pretenden ser generalizables estadísticamente, sino fértiles teóricamente para describir e interpretar el caso en estudio y ser transferibles a otros casos. Su validación está referida a la seriedad y rigurosidad del proceso de construcción del/los esquemas conceptuales y a la mencionada 'fertilidad teórica'. La subjetividad deviene componente de la construcción del dato científico" (Sirvent, 2010, p.151).
} 
teniendo en cuenta el significado que actores e investigadores le asignan a un hecho social para poder conocerlo (Sirvent, 2008; Vasilachis, 2007). Aun cuando referimos a un escenario natural, en esta instancia tal como dijimos realizamos una intervención en ese escenario y por lo tanto hemos construido nuevas condiciones. Pero el hecho de trabajar de manera sistemática durante dos años consecutivos con la docente, los estudiantes, en clase y en instancias extra clase en la constitución de un dispositivo didáctico, dio lugar a que se constituyera un nuevo escenario natural en el que se desarrolló la secuencia objeto de estudio.

Tal como hemos mencionado en el capítulo previo es posible poner en diálogo las diversas perspectivas subsumidas en el marco de las investigaciones basadas en diseños didácticos (designed-based researches) (Ruthven, Laborde, Leach y Tibergein, 2009). Nos interesa en especial retomar aquí la manera de concebir el vínculo entre diseño teórico y puesta en aula de las investigaciones de este marco. Esas perspectivas asumen como uno de sus propósitos la explicación de cómo los diseños se desarrollan en escenarios auténticos. El sentido es no sólo documentar aquello que funciona o no, sino especialmente centrarse en aquellas interacciones que hagan posible afinar la comprensión acerca de las cuestiones de aprendizaje involucradas (The Design-Based Research Collective, 2003).

Tomando en cuenta el trabajo desarrollado durante el diseño y puesta en aula entre docente e investigadora, podemos establecer relaciones con investigaciones de diseño didáctico que se agrupan bajo la denominación ingeniería cooperativa (cooperative engineering) (Joffredo-Le Brun. Morellato, Sensevy y Quilio, 2018; Morales, Sensevy y Forest, 2017; Sensevy, Forest, Quilio, Morales, 2013). Las investigaciones encaradas desde esta perspectiva involucran el trabajo conjunto de docentes e investigadores que comparten problemas relacionados con la práctica. En general son problemas de enseñanza vinculados con un determinado contenido del currículum. La primera etapa en este proceso de ingeniería consiste en reflexionar acerca del contenido a trabajar para establecer una relación colectiva (y no sólo individual) con este contenido. Y para ello es necesario romper con la oposición entre teoría y práctica: investigador que piensa el diseño /docente que lo actúa.

Para trabajar con el problema no será suficiente volver a pensar de manera individual la naturaleza de ese conocimiento a enseñar. En realidad para investigadores y docentes será crucial hacerlo de manera cooperativa para construir un diseño didáctico específico y elaborar estrategias de enseñanza, ambos aspectos fuertemente delineados por el conocimiento en juego (Sensevy, Forest, Quilio, Morales, 2013). Esta perspectiva se aleja así de la división del trabajo propia de otras modalidades, como aquellas en que 
los profesores aplican diseños elaborados y validados por investigadores o las que son los docentes por su propia cuenta quienes recuperan y adaptan algunos dispositivos que en principio estiman relevantes. A ese primer dualismo entre teoría y práctica se le asocia otro entre fines y medios. En ocasiones cuando investigadores y docentes trabajan juntos, la división del trabajo implica que sean los investigadores quienes tienden a definir los propósitos fundamentales y las metas, mientras que son los docentes quienes tienen que encontrar los medios concretos para lograr esos fines (Morales, Sensevy, Forest, 2017).

Tal como delineamos, nuestra investigación se relaciona con la ingeniería cooperativa a través de la manera de concebir y actuar el vínculo entre docente e investigadora durante el proceso de diseño e implementación de las secuencias didácticas. Durante ese proceso fue imprescindible construir de manera cooperativa la relación entre teoría $y$ práctica (pensando tanto en el contenido disciplinar como en el dispositivo concreto de trabajo con ese conocimiento). La manera cooperativa de trabajar durante el diseño y la implementación se puede vincular con el principio de simetría, uno de aquellos en los que se basa la ingeniería cooperativa. Este principio establece que a priori tanto docente como investigadora son capaces de proponer modos adecuados de actuar o formas relevantes de conceptualizar la práctica durante el diseño elaborado (Morales, Sensevy, Forest, 2017). Así también, en nuestro trabajo sostuvimos de manera conjunta durante el desarrollo los propósitos consensuados y reflexionamos al poner en discusión los medios para alcanzarlos.

Un aspecto que en general comparten las investigaciones basadas en diseños didácticos (designed-based researches) y es una característica distintiva de la ingeniería cooperativa es lo iterativo del proceso de investigación. Ello implica una acción recursiva de trabajo entre investigadores y docentes, al diseñar, implementar, analizar lo sucedido, rediseñar, volver a implementar y así sucesivamente (Sensevy, et al 2013). En nuestro caso, no hubo rediseño a partir de lo que surgió del análisis de la implementación de la secuencia didáctica sobre ciclo celular, ni nueva implementación. Por lo tanto no compartiría esa condición. Sin embargo, si pensamos en el proceso completo de trabajo conjunto que desarrollamos durante dos años consecutivos, podemos identificar una estructura iterativa de ese proceso dado que hubo instancias de diseño, puesta en aula, análisis, nuevo diseño, nueva implementación de diferentes secuencias didácticas. Aquello sucedido durante el primer año de trabajo cooperativo permitió consolidar y enriquecer la etapa siguiente de trabajo conjunto.

\subsection{Definición del problema, ajuste de preguntas y objetivos de investigación}


El problema que delimitamos se ubica en una realidad que, aunque conocida, nos interpelaba con una serie de interrogantes. Como anunciamos, el ámbito de inserción de esta investigación fue la enseñanza de Biología en el nivel superior, un espacio vinculado estrechamente con nuestra experiencia docente de más de veinte años de trabajo. Fue justamente este ámbito conocido el que nos convocó e interpeló para desandar algunas certezas y así poder construir una mirada que cuestionara certidumbres y problematizara esa realidad. En este sentido, acordamos que:

Es en esa problematización que está la génesis de la investigación científica, al identificar la situación problemática como el conjunto de cuestiones que a un investigador lo preocupa, lo fascina, lo asombra, lo enfrenta a su ignorancia, lo motiva para investigar. Una suerte de espacio de interrogantes sin respuesta inmediata que demandan un proceso de investigación: es lo que no se sabe.

Problematizar la realidad es mirarla críticamente para "desnaturalizar" lo que aparece como "natural"; es traspasar con una pregunta la apariencia de los fenómenos para descubrir la trama de los factores que dan cuenta de por qué las cosas son como son y no de otra manera y, por lo tanto, pueden ser de otra manera. (Sirvent, Monteverde, Clerici, Peruzzo y Agulló, 2016: 8)

El lugar en el que se desarrolló la investigación fue una institución pública de formación docente inicial de la que tanto esta investigadora, como la docente que compartió la experiencia, formábamos parte. En el relevamiento de antecedentes no encontramos avances sustantivos de investigaciones que se ocuparan de la enseñanza de temas de biología celular, a través del trabajo con prácticas de lectura y escritura. Consideramos que en ese contexto de formación de formadores esta tesis podía resultar un aporte al conocimiento sobre las acciones didácticas. En este sentido es que pensamos que cobra particular relevancia el problema que abordamos en esta investigación y que está estrechamente asociado a la práctica docente y que en consonancia con lo planteado por Sirvent et al (2016) y que citamos más arriba, nos preocupa, fascina, asombra, nos enfrenta a nuestra ignorancia y nos motiva para investigar. Expresamos ese problema en la pregunta general:

¿Cómo se desarrolla una secuencia didáctica que integre lectura, escritura y oralidad para la enseñanza de un contenido disciplinar específico, en el contexto de una asignatura del Profesorado de Biología?

Para abordarlo, hemos desagregado ese interrogante global en una serie de preguntas más puntuales, que orientaron esta investigación y que presentamos a continuación.

- ¿Qué características adquieren las situaciones de escritura, lectura y oralidad integradas a un contenido disciplinar durante la implementación de una secuencia didáctica para enseñar el ciclo celular? 
- ¿Qué características asumen las intervenciones orales docentes durante el desarrollo de la secuencia didáctica y qué generan en los estudiantes con relación al conocimiento en juego?

- ¿Cuáles son las condiciones de enseñanza que presentan mayor potencialidad para el aprendizaje del ciclo celular en esta propuesta?

- ¿Qué desafíos, resistencias y logros surgen al trabajar de manera integrada la escritura, la lectura y la oralidad en la enseñanza del ciclo celular, en el contexto de una asignatura del Profesorado de Biología?

Las primeras preguntas remiten directamente a decisiones relacionadas con la acción didáctica y al cómo hacer, poniendo énfasis en la perspectiva docente, mientras que otras preguntas incorporan a los estudiantes. Consideramos que todas están estrechamente vinculadas entre sí al operar como si fueran el zoom de una lente que nos permite un ajuste de mayor precisión al enfocar el objeto de indagación.

En consonancia con el problema enunciado y las preguntas que nos fuimos planteando, formulamos los objetivos específicos del trabajo y que se detallan a continuación:

- Describir las situaciones de escritura, lectura y oralidad integradas en una secuencia de enseñanza sobre ciclo celular.

- Caracterizar las intervenciones orales docentes en las situaciones analizadas.

- Comprender qué generan en los estudiantes en relación al conocimiento en juego.

- Identificar aquellas condiciones didácticas particularmente asociadas a estas situaciones e intervenciones que favorecen el aprendizaje del ciclo celular.

- Reconocer desafíos, resistencias y logros que surgen y se pueden vincular con el trabajo con las situaciones de escritura y lectura analizadas.

Presentaremos ahora algunos tramos del recorrido cognitivo y vivencial realizado durante el proceso, de manera tal de fundamentar las decisiones metodológicas a través de aquello que Sirvent denomina cocina de la investigación y que representa:

Al conjunto de procedimientos metodológicos concretos, de caminos elegidos para poner en acto en el día a día de nuestro quehacer investigativo los conceptos vertebrales del hacer ciencia de lo social. Es la descripción de cómo hacemos investigación en el cotidiano de nuestro trabajo de indagación científica, de cómo "amasamos" la teoría y la empiria cual artistas para dar forma a la escultura de nuestros resultados, de cómo ponemos en juego nuestras relaciones con el objeto de investigación. En otras palabras, nos estamos refiriendo a nuestro oficio cotidiano de investigador. (Sirvent, 2010: 135) 
Comenzamos por el contexto y su devenir, para después dar cuenta de cómo influyó en las decisiones que tomamos al configurar el problema. Posteriormente describimos las diferentes estrategias de recolección de datos y los principales lineamientos que guiaron el análisis que realizamos para esta tesis.

\section{3. Contexto de intervención didáctica. Decisiones metodológicas acerca de dónde y cuándo situar el problema}

La investigación se llevó a cabo en un Instituto Nacional de Formación Docente de gestión pública, ubicado en el partido de General San Martín, en la provincia de Buenos Aires. Esa institución es parte de una unidad académica que brinda formación en los diferentes niveles de escolaridad: jardín de infantes, nivel primario, nivel secundario y nivel superior. En ella se cursan varias carreras de formación docente inicial, la mayoría en el turno vespertino. Nuestra indagación proponía un estudio cualitativo interpretativo que incluyó el diseño de secuencias de enseñanza y su desarrollo en asignaturas del Profesorado en Educación Secundaria de Biología.

Se trabajó de manera conjunta con la docente $S$, que tenía a su cargo diferentes asignaturas disciplinares: Biología y Laboratorio II en segundo año, Biología Celular en tercero y Ecología en cuarto año del profesorado de Biología. Además era -al momento de realizar la investigación- la coordinadora del departamento de Ciencias Naturales de la institución.

En esa misma institución y carrera de formación docente trabajé durante varios años como profesora de materias del cuarto año. Seleccionar una institución conocida permitía accesibilidad, una condición que resultaba imprescindible asegurar en un estudio de este tipo que iba a requerir mucho tiempo de permanencia en el aula, y por lo tanto debía ser avalado por los referentes institucionales.

La docente convocada (S) reconocía la potencialidad que tiene trabajar con la lectura y la escritura para aprender, a la vez que consideraba posible enseñar a leer y escribir en las materias de nivel superior. Así también estaba interesada en pensar de manera conjunta estrategias de trabajo didáctico, porque aun cuando había incorporado prácticas de lectura y escritura durante la enseñanza de las materias, encontraba dificultades para integrarlas y acompañar esas prácticas durante las clases. Creemos que éste fue un aspecto clave para su involucramiento personal y profesional ya que presentaba desafíos, tanto para la docente como para la investigadora, dado que articular la práctica de enseñanza con la perspectiva teórica representa un aspecto crucial de la didáctica (Lucarelli, 2010). 
A la vez, queremos mencionar que cuando encaramos esta investigación ya existía un vínculo laboral entre la profesora y esta tesista, como parte de la misma cátedra del Ciclo Básico Común de la UBA. Aunque como conformábamos equipos docentes de dos materias diferentes nunca habíamos trabajado juntas en un mismo aula. A través de ese conocimiento previo de muchos años se estableció un vínculo de afecto y respeto mutuo. Esa cercanía favoreció la intensidad y el compromiso que hubo, tanto en la etapa preliminar de intercambio y preparación de los diseños como a lo largo de la implementación. Durante esas instancias la tensión entre teoría y práctica fue objeto de reflexión, discusión y argumentación, al diseñar las secuencias e implementarlas de manera conjunta.

Para elaborar las secuencias didácticas de manera colaborativa partimos de un diseño preliminar con propuestas realizadas por esta tesista a partir de conversaciones con la docente acerca de sus intereses didácticos con relación a los contenidos específicos. Pero a la vez esas propuestas eran enriquecidas por aportes de la docente, como por ejemplo textos didácticos, consignas de actividades de escritura ya puestas en práctica, bibliografía para sugerir a los estudiantes, imágenes que enviamos a los estudiantes por mail (en pdf o ppt), entre otras contribuciones al diseño y puesta en aula de las secuencias.

La etapa de diseño de estas secuencias de enseñanza no precedió totalmente a la implementación. Se realizó un diseño inicial maleable, que contenía alternativas de acción de manera tal de ir ajustando tiempo didáctico, contenidos y actividades a medida que se desarrollaba la puesta en aula. Eso implicó tomar decisiones metodológicas a partir de aquello que iba sucediendo, en ese sentido las etapas del proceso investigativo se solaparon y lo tornaron recursivo, flexible y dinámico.

\subsubsection{El devenir del contexto de intervención. Decisiones para reajustar dónde y cuándo situar el problema}

Tal como dijimos, en primera instancia seleccionamos la institución y acordamos formar un equipo con la docente S. Con ella decidimos a fines del año 2010 comenzar con el diseño de situaciones didácticas para la asignatura del segundo año que tenía a cargo: Biología y Laboratorio II. En esa primera instancia acordamos trabajar en el diseño conjunto de una secuencia para abordar la alimentación, un contenido disciplinar que suele considerarse sencillo, pero sin embargo es una noción compleja condicionada socialmente (Rivarosa, De Longhi y Astudillo, 2011).

Pero a la vez, decidimos comenzar con una secuencia previa a desarrollar durante el primer mes de clase, con el objetivo de crear las condiciones para que el leer y escribir 
para aprender no fuera objeto de extrañeza para los estudiantes, sino que ya hubieran naturalizado esas instancias de trabajo. En esa primera secuencia se retomaron contenidos generales de Biología ya estudiados (características de los seres vivos, niveles de organización) con la intención de complejizar, contextualizar y contribuir al desarrollo de una concepción sistémica e integrada de los seres vivos. En realidad, comenzar al inicio del cuatrimestre y en la primera materia que los estudiantes cursaban con la docente S permitía ir visibilizando el leer y escribir, al ir instaurando prácticas de escritura sistemática con entrega a la docente y devolución por escrito. Ese tipo de trabajo no suele ser habitual en el nivel superior y las instancias de escritura en las asignaturas que cursaban los estudiantes solían quedar relegadas sólo a las evaluaciones parciales.

Ese año cursaban la asignatura Biología y Laboratorio II 26 estudiantes de los profesorados de Biología y Química (primer y segundo año es común a ambos profesorados), 10 de ellos habían comenzado a cursar la materia el año previo y habían abandonado la cursada.

El tiempo didáctico que habíamos planificado inicialmente para estas secuencias se extendió más de lo previsto por diferentes razones. Uno de los motivos fue que el trabajo en clase con tareas de escritura y lectura, así como las devoluciones de las tareas que se retomaban para reajustar consignas y revisar y compartir cuestiones globales, demandó más tiempo de clase que el previsto en cada diseño. En particular, la implementación de la secuencia didáctica sobre alimentación, que habíamos pensado inicialmente como objeto de indagación para esta tesis, presentó varios inconvenientes. Comenzamos con ella después de la primera evaluación parcial, un momento que coincidió con parciales de otras asignaturas, por lo cual hubo muchos estudiantes ausentes durante las primeras dos semanas de implementación. Se sumaba a ello que la temática alimentación les parecía sencilla y la manera de abordarla no los convocaba. ${ }^{6}$

Así las cosas, antes de finalizar el curso nos reunimos para evaluar cómo seguir. Teníamos en ese momento dos opciones para continuar:

\footnotetext{
${ }^{6}$ Complejizando la situación, después de esas dos semanas comenzaron las vacaciones de invierno y posteriormente un turno para rendir exámenes finales, por lo cual hubo un receso de aproximadamente un mes que "atravesó" la secuencia. A continuación de ese receso retomamos el trabajo con la secuencia sobre alimentación, pero tuvimos que interrumpir las observaciones de clase una semana después, a finales de agosto, por razones personales de la tesista debido a un problema importante de salud familiar que hizo que no pudiera continuar con las observaciones de clase durante ese año.
} 
- Implementar la secuencia sobre alimentación, con los ajustes necesarios, al año siguiente con un nuevo grupo de estudiantes en la asignatura Biología y Laboratorio II.

- Diseñar e implementar una nueva secuencia para abordar otro contenido disciplinar y trabajar con los mismos estudiantes (o parte de ellos) al año siguiente en la asignatura del tercer año (Biología celular) a cargo de la misma docente S.

A la vez, en ese momento del año consultamos por escrito a los estudiantes que estaban terminando de cursar Biología y Laboratorio II, acerca de los logros y dificultades del trabajo realizado. Les preguntamos también cuáles eran las recomendaciones que le harían a la docente para que tuviera en cuenta al elaborar una propuesta para los alumnos que cursaran esa materia el año próximo. En la consulta no hicimos ninguna referencia particular a las secuencias didácticas motivo de análisis.

En varias respuestas mencionaron que consideraban extenso el tiempo dedicado a algunos contenidos (todas las referencias fueron con relación a temas de la primera parte del año). También algunos estudiantes comentaron de manera específica que no les había gustado ni habían comprendido el sentido de trabajar con diferentes materiales de la web en la secuencia de alimentación. A la vez, mencionaron que había quedado poco tiempo para aquellos temas que consideraban más importantes y que tenían que saber en su vida profesional como docentes ${ }^{7}$. Se referían así a la estructura y fisiología de los diferentes sistemas de órganos que se habían abordado en la segunda parte de ese año.

Fue así que al finalizar 2011 tomamos la decisión de elaborar una nueva secuencia para implementar en la materia Biología Celular al año siguiente. Quisimos continuar con estudiantes que ya habían participado de las secuencias diseñadas. Consideramos que era una forma de capitalizar el trabajo que ya habíamos hecho para instalar cierto tipo de prácticas de escritura y lectura, como parte de la enseñanza de las asignaturas a cargo de la docente S.

Nos interesó seleccionar un contenido de esa asignatura que fuera difícil de aprender; con el propósito de que el trabajo recursivo con la escritura y el tiempo didáctico dedicado a ello, adquiriera mayor sentido para los estudiantes. Y a la vez pudiéramos acompañarlos durante la lectura de textos propios de Biología Celular como insumos para las tareas de escritura. Para seleccionar qué contenido abordar se consultó a la

\footnotetext{
${ }^{7}$ Las palabras en cursiva en esta frase representan términos literales incluidos en algunas respuestas escritas y en las entrevistas realizadas con posterioridad a la implementación de la secuencia efectivamente analizada.
} 
docente $S$ cuáles consideraba que eran los temas de esta asignatura en los que surgían mayores dificultades para los alumnos. Así también por correo electrónico se les preguntó a estudiantes que habían cursado la asignatura en años previos, cuáles eran los contenidos de la asignatura Biología celular que les habían resultado más difíciles de aprender.

A partir de la información obtenida decidimos diseñar una nueva secuencia didáctica, en este caso para enseñar el ciclo celular. Fue entonces que esta última secuencia se constituyó en unidad de análisis de esta tesis. Las condiciones en las que se desarrolló el diseño y la implementación de esta tercera secuencia estuvieron íntimamente arraigadas en aquello que sucedió durante el año previo de trabajo. Fue por ello que consideramos necesario incluir en este capítulo el devenir de la intervención didáctica como forma de visibilizar el amasado de esa unidad de análisis y así dar cuenta de la cocina de la investigación (Sirvent, 2010).

\subsection{Decisiones metodológicas en torno a la secuencia didáctica seleccionada}

Como decíamos, el trabajo realizado para esta tesis se centró en el análisis de la secuencia didáctica que se desarrolló en la materia Biología Celular. Esa secuencia fue diseñada para abordar el ciclo celular que, tal como dijimos, fue un contenido referido por alumnos y docente como difícil de aprender.

Algunas de las razones por las que el contenido a enseñar fue considerado difícil remiten a lo complejo que resulta abordar procesos que requieren pensar en cambios temporales y espaciales dados por la sucesión de eventos que ocurren a diferentes niveles de organización de la materia. En la secuencia se trabajó durante dos meses con el contenido ciclo celular en el que suceden eventos microscópicos a diferentes niveles de complejidad: se modifican moléculas que darán como consecuencia cambios a nivel celular. Esas transformaciones influyen a nivel del organismo y es el organismo como un todo quien a su vez modula esas transformaciones. Se establece así una red de sucesos biológicos que consideramos necesario trabajar recursivamente; nos extenderemos en ese sentido en el próximo capítulo en el que describiremos la secuencia analizada para esta tesis.

El diseño inicial funcionó como una hipótesis de trabajo dado que cada plan de clase con ciertas propuestas de actividades se terminó de configurar a partir de decisiones tomadas en conjunto con la docente. Esas decisiones surgían tanto a partir de la revisión e intercambio de aquello registrado en el cuaderno de notas durante la puesta en aula, como de un primer relevamiento de lo sucedido en cada clase a través de la escucha del registro del audio, y en algunos casos de las producciones escritas de los 
estudiantes. Todos estos insumos influían a la hora de decidir si era necesario para la clase siguiente incorporar alguna tarea que reforzara el trabajo con ciertas relaciones conceptuales, o dar tiempo de clase para que se pudieran socializar escritos que favorecieran compartir dudas acerca de cómo encarar cierta propuesta de escritura.

\subsection{Decisiones para enfocar el análisis del desarrollo de la secuencia didáctica}

Después de una primera revisión de los datos recogidos (registros y transcripciones de las observaciones de clase, entrevistas finales y producciones de los estudiantes), seleccionamos dos instancias de trabajo en clase para analizar en profundidad en esta tesis y que se desarrollaron durante la clase 1 y las clases 4 y $5 .{ }^{8}$ Ahora bien, ¿cuáles fueron los criterios por los que seleccionamos estas situaciones?

En primer lugar, ambas instancias comenzaron con una situación de escritura individual realizada en el aula, y eso era relevante dado que nos interesaba enfocar en la escritura en tanto práctica epistémica. Queríamos conocer qué sucedía alrededor de una consigna de escritura que presentaba ciertos desafíos porque implicaba retomar algo conocido, pero a la vez requería abordar conceptos más difusos o relaciones poco claras para los alumnos. Este tipo de práctica de escritura, que en un sentido es desafiante pero a la vez se ancla en lo conocido, puede ser potencialmente epistémica (Bazerman, 2009). A la vez, el hecho de que los alumnos escribieran en clase nos permitió observar las acciones que ocurrieron mientras producian sus escritos, y así registrar las consultas a la docente, los comentarios que hacían a toda la clase en relación con la tensión que provocaba en algunos estudiantes el sentir que no sabían y también nos permitió conocer a qué recursos apelaban algunos cuando percibían esa tensión.

Las dos situaciones de escritura demandaron prácticas relevantes para la enseñanza de las ciencias desde la perspectiva asumida. Pero a la vez, ambas situaciones eran diferentes. Para la tarea de escritura inicial (clase 1) los estudiantes tenían que presentar argumentos para explicar qué sabían acerca de dos cuestiones (cómo surgen las diferentes funciones de las células del mismo organismo y cómo a partir de una célula se forman todas las células de un ser humano). $Y$ para hacerlo tenían que relacionar una célula particular con el organismo del que formaba parte, es decir se les pedía pensar en las células en contexto, como partes de un todo. Consideramos que tanto argumentar como pensar en escenarios de diferente nivel de organización (una célula y un organismo humano) eran condiciones de la tarea que podían resultar desafiantes.

\footnotetext{
${ }^{8}$ Ellas son las que subrayamos en la tabla 3.1 del capítulo 3 y cuyo análisis en profundidad presentamos en los capítulos 4 y 5 que presentan resultados.
} 
En la situación de escritura desarrollada en la clase 4, ya promediando la secuencia, el tipo de tarea fue diferente. Se les pidió que escribieran un texto refiriendo a la vida de una célula en particular y que relacionaran en ese escrito una serie de conceptos disciplinares referidos al ciclo celular; para hacerlo era necesario establecer relaciones temporales y causales entre eventos de la vida de esa célula. En ambos casos consideramos que la situación de escritura podía constituirse en un desafío, pero a la vez era algo que los estudiantes podían abordar. Ambos tipos de escritos eran pertinentes y claves para el trabajo en esta secuencia. En el primer caso la consigna demandaba escribir para explicar y dar razones, y en el segundo caso escribir para relacionar conceptos disciplinares.

En segundo lugar, esas situaciones de escritura no estaban aisladas sino que se articularon con una situación de lectura realizada en parejas o pequeño grupo, también en el aula. En la situación de la primera clase esa lectura permitía vincular de manera implícita aquello acerca de lo que se escribió, con lo relatado en un texto didáctico escrito por la docente. Aun cuando ese texto no respondía a las preguntas que contenía la primera consigna de escritura, aludía a un contexto común (la diversidad de células humanas). En el segundo caso, que presentamos en el capítulo 5 de Resultados, los alumnos leyeron los breves textos que habían escrito cinco de ellos. Esa lectura formó parte de una tarea de revisión que se vinculaba de manera explícita con la situación de escritura realizada la clase previa.

Y por último en cada caso la situación de escritura individual, seguida por una lectura en pequeño grupo confluyó en una situación de diálogo plenario en la que se habló acerca de lo leído. Así se contrastaron saberes, se plantearon dudas, se expresaron interpretaciones, se argumentó para sostener una posición o fundamentar sugerencias.

En el siguiente esquema representamos las prácticas que acabamos de describir.

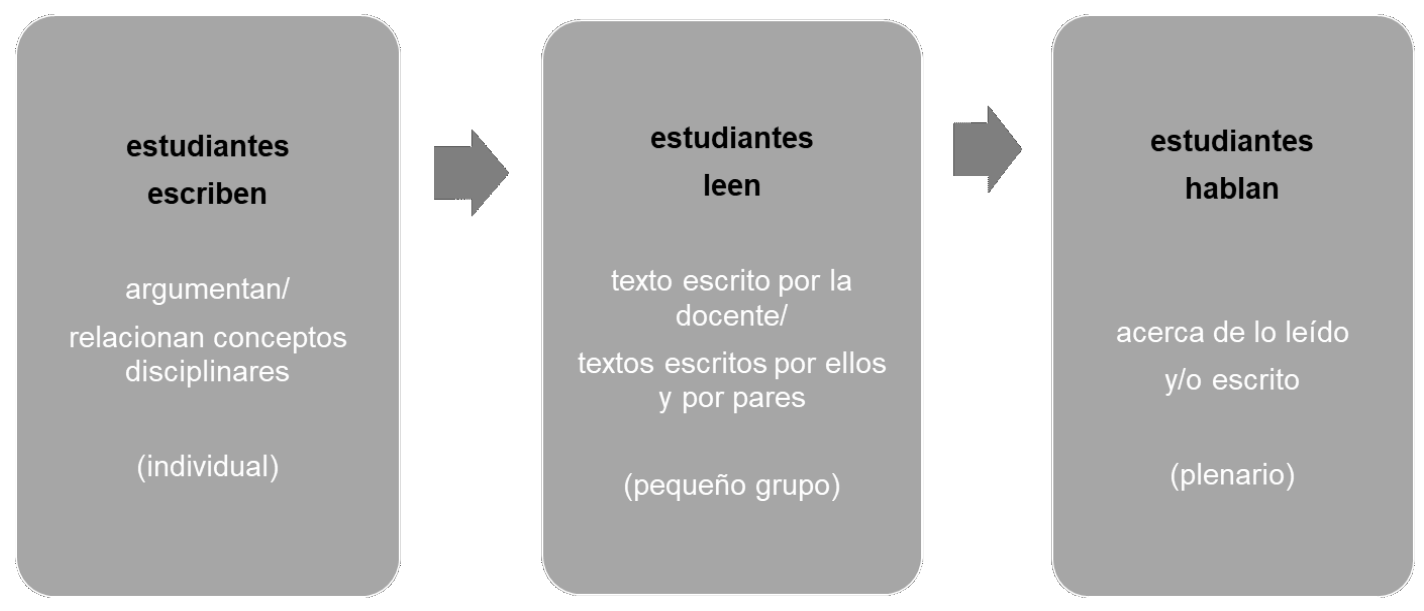


De modo que en ambos casos se comenzó por escribir de manera individual en clase, para después leer en pequeños grupos a partir de una consigna de lectura. Y finalmente hablar durante situaciones de plenario, en las que interactuaron pares y docente para retomar lo trabajado en el pequeño grupo. Estas situaciones que integraron escritura, lectura y oralidad a la enseñanza de un contenido disciplinar como el ciclo celular fueron focos en los que profundizamos durante el análisis realizado para esta Tesis de Maestría. En este apartado las tomamos en conjunto para mostrar el formato común que tenían. Pero a la vez la relevancia de la selección está dada por las diferencias entre esos dos focos de análisis, tal como describiremos con mayor detalle en los capítulos 4 y 5 de Resultados.

\subsection{Estrategias de recolección y organización de datos para el análisis}

En los estudios cualitativos de corte interpretativo es habitual utilizar diversos instrumentos de recolección de información con el propósito de abordar desde diferentes perspectivas la realidad del objeto de estudio.

Para recabar datos en esta investigación hicimos observaciones de clase, tanto en la etapa previa del primer año de trabajo conjunto con la docente como durante la implementación de la secuencia analizada para esta tesis. Los registros escritos y en audio de esas observaciones realizados con la presencia de esta tesista en el aula, fueron la fuente principal de información para esta tesis.

A la vez, se recogieron todas las producciones escritas de los estudiantes en las sucesivas versiones y las devoluciones que se hicieron a cada escrito. Al finalizar la tercera secuencia se entrevistó a los nueve alumnos que cursaron los dos años de manera sucesiva y estuvieron presentes en las tres secuencias didácticas elaboradas. También se realizó una entrevista final a la profesora a cargo de los cursos y se grabaron algunas de las sesiones de trabajo conjunto durante el diseño y la implementación.

De esta manera, se obtuvieron tres tipos de datos: las interacciones orales entre la profesora y los alumnos durante las clases, las producciones escritas de los alumnos que incluían las devoluciones individuales escritas y las entrevistas finales a alumnos y a la docente.

\subsubsection{Observación, registro y transcripción de clases}

En consonancia con el tipo de investigación encarada, nuestro principal instrumento para obtener información fueron las observaciones de clase, dado que constituyen una vía privilegiada de acceso para su estudio (Edelstein, 2011). 
En relación con el análisis realizado en esta tesis nos interesa puntualizar los siguientes aspectos, que consideramos relevantes para contextualizar el diseño y las observaciones de clase durante la implementación de la secuencia didáctica ciclo celular:

- Hubo varios meses de trabajo previo conjunto con la docente $S$ en diseño e implementación de secuencias didácticas. Eso implicó que ya hubiéramos reflexionado acerca de lo que sucedía durante la interacción en plenarios y discutido cómo favorecer la participación de todos los estudiantes durante esas situaciones de clase.

- La población de estudiantes que cursaba Biología celular ya había trabajado con escritura y lectura de manera intensiva e integrada a la enseñanza de contenidos disciplinares de la Biología con la docente $S$ y esta tesista durante el año previo. Esa práctica estaba naturalizada y la producción y entrega de escritos formaba parte del contrato didáctico acordado; como así también era aceptado el tipo de devolución escrita que realizábamos a las producciones.

La asignatura Biología Celular del $3^{\circ}$ año del profesorado tenía previsto en el diseño curricular dos horas reloj semanales. En esta institución el horario asignado era los días viernes de $18 \mathrm{hs}$ a $20 \mathrm{hs}$, siendo el primer módulo del turno vespertino. Con relación a la secuencia didáctica ciclo celular analizada para esta tesis, se observaron todas las clases durante los dos meses en las que se implementó. Esto fue desde el 11 de mayo del 2012 al 13 de julio del mismo año, día en que se tomó la evaluación parcial que registramos como clase 8 . En la siguiente tabla 2.1 indicamos los días en que efectivamente se desarrollaron las clases, así como los alumnos presentes y ausentes en cada una de ellas.

Tabla 2.1

Fechas en las que se implementó la secuencia didáctica ciclo celular

\begin{tabular}{|c|c|c|c|c|c|c|c|c|}
\hline Clase & $\mathbf{1}$ & $\mathbf{2}$ & $\mathbf{3}^{\mathbf{9}}$ & $\mathbf{4}$ & $\mathbf{5}$ & $\mathbf{6}$ & $\mathbf{7}$ & $\mathbf{8}$ \\
\hline Día & $11 / 5$ & $18 / 5$ & $1 / 6$ & $8 / 6$ & $15 / 6$ & $22 / 6^{10}$ & $29 / 6$ & $13 / 7^{11}$ \\
\hline
\end{tabular}

\footnotetext{
${ }^{9}$ Esta clase se llevó a cabo dos semanas después de la clase 2 porque el viernes 25 de mayo del 2012 fue feriado por fecha patria.

${ }^{10} \mathrm{El}$ día viernes 22 de junio hubo paro del gremio de camioneros, hubo rumores de un paro total de transportes, por lo que algunos alumnos estuvieron ausentes porque supusieron que no podrían retornar a sus casas al término de las clases a la noche.

${ }^{11}$ El día viernes 6 de julio de 2012 no se realizó la evaluación parcial prevista porque ese día hubo cese de actividades en las escuelas públicas y privadas, la administración pública, judiciales y hospitales de la provincia de Buenos Aires, como reclamo por el pago del aguinaldo fraccionado.
} 


\begin{tabular}{|c|c|c|c|c|c|c|c|c|}
\hline $\begin{array}{c}\text { Alumnos } \\
\text { presentes }\end{array}$ & 9 & 8 & 9 & 6 & 9 & 4 & 8 & 8 \\
\hline $\begin{array}{c}\text { Alumnos } \\
\text { ausentes }\end{array}$ & - & Noelia & - & $\begin{array}{c}\text { Abigail } \\
\text { Camilo } \\
\text { Noelia }\end{array}$ & - & $\begin{array}{c}\text { Abigail } \\
\text { Alba } \\
\text { Camilo } \\
\text { Noelia } \\
\text { Vanesa }\end{array}$ & Yanina & Cristóbal \\
\hline
\end{tabular}

Decidimos no utilizar guías con categorías preestablecidas para las observaciones, dado que esos esquemas producen una reducción de los datos obtenidos, y por tanto pueden inhibir una visión amplia de las situaciones objeto de análisis (Edelstein, 2011). En su lugar intentamos registrar todo aquello que nos permitiera reconstruir lo que aconteció durante las clases; nos centramos en particular en las interacciones que sucedían durante el trabajo con situaciones de escritura y lectura.

Para el registro de datos utilizamos un grabador digital y un cuaderno de notas. Durante las observaciones registramos por escrito datos tales como: la hora de inicio y finalización de cada clase, la presencia de los alumnos y su distribución mediante un croquis con su ubicación, y las anotaciones que la profesora realizaba en el pizarrón. Así también anotamos algunas de las interacciones verbales y gestos que consideramos relevantes. Por ejemplo, la manera en que los estudiantes entregaban los escritos a la docente, las actitudes de los alumnos al pasar al pizarrón a dibujar a pedido de la docente, las acciones de los estudiantes durante las situaciones de escritura (si leían sus apuntes o la bibliografía al realizar un escrito en clase, si consultaban con compañeros), y todo aquello que consideramos que permitiría reconstruir lo sucedido durante las clases.

A su vez, el registro de audio nos permitió recuperar las intervenciones verbales de la profesora y los alumnos durante la clase. Para ello, utilizamos el grabador de dos maneras:

a. Para el registro del grupo completo durante las situaciones de plenario o en las explicaciones de la docente, ubicábamos el grabador en un banco de la primera fila. De esta manera registramos tanto la voz de la profesora como las de los estudiantes que intervenían en esas situaciones. En este caso, el hecho que hubiera pocos alumnos en el curso nos permitió tener un registro más exhaustivo de las interacciones que sucedían con el grupo completo, dado que los estudiantes en general se ubicaban en dos filas de bancos. Aun así, hubo fragmentos del audio en que algunas voces se superponían y las intervenciones de aquellos alumnos que hablaban en voz más baja (Alba, Noelia, Yanina y 
Cristóbal) no resultaron audibles en situaciones de plenario. Es por ello que las intervenciones de algunos alumnos resultaron más visibles en el registro dado que siempre quedaron audibles.

b. Para registrar el trabajo en los pequeños grupos ubicamos el grabador en un grupo seleccionado, pero previamente les pedíamos permiso para hacerlo. Esta práctica ya estaba naturalizada en el curso dado que se había realizado el año previo con los mismos estudiantes y se les había explicado el sentido que tenía. Dependiendo de la duración de esta tarea grabamos la interacción de un único grupo o cambiamos la ubicación del grabador durante el trabajo, de manera tal de registrar parcialmente las discusiones en dos o tres grupos.

Los audios fueron escuchados sucesivas veces y transcriptos para su posterior análisis. Armamos así documentos escritos de cada clase que enriquecimos con los demás datos registrados y los asociamos a la versión de la planificación previa de cada clase. En esos documentos que recogieron las transcripciones consignamos relatos de aquello que sucedía al inicio de una situación de enseñanza, o durante el ingreso al aula, o al entregar un escrito a la profesora recuperando otros datos registrados. Para dar cuenta del tiempo didáctico que se había dedicado a las diferentes situaciones de clase, indicamos en el registro tiempo parcial de grabación.

En esas transcripciones registramos las intervenciones orales de la profesora con la letra $S$ que refiere a su nombre, esta manera de registrar su voz fue comunicada y acordada con la profesora. A cada estudiante se le asignó un nombre ficticio que comenzaba con la misma letra que su nombre real. Consideramos que reconstruir aquello que le sucedía a un alumno en particular durante las situaciones de lectura y escritura sería más sencillo si era posible pensar en un actor, y en cambio resultaría más difícil de seguir si les asignábamos letras. A la vez, para nosotros durante el análisis y la discusión referirnos a alumnos particulares con nombre nos permitía asociar diferentes clases de datos: sus producciones escritas, su voz durante las entrevistas finales y sus intervenciones durante las clases en esta secuencia. Es así que decidimos utilizar nombres que nosotras como investigadoras pudiéramos asociar a los alumnos reales, pero a la vez nos permitieran preservar su identidad.

En los registros de transcripción numeramos los turnos de habla para su mejor seguimiento en el análisis.

\subsubsection{Producciones escritas de los estudiantes}

Se recogieron todas las producciones escritas de los alumnos a medida que las iban realizando, tanto en primera versión, como el texto con la devolución docente, así como 
las nuevas versiones reescritas. Si estaban en papel se fotocopiaron de manera tal de devolver el texto original al estudiante y si estaban digitalizadas se guardaron todos esos archivos enviados por mail. También se fotocopiaron los primeros parciales durante los dos años en los que se trabajó con la docente $S$. Las devoluciones escritas a los textos de los alumnos fueron realizadas tanto por la docente como por esta tesista y previamente habíamos acordado la manera de hacerlas.

\subsubsection{Entrevistas a estudiantes y a la docente}

Realizamos entrevistas a los nueve estudiantes unos meses después de finalizada la implementación de la secuencia didáctica analizada para esta tesis. Se llevaron a cabo en la misma institución escolar, en otra aula y en el horario de cursada. Fueron entrevistas del tipo semiestructuradas con un guión flexible que admitía repreguntas y caminos alternativos de indagación, realizadas de manera individual ${ }^{12}$.

Las entrevistas se audiograbaron y estaba previsto centrarnos en analizar la secuencia didáctica acerca de ciclo celular. Se les preguntó por la propuesta de manera global pidiéndoles que contrastaran con otras asignaturas y plantearan semejanzas y diferencias. Varios estudiantes remitieron también al año previo de trabajo. Para después consultarles acerca de las situaciones didácticas concretas. Durante las entrevistas tuvieron a su disposición las consignas de todas las actividades de manera tal que actuaran como soporte para recordar cuáles les habían aportado para aprender desde su perspectiva y en cuáles habían tenido dificultades. Finalmente preguntamos acerca de cómo estudiaban para las evaluaciones, si utilizaban libros, sus propios apuntes, otros materiales y estrategias.

También entrevistamos a la docente al finalizar la secuencia didáctica en un formato del mismo tipo. Es decir, una entrevista centrada en el desarrollo de la secuencia didáctica, cuáles habían sido aspectos positivos y negativos para los estudiantes. A la vez, le pedimos que estableciera semejanzas y diferencias entre su trabajo previo en la asignatura y el que había realizado ese año; para después consultarle acerca de su percepción de lo sucedido durante algunas situaciones didácticas. Así como qué consideraba que aportaba la escritura en este contexto de trabajo.

Posteriormente se desgrabaron las entrevistas y se realizó la transcripción de ese audio para analizar y poner en relación esas voces con los datos obtenidos a partir de las observaciones de clase.

12 Vanesa invitó a Alba a participar de su entrevista, por ese motivo la segunda parte de esa entrevista no fue individual. 


\subsection{Estrategias utilizadas para el análisis de datos}

En la investigación encarada para esta tesis consideramos que tanto la inmersión extensa en el campo como el hecho de utilizar múltiples fuentes de datos, favoreció el amasado de la empiria con nuestros referentes teóricos. Tal como dijimos, no adecuamos los datos a categorías prefiguradas para aplicar y verificar hipótesis previas, sino que efectuamos categorizaciones y contextualizaciones preliminares a partir de los datos (Maxwell y Miller, 2008). A partir de ese análisis preliminar exploramos las referencias conceptuales y volvimos a los datos para refinar el análisis. Es decir, partiendo de la información recogida, construimos datos y los organizamos en categorías de análisis; y a través de la teoría enriquecimos la mirada sobre ese objeto en un proceso recursivo y de algún modo iterativo.

Para iniciar el análisis de las clases vinculamos los documentos escritos que contenían las transcripciones completas de los audios de cada clase, con las notas obtenidas en el campo y los planes de clase planteados como hipótesis previas. A partir de ellos realizamos un proceso de análisis manual, al leerlos de manera reiterada permitieron armar una suerte de esquema de lo que se desarrolló en cada clase. Ese boceto remitía a la dinámica de clase, y funcionó como soporte para identificar e interpretar diferentes momentos de trabajo en el aula, asociados tanto a cada situación de enseñanza, como a episodios que tenían rasgos particulares aun dentro de la misma situación de trabajo.

A la vez, en esos materiales fuimos marcando las regularidades que emergían, por ejemplo en relación con las intervenciones orales de la docente. Esas intervenciones no fueron analizadas de manera aislada del contexto, sino que nos enfocamos en la interacción didáctica. Desde la perspectiva de la Teoría de la acción didáctica conjunta (JATD) (Sensevy, 2007), que considera la acción docente como esencialmente transaccional se buscaron las co-acciones de los estudiantes procurando no desagregar esas unidades durante el análisis. No sólo nos interesó identificar y sistematizar las regularidades, sino también lo singular que tuviera alguna relación con nuestras preguntas de investigación y que se manifestaba a través de marcas en el discurso.

Aunque se leyeron todas las producciones de los estudiantes en las sucesivas versiones, seleccionamos para su análisis en profundidad sólo aquellos escritos que fueron realizados durante las clases como parte de las actividades 1, 2 y 6 . En los próximos capítulos presentamos ese análisis y lo ponemos en relación con los datos obtenidos de las situaciones de escritura en clases.

Por último, mencionamos el análisis de las entrevistas a estudiantes y docentes que utilizamos para complementar o interpelar, según el caso, los datos construidos a partir 
del análisis de observaciones de clases. Seleccionamos para incluir en esta tesis sólo algunos fragmentos que consideramos pertinentes porque nos daban la posibilidad de enriquecer aquello que íbamos interpretando. Sin embargo, todas las entrevistas fueron escuchadas reiteradas veces, y transcriptas aquellas partes que referían a situaciones de clase analizadas en profundidad, al trabajo global durante la secuencia didáctica para aprender ciclo celular y a las menciones a su relación con la escritura que hicieron varios estudiantes.

\subsection{Acerca de la validez del estudio}

Consideramos que tuvimos en cuenta criterios de rigurosidad científica tal como demanda una investigación cualitativa, en tanto hemos intentado aportar a la confiabilidad a través de un registro minucioso de datos y procesos. En ese sentido realizamos una triangulación teórica, de datos y metodológica como aporte a la validación del trabajo de investigación realizado.

En relación con el primer tipo, se triangularon diferentes referentes teóricos y aportes conceptuales que abrevan en distintos campos disciplinares tal como presentamos y pusimos en relación en el capítulo previo y seguimos haciéndolo en los capítulos de resultados. Así también hemos presentado avances y resultados de este trabajo de investigación en diversos espacios académicos como manera de compartir y poner en discusión aquellas interpretaciones y resultados que íbamos consolidando y obtener devoluciones por parte de colegas de diferentes perspectivas.

Por otra parte, hemos realizado observaciones por períodos extensos de manera tal de comprender las lógicas de funcionamiento del sistema en el que pretendimos intervenir. A la vez, entrevistamos a todos los actores del proceso y realizamos análisis documental de múltiples materiales (producciones escritas de estudiantes, correos electrónicos, evaluaciones escritas, materiales con imágenes y audiovisuales, bibliografía). Ello aportó a una triangulación metodológica y de datos al recabar distinta información a través de diferentes métodos de manera tal de confrontarla y complementarla.

Para finalizar, mencionamos que en este capítulo hemos descripto las decisiones metodológicas tomadas en nuestra investigación para abordar el desarrollo en el aula de una secuencia didáctica que entrelaza lectura y escritura para aprender contenidos biológicos (ciclo celular), en una asignatura de la formación inicial de profesores de Biología. En el próximo capítulo presentamos la secuencia didáctica efectivamente implementada, describiendo las clases y caracterizando las situaciones de escritura, lectura y oralidad desarrolladas durante la puesta en aula. 


\section{CAPÍTULO 3}

Acerca de la secuencia didáctica sobre ciclo celular: situaciones de enseñanza e intervenciones docentes

\subsection{Presentación de la secuencia de enseñanza implementada}

En este capítulo describimos la secuencia didáctica que efectivamente se implementó y analizó para esta tesis. Estuvo conformada por diversas situaciones de enseñanza que proponían escribir, leer y hablar para aprender lo que sucede durante el ciclo de vida de las células.

Tal como mencionamos en el capítulo previo al presentar nuestro problema de investigación, nos interesó conocer ¿Cómo se desarrolla una secuencia didáctica que integre escritura, lectura y oralidad para la enseñanza de un contenido disciplinar específico en el contexto de una asignatura del Profesorado de Biología? Esa pregunta general dio lugar a interrogantes más específicos que orientaron nuestro trabajo de investigación y subyacen al diseño de la secuencia didáctica analizada para esta tesis. Así, indagamos acerca de las características que adquirieron esas situaciones de enseñanza durante la implementación. En este capítulo describimos todas ellas, sistematizando lo general y caracterizando lo particular que asumieron esas situaciones de escritura, lectura y oralidad durante la puesta en aula de la secuencia didáctica.

Esa descripción nos permite un primer abordaje de la secuencia para identificar algunas de las condiciones de enseñanza que promovieron aprender el ciclo celular. Esas condiciones se enmarcan en una propuesta situada y por ello pensada para un contexto educativo particular. En este caso un aula de nivel superior de formación docente inicial, en una asignatura disciplinar específica como Biología celular y en el marco de asumir una perspectiva teórica y didáctica acerca de qué, cómo y para qué enseñar ese contenido biológico.

Tal como dijimos en el capítulo de referentes teóricos de esta tesis, compartimos la idea de que la perspectiva disciplinar que se asume da cuenta y configura los objetos a enseñar. Desde una mirada sistémica para concebir las células y los seres vivos, abordamos el ciclo celular como modelo de la vida de una célula. Esta perspectiva implica considerar que cada evento biológico se relaciona con muchos otros. Es por ello que lo que ocurre en una etapa de la vida de una célula dependerá tanto de las interacciones entre moléculas que suceden en ese momento, como de aquello que transcurrió en otros momentos de la vida de esa célula. A su vez, concebir a los sistemas vivos desde este enfoque implica relacionar lo que sucede en la célula en cuestión con el ambiente con el que interactúa esa célula. En el caso de un organismo pluricelular, 
como un humano, ese ambiente incluye lo que acontece en otras células contiguas o distantes del organismo y que forman parte del ambiente con el que interactúa (Lewontin, 2001; Meyer, 1979; Morin, 1993).

A partir del trabajo durante esta secuencia se pretendía que los estudiantes construyeran una noción más integrada y compleja del modelo celular. En este sentido, articulamos lo que sucedía a diferentes niveles de organización para relacionar los procesos moleculares que ocurren habitualmente en las células con el funcionamiento de esa célula, así como con el organismo del que formaba parte. Diseñamos situaciones de enseñanza para promover que los estudiantes pudieran establecer diferentes tipos de relaciones entre estructuras (componentes celulares) y eventos (procesos metabólicos y/o celulares). En esta instancia de formación nos interesaba que pudieran construir una noción más compleja, profunda e integral del ciclo celular, articulando temas que suelen presentarse en la formación de nivel medio como compartimentos estancos. Queríamos que los alumnos pudieran asumir el desafío de no sólo conocer qué sucede en un proceso molecular (duplicación del ADN, por ejemplo), sino también prever cuáles eran las relaciones temporales, espaciales y funcionales de ese proceso en la vida de una célula dada y del ser vivo del que forma parte.

Consideramos que el trabajo con escritura y lectura promueve volver desde diferentes ángulos sobre un mismo objeto de conocimiento. Al ampliar el tiempo didáctico dedicado al trabajo con ese contenido es posible expandir y profundizar el conocimiento acerca del tema en cuestión (Bazerman, 2009; Hand y Prain, 2012; Tynjälä, Mason, y Kirsti, 2001).

Algunas de las tareas que integraban la escritura y lectura al trabajo con los contenidos se realizaban enteramente durante la clase, pero hubo otras en las que parte del trabajo se llevaban a cabo fuera del aula y permitían además ampliar el tiempo didáctico y articular una clase con la siguiente. Aun cuando se escribiera o se leyera en otro momento y lugar, todas las prácticas de escritura y lectura estuvieron entrelazadas con la enseñanza disciplinar durante las clases de la secuencia didáctica (Carlino, Iglesia, Laxalt, 2013).

\subsection{Desarrollo de la secuencia didáctica en el aula}

Tal como dijimos, este capítulo se centra en el desarrollo de la secuencia en el aula. Nos interesa que las situaciones de escritura y lectura analizadas en profundidad para esta tesis puedan ser leídas como partes articuladas de una secuencia didáctica. También queremos mostrar aquí cómo se trabajó de manera sistemática con diversas 
prácticas de escritura y lectura para aprender biología celular durante toda esa secuencia didáctica.

Como instancia previa a esta secuencia, los estudiantes habían trabajado con aspectos generales de las células, buscando y analizando imágenes de diferentes formatos que representaban células, para así revisar estructura y función de sus componentes. Ahora la intención fue trabajar con aquello que sucedía durante la vida de las células, y de esa manera modelizar el ciclo celular, pero a la vez poder pensar en los diferentes tipos celulares y sus estilos de vida.

La tabla 3.1 que incluimos a continuación muestra de manera esquemática las situaciones y los contenidos que se desarrollaron en cada una de las clases durante la implementación de la secuencia didáctica. A la vez, en ella indicamos si los estudiantes escribieron, leyeron, hablaron o representaron mediantes dibujos; y si lo hicieron de manera individual, en parejas, pequeño grupo o en plenario con toda la clase y la coordinación docente. También mencionamos si la acción se realizó durante la clase, entre clases o si se abarcó ambas instancias de trabajo.

Tabla $3.1^{13}$

Descripción de la secuencia didáctica Ciclo Celular

\begin{tabular}{|c|c|}
\hline Clase & Situaciones $^{14}$ \\
\hline $\begin{array}{c}\text { I } \\
\text { Unidad y diversidad } \\
\text { de los } \\
\text { ciclos celulares }\end{array}$ & 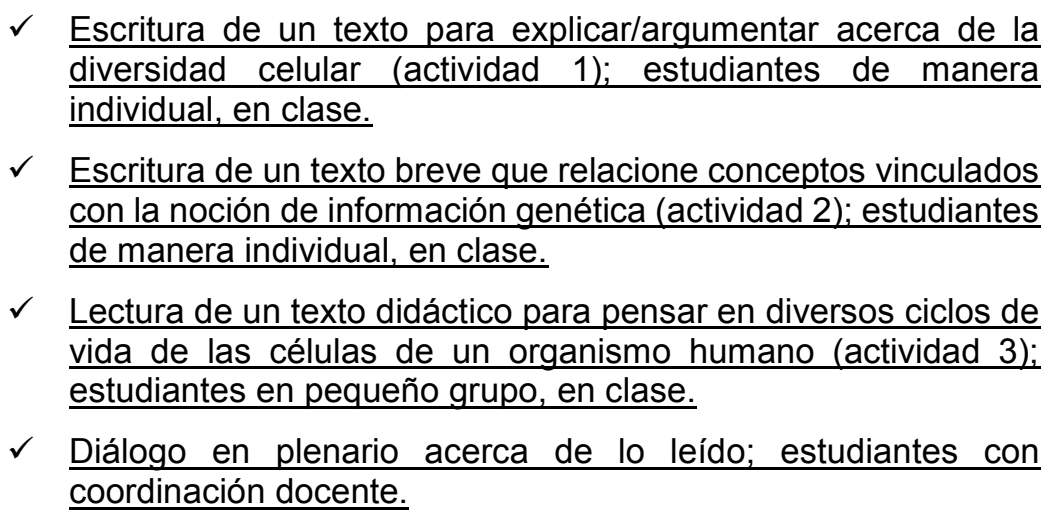 \\
\hline $\begin{array}{c}\text { II } \\
\text { Duplicación de ADN } \\
\text { como evento clave } \\
\text { del Ciclo Celular }\end{array}$ & $\begin{array}{l}\checkmark \quad \text { Exposición oral de la docente acerca de las etapas del ciclo } \\
\text { celular, y de la duplicación del ADN como proceso metabólico } \\
\text { clave del ciclo de una célula en división. } \\
\checkmark \quad \text { Representación de los eventos que suceden durante la } \\
\text { duplicación de ADN, mediante una secuencia de imágenes } \\
\text { dibujadas por la docente en el pizarrón. Relación de esas } \\
\text { imágenes con los esquemas de la bibliografía sugerida } \\
\text { mediante exposición dialogada de la docente. }\end{array}$ \\
\hline
\end{tabular}

\footnotetext{
${ }^{13}$ La numeración de las actividades corresponde al orden de presentación de cada tarea a los estudiantes.

${ }^{14}$ Las consignas de todas las situaciones de enseñanza se incluyeron en el Anexo.
} 


\begin{tabular}{|c|c|}
\hline & $\begin{array}{l}\checkmark \text { Lectura de bibliografía sugerida sobre duplicación de ADN; } \\
\text { estudiantes de manera individual?, entre clases. } \\
\checkmark \quad \text { Lectura de un listado desordenado de eventos que suceden } \\
\text { durante la duplicación de ADN para ordenarlos } \\
\text { cronológicamente; estudiantes de manera individual, entre } \\
\text { clases (actividad 4). }\end{array}$ \\
\hline $\begin{array}{l}\text { III } \\
\text { Profundizar } \\
\text { en la } \\
\text { duplicación } \\
\text { del ADN }\end{array}$ &  \\
\hline $\begin{array}{c}\text { IV } \\
\text { Duplicación de ADN } \\
\text { y } \\
\text { Mitosis } \\
\text { como procesos del } \\
\text { Ciclo Celular }\end{array}$ & $\begin{array}{l}\checkmark \text { Explicación docente de diversas cuestiones vinculadas con la } \\
\text { duplicación de ADN (duplicación de telómeros y ocurrencia de } \\
\text { mutaciones), a partir de la bibliografía leída por los estudiantes. } \\
\checkmark \quad \begin{array}{l}\text { Diálogo en plenario acerca de la tarea entre clases de escritura } \\
\text { (actividad 5). Lectura de algunos escritos para compartir cómo }\end{array} \\
\text { escribir aquello pedido. } \\
\checkmark \quad \begin{array}{l}\text { Escritura de un texto breve relacionando conceptos } \\
\text { disciplinares del Ciclo Celular (actividad 6); estudiantes de }\end{array} \\
\checkmark \begin{array}{l}\text { manera individual, en clase. } \\
\text { Diálogo en plenario acerca de lo escrito en la actividad previa; }\end{array} \\
\checkmark \begin{array}{l}\text { estudiantes con coordinación docente. } \\
\text { Diseño de diapositivas de un power point con texto escrito e } \\
\text { imágenes para describir las etapas de la mitosis (actividad 7) a } \\
\text { partir de la lectura de bibliografía sugerida; estudiantes, en } \\
\text { parejas y como tarea entre clases. }\end{array}\end{array}$ \\
\hline $\begin{array}{c}\mathbf{V} \\
\text { Las etapas del } \\
\text { ciclo celular } \\
\mathbf{y} \\
\text { la transformación } \\
\text { de los cromosomas }\end{array}$ & 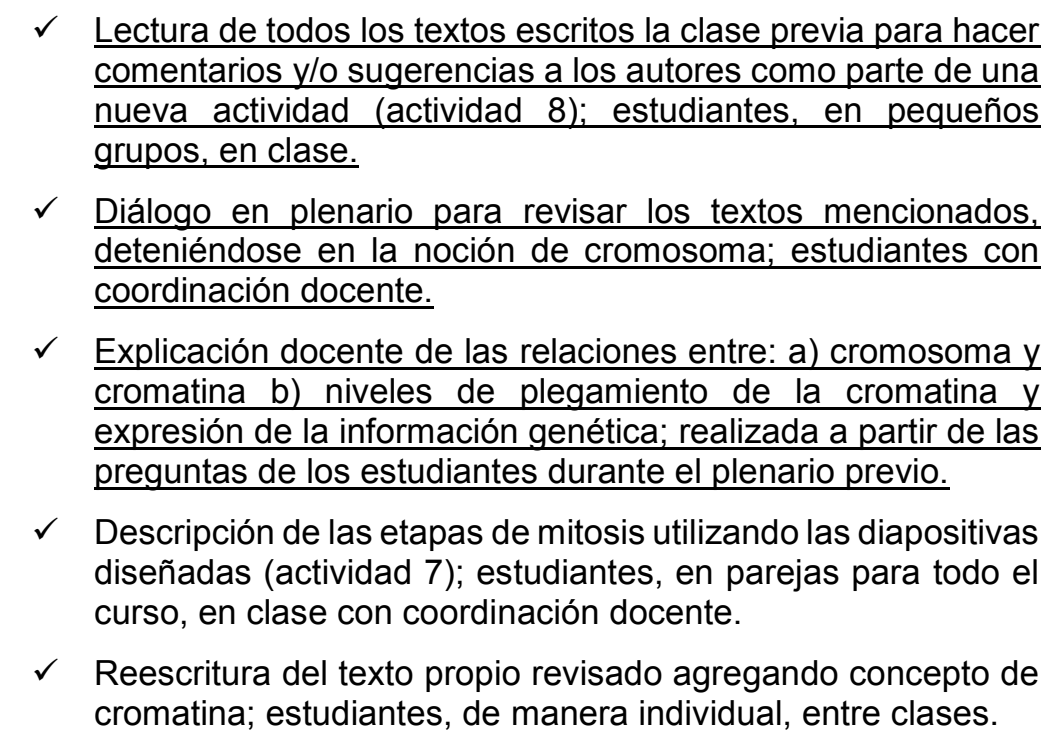 \\
\hline
\end{tabular}




\begin{tabular}{|c|c|}
\hline & $\begin{array}{l}\checkmark \text { Representación mediante dibujos de células y sus } \\
\text { cromosomas en etapas de la mitosis (actividad 9); } \\
\text { estudiantes, de manera individual y entre clases. } \\
\checkmark \quad \text { Escritura de un texto contrastando funciones posibles de la } \\
\text { mitosis en un organismo unicelular (levadura) y en uno } \\
\text { pluricelular (una planta), (actividad 10); estudiantes, de } \\
\text { manera individual y entre clases. }\end{array}$ \\
\hline $\begin{array}{l}\text { VI } \\
\text { Mitosis como evento } \\
\text { del Ciclo Celular } \\
\qquad y \\
\text { las consecuencias en } \\
\text { los organismos }\end{array}$ & 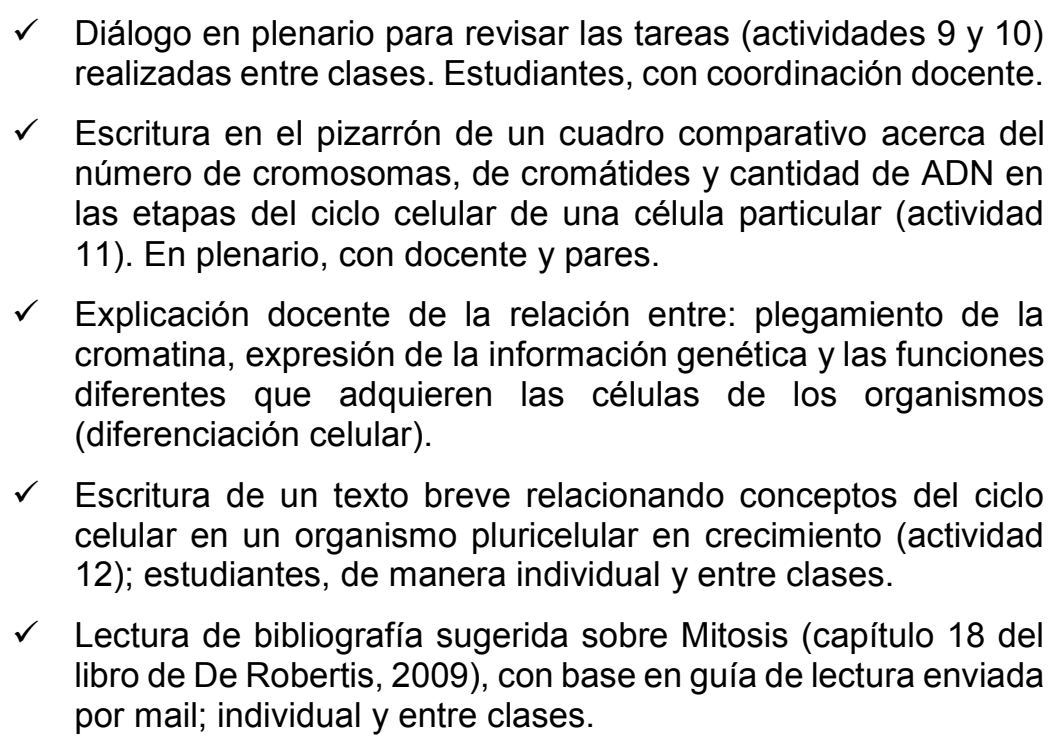 \\
\hline $\begin{array}{c}\text { VII } \\
\begin{array}{c}\text { Integración } \\
\text { del }\end{array} \\
\text { Ciclo Celular }\end{array}$ & $\begin{array}{l}\checkmark \quad \text { Lectura de imágenes de células para recuperar información } \\
\text { acerca de etapas de mitosis y complemento cromosómico } \\
\text { (actividades 13,14 y 15); en clase y en pequeño grupo. } \\
\checkmark \quad \text { Representación de células de un organismo particular, a través } \\
\text { de esquemas en diferentes etapas del Ciclo Celular (actividad } \\
\text { 16); en clase y en pequeño grupo. } \\
\checkmark \quad \text { Escritura de un texto que describa los cambios moleculares que } \\
\text { regulan las etapas del Ciclo Celular refiriendo al embrión de la } \\
\text { actividad 13 (actividad 17); en pequeño grupo y en clase. } \\
\checkmark \quad \text { Escritura de justificaciones para fundamentar si enunciados } \\
\text { acerca de la diferenciación celular son verdaderos o falsos } \\
\text { (actividad 18); en clase y en pequeño grupo. } \\
\checkmark \quad \begin{array}{l}\text { Diálogo en plenario a partir de lo realizado en pequeños grupos } \\
\text { para revisar e integrar los eventos del ciclo celular; estudiantes, } \\
\text { en clase con coordinación docente. }\end{array}\end{array}$ \\
\hline $\begin{array}{c}\text { VIII } \\
\text { Evaluación } \\
\text { parcial }\end{array}$ & $\begin{aligned} & \checkmark \text { Escritura en clase de manera individual: } \\
& \text {. para completar cuadro comparativo } \\
& \text { - para mencionar o describir } \\
& \text { - para relacionar conceptos disciplinares } \\
& \checkmark \quad \text { Representación de células en clase de manera individual. }\end{aligned}$ \\
\hline
\end{tabular}

Para esta tesis se analizaron en profundidad las situaciones que subrayamos en la tabla 3.1, durante las cuales los estudiantes escribieron, leyeron y hablaron acerca de lo leído 
y/o escrito. En los dos próximos capítulos (4 y 5) presentamos el análisis y la discusión del desarrollo de esas situaciones de enseñanza.

A continuación describimos las clases 1 a 7 de la secuencia didáctica centrándonos en el sentido que tenían las situaciones mencionadas en la tabla precedente. La clase 8 correspondió a la evaluación parcial presencial.

\section{- Clase 1. Unidad y diversidad de los ciclos celulares}

Durante esta clase de inicio de la secuencia nos propusimos hacer explícita la tensión entre unidad y diversidad celular para que los estudiantes pudieran pensar en un modelo de ciclo celular que incluyera diferentes estilos de vida y los relacionara con las funciones que cumplen las células en un organismo pluricelular.

Comenzamos con tareas de escritura individual, en ellas se les pidió a los alumnos que escribieran para explicar qué sabían acerca de ¿Cómo a partir de una célula se forman todas las células de un ser humano? y ¿Cómo surgen las diferentes funciones de esas células?; y también les solicitamos que relacionaran una serie de términos (ADN, genes, cromosomas, información genética) asociados alrededor de la noción de información genética. La intención fue empezar escribiendo para poner en papel qué se sabía acerca de los temas a trabajar, aquello que, tal como planteamos en el capítulo de referentes teóricos, denominamos demanda de aprendizaje (Leach y Scott, 2000; 2003).

Esa primera instancia de trabajo individual realizado en esta clase expuso a los estudiantes a una situación de revisión de aquello que conocían acerca de la información genética de las células de un organismo y las funciones que cumplen esas células. A la vez, el hecho de que fuera por escrito e individual nos permitió tener una primera producción que diera cuenta de algunas ideas a las que era posible volver si fuera necesario. Estas primeras actividades de escritura tuvieron un doble propósito: a) conocer cómo cada estudiante resolvía la relación entre información genética y función celular, en particular, si referían y usaban en su explicación el proceso en el que se copia esa información (duplicación del $A D N$ ) y b) promover que pensaran en la relación entre información genética y función celular para ponerla en discusión durante el trabajo en la secuencia. En este último sentido, acordamos con Elbow (2004) en que escribir a partir de hipótesis propias favorece que los estudiantes hagan conscientes sus incertezas relacionadas con ese conocimiento, y ese hecho podría dar lugar a que problematicen aquello a trabajar. 
Después de las tareas de escritura se realizó en pequeño grupo la lectura de un texto escrito por la docente para esta instancia ${ }^{15}$, que refería a la diversidad de "vidas" o ciclos celulares de las células de un organismo humano, para intentar recuperar los casos particulares mencionados en el texto, tomando como criterio central la periodicidad del ciclo celular. Aun cuando las situaciones de escritura y lectura eran independientes, estaban articuladas dado que abordaban la diversidad celular en un organismo. En esta instancia, consideramos que la lectura realizada en pequeño grupo podía promover la discusión, el intercambio de ideas y el planteo de preguntas (en el capítulo 4 de esta tesis analizamos aquello que sucedió a partir de esta lectura). Por estas razones decidimos que la lectura y la tarea asociada a ella fuera grupal.

Por último, se trabajó en plenario para reordenar y consensuar con toda la clase los "estilos de vida" (y así los ciclos celulares) mencionados en el texto. Este momento fue muy importante para habilitar la participación de todos los estudiantes e instalar una modalidad dialógica de trabajo (Dysthe, 1996, 2000).

En esta clase los estudiantes plantearon preguntas tanto durante las tareas de escritura, como en los momentos de lectura en pequeño grupo y de diálogo en plenario. Consideramos que estas actividades generaron condiciones que promovieron la reflexión acerca del ciclo celular. Adquirieron esa función en consonancia con la acción de la docente durante el trabajo con estas tareas y en especial durante la situación de plenario. La dualidad entre expresión y reticencia de la docente en esta clase inicial fue relevante para favorecer la participación de los estudiantes en lo que Sensevy denomina el juego del saber (Sensevy, 2012). Presentaremos el análisis de episodios sucedidos en esta clase en el capítulo 4 de resultados.

\section{- Clase 2. Duplicación de ADN como evento clave del Ciclo Celular}

La acción principal durante esta clase fue la explicación docente del proceso de duplicación del ADN. En primera instancia se ubicó ese proceso en la vida de una célula y para ello se retomó lo trabajado a partir de la lectura previa acerca de los diferentes ciclos de vida. Era importante que los alumnos pudieran asociar la duplicación del material genético con la división celular y ello implicaba dejar en claro que ese proceso no sucedía en todos los ciclos de vida sino sólo en aquellas células que se dividían.

La profesora comenzó esta segunda clase presentando un esquema del ciclo celular típico. Con la participación de los estudiantes retomó lo trabajado en la clase previa respecto a que algunas células no se dividen nunca, otras pasan rápido por las etapas

\footnotetext{
${ }^{15}$ El texto "Una vida, muchos estilos de vida" se incluyó en el Anexo
} 
del ciclo y se dividen, otras crecen lentamente y tardan en dividirse. La docente retomó la idea de periodicidad como criterio diferencial de estilos de vida, es decir de estilos de ciclo celular, para así ubicar la duplicación de ADN en ese esquema inicial. Lo central en esta instancia era relacionar el sentido de la duplicación con la división celular, e institucionalizar (Brousseau, 2007) que sólo aquellas células que duplican su ADN se dividen, repartiéndose esas copias entre las células hijas.

Nos interesó que los estudiantes pudieran pensar ese proceso metabólico como una secuencia de eventos moleculares relacionados. A la vez, que pudieran comprender la relación que tenía la duplicación de la información genética con la vida de una célula. $Y$ así poder pensar que lo que les ocurre a las células se vincula con la vida de un organismo, por ejemplo con el crecimiento de un ser vivo, la regeneración y renovación de tejidos.

En los textos que los estudiantes habían escrito en respuesta a la actividad inicial no habían mencionado la duplicación del ADN como un proceso necesario para que las células se dividieran. Aun cuando la explicación de este proceso era una situación ya prevista en la secuencia, a partir de esa información acordamos darle mayor visibilidad y relevancia; por ello se trabajó para que los estudiantes pudieran establecer múltiples relaciones entre este proceso y otros.

Se dedicó la parte central de esta clase a la exposición, por parte de la docente, del proceso de duplicación del ADN. La intención fue que la explicación colaborara para poder pensar en un proceso que se desarrolla en tiempo y espacio.

Para ello la profesora dibujó en el pizarrón una serie de esquemas que representaban de manera secuenciada momentos del proceso de manera tal de ir anclando en cada dibujo su exposición. Mencionó las diferentes enzimas involucradas, presentándolas como diversos actores con funciones específicas que harían su ingreso a un escenario y se las representaría actuando en ese proceso. La docente explicó el proceso haciendo hincapié en los roles de esas enzimas y en cómo sus características dan cuenta de lo que va ocurriendo durante la duplicación del ADN. A la vez, durante la explicación fue vinculando los dibujos que había realizado en el pizarrón con las imágenes incluidas en la bibliografía que los estudiantes tenían en sus bancos. El trabajo con la interpretación de imágenes en Biología es muy importante para poder conceptualizar acerca de procesos biológicos con alto nivel de abstracción y modelizar las interacciones que suceden durante esos procesos.

Como tarea para la clase siguiente se solicitó a los estudiantes que leyeran la bibliografía sugerida y se envió un par de días después por mail una consigna de trabajo 
entre clases elaborada a partir de la escucha del registro grabado de la exposición de la profesora. Para diseñar esa tarea transcribimos algunas frases que usó la docente $S$ durante la explicación de la duplicación del ADN. Ubicamos esas frases, que referían a acciones durante el proceso, desordenadas en un listado y solicitamos a los estudiantes que las organizaran de manera cronológica como una secuencia de eventos que se suceden en tiempo y espacio.

Para realizar la actividad los alumnos debían volver a los apuntes de clase, que además de notas incluían la serie de dibujos en los que la docente había representado secuencialmente el desarrollo del proceso de replicación. También se podía relacionar esa serie de eventos con los dibujos y el texto del capítulo 17 del libro Fundamentos de Biología Celular y Molecular (De Robertis e Hib, 2004) que la docente había recomendado como bibliografía y varios alumnos tuvieron a mano durante la clase. Esta consulta se promovió porque una de las consignas de la actividad pedía explícitamente relacionar las frases a ordenar con los esquemas de la bibliografía, transformándolas en epígrafes de las imágenes del libro.

A través de esta tarea quisimos promover una revisión del proceso de duplicación por parte de los estudiantes, y problematizar la temporalidad de la ocurrencia de eventos que suceden durante la duplicación del ADN (así como en otros procesos biológicos). Algunos eventos mencionados eran sucesivos, otros simultáneos y también uno en particular ocurría continuamente durante el proceso. Para decidir cómo ordenar la secuencia de eventos los estudiantes tuvieron que detenerse a explicitar y reflexionar acerca de estas cuestiones.

\section{- Clase 3. Profundizar en la duplicación de ADN}

La tercera clase comenzó con la revisión en pequeño grupo de la actividad 4 que los estudiantes habían realizado de manera individual entre clases. Esta primera revisión dio lugar a intensos intercambios dentro de los grupos acerca del orden adecuado de los eventos. Consideramos que fue una buena instancia para que pudieran contrastar los ordenamientos que cada uno había propuesto, a la vez podían consultar con nosotras, docente e investigadora, y argumentar dentro del grupo acerca de las razones que tenían para ubicar una frase en determinado orden.

Un primer problema lo constituyó decidir cuál era la secuencia temporal, si era una única posible o había diferentes opciones que podían ser válidas; por ejemplo en qué orden ubicar aquellas frases que referían a la acción de alguna enzima que actuaba a lo largo de casi todo el proceso de duplicación (la acción de la enzima Topoisomerasa). Esa duda hizo que algunas estudiantes consultaran con la docente cuál era la ubicación 
correcta para esa frase. La profesora sugirió releer la bibliografía, y ella misma lo hizo a la vez, para decidir si era necesario dar pistas en ese sentido o no. Que los estudiantes puedan ejercer su rol como lectores autónomos en clase, y así asumir la responsabilidad de comprender y validar sus interpretaciones, requiere generar y sostener ciertas condiciones didácticas. Eso implica propiciar un trabajo sostenido con los textos distribuyendo responsabilidades con relación a la lectura, para evitar que la responsabilidad del estudiante como lector quede desdibujada (Lerner, 2002).

Una segunda cuestión a resolver fue que algunos de los eventos mencionados en las oraciones parecían similares, pero involucraban a diferentes actores (enzimas). A la vez había entre las frases algunas referidas a la misma enzima como actora pero que realizaba una acción diferente (ADN polimerasa lee, ADN polimerasa une). Ello contribuyó a que tuvieran que poner atención en quién (qué enzima: ADN polimerasa, ARN polimerasa, etc.) actuaba; pero, a la vez, en cuál era la acción que realizaba. Los intercambios que registramos dentro del pequeño grupo dieron cuenta de un interesante trabajo. En un grupo, una de las integrantes (Vanesa) explicó a una compañera (Abigail) cómo leer esas frases, así le sugirió que no pusiera atención sólo en el nombre de la enzima sino también en cuáles eran las acciones que realizaba. Esta instancia de trabajo compartido resultó interesante dado que dio cuenta de cómo el término científico (en este caso ADN polimerasa) en ocasiones se lleva toda la atención del lector y puede invisibilizar la acción que realiza esa enzima.

Después de esa revisión en pequeño grupo, dedicamos la mayor parte de la clase al trabajo en plenario que permitió revisar, plantear preguntas, analizar y contrastar lo que se había resuelto al interior de los grupos con aquello que decía el libro y lo que había propuesto la docente durante la explicación en la clase acerca del proceso.

Al finalizar esta clase se les entregó a los estudiantes una consigna de escritura, que correspondía a la actividad (5). En ella se les pidió escribir para la semana siguiente un texto que ubicara a la duplicación de ADN en un contexto real de una célula humana en el que podría estar sucediendo ese proceso, utilizando como base para ese escrito las frases de la actividad en la que se debía ordenar eventos.

\section{- Clase 4. Duplicación de ADN y Mitosis como procesos del Ciclo Celular}

En la primera parte de la clase 4 se trabajó con la explicación de dos temas, que se vinculaban con la duplicación de ADN y que se les había pedido a los alumnos que leyeran de la bibliografía sugerida. Esos temas eran: a) la duplicación de los extremos de las moléculas de ADN que forman a los cromosomas (los telómeros) y b) la ocurrencia de mutaciones durante la duplicación de ADN. Ambos permitían revisar los 
sucesos que ocurren durante el proceso de duplicación de $A D N$ al recuperar algunas particularidades.

A continuación de esa explicación hubo un diálogo en plenario en el que la docente retomó la consigna del escrito que se había solicitado como tarea entre clases (actividad 5). Una de las alumnas le había comentado al inicio de la clase que había intentado hacer el escrito, pero no sabía cómo ubicar ese relato en una célula. Este aspecto que menciona la alumna, poner en contexto la descripción de un evento molecular, suele ser algo que desconcierta a los estudiantes cuando abordan este tipo de consigna de escritura.

Así, resulta un desafío decidir cómo ubicar en un contexto real y posible un proceso de este tipo que puede parecer descontextualizado y general. Nuestra intención fue forzar a los estudiantes a pensar en esos contextos, dado que a partir de investigaciones previas consideramos que hacerlo favorece que puedan construir relaciones entre procesos metabólicos, las células en las que ocurren y el organismo del que forman parte esas células (De Micheli e Iglesia, 2017; Iglesia, 2014; Iglesia y De Micheli, 2007). $Y$ eso resulta relevante, en especial para estos estudiantes, dado que como futuros docentes tendrán que seleccionar y diseñar tareas para sus alumnos.

En esta ocasión la docente releyó la consigna de trabajo y se detuvo en la referencia que se hacía a una célula humana particular; y ejemplificó que era necesario decidir si la célula en cuestión sería una célula de un embrión, de un niño o de un adulto y en función de esa decisión qué estaban haciendo la célula y el organismo de los que hablarían (creciendo, renovando o regenerando tejidos). Algunos estudiantes (Cristóbal, Oscar, Brenda) mencionaron los contextos elegidos. Vanesa, la alumna que había solicitado la aclaración, pidió si los compañeros podían leer sus textos, así ella después se inspiraba. Dos de ellos lo hicieron y hubo consultas, aclaraciones a partir de esa lectura compartida. Nos interesa aquí en esta descripción mencionar esta instancia, dado que aun cuando no fue planificada en el diseño, efectivamente sucedió en la implementación y de alguna manera aporta a comprender cómo se fue estableciendo una modalidad dialógica de trabajo en el aula. Dar tiempo didáctico a la lectura de los escritos de los pares de manera tal de pensar en contextos posibles aportó modelos para abordar el propio texto. Las intervenciones de la docente $\mathrm{S}$ generaron condiciones que permitieron que hablar acerca de cómo escribir tuviera lugar en la clase y ese diálogo a la vez permitió reforzar cuándo, dónde y para qué, sucede la duplicación del ADN. 
Una hora después del inicio de la clase la docente presentó la actividad (6) de escritura de un texto relacionando conceptos disciplinares acerca del Ciclo Celular. Entregó la consigna y les pidió un escrito "cortito para que se ubiquen mentalmente y para retomar ciclo celular" (S: 354 - Clase 4). Al finalizar la escritura individual se desarrolló un diálogo en plenario acerca de lo que cada uno había escrito, qué relaciones habían establecido, las dudas que habían surgido. Esta situación de escritura en clase, el diálogo posterior y las producciones escritas, fueron analizados en profundidad para esta tesis. Presentamos ese análisis en el capítulo 5 de resultados.

Al finalizar la clase, la docente presentó la consigna de la actividad (7) para ser realizada en parejas entre clases. Esta tarea tuvo como propósito que los estudiantes revisaran aquello que ya sabían sobre la división celular mitosis. En los escritos previos esa división había sido mencionada y referidos los acontecimientos que en ella ocurrían. También durante la clase al ubicar la duplicación de ADN sólo en células que se dividen, se había representado en el pizarrón la separación de las copias de material genético que se obtenían y el reparto a células hijas.

Debido a estas razones consideramos que los estudiantes podían abordar la tarea solicitada que consistió en el diseño de dos o tres diapositivas, por parejas, para armar con todo el grupo un power point que describiera qué sucedía con los cromosomas durante las etapas de la mitosis. Se les sugería en la consigna escrita que les entregamos, acudir a diferentes materiales como algunos libros de la biblioteca, el capítulo correspondiente de la bibliografía y también a materiales de la web. Les pedimos que enviaran durante la semana esas diapositivas al mail de la asignatura así armábamos el power point completo y se los reenviábamos para que todos lo tuvieran antes de la presentación que se haría durante la clase siguiente.

\section{- Clase 5. Las etapas del Ciclo Celular y la transformación de los} cromosomas

Esta clase comenzó con una actividad que no teníamos prevista inicialmente en la secuencia pero que diseñamos después de leer los escritos que los estudiantes produjeron durante la clase anterior como parte de la actividad (6). Al leer estos breves textos notamos que había algunas dificultades al referir a la sucesión de eventos, pero en especial con la relación entre cromosomas y cromátides hermanas. Fue por ello que diseñamos esta nueva actividad (8) en la que les solicitamos a todos los estudiantes que leyeran esos textos (no estaban identificados los autores) como parte de una actividad de revisión. Asumimos que contrastar los diferentes escritos realizados por los pares a partir de una misma consigna podía funcionar como actividad desafiante. Por lo 
tanto, podía actuar como oportunidad para reflexionar acerca de las relaciones que se habían establecido, no sólo las que cada uno había propuesto sino también las que los demás estudiantes habían planteado.

En una primera instancia se revisaron los escritos en pequeños grupos durante media hora de clase, de acuerdo a lo solicitado en la consigna de la tarea (les pedimos que pensaran en sugerencias para los autores de cada texto) para después trabajar en una situación de plenario coordinado por la docente. Esta instancia de diálogo plenario se desarrolló durante gran parte de la clase. Dio lugar a momentos de revisión de la explicación de contenidos ya trabajados, así como a la explicación de nuevos contenidos. Ambas instancias surgieron a partir de preguntas que los estudiantes plantearon durante la revisión de los textos. Así, la docente volvió sobre lo trabajado para fortalecer la relación entre duplicación de ADN y la formación de cromátides hermanas de los cromosomas. Para después explicar la relación entre cromosoma y cromatina, y dar cuenta de cambios en la organización del material genético durante el ciclo celular fue necesario introducir este último concepto (cromatina). Y a la vez, refirió a los cambios en los niveles de compactación de esa cromatina y los vinculó con la expresión de la información genética durante la vida de una célula.

Tanto las producciones de los estudiantes, como los intercambios que sucedieron durante las instancias de plenario y explicación docente asociada a ese diálogo fueron analizados en profundidad en el capítulo 5 de esta tesis.

Durante la última parte de la clase los estudiantes por parejas o tríos describieron las etapas de la división celular mitosis utilizando las diapositivas del power point que habían diseñado para la tarea (7). Durante esta instancia la docente hizo preguntas jerarquizando algunas de las menciones que los estudiantes planteaban, así como también intervino para que se detuvieran en las imágenes de los cromosomas en cada etapa de la división que cada grupo había incluido.

Finalmente se les solicitó a los alumnos algunas tareas entre clases: en primer lugar que cada uno reescribiera el texto de la actividad (6) que se había revisado en esta clase, pero que ahora incluyeran y relacionaran la noción de cromatina. En segundo lugar, se les entregaron por escrito las consignas de dos actividades para realizar de manera individual y que permitían volver sobre la división celular mitosis. En una de ellas (9) se les pidió dibujar células y cromosomas en etapas de mitosis. Esta tarea requería pensar qué les ocurría a los cromosomas en los diferentes momentos de la división y cómo representar esos cambios durante las diferentes fases. 
En la actividad (10) se les solicitó que en relación a la mitosis pensaran y compararan esa división en dos células concretas en las que adquiría funciones diferentes. En una de las células de la raíz de una planta que estaba creciendo y que formaba parte de un organismo pluricelular; y en la única célula de un organismo unicelular cuya división implica reproducción en vez de crecimiento, ya que las nuevas células se constituyen en nuevos individuos.

- Clase 6. Mitosis como evento del Ciclo Celular y las consecuencias en los organismos

Al inicio de esta clase se revisaron en pequeños grupos las actividades (9) y (10). Les pedimos a dos estudiantes que dibujaran en el pizarrón las células en diferentes etapas de mitosis como solicitaba la actividad (9) para así revisar esos esquemas y retomar las dudas que surgían, por ejemplo acerca de cómo representar a los cromosomas y sus cromátides hermanas; o sobre las nociones de ploidía y cromosomas homólogos que se habían presentado al finalizar la clase previa. La actividad (10), que tal como dijimos pedía comparar las consecuencias de la mitosis en dos seres vivos diferentes, tuvo como propósito poner en evidencia la relación entre esta división celular y la reproducción asexual, así como recordar la función de crecimiento que tiene en organismos pluricelulares. Ambas eran actividades que permitían revisar las características de ese tipo de división celular e institucionalizar algunas nociones pertinentes alrededor de ella.

Durante la clase les entregamos a los alumnos la consigna escrita de una nueva actividad (11). Esta tarea consistió en completar una tabla de doble entrada que permitía comparar células de un organismo particular (un chimpancé en este caso), que se encontraban en diferentes etapas de su ciclo celular. Los criterios de comparación fueron: la cantidad de cromosomas y de ADN de cada célula; así como el número de cromátides y de moléculas de ADN que tenía cada cromosoma en cada una de esas células. Este tipo de situación de escritura que requiere completar con algo breve un cuadro comparativo, es un tipo de actividad característica en la enseñanza de Biología; teniendo en cuenta criterios pertinentes al caso, en ella se pueden comparar seres vivos, células, procesos metabólicos, etc. El hecho de comparar y así contrastar, para hacer explícitas similitudes y diferencias entre estructuras o eventos, hace posible pensar en regularidades.

En este caso la tarea permitía sintetizar y abstraer una serie de datos relacionados con el ciclo celular y ello implicaba un desafío importante para decidir cómo completarla. Por ejemplo, decidir qué número de cromosomas o la cantidad de ADN tendría una célula 
en cada etapa del ciclo celular, implicaba relacionar los cambios que sucedían en la vida de esa célula.

La docente explicó cómo trabajar con esta actividad, y les dio un tiempo de clase para que cada quien la completara y pudiera ir consultando las dudas que surgían, para después representar la tabla correspondiente en el pizarrón e ir consensuando la versión final entre alumnos y docente, a la vez que se discutían los argumentos durante el plenario. Esta actividad dio oportunidad de revisar el ciclo celular a partir de pensar qué ocurría con el ADN y los cromosomas durante diferentes momentos de ese ciclo.

Por último, la docente retomó la relación entre niveles de plegamiento de la cromatina y expresión de la información genética que había presentado durante la clase previa. Ahora, incluyó en esa relación la noción de diferenciación celular y así vinculó la expresión genética con las funciones diferentes que adquieren las células de los organismos dado que producen distintas proteínas, aun cuando tienen la misma información genética. Ese aspecto, que todavía estaba pendiente, era necesario para poder pensar en funciones diversas de las células de un organismo pluricelular. Para reforzar el recorrido en este sentido durante la clase siguiente se trabajó con una actividad (18) para justificar si ciertas frases referidas a expresión y diferenciación eran verdaderas o falsas.

Como tarea entre clases solicitamos que escribieran un breve texto relacionando conceptos disciplinares sobre ciclo celular en un organismo en crecimiento (ya no en una célula como se había pedido en la actividad 6) y que lo enviaran por mail. Así también, les enviamos por correo electrónico una guía para acompañar la lectura de la bibliografía sugerida sobre mitosis (capítulo 18 del libro de De Robertis e Hib, 2004) ${ }^{16}$. El propósito de trabajar con una guía fue ayudarles a jerarquizar la diversidad de temas que aborda el capítulo mencionado. Las últimas clases de la secuencia estuvieron intercaladas con algunos días sin clases, debido a un feriado y anuncios de paro de transporte. Tuvimos menos tiempo de trabajo en clase con este capítulo de la bibliografía, por esa razón decidimos diseñar una guía para acompañar la lectura durante la preparación de la evaluación parcial.

\section{- Clase 7. Revisión e integración del Ciclo Celular}

Para esta clase de preparación de la evaluación parcial diseñamos una serie de nuevas actividades (13 a 18). La intención era que los estudiantes las resolvieran durante la

\footnotetext{
${ }^{16}$ La guía de lectura se incluyó en el Anexo
} 
clase en pequeños grupos con el propósito de revisar e integrar lo trabajado a lo largo de toda la secuencia.

En las primeras tres actividades los alumnos tenían que reconocer en diferentes imágenes de células (dibujos y fotografías) las etapas de la división celular mitosis y el número de cromosomas que tenía la célula que hacía esa división.

Más allá de que todos trabajaron con la serie completa de actividades, la docente asignó a cada integrante de cada grupo una parte de la actividad (16) que consistía en dibujar ciclos celulares sucesivos de células de un organismo particular desde la célula inicial que lo formó. Ese par de esquemas que fue asignado a cada alumno para representar en el pizarrón, correspondía a dos momentos diferentes del crecimiento del embrión referido en la consigna. El hecho de hacerse cargo cada estudiante de un par de dibujos funcionó como elemento de tracción para la resolución de la tarea. A la vez, para ello tuvieron que recuperar la secuencia de divisiones que había tenido ese embrión para poder decidir cómo representaban a los cromosomas en la célula particular asignada.

Mientras los alumnos iban pasando al pizarrón a completar los sucesivos esquemas de células, en los grupos discutieron acerca de las etapas representadas por las imágenes y cómo sería mejor dibujar a los cromosomas en cada etapa. Tener que dibujar en el pizarrón puso en discusión cuándo terminaba una etapa y empezaba la siguiente, como ocurrió al representar el momento de citocinesis, que corresponde a la separación del citoplasma, o al representar la separación y migración de cromátides hacia polos opuestos durante anafase.

Que cada estudiante se hiciera cargo de dibujar en el pizarrón algunos esquemas de una serie que correspondía a diferentes etapas y ciclos sucesivos de un organismo, tal como pedía esa actividad (16), resultó algo desafiante y permitió compartir y consensuar modelos de representación. Así surgieron preguntas acerca de qué representaban los colores que algunos alumnos habían usado para mostrar ciertos cambios en los cromosomas, consultas acerca de si las cromátides estaban realmente dispuestas en cruz (como una $\mathrm{X}$ ) o si eso era sólo una forma sencilla de representar pero que podía inducir confusiones. Esos intercambios dieron lugar a que la docente interviniera mostrando diferentes planos de observación de las células y, por lo tanto, distintas maneras posibles de dibujar lo observado o representado.

Tanto la docente como la investigadora recorrimos los pequeños grupos para responder consultas, formular preguntas para instalar dudas, observar cómo dibujaban la secuencia completa y orientar el trabajo que estaban haciendo. 
En la última parte de la clase se trabajó también en pequeños grupos justificando si eran verdaderas o falsas ciertas frases referidas a expresión de la información genética y la diferenciación celular. La docente asignó a cada uno de los estudiantes que integraban los pequeños grupos una de las frases de esa actividad (18) para que retomaran en el plenario la decisión de si era verdadera o falsa y cómo justificaban esa aseveración. Cuando se revisó esta actividad entre todos, la docente intervino especialmente para consensuar las justificaciones. De esta manera pretendía profundizar lo trabajado durante las clases 5 y 6 acerca de la expresión de la información genética y los niveles de compactación de la cromatina, así como la diferenciación de las células relacionada con ese cambio de conformación de la cromatina.

Se les solicitó a los estudiantes que aquellas actividades que no habían alcanzado a escribir en clase las enviaran por correo electrónico y consultaran las dificultades hasta el día del parcial que se realizó la semana siguiente. La docente finalizó comentando la función y el sentido que tenía la guía de lectura diseñada para el capítulo 18 del libro, que se había enviado por mail, dado que era la primera vez que leían bibliografía con una guía de lectura orientada.

\section{- Clase 8. Evaluación}

Aun cuando no analizamos la situación de evaluación parcial en esta tesis, describiremos brevemente el instrumento de evaluación para relacionarlo con lo trabajado durante la secuencia didáctica.

A partir de un enunciado inicial con datos sobre una especie de monos aulladores nativos de la zona mesopotámica, diseñamos las diferentes actividades de la evaluación parcial. Esa información fue retomada en varias de las consignas del parcial y aportaba un contexto para pensar las células y lo que sucedía en ellas. Incluimos distintas situaciones de escritura con las que habíamos trabajado, tales como escribir para explicar, para relacionar conceptos disciplinares, para describir qué sucedía durante la vida de una célula y para completar un cuadro comparativo.

El parcial fue extenso y exhaustivo, los estudiantes tuvieron que recorrer todos los temas trabajados, tanto en la secuencia sobre ciclo celular como aquellos que formaron parte de la secuencia previa en la que se trabajó con aspectos generales de las células. Todos los alumnos presentes aprobaron el parcial, sólo Cristóbal estuvo ausente por el nacimiento de su hijo y rindió la evaluación con posterioridad.

\subsection{Las situaciones de escritura en la secuencia didáctica implementada}

La incorporación de diferentes instancias para escribir en clase y entre clases fue una decisión didáctica que tuvimos en cuenta para el diseño. Aquí caracterizamos los tipos 
de situaciones de escritura que formaron parte de la secuencia implementada con el objetivo de mostrar su diversidad. ${ }^{17}$

Decidimos incluir en la secuencia situaciones en las que los alumnos explicaran o argumentaran acerca de una cuestión (a). Esta práctica relevante en la enseñanza de las ciencias naturales, entre otros motivos debido a la concepción de ciencia que permite construir, demanda que los estudiantes tengan que dar cuenta de las razones que les permiten sostener ciertas concepciones. Así favorece que se establezcan relaciones entre argumentos de diferente nivel para fundamentar aquello que se sostiene. Además, el hecho de poner en discusión los diferentes argumentos permite profundizar el conocimiento acerca del tema en cuestión, así como transformar certezas supuestamente inamovibles en problemas para que admitan ser cuestionadas.

A la vez, diseñamos situaciones de escritura que demandaron establecer relaciones entre conceptos disciplinares de manera explícita (b). Ese tipo de situación que requirió vincular conceptos que aludían a diferentes momentos de la vida celular y/o a distintos niveles de organización de la materia (moléculas, células, organismo) se condice con el enfoque sistémico que enmarca la propuesta; esas relaciones podían ser temporales, espaciales, funcionales según fuera pertinente. Se les solicitaba ubicar aquello de lo que se escribía en el contexto celular de un organismo, de manera tal de favorecer que pensaran en los procesos moleculares y celulares en un ser vivo.

El tercer tipo de tarea de escritura que incluimos en la secuencia fue aquel en el que los estudiantes tuvieron que describir o relatar un evento, fuera éste un proceso molecular o celular (c). Todas fueron instancias en las que los estudiantes leyeron para escribir, es decir recuperaron otros materiales ( $y$ esto se sugería de manera explícita en la consigna entregada), tales como apuntes de clase, imágenes de la web y/o de la bibliografía y los capítulos correspondientes del libro que la docente sugirió como bibliografía de base. En este caso, el propósito fue que esos escritos funcionaran como producciones propias que pudieran servir como resúmenes para estudiar ciertos temas para la evaluación parcial. Pero a la vez, para elaborar esas producciones era necesario leer, releer y organizar diferentes materiales en un texto coherente y situado. Por ello, esa escritura también tenía la potencialidad de ser epistémica y funcionó como práctica de estudio, tal como manifestaron varios alumnos en las entrevistas finales que realizamos.

En último lugar mencionamos los cuadros comparativos (d), un tipo de actividad habitual en la enseñanza de las ciencias naturales. En ocasiones estos cuadros se presentan ya

\footnotetext{
17 Las tablas presentan las situaciones en su orden de aparición durante el desarrollo de la secuencia.
} 
completos y los alumnos los memorizan para las evaluaciones, que consisten en reproducir parte de esa información. Aquí este tipo de actividad tuvo el propósito de sintetizar las transformaciones que sufren los cromosomas durante el ciclo celular y así poder comparar las diferentes etapas de ese ciclo. Por ello era crucial trabajar con las razones que permitían fundamentar que en determinado casillero se completara con cierto número y no otro.

A continuación en la tabla 3.2 sintetizamos las actividades implementadas que correspondían a cada categoría, las consignas de todas ellas fueron incluidas en el anexo de esta tesis, como hemos indicado en la descripción de las clases de la secuencia didáctica.

Tabla 3.2

Situaciones de escritura

\begin{tabular}{|c|c|c|c|}
\hline $\begin{array}{l}\text { Situación de } \\
\text { escritura }\end{array}$ & Actividad & Organización & Conceptos a trabajar \\
\hline \multirow{3}{*}{$\begin{array}{l}\text { a. Escribir } \\
\text { para explicar, } \\
\text { justificar, } \\
\text { argumentar }\end{array}$} & Actividad 1 & $\begin{array}{l}\text { Individual } \\
\text { En clase } 1\end{array}$ & $\begin{array}{l}\text { Diversidad celular, } \\
\text { función e información } \\
\text { genética. }\end{array}$ \\
\hline & Actividad 9 & $\begin{array}{l}\text { Individual } \\
\text { Entre clases } 5 \text { y } 6\end{array}$ & $\begin{array}{l}\text { Mitosis y sus } \\
\text { consecuencias en } \\
\text { organismos unicelulares y } \\
\text { pluricelulares. }\end{array}$ \\
\hline & Actividad 14 & $\begin{array}{l}\text { En pequeño grupo } \\
\text { En clase } 7\end{array}$ & $\begin{array}{l}\text { Cromatina, relación entre } \\
\text { expresión y diferenciación } \\
\text { celular. }\end{array}$ \\
\hline \multirow{3}{*}{$\begin{array}{l}\text { b. Escribir } \\
\text { para } \\
\text { relacionar } \\
\text { conceptos } \\
\text { disciplinares }\end{array}$} & Actividad 2 & $\begin{array}{l}\text { Individual } \\
\text { En clase } 1\end{array}$ & $\begin{array}{l}\text { ADN, genes, } \\
\text { cromosomas, e } \\
\text { información genética. }\end{array}$ \\
\hline & Actividad 6 & $\begin{array}{l}\text { Individual } \\
\text { En clase } 4\end{array}$ & $\begin{array}{l}\text { Contexto: La vida de una } \\
\text { célula epitelial. } \\
\text { Relacionar: etapa } S \text { de } \\
\text { interfase, mitosis, } \\
\text { cromátides hermanas, } \\
\text { ADN, cromosomas }\end{array}$ \\
\hline & $\begin{array}{l}\text { Actividad } 6 \\
\text { Reescritura }\end{array}$ & $\begin{array}{l}\text { Individual } \\
\text { Entre clases } 5 \text { y } 6\end{array}$ & $\begin{array}{l}\text { Mismo contexto y } \\
\text { términos agregando } \\
\text { cromatina al conjunto de } \\
\text { conceptos a relacionar. }\end{array}$ \\
\hline
\end{tabular}




\begin{tabular}{|c|c|c|c|}
\hline & Actividad $10^{18}$ & $\begin{array}{l}\text { Individual } \\
\text { Entre clases } 6 \text { y } 7\end{array}$ & $\begin{array}{l}\text { Contexto: una planta cuya } \\
\text { raíz está creciendo } \\
\text { Relacionar cromatina, } \\
\text { duplicación de } A D N \text {, } \\
\text { cromátides hermanas, } \\
\text { mitosis y enzimas }\end{array}$ \\
\hline \multirow{3}{*}{$\begin{array}{l}\text { c. Escribir para } \\
\text { describir } \\
\text { eventos } \\
\text { biológicos }\end{array}$} & Actividad 5 & $\begin{array}{l}\text { Individual } \\
\text { Entre clases } 2 \text { y } 3\end{array}$ & $\begin{array}{l}\text { Eventos que ocurren } \\
\text { durante el proceso de } \\
\text { duplicación de ADN en el } \\
\text { contexto de una célula } \\
\text { real. }\end{array}$ \\
\hline & $\begin{array}{l}\text { Actividad } 7 \\
\text { Diseñar } \\
\text { diapositivas. }\end{array}$ & $\begin{array}{l}\text { En parejas } \\
\text { Entre clases } 4 \text { y } 5 \\
\text { Clase 5: exposición }\end{array}$ & $\begin{array}{l}\text { Etapas de la Mitosis. } \\
\text { ¿Qué les sucede a los } \\
\text { cromosomas? }\end{array}$ \\
\hline & Actividad 17 & $\begin{array}{l}\text { En pequeño grupo } \\
\text { En clase } 7\end{array}$ & $\begin{array}{l}\text { Regulación de las etapas } \\
\text { del ciclo celular }\end{array}$ \\
\hline $\begin{array}{l}\text { d. Escribir para } \\
\text { completar un } \\
\text { cuadro } \\
\text { comparativo }\end{array}$ & Actividad 11 & $\begin{array}{l}\text { En pequeño grupo } \\
\text { En clase } 6\end{array}$ & $\begin{array}{l}\text { Relación entre etapas del } \\
\text { ciclo celular y los eventos } \\
\text { que involucran al ADN y } \\
\text { los cromosomas }\end{array}$ \\
\hline
\end{tabular}

\subsection{Las situaciones de lectura en la secuencia didáctica implementada}

En diferentes momentos de la secuencia se desarrollaron situaciones de lectura; además de aquellas instancias en las que se leyó con el propósito de escribir y que fueron mencionadas en el apartado previo y descriptas en el relato de cada clase.

En primera instancia mencionamos la lectura de materiales didácticos (a) que refiere a la lectura de escritos incluidos como parte de las tareas en clase o entre clases. Más allá que todas las consignas de las actividades requerían que los alumnos leyeran para recuperar información y pensar en contexto, nos referiremos aquí a aquellas tareas que incluían materiales más extensos, además de la consigna concreta que indicaba qué hacer con ellos. En particular, hubo dos situaciones durante la secuencia en las que los alumnos leyeron textos que recuperaban el discurso docente. Una de ellas fue la lectura de un texto escrito por la docente para esta secuencia, realizada durante la primera clase y que dio lugar a situaciones de diálogo en pequeño grupo y en plenario, analizadas en profundidad en el capítulo próximo. La otra situación correspondió a una tarea en la que solicitamos a los estudiantes que leyeran y organizaran

\footnotetext{
18 Tomado de Acerca de organismos, células, genes y poblaciones. De Micheli, Donato, Goveto, Iglesia y Otero. Ediciones Villoldo Yanele, Buenos Aires, 2006. Agregamos el término enzimas al conjunto de términos a relacionar.
} 
cronológicamente una serie de frases desordenadas que fueron transcriptas a partir de la explicación previa que realizó la docente del proceso de duplicación de ADN.

En segundo término nos referimos a las situaciones de lectura de la bibliografía que había seleccionado la docente y que se realizó entre clases (b). A la vez, algunos alumnos llevaban los libros o fotocopias de los capítulos seleccionados al aula y los releían para trabajar en las actividades de la secuencia. En varios casos se usó la bibliografía para comparar imágenes o referir a qué decía y cómo lo hacía el autor para retomar dudas que surgían al contrastar esa voz con el discurso de la docente. Al finalizar cada clase se solicitó a los estudiantes que leyeran algunos apartados de los capítulos de la bibliografía seleccionada para esta secuencia, lo correspondiente a esa clase y para anticipar la siguiente. En particular, para el capítulo 18 diseñamos una guía de lectura que enviamos por mail, dado que debido a factores externos (un paro, un feriado), ese material tuvo poco tiempo de discusión en el aula, tal como mencionamos oportunamente.

Otra situación que involucró la lectura fue la revisión de textos propios y de pares (c) y que correspondió a la que denominamos actividad (8) y analizamos en profundidad en el capítulo 5 de esta tesis.

En las entrevistas varios alumnos mencionaron la lectura de otros materiales bibliográficos que complementaron la lectura de los capítulos sugeridos por la docente. En algunos casos señalaron el libro Biología de Helena Curtis como un texto que les permitía un primer acercamiento al tema que se trataba, para después leer el material sugerido.

En la tabla 3.3 que incluimos a continuación, se presentan todas las situaciones de lectura de la secuencia de manera esquemática.

Tabla 3.3

Situaciones de lectura

\begin{tabular}{|c|c|c|c|}
\hline $\begin{array}{c}\text { Situación de } \\
\text { lectura }\end{array}$ & Qué se leyó & Organización & Conceptos a trabajar \\
\hline \multirow{2}{*}{$\begin{array}{ll}\text { a. } & \text { Leer } \\
\text { materiales } \\
\text { didácticos } \\
\text { escritos para } \\
\text { la secuencia }\end{array}$} & $\begin{array}{l}\text { Actividad } 3 \\
\text { Lectura de un texto } \\
\text { didáctico escrito por la } \\
\text { docente, para pensar } \\
\text { en ciclos celulares }\end{array}$ & $\begin{array}{l}\text { En pequeño grupo } \\
\text { En clase } 1\end{array}$ & $\begin{array}{l}\text { Ciclo celular } \\
\text { Diversidad de ciclos }\end{array}$ \\
\hline & $\begin{array}{l}\text { Actividad } 4 \\
\text { Lectura de un listado } \\
\text { de eventos que } \\
\text { suceden en la } \\
\text { duplicación de ADN, } \\
\text { transcriptos a partir de }\end{array}$ & $\begin{array}{l}\text { Individual } \\
\text { entre clases } 2 \text { y } 3 \\
\text { En pequeño grupo }\end{array}$ & Duplicación de ADN \\
\hline
\end{tabular}




\begin{tabular}{|c|c|c|c|}
\hline & $\begin{array}{l}\text { la explicación docente } \\
\text { dada la clase previa. }\end{array}$ & en clase 3 & \\
\hline \multirow{2}{*}{$\begin{array}{l}\text { b. Leer } \\
\text { bibliografía } \\
\text { sugerida por } \\
\text { la docente }\end{array}$} & $\begin{array}{l}\text { Capítulo 17: } \\
\text { Duplicación del ADN } \\
\text { Biología celular } \\
\text { De Robertis (2009) }\end{array}$ & $\begin{array}{l}\text { Individual } \\
\text { Entre clases } 2 \text { y } 3 \\
\text { Entre clases } 3 \text { y } 4\end{array}$ & $\begin{array}{l}\text { Duplicación de ADN } \\
\text { Mutaciones }\end{array}$ \\
\hline & $\begin{array}{l}\text { Capítulo 18: Mitosis } \\
\text { Biología celular } \\
\text { De Robertis (2009) } \\
\text { (con guía de lectura) }\end{array}$ & $\begin{array}{l}\text { Individual } \\
\text { Entre clases } 4 \text { y } 5 \\
\text { Entre clases } 5 \text { y } 6 \\
\text { Entre clases } 6 \text { y } 7\end{array}$ & $\begin{array}{l}\text { Ciclo celular } \\
\text { Mitosis } \\
\text { Regulación del ciclo } \\
\text { celular }\end{array}$ \\
\hline $\begin{array}{l}\text { c. Leer } \\
\text { textos propios } \\
\text { y de pares }\end{array}$ & $\begin{array}{l}\text { Actividad } 7 \\
\text { Textos elaborados } \\
\text { previamente por los } \\
\text { estudiantes }\end{array}$ & $\begin{array}{l}\text { En pequeño grupo } \\
\text { En plenario } \\
\text { En clase } 5\end{array}$ & $\begin{array}{l}\text { Ciclo celular } \\
\text { Cromosomas }\end{array}$ \\
\hline
\end{tabular}

\subsection{Las situaciones de diálogo en la secuencia didáctica implementada}

Durante el trabajo con escritura y lectura también previmos situaciones de diálogo. Esas situaciones se organizaron de dos maneras principales: a) diálogo en pequeño grupo y b) diálogo en plenario.

Las instancias de diálogo en pequeño grupo (a) que fueron previstas en el diseño estuvieron asociadas a situaciones de escritura y/o de lectura previa. Estos momentos se desarrollaron con la intención de que los alumnos pudieran plantear dudas y reflexiones tanto a sus pares como a la docente y la investigadora durante la recorrida de los grupos de trabajo. Ese intercambio más íntimo hizo posible una primera instancia de revisión de aquello trabajado y dio oportunidades durante la clase para contrastar las diferentes maneras de abordar esa tarea.

A su vez, las situaciones de diálogo en plenario (b) estuvieron coordinadas por la docente y en general ocurrieron después de la interacción dentro del pequeño grupo. Fueron incluidas en la secuencia para promover la participación de todos los estudiantes, al institucionalizar el conocimiento acerca de lo trabajado.

En la siguiente tabla 3.4 se presentan las diferentes situaciones de diálogo que ocurrieron durante la implementación de la secuencia didáctica y que describimos en dos modalidades. 
Tabla 3.4

Situaciones de diálogo

\begin{tabular}{|c|c|c|c|}
\hline $\begin{array}{l}\text { Situación de } \\
\text { diálogo }\end{array}$ & Actividad & Qué propone la tarea & Qué se trabaja \\
\hline \multirow{4}{*}{$\begin{array}{l}\text { a. en } \\
\text { pequeño } \\
\text { grupo }\end{array}$} & $\begin{array}{l}\text { Actividad } 3 \\
\text { Clase } 1\end{array}$ & $\begin{array}{l}\text { Leer texto didáctico, } \\
\text { interpretación de título y } \\
\text { criterios de clasificación de la } \\
\text { diversidad ciclos celulares. }\end{array}$ & $\begin{array}{l}\text { Ciclo celular } \\
\text { Diversidad de ciclos }\end{array}$ \\
\hline & $\begin{array}{l}\text { Actividad } 4 \\
\text { Clase } 3\end{array}$ & $\begin{array}{l}\text { Revisar ordenamiento de } \\
\text { eventos de la duplicación de } \\
\text { ADN propuesto de manera } \\
\text { individual, para contrastar con } \\
\text { pares. }\end{array}$ & $\begin{array}{l}\text { Duplicación del ADN } \\
\text { Rol de las enzimas } \\
\text { Ocurrencia de eventos } \\
\text { celulares simultáneos y } \\
\text { sucesivos }\end{array}$ \\
\hline & $\begin{array}{l}\text { Actividad } 8 \\
\text { Clase } 5\end{array}$ & $\begin{array}{l}\text { Revisar textos escritos por los } \\
\text { pares para hacer sugerencias } \\
\text { a los autores. }\end{array}$ & $\begin{array}{l}\text { Ciclo celular } \\
\text { Cromosomas }\end{array}$ \\
\hline & $\begin{array}{l}\text { Actividades } 13 \text { a18 } \\
\text { Clase } 7\end{array}$ & $\begin{array}{l}\text { Interpretar imágenes, dibujar } \\
\text { células y cromosomas, } \\
\text { justificar afirmaciones. }\end{array}$ & $\begin{array}{l}\text { Mitosis. Cromosomas, } \\
\text { Cromatina, relación } \\
\text { entre expresión y } \\
\text { diferenciación celular }\end{array}$ \\
\hline \multirow{5}{*}{$\begin{array}{l}\text { b. en } \\
\text { plenario }\end{array}$} & $\begin{array}{l}\text { Actividad } 3 \\
\text { Clase } 1\end{array}$ & $\begin{array}{l}\text { Contrastar interpretaciones del } \\
\text { título de la lectura y criterios } \\
\text { de clasificación de ciclos } \\
\text { celulares decididos en cada } \\
\text { grupo. }\end{array}$ & $\begin{array}{l}\text { Ciclo celular } \\
\text { Diversidad de ciclos } \\
\text { Argumentar para } \\
\text { sostener interpretación }\end{array}$ \\
\hline & $\begin{array}{l}\text { Actividad } 4 \\
\text { Clase } 3\end{array}$ & $\begin{array}{l}\text { Cotejar lo resuelto en el } \\
\text { pequeño grupo en relación con } \\
\text { la secuencia temporal de los } \\
\text { eventos que suceden durante } \\
\text { duplicación del ADN. }\end{array}$ & $\begin{array}{l}\text { Duplicación del ADN } \\
\text { Rol de las enzimas } \\
\text { Eventos simultáneos y } \\
\text { sucesivos }\end{array}$ \\
\hline & $\begin{array}{l}\text { Actividad } 5 \\
\text { Clase } 4\end{array}$ & $\begin{array}{l}\text { Compartir textos escritos } \\
\text { acerca de duplicación de ADN } \\
\text { para reflexionar acerca de } \\
\text { modelos posibles para escribir } \\
\text { el propio. }\end{array}$ & $\begin{array}{l}\text { Cómo escribir: poner en } \\
\text { el contexto de una } \\
\text { célula de un organismo } \\
\text { humano el escrito } \\
\text { pedido. }\end{array}$ \\
\hline & $\begin{array}{l}\text { Actividad } 6 \\
\text { Clase } 4\end{array}$ & $\begin{array}{l}\text { Hablar acerca de las } \\
\text { relaciones que se } \\
\text { establecieron en el escrito y } \\
\text { contrastarlas. }\end{array}$ & $\begin{array}{l}\text { Reflexionar acerca de } \\
\text { cuáles eran los vínculos } \\
\text { posibles entre los } \\
\text { conceptos a relacionar } \\
\text { en el escrito. }\end{array}$ \\
\hline & $\begin{array}{l}\text { Actividad } 8 \\
\text { Clase } 5\end{array}$ & $\begin{array}{l}\text { Contrastar las sugerencias } \\
\text { realizadas dentro de cada } \\
\text { grupo para discutir } \\
\text { argumentos. }\end{array}$ & $\begin{array}{l}\text { Transformación de los } \\
\text { cromosomas durante el } \\
\text { ciclo celular. } \\
\text { Relación con } \\
\text { duplicación de ADN }\end{array}$ \\
\hline
\end{tabular}




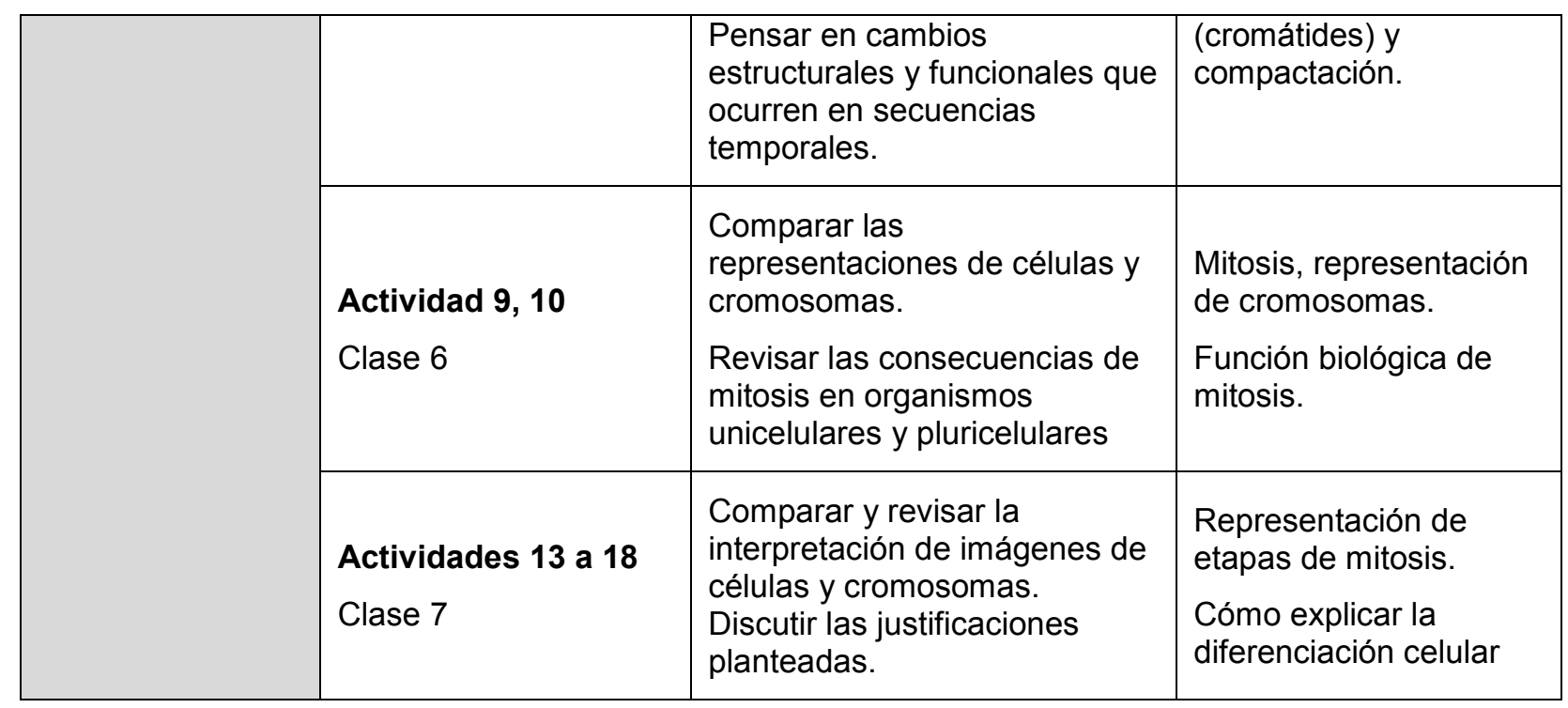

\subsection{El lugar de las intervenciones docentes en el diseño didáctico}

A partir de la experiencia del año previo, intentamos asegurar para esta secuencia que no fueran sólo los alumnos que siempre intervenían en clase ante el requerimiento de la profesora los únicos que participaran, sino que todos los estudiantes se vieran interpelados a hacerlo. En parte por ello en el diseño de la secuencia incluimos instancias de trabajo que favorecieran que la profesora pudiera generar una modalidad de regulación más dialógica que diera pie a que los estudiantes intervinieran y participaran.

Esas previsiones se establecieron en las reuniones entre la investigadora y la docente, en las que se elaboró el diseño inicial de la secuencia. Así como también en los encuentros e intercambios durante la implementación, en los que se delinearon y ajustaron las tareas que finalmente se desarrollaron en las clases. Se discutió y acordó con la docente cómo intervenir para presentar un tema o una tarea de escritura, pero en especial se trabajó con la dualidad entre reticencia y expresión (Sensevy, 2015). Eso implicó para la docente la tensión de sostener una actitud alerta para no anticipar sus interpretaciones y así clausurar tempranamente la reflexión alrededor de ciertas nociones (Espinoza, Casamajor y Pitton, 2009).

En el diseño se previeron varias instancias para que la docente no sólo pudiera recuperar lo que cada alumno quiso decir, sino que pusiera esos dichos en tensión al articularlos entre sí, dando lugar a la multivocidad en el aula (Dysthe, 1996, 2000). Se intentó prever quiénes eran los que habitualmente ejercían roles más visibles en el grupo y a quiénes iba a ser necesario convocar especialmente y dar tiempo para que pudieran expresar su perspectiva. La experiencia del año previo fue crucial en este sentido, esta 
vez era un grupo más reducido y se conocían la docente y los nueve alumnos que cursaban la asignatura; por lo tanto fue más sencillo anticipar aquello que podría desencadenarse al discutir en plenario.

En el diseño se previeron explícitamente diferentes modalidades de intervención docente, que describiremos brevemente:

- intervenciones orales en la clase. Por ejemplo, al presentar y/o explicar un nuevo contenido disciplinar, al definir una tarea a realizar, al regular durante el trabajo en pequeño grupo, al coordinar las situaciones de plenario;

- intervenciones escritas entre clases. Por ejemplo, de feedback al devolver las tareas de escritura; al solicitar tareas pendientes y recordar cuestiones relevantes para la clase siguiente por correo electrónico.

Aun cuando las intervenciones por escrito no serán analizadas para esta tesis, las mencionamos porque formaron parte de las condiciones de enseñanza que se constituyeron durante la implementación. Así como las intervenciones orales, también ejercieron un papel relevante en las condiciones de enseñanza generadas desde la perspectiva de los alumnos y la docente.

En las entrevistas orales realizadas al finalizar la secuencia, varios alumnos le dieron al tipo de devolución realizada a sus producciones escritas un lugar relevante para comprender el tema en el que estaban trabajando. Ese lugar estaba asociado a la posibilidad de seguir reelaborando a partir de preguntas y orientaciones que, aunque no decían cómo modificar el escrito, aportaban ciertas pistas para releer y reescribir. Así también la docente durante la entrevista final destacó el rol de las devoluciones escritas para orientar y sugerir a través de preguntas, y mencionó cómo ella había modificado su manera de devolver/corregir por escrito las tareas a partir del trabajo conjunto con la investigadora durante el año previo. Esas intervenciones realizadas por escrito por la docente y/o la investigadora fueron devoluciones de las tareas de escritura propuestas tanto en la secuencia analizada como durante el trabajo previo.

En los dos próximos capítulos de resultados (capítulo 4 y 5) presentamos el análisis y la sistematización de las intervenciones orales realizadas por la docente durante el trabajo con situaciones de lectura y escritura, en las que esas tareas fueron motor y parte de las interacciones en clase.

\subsection{La propuesta de enseñanza desde la perspectiva de los estudiantes}

Para cerrar la descripción de la secuencia didáctica implementada presentamos la perspectiva de los estudiantes. Para ello compartimos el análisis de fragmentos de entrevistas realizadas a estudiantes al finalizar la secuencia didáctica, en ellos refieren 
a la propuesta de enseñanza en la que se enmarca la secuencia didáctica analizada. En las entrevistas solicitamos a los estudiantes que contrastaran la propuesta con el trabajo realizado en otras asignaturas, planteando semejanzas y diferencias, como manera de pensar en contrastes y así poder caracterizar la propuesta. En las respuestas hubo diversos aspectos mencionados, retomamos en particular aquellos que lo fueron de manera recurrente, como las menciones a: a) las actividades, b) la interacción en clase y c) la relación con el futuro rol docente.

En esta primera selección las estudiantes refieren al trabajo propuesto durante la secuencia como práctica de estudio y su relación con el proceso de aprendizaje.

Las situaciones de enseñanza como promotoras de aprendizaje

\begin{tabular}{|c|c|c|}
\hline Yanina & $\begin{array}{l}\text { Esta materia me pareció muy activa en forma de actividades. Todo } \\
\text { el tiempo hay que hacer algo, todo el tiempo hay que hacer cosas. } \\
\text { Es como que hay que estar moviéndose; (...) leer, hacer textos, } \\
\text { hacer actividades, ponerse, leer, es todo el tiempo así. } \\
\text { A mí me gusta mucho cómo se encaran las actividades en } \\
\text { relación con el parcial. Yo siento que las actividades ayudan } \\
\text { muchísimo al parcial. Si no hubiera tantas actividades por ahí me } \\
\text { sacaría más baja nota (...) Entonces uno ya viene con ese ritmo, lo } \\
\text { estudió así, lo resolvió así y eso es mejor. }\end{array}$ & $\begin{array}{l}\text { Actividades } \\
\text { como } \\
\text { práctica de } \\
\text { estudio } \\
\text { (relación con } \\
\text { evaluación) }\end{array}$ \\
\hline Vanesa & $\begin{array}{l}\text { En particular con esta secuencia la verdad que fue muy positivo, } \\
\text { sentí que habíamos trabajado lo suficiente como para después } \\
\text { llegar al parcial y me resultó mucho más ameno. (...) cuando } \\
\text { hicimos estas actividades como que pudimos, por lo menos a mí me } \\
\text { pasó, que pude ordenar y entender a dónde iba. Entonces } \\
\text { cuando me encontré en el parcial, no me sorprendió. }\end{array}$ & $\begin{array}{l}\text { Actividades } \\
\text { como } \\
\text { práctica de } \\
\text { estudio } \\
\text { (relación con } \\
\text { evaluación) }\end{array}$ \\
\hline Abigail & $\begin{array}{l}\text { En realidad me gustó muchísimo, porque hicimos muchas, } \\
\text { muchas actividades. Y eso me hizo aprender bien el tema. } \\
\text { Porque muchas veces cuando al estar en casa y leer los libros } \\
\text { parece que ahí está la verdad de todo, pero no. Con los dibujos y } \\
\text { todas veces que practicamos y las actividades, eso me ayudó un } \\
\text { montón. En realidad creo que es la materia con la que más } \\
\text { trabajamos; es la única materia en la que tenemos que hacer las } \\
\text { redacciones y tenemos muchas más actividades que en las otras. } \\
\text { (La desventaja es) que siempre las estoy debiendo, ja ja. Si pudiese } \\
\text { con todo y estar bien al día. Genial! }\end{array}$ & $\begin{array}{l}\text { Actividades } \\
\text { como } \\
\text { práctica de } \\
\text { estudio }\end{array}$ \\
\hline
\end{tabular}

Un elemento común que surgió en estas expresiones fue la mención al trabajo sistemático con muchas actividades que fue catalogado como un aspecto positivo de la secuencia (y de la asignatura en general). En particular, Yanina y Vanesa, consideraron que trabajaron lo suficiente (Vanesa) o que las actividades le ayudaron muchísimo (Yanina) en relación con su preparación para la evaluación parcial. Por su parte Abigail mencionó los dibujos y las redacciones como parte de aquellas actividades que le 
hicieron posible aprender bien el tema. En los tres casos que seleccionamos queda implícita la pertinencia de esas tareas en función de aquello a aprender y por ello se constituyeron en prácticas de estudio.

La primera condición que destacamos aquí fue el trabajo sistemático con diversas tareas que incluyeron leer, escribir y dibujar. Estas actividades adquirieron sentido dado que se vincularon con aquello explicado en clase y evaluado en los parciales. Pero ese trabajo continuo con actividades adquirió relevancia en función de cómo se trabajó durante esas situaciones de enseñanza. Cada instancia no fue sólo entre el estudiante y la docente sino que ese trabajo individual se articuló con situaciones de trabajo en pequeño grupo y/o de diálogo plenario. Esa interacción que fue promovida de manera recurrente por la docente fue destacada en los siguientes fragmentos de entrevistas.

Las situaciones de enseñanza, interacción dialógica y escritura

\begin{tabular}{|c|c|c|}
\hline Brenda & $\begin{array}{l}\text { Esta materia es como que dentro de lo teórica que es, es mucho } \\
\text { más práctica. Hay mucha interacción. Es lo que la hace más } \\
\text { dinámica y más amena. (...) Interactuamos entre todos, el que se } \\
\text { queda callado, olvídate! No hay uno que se pueda quedar callado } \\
\text { con } S \text {, porque dice “ ¿A ver vos qué opinás? ¿Y vos qué opinás?” } \\
\text { No hay forma, si no querés que te pregunte, faltá, porque si no, no } \\
\text { hay forma. }\end{array}$ & $\begin{array}{l}\text { Es práctica } \\
\text { Interacción } \\
\text { dialógica }\end{array}$ \\
\hline Camilo & $\begin{array}{l}\text { Quizás la diferencia principal es que en esta materia hay mucha } \\
\text { escritura. Las otras materias es más de escuchar y anotar. Acá } \\
\text { los temas son como más hablados y en otras (materias) son } \\
\text { más estructurados. La diferencia entre escuchar a } \mathrm{S} \text { y escuchar a } \\
\text { otros profesores es que S es más ¿cómo decirlo? más abierta. } \\
\text { Parece más una charla de café, no en mal sentido. No sé para mí } \\
\text { las clases de esta Biología es como única, solo en esta materia } \\
\text { se escribe en el sentido de trabajar con escritura durante todo } \\
\text { el año, es continuo esto de trabajar con escritura. }\end{array}$ & $\begin{array}{l}\text { Escribir de } \\
\text { manera } \\
\text { sistemática }\end{array}$ \\
\hline
\end{tabular}

Brenda refiere a la interacción continua durante el trabajo en la materia y asume esa condición como aquello que la hace amena y dinámica. Incluso representa de manera dialogada la modalidad de intervención que la docente actúa durante las situaciones de diálogo plenario. Es en este sentido, que Lerner refiere al desafío que supone:

crear condiciones didácticas que contribuyan efectivamente a transformar la diversidad en una ventaja pedagógica que permitan articular el aprendizaje cooperativo y el trabajo personal de cada alumno, que hagan posible coordinar la construcción social del conocimiento y la responsabilidad individual.(Lerner, 2002:15)

Esas condiciones a las que refiere Lerner no sólo deben ser instaladas, sino que continuamente habrá que resignificarlas modificando el contrato establecido. Si al trabajar con las actividades propuestas se plantean interrogantes y se configura un problema, será el medio didáctico quien hará posible (o no) que el conocimiento pueda 
ser cuestionado y debatido con argumentos racionales por alumnos y docentes. Esta construcción conjunta sólo sería posible si el contrato didáctico fuera tal que en ciertos momentos la docente otorgara la responsabilidad acerca del conocimiento a los alumnos tal como expresa Brenda y retomaremos al analizar la interacción didáctica en los próximos capítulos. Desde la perspectiva de análisis asumida concebimos la clase como un grupo, así los alumnos constituyen ese colectivo y no son sólo individuos en interacción (Tiberghien, 2016).

También Camilo refirió a lo hablado, lo charlado como algo distintivo de la propuesta. Aun cuando no le preguntamos qué quiso decir al mencionar que la docente $S$ era más abierta y que escucharla parecía como una charla de café, después de analizar los registros de clases, podemos plantear que esa analogía remitía a la interacción entre diferentes voces, la dialogicidad a la que refiere Dysthe $(1996,2002)$. Además de la interacción oral como característica distintiva de la materia y de la secuencia que analizamos, Camilo mencionó el trabajo continuo con tareas de escritura como una característica propia que hace a la unicidad del espacio disciplinar. En el próximo capítulo presentaremos la perspectiva de estudiantes acerca de desafíos, resistencias y logros en relación con las situaciones de escritura.

Por último, seleccionamos las menciones de Yanina y Noelia con relación a cómo la propuesta fue vista como modelo para la propia práctica, en tanto futuras profesionales docentes.

Las situaciones de enseñanza como modelos al pensar en la propia práctica docente

\begin{tabular}{|l|l|l|l|}
\hline Yanina & $\begin{array}{l}\text { Está bueno, porque uno se está formando para ser docente. Y } \\
\text { cuando vos sos docente, tenés que hacer eso con los chicos. Primero } \\
\text { porque si vos estás parado dando clase y anotando en pizarrón, no te } \\
\text { van a dar pelota. Entonces siempre es como que tenés que mandarlos a } \\
\text { leer, a resolver algo. Está bueno adoptar ese ritmo. }\end{array}$ & $\begin{array}{l}\text { Rol } \\
\text { docente }\end{array}$ \\
\hline Noelia & $\begin{array}{l}\text { Incluso cuando dé clases y puedo me gustaría hacer así, es que ellos } \\
\text { (sus alumnos) armen textos. No que estudien de memoria, que no se lo } \\
\text { aprendan de memoria. Que puedan relacionar, como la cigarra (en } \\
\text { referencia a una situación de escritura de la primera secuencia de } \\
\text { trabajo) y eso, je, je. }\end{array}$ & $\begin{array}{l}\text { Rocente } \\
\text { docenta }\end{array}$ & \\
\hline
\end{tabular}

Yanina refirió a la modalidad de trabajo en la propuesta con los estudiantes haciendo algo en oposición a un rol más tradicional en el que estar dando clase representaría sólo el habla docente y su escritura en el pizarrón para que los estudiantes copiaran. Por su parte, Noelia hizo referencia al trabajo con escritura como algo valioso para incorporar a su propia práctica de enseñanza, inferencia que realizó a partir de su propia experiencia como estudiante que se enfrentó a diversas situaciones de escritura. 
Durante la secuencia no previmos momentos en los que los futuros docentes, además de ejercer quehaceres propios de lectores y escritores, pudieran conceptualizar de manera colaborativa acerca de esas prácticas en las que habían participado. Y así desarrollar aquello que Lerner, Stella y Torres (2009) denominaron situaciones de doble conceptualización. Sin embargo, en diferentes instancias de las entrevistas varios alumnos relacionaron aquello que habían vivido durante el desarrollo de las secuencias con decisiones a tomar en relación con su práctica profesional futura. Aun cuando estas menciones a las situaciones de lectura, escritura y oralidad, no fueron indicadores de que los alumnos hubieran reflexionado sobre el aporte a la enseñanza de contenidos disciplinares, sí dieron cuenta de que esas prácticas se tornaron visibles para ellos. Y al ser visibilizadas quizás podrían transformarse en objeto de reflexión y ser problematizadas al diseñar sus propuestas de enseñanza. 


\section{CAPÍTULO 4}

\section{Escribir y leer para reflexionar sobre el ciclo celular}

Acerca de cómo las intervenciones docentes modulan y modelan el juego didáctico Introducción

En este capítulo presentamos el análisis de las situaciones de enseñanza desarrolladas en la primera clase de la secuencia didáctica. Durante esas situaciones los estudiantes escribieron de manera individual, leyeron y comentaron en pequeño grupo, para después dialogar en plenario acerca de lo leído. Las tareas los interpelaron para reflexionar sobre la relación entre las células y el organismo pluricelular que constituyen, en consonancia con la perspectiva sistémica de los seres vivos que enmarca a la propuesta.

A través de este análisis caracterizamos con mayor detalle las situaciones didácticas con la intención de identificar algunas condiciones de enseñanza generadas en esta clase inicial que podrían favorecer aprender acerca del ciclo celular.

En particular, nos centramos aquí en el análisis de la interacción oral que se sucedió en diferentes momentos de la clase. Así describimos y categorizamos las intervenciones orales docentes realizadas durante esa interacción, con la intención de responder nuestra pregunta acerca de las características que asumen esas intervenciones durante el desarrollo de la secuencia. Esa descripción se sustentó en la concepción de que la acción didáctica es una práctica conjunta y se establece durante la comunicación entre profesor y alumnos, y como tal es cooperativa y esencialmente dialógica (Sensevy, 2007). Desde esta perspectiva no es posible aislar las intervenciones del contexto, sino que es necesario analizarlas in situ, dado que adquieren sentido en función de la tarea y de la interacción que se establece con los estudiantes. Es por ello que en consonancia con este enfoque nos interesó identificar qué generaron esas intervenciones en los estudiantes y cómo aportaron al aprendizaje de aquello trabajado.

Con la intención de mostrar cómo se desarrolló ese juego didáctico y cuáles fueron los roles que los actores (docente y alumnos) asumieron en la transacción (Sensevy 2014), analizamos en profundidad ciertas escenas. En particular, en ellas nos referimos a cómo las intervenciones docentes tuvieron relevancia en la constitución del medio didáctico, al regular la acción de los estudiantes que debieron actuar motu proprio (Sensevy, Gruson y Forest, 2015). Para caracterizar esa acción didáctica conjunta resultó necesario identificar cómo los estudiantes orientaron su actuar, tanto si lo hicieron a partir de los hábitos instaurados por contrato didáctico, o al establecer relaciones epistémicas con el medio (milieu). Por ello nos detuvimos especialmente en la relación 
dialéctica entre medio y contrato didáctico en esta primera clase de la secuencia (Sensevy, 2009; 2012; Rickenman, 2007). A la vez, delineamos algunos de los desafíos y resistencias asociados a situaciones de enseñanza, tales como las desarrolladas durante esta clase, partiendo de lo sucedido en el aula con relación a la ruptura del contrato y el enfrentamiento al medio como antagonista (Brousseau, 2007).

La siguiente tabla presenta de manera esquemática las situaciones de enseñanza de esta primera clase.

Tabla 4. A

Clase 1. Situaciones de enseñanza

\begin{tabular}{|c|c|c|l|l|}
\hline Clase & Tarea & Organización & \multicolumn{3}{|c|}{ ¿Qué se hizo? } \\
\hline 1 & 1 & individual & $\begin{array}{l}\text { Escritura de dos textos para explicar } \\
\text { relaciones entre células y organismo } \\
\text { (origen y diversidad de las células de un } \\
\text { organismo) }\end{array}$ & $\begin{array}{l}\text { escribir } \\
\text { para } \\
\text { explicar }\end{array}$ \\
\hline $\mathbf{1}$ & $\mathbf{2}$ & individual & $\begin{array}{l}\text { Escritura de un texto para establecer } \\
\text { relaciones entre conceptos disciplinares }\end{array}$ & $\begin{array}{l}\text { escribir } \\
\text { para } \\
\text { relacionar }\end{array}$ \\
\hline $\mathbf{1}$ & $\mathbf{3}$ & pequeño grupo & $\begin{array}{l}\text { Lectura de un texto didáctico escrito por } \\
\text { la docente: Una vida con muchos estilos } \\
\text { de vida para reflexionar acerca de la } \\
\text { diversidad de ciclos de vida. }\end{array}$ & $\begin{array}{l}\text { reflexionar relacionar } \\
\text { lenara }\end{array}$ \\
\hline $\mathbf{1}$ & $\mathbf{3}$ & plenario & $\begin{array}{l}\text { Diálogo sobre lo leído y pensado, en } \\
\text { plenario coordinado por la docente. }\end{array}$ & $\begin{array}{l}\text { hablar para } \\
\text { debatir lo } \\
\text { leído }\end{array}$ \\
\hline
\end{tabular}

En el apartado 4.1 del capítulo presentamos las tareas de escritura inicial y el análisis de las producciones realizadas por los alumnos. Este análisis aportó pistas para interpretar algunas de las preguntas que enunciaron los estudiantes durante el trabajo posterior en pequeño grupo y plenario. En el apartado 4.2 describimos la propuesta de lectura posterior a la escritura. En el siguiente apartado (4.3) nos centramos en el análisis de la interacción oral en torno a las tareas de escritura, lectura y diálogo plenario desarrolladas durante esta clase. En ese apartado caracterizamos las intervenciones orales docentes como reguladoras de esa interacción. Por último en 4.4 incluimos la perspectiva de estudiantes acerca de situaciones de enseñanza como las analizadas en este capítulo.

Además del análisis de las observaciones de clase que constituyó nuestra fuente principal de datos, incluimos en el desarrollo del capítulo información proveniente del 
análisis de entrevistas a estudiantes para dar cuenta de qué les sucedió al encarar tareas como las propuestas y qué les aportó ese tipo de situación en particular.

\subsection{Propuesta inicial de escritura y contexto de producción}

Durante la primera tarea cada estudiante produjo un escrito para explicar y relacionar ciertos procesos realizados en las células con el organismo. El objetivo fue que, para escribir ese texto, tuvieran que apelar al modelo de célula que habían construido hasta el momento y así revisaran si les resultaba operativo para esa demanda. A partir de la lectura de bibliografía y la experiencia de $\mathrm{S}$ (la profesora) en instancias previas de enseñanza del tema en esta asignatura, supusimos que la noción de célula que los estudiantes utilizarían sería estática, concebida como eminentemente estructural y poco contextualizada en el organismo del que formaba parte. Un modelo celular simplificado que podría generar dudas cuando tuvieran que explicar cómo a partir de una célula se obtenía un individuo, o por qué las células de un mismo individuo eran diferentes en estructura y función. De esa manera, previmos que la tarea de escritura pondría en tensión la noción de célula construida hasta el momento.

En esta actividad los estudiantes no tuvieron que dar cuenta de algo estudiado en la asignatura, sino que necesitaron utilizar aquello aprendido en otro momento y lugar para explicar cuestiones en las que se les requirió combinar información e ideas propias. Aun cuando la actividad pudo ser desafiante para algunos estudiantes, consideramos que era pasible de ser abordada. Esa clase de tareas de escritura que se anclan en ideas conocidas pero implican desafíos pueden tener potencialidad epistémica (Bazerman et al 2005, Bazerman, 2009), porque además de permitir recordar lo que se había pensado y dicho, el escribir invita a revisitar aquello pensado y dicho de otra manera (Olson, 1998). Este rol de la escritura como promotora de nuevos aprendizajes se vincula con el hecho de que para producir esa clase de escritos se requiere volver sobre conceptos ya conocidos, pero en esa nueva instancia es necesario integrarlos en un contexto diferente. $\mathrm{Y}$ esa vuelta sobre el contenido disciplinar para poder utilizarlo en otra situación, puede favorecer que se enriquezca el conocimiento acerca de él (Tynjala, Mason y Lonka, 2001).

En particular, iniciar un tema escribiendo en vez de empezar con una lectura o hablando acerca de él, pone en práctica la forma en que la reflexión y el aprendizaje funcionan mejor: como un proceso de planteo y ajustes sucesivos de hipótesis personales donde el rol del estudiante es activo, en vez del tradicional rol pasivo (Elbow, 2004). Es así que nuestra hipótesis inicial fue que escribir permitiría que los estudiantes reflexionaran acerca de qué sabían del tema, además de tener un registro escrito hacia el cual se 
podría volver para tener en cuenta las principales dificultades que podían surgir al pensar en las células como estructuras dinámicas y diversas. Por ello concebimos esas primeras actividades escritas como una manera de indagar cuál era la demanda de aprendizaje (Leach y Scott, 2000) con relación al contenido a trabajar en la secuencia, para este grupo de estudiantes en especial.

Esta actividad de escritura, realizada de manera individual al inicio de la primera clase, resultó una situación novedosa que generó tensión, aun cuando se aclaró que ese escrito sólo tenía como función conocer aquello que recordaban acerca del tema. En parte, porque fue la primera vez que tuvieron que escribir en el aula textos de esas características en una situación que no era una instancia de acreditación. ${ }^{19}$ Por ello, fue necesario tener en cuenta el contexto particular que conformaba el aula de una institución de nivel superior en la que futuros profesores escribieron para la docente, y como en general esos escritos se utilizan para demostrar aquello que se sabe, no saber generó tensión. En parte debido al contrato didáctico implícito, a través del cual los alumnos tuvieron determinadas expectativas acerca del sentido que pudo tener esa escritura para la docente.

En este caso, en que la escritura tenía y tuvo otra función, resultó pertinente analizar cómo fueron redefinidas esas normas que estableció el contrato didáctico al incorporar lo novedoso (escribir para reflexionar y aprender) en una relación dialéctica con lo ya conocido (escribir para comunicar lo aprendido). Presentamos las consignas de la actividad 1 de la secuencia y describimos sus características a continuación:

\section{Actividad 1}

Nuestro cuerpo está formado por células con estructura y funciones diversas: células nerviosas, epiteliales, sanguíneas, musculares, etc. Todas esas células tienen información genética.

a) Las células beta del páncreas producen la proteína insulina, una hormona que interviene en la regulación del nivel de glucosa sanguínea. Las células nerviosas no producen esta proteína, pero producen otras. ¿Cómo podrías explicar que las células del páncreas sí produzcan insulina y las nerviosas no lo hagan? ¿Las células del páncreas y las nerviosas de tu cuerpo tienen la misma información genética, o cada tipo celular tiene parte de la información?

b) Todos los organismos de reproducción sexual se originan a partir de una primera célula denominada cigota, esa célula contiene la información genética que aportaron los progenitores. ¿Cómo podés explicar que a partir de esa única célula, en algunos meses, se forme un embrión con varios millones de células? Menciona qué sucesos consideras que deben ocurrir para formar un individuo pluricelular, por ejemplo un bebé humano.

\footnotetext{
19 Durante el año previo los estudiantes habían realizado escritos de este estilo en varias ocasiones como parte de las actividades de tarea extra clase a realizar en sus casas. Durante ese año en el aula escribieron otro tipo de textos, como toma de notas o ampliación de respuestas a consignas que funcionaban como una guía personal para el intercambio oral sobre el tema, escrituras privadas que no tenían otro destinatario más allá del productor. También realizaron escritos de opinión anónimos para evaluar desde su perspectiva, situaciones de enseñanza en las que habían participado. Las instancias escritas de evaluación parcial individual fueron realizadas en clase sin consulta al material bibliográfico, e incluyeron actividades que demandaron explicar, así como relacionar diversos conceptos.
} 
En el enunciado de la actividad 1a) se planteó mediante un ejemplo la situación que los estudiantes debían explicar. En este caso elegimos mencionar las células beta del páncreas y la proteína insulina porque fueron conceptos utilizados por los alumnos al trabajar el tema nutrición humana durante la asignatura del año anterior (Biología y Laboratorio II) que también tuvo a cargo la profesora S. En este enunciado se comparan dos tipos celulares que producen proteínas diferentes. La intención fue hacer explícito desde el inicio que el modelo de célula a trabajar debería dar cuenta de la diversidad celular. Y así interpelar la idea de una célula descontextualizada y global, que no alcanzaría para explicar las cuestiones planteadas.

En esa primera consigna se incluyeron dos preguntas; la primera de ellas (¿Cómo podrías explicar que las células del páncreas sí produzcan insulina y las nerviosas no lo hagan?) puso en foco el hecho de que células del mismo individuo pueden ser diferentes en aquello que producen, e intentaba así hacer pensar a los alumnos en la relación entre estructura y función. Este era un aspecto relevante para construir un modelo celular más complejo tal como pretendíamos, dado que ponía en tensión la unidad y diversidad de las células de un mismo organismo. A la vez, implicaba poner a prueba la relación entre eventos que se suceden en la vida de una célula. Estos eran: duplicación del $A D N$, en tanto proceso metabólico que asegura copias idénticas de información genética, división mitótica, un evento que da lugar a la formación de células genéticamente iguales al repartirse esas copias, y la diferenciación celular de esas células idénticas desde el punto vista genético pero que expresan diferentes proteínas y tienen distintas funciones.

A partir de la consigna los estudiantes tuvieron que pensar en células particulares del propio cuerpo, a las que ubicamos dándoles nombre y asignando funciones. La pregunta pretendió ser concreta, por eso no se refirió a cuestiones generales, sino a una molécula particular (proteína insulina) que cierto tipo de células (células beta del páncreas) produce, y otra clase de células (células nerviosas) que no lo hace y ese hecho se relaciona con la función que desempeña cada clase de células. Dado que la capacidad de producir proteínas está informada en los genes que cada célula tiene, asumimos que los alumnos podían relacionar información genética con esa producción de proteínas. Es por ello que la segunda pregunta ¿Las células del páncreas y las nerviosas de tu cuerpo tienen la misma información genética, o cada tipo celular tiene parte de la información? intentó hacer más precisa la respuesta que dieran los alumnos e indagó específicamente en cómo suponían los estudiantes que era la información genética que tenía cada tipo celular de un organismo pluricelular.

La segunda parte de esta actividad (1b) complementaba al ítem previo, dado que solicitaba pensar en la primera célula que da origen a un ser humano y mencionaba que 
esa célula tiene información genética aportada por los progenitores. En la pregunta se les pidió a los alumnos que explicaran cómo, a partir de esa única célula con cierta información genética heredada de los progenitores, se obtienen en poco tiempo millones de células. Esperábamos que los estudiantes, para poder incluir en la explicación el aumento en número de células, refirieran a la división celular. A la vez, queríamos conocer si incluían en su explicación el evento en el que se realiza la copia de la información genética (la duplicación del $A D N$ ); por ello se reforzó la pregunta solicitándoles que mencionaran los sucesos que ocurrían. Asimismo, para que tuvieran que pensar en eventos sucesivos en la vida de un organismo se mencionó en la consigna 1b) diferentes estadios de su vida (cigota, embrión y bebé). A pesar de referir a un contexto cotidiano, como la formación de un bebé o la comparación entre células del propio cuerpo, decidimos utilizar en las consignas diferentes términos disciplinares (proteína insulina, células beta del páncreas, regulación del nivel de glucosa sanguínea, información genética, reproducción sexual, cigota, embrión, individuo pluricelular). La intención fue que al utilizar esos conceptos en las explicaciones pusieran en juego las representaciones y conocimientos previos acerca del modelo celular.

Como parte de esta situación inicial de escritura incluimos la actividad 2 cuya consigna presentamos más abajo. La consigna solicitaba relacionar el concepto de información genética con otros términos disciplinares asociados que pertenecen al mismo campo conceptual, con la intención de conocer cuáles eran las relaciones que los estudiantes establecían entre esos términos que seguramente podían pensar por separado. En este caso no les pedimos que ubicaran esas relaciones en algún contexto particular.

\section{Actividad 2}

Cuando nos referimos al concepto "información genética" suelen surgir varios términos asociados. Les pedimos que escriban una o dos oraciones en las que relacionen los siguientes conceptos: $A D N$, genes, cromosomas e información genética. Úsenlos de manera explícita y en el orden que prefieran

En el apartado siguiente presentamos el análisis de las producciones escritas de los alumnos.

\subsection{1. ¿Qué dicen los escritos? Análisis de las producciones}

Los escritos expresaban algunas de las hipótesis iniciales de los estudiantes. La primera actividad (1a) tuvo como propósito conocer cómo los alumnos explicaban la relación entre información y función celular. Se clasificaron las respuestas que dieron los estudiantes a esta actividad en dos categorías principales ( $A$ y $B$ ), siendo el criterio de clasificación la referencia a la cuestión que consideramos central en este ítem, esto es si la información genética de las células del mismo individuo es idéntica o diferente: 
A. Las células del mismo individuo tienen la misma información genética, a la vez que el organismo tiene células con diferente función.

B. Las células del mismo individuo tienen distinta información genética y por lo tanto funciones específicas.

En las respuestas de cuatro alumnos (Brenda, Oscar, Yanina, Noelia) quedó explícito que las células de un individuo tenían la misma información genética, por ello fueron consideradas respuestas tipo $\mathrm{A}$.

Brenda y Oscar consideraron que las células tenían la misma información y a la vez explicaron la producción de distintas proteínas refiriendo a diferencias en la expresión genética.

Actividad 1 a. ${ }^{20}$

Las células tienen la misma información y su función depende de la expresión

\begin{tabular}{|l|l|}
\hline Brenda & $\begin{array}{l}\text { En las células del páncreas se sintetiza esta proteína porque en ellas se expresa } \\
\text { el material genético que codifica para tal, no así sucede en las células nerviosas. } \\
\text { En esas células se expresará otra secuencia del material genético que codificará } \\
\text { para otra proteína. Todas las células de nuestro cuerpo tienen la misma } \\
\text { información. La diferencia es que en algunas se expresará cierta información y en } \\
\text { otras otra. }\end{array}$ \\
\hline Oscar & $\begin{array}{l}\text { Las células del páncreas y las nerviosas poseen la misma información genética. } \\
\text { células están especializadas para sintetizar insulina, inclusive no todas las células } \\
\text { del páncreas se ocupan de ella. Las neuronas se especializaron para cumplir otra } \\
\text { tarea. Conduce el impulso nervioso. }\end{array}$ \\
\hline
\end{tabular}

En los textos de Brenda y Oscar se concluye que la función depende de la expresión, según cuáles eran los genes que se expresaban, se producirían ciertas proteínas responsables de la especificidad celular. Es decir, la información estaba presente en todas, pero en algunas células (por ej. del páncreas) se expresaba parte de ella y por lo tanto se producían ciertas proteínas (insulina), responsables de funciones particulares (regulación nivel glucosa sanguínea) y en otras células (nerviosas) se expresaban otras secuencias de información y se producirían otras proteínas que darían como consecuencia una función diferente. Esta explicación que consideraba que la expresión de los genes determina la función celular resultó la más ajustada con la científica.

Por su parte, las respuestas de Noelia y Yanina también incluyeron la referencia explícita a la presencia de la misma información genética en todas las células de un individuo, pero atribuyeron las diferencias estructurales y funcionales a la función que debía cumplimentar cada tipo celular.

\footnotetext{
${ }^{20}$ Las negritas en todos los textos de esta actividad fueron agregadas por la investigadora.
} 
Actividad 1 a.

Las células tienen la misma información, pero cumplen distintas funciones

\begin{tabular}{|l|l|}
\hline Yanina & $\begin{array}{l}\text { Todas las células del cuerpo tienen la misma información genética, pero el } \\
\text { cuerpo tiene células diferenciadas que dan origen a los distintos órganos, } \\
\text { glándulas, etc. Que el páncreas produzca insulina se debe a que sus células están } \\
\text { preparadas para cumplir esa función, es por eso que las células nerviosas no lo } \\
\text { hacen ya que sus células no están especializadas para hacerlo, pero sí producen } \\
\text { ciertas proteínas que necesitan. }\end{array}$ \\
\hline Noelia & $\begin{array}{l}\text { Porque las células del páncreas son las encargadas de disminuir el exceso de } \\
\text { glucosa y tienen específicamente dicha función, mientras que las células nerviosas } \\
\text { se encargan de funciones relacionadas con el sistema nervioso. Ambas tienen la } \\
\text { misma información genética solo que cada tipo celular debe contener alguna } \\
\text { característica en particular que permita que cada célula se especifique. }\end{array}$ \\
\hline
\end{tabular}

Yanina mencionó que una célula hace "lo que está preparada para hacer", pero no vinculó explícitamente esa función diferente con la información. Parece que hubo una desconexión entre el hecho de que todas las células tuvieran la misma información con la posibilidad de realizar funciones diferentes. En el texto de Noelia, ese hueco explicativo también está presente; ella afirmó que ambas células están encargadas de funciones diferentes, pero aunque no dio las razones de esa especificidad, al finalizar la oración aclaró que "cada tipo debe contener alguna característica particular que permita que esa célula se especifique", dando a entender que suponía algún sentido a esa especificidad.

En otras cuatro respuestas, los alumnos (Vanesa, Abigail, Alba y Camilo) expresaron que las células tenían diferente información genética y por ello cumplían diferentes funciones, serían entonces respuestas de tipo B.

\section{Actividad 1 a.}

Las células tienen diferente información y funciones especificas

\begin{tabular}{|c|l|}
\hline Vanesa & $\begin{array}{l}\text { Las células del páncreas producen insulina, porque estas células tienen una función } \\
\text { especial, o sea son células especializadas. Por lo tanto, la información genética que } \\
\text { portan, serán para cumplir dicha información. Es decir, que cada tipo celular tiene } \\
\text { parte de la información. }\end{array}$ \\
\hline Alba & $\begin{array}{l}\text { Las células beta del páncreas difieren de las células nerviosas en cuanto a su } \\
\text { estructura y función. O sea cada una de este tipo celular tienen parte de la } \\
\text { información genética por eso tienen forma y función distinta. Unas se encargan de } \\
\text { producir insulina y otras se encargan de producir receptores entre otras funciones }\end{array}$ \\
\hline Abigail & $\begin{array}{l}\text { Qué una u otra célula produzca o no, va a depender de la información genética, ya } \\
\text { que ésta va a determinar qué función va a cumplir. En este caso las células beta } \\
\text { poseen la información que les indica que secrete insulina, en cambio las células } \\
\text { nerviosas no. En mi caso creo que ambas células contienen parte de la } \\
\text { información. Pero hay otra parte de información que le indica la función específica }\end{array}$ \\
\hline
\end{tabular}




\begin{tabular}{|l|l|}
\hline \multirow{6}{*}{ Camilo } & $\begin{array}{l}\text { Porque las células beta son específicas del páncreas. Así que éstas tendrán } \\
\text { funciones distintas a las nerviosas. Estas funciones, distintas entre las betas y las } \\
\text { nerviosas, supongo que se debe a que la información genética de estas células } \\
\text { es distinta. Las betas se "crearán" a partir de la información genética de otras } \\
\text { células del páncreas por reproducción (o no) y las nerviosas a partir de la } \\
\text { reproducción de otras células nerviosas. Quizás por eso cada célula tiene la } \\
\text { información genética distinta y funciones específicas }\end{array}$ \\
\hline
\end{tabular}

Vanesa, Abigail y Alba mencionaron en sus textos que cada célula tiene "parte de la información" y es por eso que cumple cierta función y no otra; de esta manera vincularon estrechamente información y función. A su vez, Camilo propuso que cada tipo de célula (las beta del páncreas y las nerviosas) provenían de la reproducción de células similares, aunque no se decidió totalmente a afirmarlo porque agregó al término reproducción "o no" entre paréntesis. Sin embargo, afirmó que supuso que ambos tipos sí tenían información distinta.

Finalmente, la respuesta de Cristóbal sólo explicitó la relación entre estructura y función que es una relación central en Biología que es posible pensar a diferentes niveles de organización y no sólo a nivel celular, pero que no era la relación solicitada en la consigna de la actividad 1a). El alumno eludió la referencia a información genética a pesar de que directamente le preguntábamos acerca de ella.

\section{Actividad 1 a.}

Las células tienen relación estructura-función

\begin{tabular}{|l|l|}
\hline Cristóbal & $\begin{array}{l}\text { Todas las células tienen una estructura que se relaciona con la función que } \\
\text { cumple en el cuerpo. En el caso de las células del páncreas estas se dedican a } \\
\text { la absorción o la eliminación de glucosa de acuerdo a la hormona que esté siendo } \\
\text { liberada por las glándulas en ese momento. }\end{array}$ \\
\hline
\end{tabular}

Las consignas de este ítem 1a) presentaban información general (Todas las células tienen información genética), pero a la vez otros aspectos ejemplificados en un caso que comparaba células (Las células beta del páncreas producen la proteína insulina (...) Las células nerviosas no producen esta proteína (...). La mayoría de las respuestas de los alumnos se refirieron al caso particular para dar cuenta de la explicación solicitada.

En la segunda parte de esta actividad (1b) se les pidió que explicaran cómo a partir de la cigota, una única célula inicial que porta la información genética de los progenitores, se podía formar un embrión con millones de células (“¿Cómo podés explicar que a partir de esa única célula, en algunos meses, se forme un embrión con varios millones de células?"). Y que cuando explicaban esta cuestión mencionaran los diferentes procesos involucrados ("Menciona qué sucesos consideras que deben ocurrir para formar un individuo pluricelular, por ejemplo un bebé humano."). A continuación presentamos los escritos que produjeron todos los estudiantes para esta actividad $1 \mathrm{~b}$. 


\section{Actividad 1b}

\begin{tabular}{|c|c|}
\hline Yanina & $\begin{array}{l}\text { Esto sucede porque esa única célula se va a dividir a través de mitosis, } \\
\text { originando las células hijas con la misma información genética donde a su vez } \\
\text { cada una volverá a dividirse por mitosis y así sucesivamente. A lo largo de la } \\
\text { vida del ser humano las células continúan dividiéndose. }\end{array}$ \\
\hline Brenda & $\begin{array}{l}\text { Esa célula cigota se reproduce. Sus células hijas a su vez se reproducen y } \\
\text { así sucesivamente hasta formar al nuevo individuo. Para formar al nuevo } \\
\text { individuo deben poder reproducirse las células, sintetizar proteínas, debe darse la } \\
\text { respiración celular y así ir creciendo y desarrollándose hasta alcanzar la forma y } \\
\text { estructura del individuo y también sus funciones. }\end{array}$ \\
\hline Noelia & $\begin{array}{l}\text { A partir de una única célula se forma un embrión con millones de células gracias } \\
\text { a la división celular. En la cual de una célula madre se obtienen dos células } \\
\text { hijas que contienen las mismas características hereditarias que la célula } \\
\text { progenitora, este proceso se denomina meiosis }{ }^{21} \text { las células siguen } \\
\text { dividiéndose y en esa división se van dando procesos que van diferenciando al } \\
\text { individuo (ser humano) y sus estructuras. }\end{array}$ \\
\hline Oscar & $\begin{array}{l}\text { Si mal no recuerdo esa primera célula, la cigota, se multiplica en un proceso } \\
\text { llamado división celular; pasa por varias etapas de multiplicación } \\
\text { aumentando el número de células para luego comenzando la diferenciación de } \\
\text { las células que formaran los tejidos, órganos y el cuerpo completo del niño. } \\
\text { Procesos de crecimiento (en número de células) y diferenciación y expresión } \\
\text { diferente de la información (ADN) en cada célula lleva a un bebé humano. }\end{array}$ \\
\hline Vanesa & $\begin{array}{l}\text { A partir de esa única célula denominada cigoto y a través de la reproducción } \\
\text { celular (mitosis); se va originando el resto de las células. Todo éste proceso } \\
\text { comandado por la información genética que portaba el cigoto. }\end{array}$ \\
\hline Abigail & $\begin{array}{l}\text { A partir de la cigota, comienzan a haber muchas células y así formar tejidos y } \\
\text { órganos que formen al nuevo individuo. En el caso de las plantas hay mucha } \\
\text { multiplicación celular y habrá células con diferentes funciones, como por } \\
\text { ejemplo nutrir al embrión, etc. Los sucesos que deben ocurrir: duplicación del } \\
\text { ADN, Mitosis. }\end{array}$ \\
\hline Camilo & $\begin{array}{l}\text { Porque esa célula contiene toda la información genética necesaria para comenzar } \\
\text { a reproducirse. División celular. }\end{array}$ \\
\hline Cristóbal & $\begin{array}{l}\text { Para que de una célula surja un bebé debe primero duplicar su ADN, después } \\
\text { dividir su citoplasma, luego formar especializaciones específicas para } \\
\text { agruparse y poder formar los distintos tejidos de los diversos órganos del cuerpo } \\
\text { humano. }\end{array}$ \\
\hline Alba & $\begin{array}{l}\text { La célula cigota es producto de la fecundación entre un óvulo y un } \\
\text { espermatozoide. El embrión es el desarrollo de esa cigota, por eso está formado } \\
\text { por un gran número de células (millones). Ese desarrollo implica un crecimiento, } \\
\text { un aumento del número de células que se compone el organismo. Estas células } \\
\text { contendrán información genética proveniente de cada uno de los progenitores. }\end{array}$ \\
\hline
\end{tabular}

${ }^{21}$ El proceso por el que se divide una cigota se denomina mitosis. La meiosis es un tipo de división celular que sólo origina las células sexuales y no todas las células del cuerpo de un individuo. 
En la mayoría de estos escritos (los primeros 8 de la tabla) mencionaron la división o reproducción celular como evento imprescindible, y en algunos casos nombraron el tipo de división involucrado (mitosis). En los cuatro primeros textos hubo referencias a sucesivas divisiones celulares para originar un individuo. En los siguientes cuatro no hubo ninguna mención que llevara a pensar en una sucesión de divisiones que podría dar cuenta de ciclos celulares. Sí, en cambio refirieron a que todas las células se originaban a partir de esa inicial, pero no explicaron cómo se obtenían todas ellas. En el noveno escrito, Alba no mencionó la división celular sino que incluyó desarrollo como el evento que origina a un embrión a partir de una célula cigota. Podría ser que estuviera confundiendo la noción de crecimiento (que resulta de la división de las células) con desarrollo (que implica la diferenciación de células).

Pero la división celular no es el único evento que permite explicar la formación de un individuo pluricelular. Además de mencionarlo también era necesario referir de alguna manera a células del mismo individuo que adquieren funciones distintas, y para ello debían mencionar al desarrollo, que sucede a través de procesos de diferenciación celular. En algunos pocos textos (3/9) se menciona de manera explícita la diferenciación celular o el desarrollo22.

A la vez, para que suceda la división celular es necesario que previamente se realice la duplicación de ADN, que fue el tema que se trabajó durante la segunda clase de la secuencia. Su baja mención (2/9) fue un aspecto que hubo que tener en cuenta al explicar ese contenido para destacar la función biológica que tiene y el lugar temporal que ocupa en el ciclo celular. Las múltiples referencias a la división celular, mitosis, también influyeron en la decisión acerca de cómo incluir ese tema en la secuencia didáctica y qué aspectos de ese contenido era relevante retomar.

Por último, el tercer escrito que los alumnos tuvieron que producir (actividad 2) fue el primero de una serie de textos de ese tipo que escribieron durante la secuencia didáctica. En esta clase de actividad los estudiantes debieron establecer relaciones entre términos disciplinares, en algunos casos para explicar ciertas situaciones y en otras sencillamente enunciar una relación conceptual. En este caso particular la intención fue que los estudiantes explicitaran un vínculo entre términos que corresponden a un mismo campo conceptual. Los breves textos que produjeron dieron cuenta, en la mayoría de los casos, de una relación estructural del tipo: la información

\footnotetext{
22 La referencia está subrayada en los textos de Brenda, Noelia y Oscar. No subrayamos la mención de desarrollo en el escrito de Alba, porque en ese caso aludió al aumento de número de células que sucede a través de la división celular y no del desarrollo.
} 
genética está contenida en el ADN o la molécula de ADN conforma a los cromosomas, como en el siguiente ejemplo:

Yanina En la molécula de ADN que se encuentra en los cromosomas podemos encontrar información genética la cual conocemos con el nombre de gen.

Así como en el texto transcripto la alumna incluyó todos los términos en una única oración, en los dos casos siguientes escribieron dos oraciones independientes, sin incluir conectores ni establecer otras relaciones lingüísticas que reforzaran el vínculo entre ambas.

\begin{tabular}{|c|l|}
\hline Vanesa & $\begin{array}{l}\text { El ADN es la molécula que porta la información genética en un ser vivo. En el } \\
\text { proceso de la división celular los cromosomas se duplican. }\end{array}$ \\
\hline Noelia & $\begin{array}{l}\text { La condensación de los cromosomas indica que está por comenzar la división } \\
\text { celular. La información genética de los individuos determina sus características }\end{array}$ \\
\hline
\end{tabular}

En ambos casos las alumnas no relacionaron a los cromosomas con los demás términos de la consigna, pero sí los vincularon con la división celular. Esta relación era posible pero la ausencia de vinculación entre cromosomas e información genética, o entre cromosomas y ADN, podría indicar que no estaba claro para ellas qué eran o cómo estaban formados los cromosomas. A la vez, podría estar indicando que consideraban que los cromosomas sólo estaban presentes en las células durante la división celular. En realidad, los cromosomas son visibles al microscopio óptico en esa etapa de la vida celular y es habitual considerar en la enseñanza media de la Biología que sólo están presentes en las células cuando "son visibles". En relación con los cromosomas, Vanesa planteó que: "En el proceso de la división celular los cromosomas se duplican", en realidad la duplicación ocurre previamente a la división, pero sólo se duplicarán si esa célula se divide. Es decir, existe una relación entre duplicación del ADN y división celular, pero no era la relación que propuso Vanesa en su texto.

A partir de lo que los estudiantes explicitaron en estas actividades pudimos plantear algunas hipótesis de trabajo para la secuencia didáctica, ajustando así la demanda de aprendizaje para este caso particular (Leach y Scott, 2000; 2002; 2003). Tal como dijimos, era necesario dar un lugar privilegiado a la enseñanza del proceso metabólico de duplicación de $A D N$ para que los estudiantes tuvieran argumentos que les permitieran sostener que todas las células de un organismo tenían la misma información genética. $Y$ por ello era pertinente que ese proceso se trabajara en contexto temporal y espacial. A la vez, para que eso fuera posible era necesario profundizar la relación entre conceptos tales como ADN y cromosomas.

\subsection{Propuesta de lectura en pequeño grupo}


La tarea de escritura inicial que describimos en los apartados previos se articuló con una actividad de lectura cuya función fue poner en tema, provocar preguntas, instalar algunos de los problemas a resolver durante la secuencia. Para ello se utilizó un texto didáctico que escribió la profesora S para esta situación de enseñanza, y que pasó por instancias de revisión y reescritura conjunta entre profesora e investigadora. En ese texto introductorio, denominado "Una vida con muchos estilos de vida", (Anexo XX), se retomó la diversidad celular en un organismo humano, cuestión relacionada con lo que los estudiantes habían tenido que explicar en las actividades de escritura.

Aun cuando el texto no planteaba respuestas a las preguntas iniciales de la actividad de escritura, a partir del análisis de lo sucedido durante la implementación, podemos considerar que para algunas estudiantes la actividad de lectura funcionó como una oportunidad para seguir pensando en la diversidad de células de un individuo y cómo se podía relacionar ese efecto con la diferenciación celular. Esa articulación entre tareas se pudo establecer porque el texto leído presentaba un relato en el que se vinculaban diversos tipos celulares de un organismo humano, a la vez que se mencionaban algunos rasgos característicos de las distintas vidas o ciclos celulares y así se ejemplificó el tema general (ciclo celular) a partir de casos particulares de células específicas.

A medida que los alumnos entregaron las respuestas escritas de la primera actividad, la profesora les fue dando el texto mencionado para la actividad siguiente. Cuando ya todos los estudiantes habían entregado su escrito inicial, la profesora encuadró la primera actividad de lectura y de esa manera expresó algunos aspectos del contrato didáctico vinculados a ella. Sin embargo, también hubo elementos del contrato implícitos y que se pusieron de manifiesto en ciertas intervenciones, tal como referiremos a lo largo del análisis de las interacciones orales en el pequeño grupo y en la situación de trabajo con la clase completa.

A continuación transcribimos un tipo de acción docente vinculada a la constitución del medio, aquélla en la que la profesora realiza una intervención para definir la tarea.

\begin{tabular}{|l|l|l|l|}
\hline 77 & $S$ & $\begin{array}{l}\text { Ésta es la primera lectura ad hoc, creada por el momento. Van a ir leyendo este } \\
\text { texto. Primero obviamente lo leen de forma individual. Lo que yo quisiera es que } \\
\text { todas aquellas preguntas que se les cruzan por la cabeza a medida que lo van } \\
\text { leyendo, las anotan, porque van a ser insumos. Por el otro lado, vayan viendo cuáles } \\
\text { son... fijense lo que dice el título: “Una vida con muchos estilos de vida", entonces } \\
\text { fijense cuáles son esos estilos de vida que va proponiendo el título, e identificarlos. } \\
\text { Y por el otro lado, quiero que identifiquen cuáles son los criterios por los cuales en } \\
\text { el título y en el texto están establecidos esos estilos de vida. ¿Está claro? }\end{array}$ \\
\hline
\end{tabular}

La profesora mencionó que el texto fue escrito ad hoc; aun cuando no aclaró que fue escrito por ella, dijo que era un texto didáctico producido para la situación de enseñanza. 
Al explicitar la consigna de trabajo $\mathrm{S}$ solicitó, en primer término, que anotaran las preguntas que les fueran surgiendo durante la lectura, porque iban a ser insumos para trabajar. De esta manera, planteó una tarea de lectura cuya propuesta inicial sería favorecer que surgieran dudas, que se formularan preguntas que serían importantes y pertinentes para la situación de enseñanza, dado que se trabajaría con ellas. A través de esa afirmación $S$ explicitó otra función que podría tener un texto, más allá de la tradicional de buscar en un escrito respuestas a preguntas que otro hizo (por ejemplo la docente); aquí $S$ jerarquizó las preguntas del alumno que podían surgir a partir de esa lectura.

A la vez, la docente acotó la tarea al plantear una consigna abierta que requería leer el texto para poder pensar de manera global e interpretar a qué aludía su título. Fue justamente esa consigna abierta la que permitió que los estudiantes expresaran diferentes interpretaciones acerca del significado de ese título más literario que biológico (como ella misma afirmó después). Por último, les solicitó identificar los posibles criterios de clasificación de la diversidad de células mencionadas en el escrito; esta última consigna fue más cerrada, de búsqueda de información en el texto con la intención de poner en evidencia la diversidad celular y en especial la variedad de ciclos celulares.

Es interesante pensar en la función que tuvo ese texto después de la situación de escritura y cómo se articuló con aquello que para algunas alumnas quedó "dando vueltas" cuando produjeron los escritos iniciales. Si los alumnos primero escriben e intentan trabajar a partir de una hipótesis propia, estarán más comprometidos en el problema propuesto; al contrastar y resignificar las propias ideas habrán establecido una relación intelectual con las ideas que se presenten después en la bibliografía y el discurso docente (Elbow, 2004). Algunos indicios de ese trabajo recursivo, al ir y volver desde la hipótesis propia planteada en el escrito inicial a lo propuesto por la lectura, se hicieron explícitos en los intercambios orales en el pequeño grupo y en el plenario general.

\subsection{Interacción en el aula en torno a las tareas de escritura y lectura.} Intervención docente y constitución del medio didáctico

A través de las intervenciones orales de algunos estudiantes y la mediación que estableció $S$, analizamos cuáles fueron las marcas en el discurso y en los gestos que permitieron dar cuenta de lo que sucedió durante las situaciones de escritura inicial, de lectura en pequeño grupo y posteriormente en plenario. En especial, describimos la categorización de las intervenciones orales realizadas por la docente, que resultaron del análisis de la transcripción de los audios registrados durante la observación de esta 
primera clase. Además de algunos datos acerca de la situación de lectura que nos pareció pertinente incluir y que obtuvimos a partir de las entrevistas realizadas al finalizar la secuencia.

\subsection{1. ¿Qué sucedió durante la tarea de escritura inicial?}

De cómo empezar escribiendo promovió dudar acerca de lo que se sabía

La profesora S entregó a cada alumno un papel con la consigna escrita a medida que fueron ingresando al aula. En esta ocasión los estudiantes tuvieron que escribir de manera individual lo que pensaban y sabían acerca de un contenido (las células), que no resultaba novedoso pero que estaba planteado de manera tal que suponía un desafío.

Esa instancia de escribir para la docente -tal como hemos dicho previamente- pareció generar tensión, que se evidenció en algunos comentarios y gestos realizados por estudiantes tanto al recibir como al entregar la tarea de escritura.

Al recibir la consigna inicial varios alumnos hicieron comentarios. Entre ellos, Camilo preguntó en voz alta si "no importa si lo que pongo está mal", ante lo cual S respondió que no importaba, que sólo quería conocer qué era lo que se acordaban del tema y en función de eso se trabajaría en la secuencia. Al terminar el escrito también hubo algunos comentarios que dieron cuenta de la sensación de quedar expuesto a la mirada docente a través del escrito entregado; como los que hicieron en voz alta dos estudiantes al decir que habian quedado escrachadas a través de ese texto.

Ahora analizaremos algunas de las interacciones sucedidas mientras los estudiantes escribían. Durante los primeros diez minutos después de la entrega de la tarea los alumnos permanecieron en silencio, leyendo la consigna y escribiendo. Sólo se escuchaba el sonido que hacía el papel cuando algunos consultaban sus apuntes, hasta que Camilo hizo una pregunta en voz alta a la profesora. A partir de esa primera consulta se generó un intercambio entre Camilo y la docente $S$, al que se sumaron otros estudiantes. A continuación en el fragmento 4.1.transcribimos ese intercambio que sucedió durante la escritura inicial.

Fragmento 4.1

Camilo consulta acerca de lo que había que escribir

Clase1. Interacción durante escritura individual (6-39)

\begin{tabular}{|c|c|l|}
\hline \multicolumn{2}{|c|}{ Turno de habla } & \multicolumn{1}{|c|}{ Transcripción } \\
\hline 6 & Camilo & $\begin{array}{l}\text { Profe... ¿En la [consigna] b) está hablando de la célula específicamente } \\
\text { reproductora? }\end{array}$ \\
\hline 7 & S & ¿En la... b? \\
\hline
\end{tabular}




\begin{tabular}{|c|c|c|}
\hline 8 & Camilo & En la b. Sí, como dice "todos los organismos de reproducción sexual"... \\
\hline 9 & S & $\begin{array}{l}\text { No, no. Está hablando de la cigota, [afirma y lee la consigna] "se originan a } \\
\text { partir de una primera célula denominada cigota, esa célula contiene la } \\
\text { información genética que aportaron los progenitores. ¿Cómo podés explicar } \\
\text { que a partir de esa única célula [o sea de la cigota], en algunos meses, se } \\
\text { forme un embrión con varios millones de células?" }\end{array}$ \\
\hline 10 & Camilo & No, pero de una célula cualquiera que se puede reproducir. O sea... \\
\hline 11 & $\mathbf{S}$ & [piensa] No, habla de esa una única célula, [remarca], habla de la cigota. \\
\hline 12 & Camilo & Ah. \\
\hline 13 & $\mathbf{S}$ & Leé todo de un saque. ¿Todos entienden lo mismo? [Dirigiéndose al curso] \\
\hline 14 & Vanesa & $\begin{array}{l}\text { No. [Aclara que no entendió lo mismo que Camilo] O sea yo lo que entendí } \\
\text { es, claro, cómo explicar que de ese desarrollo de la célula que es la cigota. } \\
\text { O sea... }\end{array}$ \\
\hline 15 & Camilo & Claro, eso. [Se superpone a Vanesa] \\
\hline 16 & Vanesa & $\begin{array}{l}\text { Se desarrolla el individuo, cómo se producen las otras células. Se forme el } \\
\text { embrión, cómo de esa célula... }\end{array}$ \\
\hline 17 & Brenda & La cigota sería el embrión, digamos. [Superponiéndose] \\
\hline 18 & Vanesa & Claro \\
\hline 19 & $\mathbf{s}$ & $\begin{array}{l}\text { La cigota es la cigota. A partir de que se empieza a reproducir es el embrión. } \\
\text { [Aclarando el alcance de cada término respecto a la intervención de Brenda]. }\end{array}$ \\
\hline 20 & Oscar & Vienen las etapas diferentes, donde ocurre multiplicación celular... \\
\hline 21 & Camilo & $\begin{array}{l}\text { ¿Sin importar cómo? Por ejemplo, el caso que el espermatozoide y el óvulo } \\
\text { se fecunden. }\end{array}$ \\
\hline 22 & Oscar & Ya está. \\
\hline 23 & Vanesa & Eso ya está. \\
\hline 24 & $\mathbf{S}$ & Ya está hecho \\
\hline 25 & Vanesa & $\begin{array}{l}\text { El embrión es el producto de eso. La meiosis ¿no? es el producto la cigota. } \\
\text { A partir de eso cómo se desarrolla el individuo. }\end{array}$ \\
\hline 26 & Oscar & Y después la diferenciación. \\
\hline 27 & Vanesa & No sé, no sé \\
\hline 28 & Oscar & Crecimiento y desarrollo. Diferenciación [en voz baja] \\
\hline
\end{tabular}




\begin{tabular}{|c|c|l|}
\hline 29 & S & $\begin{array}{l}\text { ¿Qué, qué es lo que estás entendiendo Camilo? [Invitándolo a seguir } \\
\text { consultando porque no parece convencido] }\end{array}$ \\
\hline 30 & Camilo & $\begin{array}{l}\text { Eh... No, porque tengo una vaga idea que..., como de cigota, pero pensé } \\
\text { que para que se forme esta célula ¿no? que hubo fecundación entre el } \\
\text { espermatozoide y el óvulo. }\end{array}$ \\
\hline 31 & $\mathbf{S}$ & Sí [afirmando lo que Camilo enuncia] \\
\hline 32 & Camilo & Entonces ¿eso pasó? \\
\hline 33 & $\mathbf{S}$ & Sí, perfecto. \\
\hline 34 & Camilo & Es la cigota y a partir de ahora... Ah listo \\
\hline 35 & $\mathbf{S}$ & Claro, sí. Estabas pensando correctamente. \\
\hline 36 & Camilo & Ah, está bien \\
\hline 37 & $\mathbf{S}$ & Pero ahora ya pasó ese acontecimiento, y ahora es el resultado.... \\
\hline 38 & Oscar & Todo lo que suceda a partir de ahí. \\
\hline 39 & $\mathbf{S}$ & A partir de ahí, claro, a partir de la fecundación. \\
\hline
\end{tabular}

El fragmento se inicia con la pregunta que realizó Camilo en [6] acerca de cuál era la célula sobre la que tenía que escribir, y si podía en ese escrito referirse a cualquier célula que se reproduce, tal como agrega en [10]. Parecería que el alumno quiso preguntar cuál era la célula denominada cigota que mencionaba la consigna, pero sin explicitarlo, posiblemente para no exponer aquello que no sabía. El término 'reproducción sexual' incluido también en la consigna pudo hacer pensar a Camilo en otra clase de célula, probablemente se estuviera refiriendo a gameta como una "célula específicamente reproductora", tal como él mismo menciona en la línea [8].

Este tipo de confusión que se presenta con términos disciplinares con propiedades en común y que se ubican en el mismo campo conceptual, es habitual entre estudiantes de Biología. Ambos términos corresponden a células, las gametas son células que intervienen en la reproducción sexual y la cigota es la célula resultante de la unión de dos gametas, la primera célula de un individuo que se origina por reproducción sexual. Esos dos términos científicos son palabras que no se emplean en la vida cotidiana, corresponden al lenguaje específico que se introduce en clases de Ciencias Naturales (Jiménez Aleixandre, 2003), pero no son términos nuevos para estos alumnos del tercer año de un Profesorado de Biología, dado que seguramente a lo largo de su historia escolar los han escuchado y leído en diversas situaciones. 
Con relación al uso que los alumnos hacen del vocabulario disciplinar, Anderberg, Svensson, Alvegard y Johansson (2008) analizan la dinámica y ambigua relación entre las concepciones de los estudiantes, los significados que asignan a ciertos términos y las expresiones que los denotan. Estos autores sostienen que el uso del vocabulario específico por parte de los alumnos no implica necesariamente que hayan comprendido el significado del concepto disciplinar, y que es frecuente que el uso de una expresión sea arbitrario y realizado sólo por asociación. Por ello, afirman que es necesario que los alumnos reflexionen explícitamente sobre la adecuación de los vínculos que establecen entre aquello que intentan expresar y las diversas maneras que utilizan para referirlo. Tener que utilizarlos en una tarea de escritura, como sucedió en este caso, podría funcionar como una oportunidad para revisar el significado que le asignaban a términos disciplinares.

Tal como se transcribe en el fragmento 4.1 la profesora habilitó la duda que planteó Camilo al releer la consigna en voz alta, e intentó orientar la lectura en línea [9] al decirle que no se quedara en el inicio de la frase (Todos los organismos de reproducción sexual) e intentara leer la consigna de manera completa para interpretar qué se esperaba que respondiera. La docente $S$ realizó un tipo de intervención que actúa sobre quehaceres de lector y/o escritor, en este caso son intervenciones que vuelven al texto, asociadas a la práctica de lector. Este tipo de intervención fue recurrente como parte de la acción de la profesora, en particular cuando los estudiantes consultaban sobre algo referido en un escrito como en este caso eran las consignas de las actividades.

En esta ocasión, S releyó en voz alta para analizar con los estudiantes qué decía lo escrito [9] y explicó su significado retomando de manera literal lo textual. Este tipo de intervención mostró en acción quehaceres de lector y escritor (Lerner, 2001), dado que para comprender algo escrito y pensar en cómo lo puede interpretar un lector, sería necesario hacer una relectura de ese texto. En especial si se considera que el significado no está en el sujeto que lee, ni sólo en el texto, sino que resulta de esa transacción entre lector y texto. Esa vuelta al escrito, que actúa de manera recurrente la docente, suele ser una práctica de lector autónomo, en la que revisa la interpretación anclándose en el escrito. A la vez, se podría relacionar con una práctica de escritor, en este caso para orientar a Camilo quien debía ajustar su producción a la consigna de la actividad.

La docente intentó orientar la lectura que Camilo hizo a propósito de la consigna y no dejarlo a una libre interpretación. Por ello mencionó reiteradamente que "la cigota" no era cualquier célula, sino que la tarea requería escribir acerca de ese tipo de célula particular. Fue en este sentido que realizó intervenciones que actúan sobre el 
contenido disciplinar, en este caso lo aclaran, por ejemplo en la línea [9] al decir: "No, no. Está hablando de la cigota." Camilo entonces preguntó si podía hablar de cualquier célula que se reproducía, y $S$ en la línea [11] reforzó su afirmación previa al decir: "No. Habla de esa una única célula, habla de la cigota."Y en [19] concluyó que "La cigota es la cigota", y por lo tanto no era el embrión; a la vez en esa aclaración relacionó ambos términos: "A partir de que se empieza a reproducir [la cigota] es el embrión". Otra intervención de este mismo tipo, aclaratoria, sucedió cuando en la línea [24], S dijo: "Ya está hecho", es decir que si hablaba de cigota la fecundación ya había sucedido.

Esas intervenciones, que aclararon el contenido disciplinar acerca del cual tenían que escribir los alumnos, tuvieron como propósito unificar interpretaciones de un término, ajustando y definiendo el alcance del concepto al que remitía. $Y$ podemos pensar que son características del tipo de conocimiento puesto en juego en clases de Biología, en tanto una ciencia natural. Los conceptos específicos a trabajar en clases de ciencias son unívocos y resulta necesario consensuar su significado. Así la cigota, una única célula en particular, no es una célula reproductora, ni es cualquier célula que se reproduce, ni es el embrión y se obtiene después de la fecundación entre el óvulo y el espermatozoide. Esta aproximación al concepto de cigota surgió de la interacción oral entre la docente y los alumnos, el alcance y pertinencia del término se puso en juego en la comunicación en el aula. Y fue la tarea de escritura la que dio la oportunidad de hablar acerca de ciertas células particulares como son cigota y gameta.

Denominamos intervenciones elusivas a otro tipo de intervención relacionada con el contenido disciplinar que refiere a aquellas cuestiones que S eludió y no retomó cuando los estudiantes las plantearon. Una intervención (que parecería una no intervención) de este tipo sería cuando Vanesa en línea [25] sostuvo que “(...) La meiosis ¿no? es el producto, la cigota.". Aquí también hubo una confusión o error en relación con el uso del término meiosis, pero $S$ no acotó nada al respecto y volvió en línea [28] a preguntar a Camilo acerca de lo que él, que fue quien hizo la pregunta inicial, había entendido.

Era importante en ese momento que Camilo pudiera comprender qué se le pedía explicar, aun cuando los términos disciplinares le resultaran confusos. Por ello $S$ realizó otras intervenciones que actuaron sobre el contenido disciplinar, de tipo aclaratorias en líneas [35] y [37]. En ellas refirió cuál era el acontecimiento -la fecundación- que sucedía previamente a la obtención de la célula cigota. Ubicarse en el escenario requerido para la tarea de escritura era un aspecto imprescindible para poder abordarla y la profesora intentó constituirlo a través de diferentes intervenciones. 
Otro tipo de intervención relevante para establecer una modalidad dialógica de trabajo fue aquella en la que se invita a participar. Tal como la que la docente enunció en la línea [13], dónde después de sugerirle a Camilo que leyera toda la consigna, consultó al curso: “¿Todos entienden lo mismo?”. A partir de esa intervención se desarrolló un intercambio en el que diferentes alumnos aportaron su propia interpretación de la consigna (en la grabación quedaron registradas las voces de Vanesa, Brenda y Oscar). Este otro tipo de acción docente favoreció que la cuestión no quedara entre la profesora y Camilo, dado que abrió un espacio de interacción en la clase al promover la participación de otros estudiantes que comentaron su propia interpretación de la consigna. A través de este tipo de intervención participativa, en la línea [27] la docente promovió que Camilo explicitara aquello que interpretó al preguntarle “¿Qué es lo que estás entendiendo Camilo?", para animarlo a seguir pensando y escribir. Otras intervenciones, como las de las líneas [29], [31] y [33], reforzaron la invitación al validar aquello que el alumno explicitó.

\subsection{2. ¿Qué sucedió durante la tarea de lectura? Interacción en el pequeño grupo: Vanesa, Abigail y Alba}

De cómo la lectura permitió seguir preguntando y reflexionando

En esta instancia se constituyeron tres grupos de trabajo; el grabador se ubicó en el grupo de Vanesa, Abigail y Alba, y se registró el intercambio oral desarrollado durante la instancia de lectura y trabajo con las consignas. Recorrimos los grupos para orientar el trabajo con la lectura, a la vez que registramos lo que se intercambió para así retomarlo durante la puesta en común.

Cuando S se acercó al grupo, las alumnas consultaron en primer término dudas acerca de los criterios de clasificación de las células y la relación con el tejido del que formaban parte. Y después plantearon diversas preguntas que iban más allá de lo que proponía la consigna de trabajo, pero que se vinculaban de alguna manera con el texto leído. También en este sentido la lectura abrió caminos para pensar en células diferentes en estructura y función. Por ejemplo, Vanesa consultó acerca del número de neuronas del bebé y el adulto, de la muerte y el nacimiento de células, y a partir de esa pregunta se sucedieron otras, todas referidas a células particulares: nerviosas y hepáticas. Fue Alba quien realizó una pregunta que intentó generalizar una propiedad mencionada en el texto que leyeron: consultó a S si "todos los tipos celulares tienen muerte celular programada". Así esta pregunta como las anteriores dieron lugar a nuevas intervenciones que actuaron sobre el contenido disciplinar; en este caso la función fue ampliar la información que presentaba el texto cuando la docente respondió acerca de las diversas cuestiones que llamaron la atención de las alumnas al leer. 
Este tipo de intervención didáctica en la que $S$ actuó sobre el contenido disciplinar en juego también fue realizada de manera recurrente a lo largo de la secuencia didáctica, a través de ella la profesora dio información que no estaba contenida en la lectura y que excedió aquello que se iba a trabajar específicamente en la secuencia. Estas intervenciones, que sucedieron ante preguntas de los estudiantes, podrían estar indicando cómo la situación de enseñanza promovió que pensaran acerca de las células, más allá de lo que solicitaba la consigna de trabajo. Y que por ello preguntaran respecto de características de ciclos celulares particulares, como por ejemplo de las células nerviosas, y lo relacionaran con lo aprendido en la escuela secundaria, tal como Vanesa expresó en una de sus intervenciones.

Como especificamos en el análisis de las producciones escritas que los alumnos realizaron en respuesta a la consigna 1a), y que presentamos anteriormente, Vanesa, Abigail y Alba habían escrito que cada tipo celular de un mismo organismo tenía "parte" de la información genética y de esa manera explicaron el hecho de que hubiera células que producían proteínas diferentes. Sus respuestas se categorizaron dentro del grupo $B$ justamente por considerar que las células de un mismo organismo tendrían diferente información genética.

Para poder argumentar por qué las células de un mismo organismo tienen en realidad la misma información genética se requería entender el sentido biológico del proceso metabólico de replicación del ADN que se iba a explicar durante la segunda clase de la secuencia didáctica. En ese proceso se duplican las moléculas de ADN, por lo tanto se produce una copia de la información genética de esa célula y éste es un requisito previo a la división celular. Sólo si esas copias son idénticas, será posible que al repartirlas durante la división de la célula original, las células hijas que las porten sean idénticas en información genética. Sin embargo, subsistía otro problema, ¿cómo era que, si las células del mismo organismo tenían idéntica información genética, podían producir proteínas diferentes, y por lo tanto tener funciones distintas? Este segundo aspecto también fue trabajado con posterioridad durante la secuencia didáctica. Fue así que las preguntas que surgieron durante esta situación inicial de enseñanza, así como las razones que las alumnas enunciaron para apoyar sus primeras hipótesis al respecto, resultaron elementos que nos permitieron analizar cómo se fue constituyendo el medio didáctico relacionado con el aprendizaje de ese contenido.

A continuación presentamos fragmentos de la transcripción del registro de observación para dar cuenta de cómo la situación de escritura inicial promovió que los estudiantes plantearan algunas de las dudas pendientes acerca del tema, que se reforzaron e hicieron explícitas durante el trabajo con la lectura. 
Organizamos los intercambios en el pequeño grupo en dos fragmentos de registros que fueron sucesivos. En el fragmento 4.2 seleccionamos la pregunta que Abigail realizó a $S$ dentro del grupo pequeño, porque consideramos que a través de ese planteo la alumna hizo explícita la relación que estableció entre la consigna dada por la docente (anotar las preguntas que surgieran) y la actividad de escritura previa. Por su parte, en el fragmento 4.3 retomamos los intercambios que ocurrieron entre las integrantes de ese pequeño grupo a partir de aquello que Abigail preguntó a la profesora S. En ambos casos, el texto a leer se constituyó en un componente del medio didáctico con el que las alumnas interactuaron; en un primer momento dio lugar al planteo de la pregunta para después funcionar como recurso para precisar cuáles eran las dudas que encerraba esa pregunta.

Fragmento 4.2

Células: origen común y diferenciación

Clase 1. Trabajo en pequeño grupo Vanesa, Abigail y Alba (a-g)

\begin{tabular}{|c|c|c|}
\hline \multicolumn{2}{|c|}{ Turno de habla ${ }^{23}$} & Transcripción trabajo en pequeño grupo \\
\hline a & Abigail & Profe, ¿acá le hacemos las preguntas o después? \\
\hline b & $\mathbf{S}$ & $\begin{array}{l}\text { No, no. Ahora, ahora. Vayan haciéndolas, así cuando las ponemos en } \\
\text { común ya las voy poniendo en el pizarrón }\end{array}$ \\
\hline c & Abigail & $\begin{array}{l}\text { Yo me quedé con una cosa de acá que está relacionado [con la lectura]. } \\
\text { Si todas [las células] tienen un origen común, por qué, yo pienso ¿no? } \\
\text { que es como que... todas las células, diferentes ¿no?, tienen un origen } \\
\text { común, una información común de todas, todas. Pero al momento } \\
\text { después se diferencian y cada una cumple su función determinada. Pero } \\
\text { creo eso que cada una tiene como una información común de todas, que } \\
\text { después se diferencia. ¿Puede ser? }\end{array}$ \\
\hline d. & $\mathbf{S}$ & (inaudible) \\
\hline e. & Abigail & Claro eso ya no engancho... no... \\
\hline f. & $\mathbf{S}$ & Volvé al texto, algo te dice el texto. \\
\hline g. & Abigail & [El texto dice] Como que tiene parte y parte [de la información genética]... \\
\hline
\end{tabular}

Las alumnas ya habían hablado acerca del significado del título y los criterios de clasificación que se proponían en el texto, las dos cuestiones incluidas en la consigna de la tarea. Después de algunos intercambios entre las estudiantes del grupo, Abigail retomó lo que $S$ había planteado al definir la tarea y le consultó cuando se acercó al grupo de trabajo. Al plantear la duda la vinculó explícitamente con la lectura, al decir en [4.2.c]: "yo me quedé con una cosa de acá que está relacionado", y retomó la noción de

\footnotetext{
${ }^{23}$ En los registros de transcripción de pequeño grupo utilizamos letras para indicar turnos de habla, de manera tal de diferenciarlos del grupo clase, en los que utilizamos números sucesivos.
} 
que las células “(...) tienen un origen común, una información común de todas, todas. Pero al momento después se diferencian y cada una cumple su función determinada." Esa relación entre información y función celular fue el problema que tuvieron que abordar en la actividad de escritura inicial, a la vez que en la lectura se mencionaban ejemplos de células con diferentes funciones pero no se hacía referencia particular a la información genética.

La docente no respondió concretamente, no clausuró la cuestión referida a la relación entre información genética y diferenciación celular; quizás la reticencia de $\mathrm{S}$ a responder se debió a que estaba previsto que esa relación se iba a trabajar a través de nuevos contenidos más adelante en la secuencia didáctica. En ese momento, para estas alumnas, no estaba claro que todas las células del mismo individuo tuvieran la misma información genética y eso era clave y previo para poder pensar cómo era que esas células idénticas genéticamente podían realizar funciones distintas, es decir conocer a qué procesos biológicos remite la diferenciación celular.

Ante la pregunta la profesora le sugirió a Abigail "Volvé a leer el texto, algo te dice el texto", con su intervención puso al escrito en el rol de aportar respuestas o al menos pistas, aun cuando esa pregunta no se relacionaba con la consigna de lectura. Esa propuesta que $S$ realizó de volver al texto es una intervención que actúa sobre el quehacer lector. En este caso, S no dio la respuesta sino que les sugirió releer, ahora con un propósito particular: buscar respuestas a preguntas propias. Si pensamos que las interacciones que se dan en clase entre alumnas y docente están condicionadas por el contrato didáctico que se establece, es importante que la profesora se ubique en la situación de enseñanza de manera tal que las alumnas interpreten que la docente les devuelve el problema (Brousseau, 2007), y por lo tanto las ubica en un rol activo.

Tal como sugirió $\mathrm{S}$, las alumnas releyeron el texto, ahora con un propósito diferente, buscando qué decía acerca de lo que preguntó Abigail. Teniendo en cuenta lo que escribieron para la actividad 1a) seguramente esa duda era compartida ${ }^{24}$. En el siguiente fragmento [4.3] retomamos los intercambios entre Alba, Vanesa y Abigail que sucedieron durante la relectura, ahora ya sin la presencia de la profesora.

Fragmento 4.3

Células: origen común y diferenciación. ¿Cuándo ocurre la diferenciación? Clase 1. Trabajo en pequeño grupo $(h-r)$

\begin{tabular}{|c|c|c|}
\hline \multicolumn{2}{|c|}{ Turno de habla } & Transcripción trabajo en pequeño grupo \\
\hline $\mathrm{h}$ & Vanesa & Acá dice lo que vos estás preguntando [dirigiéndose a Abigail]. \\
\hline
\end{tabular}

${ }^{24}$ Como ya hemos dicho, tanto Abigail como Vanesa y Alba respondieron que las células tenían diferente información genética para explicar cómo podían realizar distintas funciones. 


\begin{tabular}{|c|c|c|}
\hline $\mathrm{i}$ & Abigail & ¿En serio? \\
\hline j & Vanesa & $\begin{array}{l}\text { Acá, acá. [Señalando en el texto, lee las frases a las que hacía referencia] } \\
\text { "Precisamente esta variedad proviene del proceso de diferenciación celular, } \\
\text { que implica numerosos cambios en la estructura y el metabolismo. Estos } \\
\text { cambios, relacionados con la expresión de los genes, permiten que esas } \\
\text { células cumplan funciones diferentes en los tejidos que conforman a los } \\
\text { órganos." }\end{array}$ \\
\hline $\mathrm{k}$ & Alba & La expresión genética. \\
\hline I & Vanesa & $\begin{array}{l}\text { La expresión genética. El tema es cuándo [ocurre la diferenciación celular] } \\
\text { A mí... }\end{array}$ \\
\hline $\mathrm{m}$ & Abigail & $\begin{array}{l}\text { Pero es como que yo entiendo que tiene mitad y mitad [de la información } \\
\text { genética]. Hace la mitad igual y después otra mitad... }\end{array}$ \\
\hline $\mathrm{n}$ & Vanesa & $\begin{array}{l}\text { El tema es cuándo [sucede] la diferenciación celular ¿Cuándo comienza } \\
\text { ese proceso de diferenciación celular? Una vez que..... sea vos tenés el } \\
\text { cigoto, la célula original, que ahí porta toda la información. Claro, ahí porta } \\
\text { toda la información genética. [Ocurre] el proceso de división celular. ¿En } \\
\text { qué momento hace la diferenciación celular? [reitera] }\end{array}$ \\
\hline o & Abigail & Después de nacer debe ser ¿no? O durante el crecimiento... \\
\hline $\mathrm{p}$ & Vanesa & $\begin{array}{l}\text { Porque implica justamente eso: "cambios en la estructura y el } \\
\text { metabolismo."[Releyendo del texto] }\end{array}$ \\
\hline$q$ & Abigail & $\begin{array}{l}\text { Esas [células] que ya se formaron, ¿van a seguir teniendo como un origen, } \\
\text { una información de origen común? }\end{array}$ \\
\hline $\mathrm{r}$ & Vanesa & $\begin{array}{l}\text { De origen común sí, porque siempre tienen un origen común. Tienen parte } \\
\text { de la información, pero cuando se van diferenciando... }\end{array}$ \\
\hline
\end{tabular}

Al retornar al texto volvió a ser foco de atención aquello que escribieron en la actividad inicial. Esa lectura no respondió a la pregunta que las alumnas se plantearon, pero como el escrito refería a la diversidad celular quizás les permitió relacionar aquello que estaba expresado en él con sus propias dudas. Y así al vincular la nueva información que aportó la lectura, replantearon esas preguntas.

Vanesa, al releer conectó lo que planteaba el texto con la pregunta que formuló Abigail, tal como expresó en [4.3.h] y [4.3.j] al informarle "dice lo que vos estás preguntando" y señalar la oración del texto cuando expresó: "acá, acá". Sin embargo, lo que leyó no pareció satisfacer sus dudas porque tal como ella misma dijo en la línea [4.3.I] y [4.3.n]: "El tema es cuándo [sucede] la diferenciación celular." Y podríamos agregar que aún pareció estar difusa la idea de "qué era la diferenciación celular", qué implicaban y cómo sucedían esos "cambios en estructura y función," tal como sintéticamente lo enunciaba el escrito. Vanesa en esa misma línea [4.3.n] expresó: "vos tenés el cigoto, que ahí porta toda la información," aquí pareció aludir a lo propuesto en la actividad de escritura que suponía esa condición inicial, y agregó que la célula inicial se dividía. Eso no generó 
conflicto y parecía tenerlo claro, retomó su duda pensando en un proceso temporal, y así volvió a expresarla al finalizar esa misma intervención [4.3.n] “¿En qué momento hace la diferenciación celular?" refiriendo al organismo y sus células.

Abigail y Vanesa compartieron algunas dudas y formularon preguntas relacionadas con lo que habían escrito en el pequeño grupo y empezaron a asociar el concepto de diferenciación celular con algunos otros términos. Abigail respondió con una posible hipótesis en [4.3.o] al decir: "Después de nacer debe ser ¿no? O durante el crecimiento." A partir de esta expresión de Abigail podemos pensar que la alumna no reconoció los distintos niveles de organización implicados en la diferenciación celular, pues un organismo cuando nace ya tiene células con diferente forma y función y eso seguramente estaba claro para Abigail. Sin embargo, podría ser que el hecho de pensar en el nivel molecular, al referir a la producción de proteínas diferentes tal como proponía la consigna de escritura, pudo haberla inducido a pensar que la diferenciación celular era un proceso distinto a aquél que da lugar a las células del cuerpo con formas y funciones particulares. En las líneas siguientes Abigail volvió a preguntar acerca de la "información de origen común" y continuó con su intento de encontrarle sentido a lo que iba pensando.

Con respecto al aprendizaje de conceptos disciplinares Anderberg et al (2008) plantearon como una de las conclusiones de su investigación que, en un inicio, los alumnos reconocen el significado de términos disciplinares aislados y establecen relaciones superficiales entre ese significado y la forma de expresarlo. Pero, a través del trabajo con el lenguaje específico, con intervenciones y tareas que permiten situar esos términos en contextos variados, sería posible abrirlos y desarrollar redes de conexiones más holísticas entre los conceptos, sus expresiones y los sucesos a los que refieren. Son los docentes, a través de un trabajo recursivo e intencional, quienes podrán promover que los estudiantes atraviesen diferentes grados de comprensión del lenguaje y la bibliografía (Anderberg, et al, 2008). Los estudiantes necesitan pensar acerca de cómo van modificando lo que intentan decir y cómo pueden reconocer el mismo significado a través de diferentes contextos y expresiones que dan cuenta de cierto hecho. $Y$ es así que ciertas tareas de escritura pueden adquirir función epistémica si enriquecen esas conexiones y de esa manera favorecen que se profundice el conocimiento (Hand y Prain, 2012).

En nuestro caso, las estudiantes pudieron asociar al proceso diferenciación celular con las funciones que adquieren los distintos tipos de células, constituyendo una relación causal lineal entre ambos, pero sin establecer aun redes de conexiones. Fue así que la relación entre el significado del concepto y su expresión a través del término 
diferenciación celular, parecía ser superficial, dado que no les permitió aun explicar cómo se producía la diversidad celular en un mismo individuo. Sin embargo, la lectura dio lugar a que ese concepto tomara entidad y se constituyera en motivo de reflexión acerca de aquello que sucedía durante la vida de las células de un organismo. La lectura motivó que las estudiantes (Abigail, Vanesa y Alba) se plantearan múltiples preguntas, algunas de ellas relacionadas con la tarea de escritura inicial y que retomamos en los episodios seleccionados, pero también muchas otras preguntas no vinculadas con la consigna específica de lectura.

Algunas de las consultas que estas estudiantes plantearon a $S$ remitían a pensar en ciclos de vida de células particulares (como las células nerviosas) y dieron lugar a extensos intercambios sobre las células y la vida de los organismos, en los que las alumnas contrastaron información previa con la que aportaba la docente. Fue así que durante esa actividad no sólo se leyó, sino que las estudiantes reflexionaron acerca de las células y sus ciclos de vida y enunciaron diferentes clases de preguntas. Un tipo fue el de aquellas preguntas que se abrían a partir del texto, que no encontraban respuesta en él sino que implicaban nueva información y requerían establecer otras relaciones (¿Todos los tipos celulares tienen muerte celular programada? [Alba] ¿Desde cuándo se plantea que en las neuronas [debió decir células nerviosas] hay células madre? [Vanesa]). Ante estas consultas $S$ respondió dando lugar en varios casos a nuevas preguntas. Otro tipo de preguntas que las estudiantes enunciaron fueron aquéllas que remitían al texto, en esas ocasiones la profesora las instó a volver y releerlo, tal como describimos previamente. El formular preguntas no es necesariamente una acción espontánea durante las clases de Biología sino que implica una forma de pensar que requiere ser promovida y desarrollada, y resulta central para comprender y aprender modos de pensar científicos (Gellon, Rosenvasser Feher, Furman. Golombek, 2009).

\subsection{3. ¿Qué sucedió al hablar acerca de lo que se leyó? Interacción en el grupo clase con coordinación docente}

En este apartado presentamos una selección de intercambios orales entre $S$ y los alumnos durante la situación de plenario posterior a la lectura del texto "Una vida con muchos estilos de vida". Transcribimos fragmentos del plenario para ejemplificar la interacción que sucedió y la interpretación que realizamos desde nuestro marco de análisis. En especial nos detenemos en aquello que promovieron ciertas intervenciones orales que realizó $S$, sin perder de vista que estamos analizándolas como parte de la acción didáctica concebida como acción conjunta, tal como ya hemos descripto en la fundamentación, y es por ello que no se analizan esas intervenciones de manera aislada sino buscando la co-acción del alumno (Sensevy, 2007; 2010). 
A fin de caracterizar con mayor detalle dos aspectos centrales a destacar es que diferenciamos en dos subapartados aquello que sucedió durante el trabajo con todo el grupo clase con coordinación docente. Así presentamos:

a) Cómo durante la revisión de la interpretación del título de la lectura, S modificó el contrato didáctico implícito al habilitar diversas respuestas posibles (4.3.3.1).

b) Cómo el trabajo en conjunto sobre la lectura dio lugar a que algunas alumnas (Vanesa y Abigail) plantearan nuevas preguntas vinculadas con la situación de escritura previa (4.3.3.2).

\subsubsection{De cómo la profesora habilitó diferentes interpretaciones}

A continuación mostramos la manera en que el contrato implícito se manifestó a través del discurso y cuáles fueron las acciones con las que $S$ modificó ese contrato a través de intervenciones orales que habilitaron a los estudiantes como lectores. Aun cuando la docente había escrito ese texto, suspendió su propia versión del significado del título, de manera tal de no obturar que los estudiantes presentaran sus opciones y argumentos.

En la siguiente transcripción (fragmento 4.4) mostramos cómo la profesora (escritora del texto) dio lugar a las voces de los alumnos lectores. En esta instancia -la primera clase de la secuencia y la primera lectura de un texto en clase- fue relevante construir una modalidad dialógica en la que las diferentes interpretaciones evidenciaran la tensión que surgió ante diferentes perspectivas (Dysthe, 2000). Esta dialogicidad no implicó sólo que los alumnos intervinieron en diferentes turnos de habla, sino que residió en la interdependencia entre las voces de los estudiantes. Estas voces no aparecieron yuxtapuestas en ese diálogo sino que dieron cuenta de un proceso de interacción que las incluyó tanto como a la voz de la docente (Dysthe, 1996). En el fragmento (4.4) sombreamos las intervenciones de $\mathrm{S}$, en este caso habilitaron a los alumnos a explicitar diferentes interpretaciones válidas, y en ese sentido es que las consideramos como intervenciones que actuaron sobre quehaceres de lector.

Fragmento 4.4

Compartiendo interpretaciones del título: células y organismo Clase 1. Plenario (108-128)

\begin{tabular}{|l|c|l|}
\hline \multicolumn{2}{|c|}{ Turno de habla } & \multicolumn{1}{c|}{ Transcripción plenario } \\
\hline 108 & Vanesa & $\begin{array}{l}\text { Esto de una vida con muchos estilos de vida...Una cosa que debatíamos } \\
\text { era que primero toma a la vida como un conjunto. O sea esto que el } \\
\text { organismo es un conjunto. Estos diferentes estilos de vida, los que } \\
\text { conviven en función de esa vida inicial. Y si partimos del cigoto como } \\
\text { unidad general y a partir de cómo se diferencian las vidas dentro de esa }\end{array}$ \\
\hline
\end{tabular}




\begin{tabular}{|c|c|c|}
\hline & & $\begin{array}{l}\text { vida, porque cómo es el nombre del título, y después los criterios sería } \\
\text { que... }\end{array}$ \\
\hline 109 & $\mathbf{S}$ & $\begin{array}{l}\text { Entonces, una vida sería para vos ¿qué vida? porque nombraste el } \\
\text { cigoto... }\end{array}$ \\
\hline 110 & Vanesa & El cigoto como la célula original, ésa es la vida como el conjunto. \\
\hline 111 & Patricia & Abigail había hecho otra interpretación \\
\hline 112 & $\mathbf{S}$ & $\begin{array}{l}\text { A ver Abigail cuál fue la otra [interpretación]. Pero está buenísimo, porque } \\
\text { fíjense que es un título que no es biológico sino literario. }\end{array}$ \\
\hline 113 & Camilo & Claro... \\
\hline 114 & $\mathbf{S}$ & $\begin{array}{l}\text { Al final les digo cuál era mi idea. Pero que cada cual... [exprese la suya] } \\
\text { O sea, era un título abierto. }\end{array}$ \\
\hline 115 & Abigail & $\begin{array}{l}\text { Yo lo que decía era que todos esos diferentes estilos de vida dan origen a } \\
\text { eso, la vida al individuo. }\end{array}$ \\
\hline 116 & Alumno & Ah, la inversa. \\
\hline 117 & $\mathbf{S}$ & Ah, pero está perfecto, son interpretaciones \\
\hline 118 & Alba & Es un poco si es el huevo o la gallina \\
\hline 119 & Camilo & Yo apoyo a Abigail porque había pensado algo parecido... \\
\hline 120 & $\mathbf{S}$ & ¿Qué habías pensado? \\
\hline 121 & Camilo & $\begin{array}{l}\text { Bueno los estilos de vida, yo lo hice más simple a los estilos, se refiere a } \\
\text { la diversidad de las células, lo que usted quiso poner. }\end{array}$ \\
\hline 122 & $\mathbf{S}$ & $\begin{array}{l}\text { ¿Vos me estás asignando a mí que yo quise poner...? [En tono jocoso de } \\
\text { pregunta] }\end{array}$ \\
\hline 123 & Oscar & Está sesgado ya...[En referencia a la autoría del texto] \\
\hline 124 & $S$ & $\begin{array}{l}\text { A ver, entre Abigail y Camilo, vos decís: "yo lo hice más simple, yo pensé } \\
\text { en las distintas..." }\end{array}$ \\
\hline 125 & Camilo & $\begin{array}{l}\text { No, no tanta explicación. Lo que yo decía es yo voy más a lo concreto. } \\
\text { Para mí los estilos de vida se referían a la diversidad de las células, que } \\
\text { haya un grupo de células con ciertas funciones, ciertas características. Y } \\
\text { después con lo que decía... }\end{array}$ \\
\hline 126 & $\mathbf{S}$ & ¿Vos qué pensabas? (dirigiéndose a Abigail) \\
\hline 127 & Abigail & No, yo a eso lo planteé mal, yo pensé que hacía referencia a tejidos. \\
\hline 128 & $\mathbf{S}$ & $\begin{array}{l}\text { Ojo! No, mal eh! Acá no hay nada que esté bien o que esté mal. Estamos } \\
\text { escuchando las interpretaciones. }\end{array}$ \\
\hline
\end{tabular}


En el inicio del fragmento seleccionado Vanesa mencionó en la línea [108] al organismo como un conjunto en el que conviven diferentes estilos de vida, la docente le pidió que aclarara a "qué vida" se refería y ella en [110] propuso su interpretación del título del texto. Según Vanesa expresó, “Una vida” refería a la célula original, el cigoto. Era esa célula quien daba origen a los "muchos estilos de vida" de las demás células del organismo, tal como mencionaba el título de la lectura. En la discusión dentro del pequeño grupo se había hablado largo rato de dos maneras posibles de pensar el título, por ello se acotó en [111] que Abigail había interpretado de otra forma "esa vida".

Retomando las intervenciones de $S$ que pusieron en juego las diferentes interpretaciones de los estudiantes acerca del título de la lectura, en la línea [112] S invitó a Abigail a plantear su propia versión al decirle “¿cuál fue la otra?” y así habilitó la posibilidad de distintas interpretaciones. Es más, reforzó esa opción al sostener que "está buenísimo, porque fíjense que es un título que no es biológico sino literario." Ese dar lugar a lo que otras voces podían decir en relación con la interpretación de un texto constituye algo propio del discurso dialógico y no suele ser lo pautado en el contrato didáctico habitual. En ese sentido, Espinoza, Casamajor y Pitton (2009) sostienen que:

En la escuela, habitualmente, es el docente quien se atribuye el derecho de decidir cuándo una interpretación es correcta o no. En general los alumnos no tienen "voz" para juzgar la pertinencia de una determinada forma de entender un texto. Muchas veces se considera que hay una sola interpretación posible y que es el docente quien la ha descubierto. (Espinoza, Casamajor y Pitton, 2009:131)

Estas autoras no proponen que los docentes renuncien a su rol didáctico sino que consideran que para constituir a los alumnos en lectores autónomos capaces de leer e interpretar, y no sólo actuar a través de la voz del docente, será necesario que los profesores intervengan activamente para favorecer que los estudiantes expliciten y contrasten sus ideas. $Y$ para ello $S$ debía ser reticente, suspender y posponer la explicitación de la propia interpretación de manera que la voz oficial no silenciara las diversas ideas de los estudiantes. Así lo hizo en la línea [114] afirmando: "Al final les digo cuál era mi idea, pero que cada cual [exprese la suya] o sea era un título abierto."

De esta manera, $\mathrm{S}$ modificó el contrato implícito por el cual es el docente quien puede decidir la interpretación adecuada, y más aún en este caso en que la docente era a la vez la autora del texto. Abigail planteó aquello que pensaba que significaba el título y $S$ reforzó esta posición de empoderar a los alumnos como lectores cuando dijo en línea [117] “Ah, pero está perfecto, son interpretaciones." S continuó actuando en este sentido al invitar a Camilo a dar su propia postura: “¿Qué habías pensado?”[120], obligando al alumno a expandir aquello que había dicho y a usar el lenguaje para referir a aquello que pensaba. 
A la vez, indujo a los alumnos a contrastar sus ideas cuando en línea [124] dijo: " $A$ ver, entre Abigail y Camilo, vos decís "yo lo hice más simple, yo pensé en las distintas...". S retomó las palabras de Camilo aparentemente pidiéndole que contara en qué aspectos se apoyaba en lo que había dicho Abigail, tal como él expresó en [119], como para entender si era la misma interpretación u otra. Camilo enunció su propia idea “(...) Para mí los estilos de vida se referían a la diversidad de las células, que haya un grupo de células con ciertas funciones, ciertas características." Y $S$ entonces invitó a Abigail a decir si acordaba o si pensaba en algo diferente al decirle: “¿Vos qué pensabas?”[126]. En esta secuencia de intervenciones $S$ hizo el intento de entender cuáles fueron las interpretaciones de Abigail y Camilo, en qué se parecían y diferenciaban, para ello los invitó a enunciarlas y compararlas. Fue la docente quien intervino con una invitación a la participación para intentar comprender qué sentido le habían dado los estudiantes al título de la lectura, y así expresaran y contrastaran sus propias interpretaciones. Esas acciones iban en el sentido de constituirlos en lectores más autónomos (Lerner, 2002). Pero esa participación no implicaba sólo decir sino que promovió una implicación cognitiva, dado que S solicitó a los estudiantes comparar lo que habían expresado para dar una vuelta más sobre la relación entre célula y organismo.

Y en eso estaban cuando Abigail respondió a la invitación calificando su propia interpretación al decir en [127] "No, yo a eso lo planteé mal, yo pensé que hacía referencia a tejidos." Esta afirmación de la alumna pareció dar cuenta de cuáles eran sus expectativas con relación a la interpretación de un escrito, sólo había una interpretación correcta según el contrato implícito y la comparación de una con otra sólo podía indicar que una estaba bien y otra mal. Dado que $S$ no hizo ninguna alusión a que lo planteado por Camilo (pensar en células individuales) fuera incorrecto, Abigail asumió que entonces su interpretación no era la adecuada.

Pero S volvió a intervenir en la constitución de ese nuevo contrato al dar otro sentido a la acción: "Ojo! No mal eh. Acá no hay nada que esté bien o que esté mal. Estamos escuchando las interpretaciones." Esa afirmación de la docente, durante la primera clase de la secuencia, otorgó sentido al intercambio de interpretaciones, en sí cada una de ellas "no estaba bien o mal", se contrastaban, pero no para calificar. Hubo aquí un corrimiento del contrato habitual en el que sólo era posible una única respuesta correcta y lo que el alumno expresaba sólo podía ser categorizado en clave dicotómica: bien o mal. Después de la última aclaración de $S$ que transcribimos, la docente fue invitando a participar a cada uno de los estudiantes que no habían dado su parecer. Por ejemplo, al decir: ¿Y otra manera de pensarlo, Yanina, Brenda, Noelia? [137]; ¿Por acá Cristóbal? [152]; ¿Y vos Yanina? [160]. Tres alumnas (Alba, Brenda y Yanina) afirmaron acordar 
con la interpretación que realizó Vanesa. Tal como planteó Brenda: "Como Vane, porque claro, a partir de una vida, después de eso se van a ir formando distintas formas de vida que son las células que se fueron diferenciando a lo largo de la vida." [159]. Y otros alumnos acordaron con Camilo y Abigail.

Aquello esperado por los estudiantes (una única interpretación válida que sería la que coincidiera con lo pensado por la profesora-autora) también se puso de manifiesto en el siguiente fragmento [4.5]. En él destacamos las intervenciones de $S$ que actuaron en el sentido de habilitar a los alumnos en tanto lectores capaces de expresar su propia interpretación. En este sentido también son intervenciones que actúan sobre quehaceres de lector.

Fragmento 4.5

La docente habilitó diferentes interpretaciones del título de la lectura Clase 1. Plenario (162-179)

\begin{tabular}{|c|c|c|}
\hline \multicolumn{2}{|c|}{ Turno de habla } & \multirow[t]{2}{*}{ Transcripción plenario } \\
\hline 162 & $\mathbf{S}$ & \\
\hline 163 & Vanesa & Bueno, ninguno de los dos, chicos... je je \\
\hline 164 & Oscar & Yo sigo opinando que lo que quiso plantear... \\
\hline 165 & Alumnos & Ja, ja \\
\hline 166 & $\mathbf{S}$ & $\begin{array}{l}\text { ¿Por qué tienen que adherir a lo que yo pensé? Para mí las dos maneras } \\
\text { de pensar me parece que son total y absolutamente legítimas. O sea a } \\
\text { partir de una vida surge una vida, la cigota surge distintos estilos de vida. } \\
\text { Y esta otra también, una vida que se conforma con distintos estilos de vida. } \\
\text { Me parece que las dos acepciones están perfectas. Y acá, vos pensaste } \\
\text { en la vida de cada una de las células con su propio estilo de vida. Este es } \\
\text { más individualista, pero también vale. Así que no les voy a decir qué es lo } \\
\text { que había pensado. }\end{array}$ \\
\hline 167 & Alumnos & Ahh, Ja, ja. \\
\hline 168 & $\mathbf{S}$ & $\begin{array}{l}\text { Pero ¡lógico! ¿Por qué voy a legitimar como yo lo pensé? ¿No los convencí } \\
\text { pensando en que cada uno lo interpretó bien? }\end{array}$ \\
\hline 169 & Vanesa & Y no. \\
\hline 170 & $\mathbf{S}$ & ¿Por qué no? \\
\hline 171 & Vanesa & Y alguna trampa tiene que tener... \\
\hline 172 & Oscar & Ah, no... ja, ja \\
\hline 173 & Patricia & $\begin{array}{l}\text { Trabajando entre las dos, yo tuve una interpretación que no era la que ella } \\
\text { había pensado también, porque justamente el título tiene esa posibilidad } \\
\text { de abrir las interpretaciones. Cuando escuchaba acá, me resultó muy }\end{array}$ \\
\hline
\end{tabular}




\begin{tabular}{|c|c|c|}
\hline & & $\begin{array}{l}\text { interesante que se abrieran esas dos posibilidades. Y aparece la tercera } \\
\text { de pensar en una vida celular y muchos estilos. }\end{array}$ \\
\hline \multicolumn{3}{|r|}{$[\ldots]$} \\
\hline 176 & s & $\begin{array}{l}\text { Fíjense, tres interpretaciones salieron. El todo... para definir a ese todo que } \\
\text { tiene distintos estilos de vida, después la vida de la cigota que da origen a } \\
\text { distintos estilos de vida. Y cada célula independientemente de dónde está } \\
\text { ubicada o de dónde haya surgido tiene distinto estilo de vida. Tiene vida } \\
\text { con su propio estilo, ¿así sería Cristóbal? [Con relación a la tercera opción } \\
\text { que había propuesto Cristóbal]. }\end{array}$ \\
\hline 177 & Cristóbal & Sí, exacto. \\
\hline 178 & Patricia & Y el texto habla de todo esto que plantearon. \\
\hline 179 & s & $\begin{array}{l}\text { Tal cual. Entonces está todo correcto. Ahora me tienen que decir ¿cuáles } \\
\text { son los estilos de vida? }\end{array}$ \\
\hline
\end{tabular}

Ante esa distribución de interpretaciones en la que algunos estudiantes se sumaron a lo que había propuesto Vanesa, otros dijeron que coincidían con Abigail, y Cristóbal propuso un tercer significado posible para el título del texto, S expresó en [162]: "Qué interesante". Vanesa le asignó la decisión de validar cuál era la "respuesta correcta". Así, imitando el decir docente, probablemente a partir de su experiencia como alumna, expresó: "Bueno, ninguna de las dos, chicos, je, je" [163] y sonrió jugando el juego de interacción esperado por contrato, en el que los alumnos opinan pero quien valida es la docente y en ocasiones eso que se plantea no guarda relación con lo propuesto por los estudiantes. También Oscar actuó al decir en [164] "Yo sigo opinando que lo que quiso plantear..." y sus compañeros rieron, reconociendo la situación en la que $S$ daría su perspectiva no sólo como docente sino a la vez como autora.

En este momento, $\mathrm{S}$ los interpeló planteando: ¿Por qué tienen que adherir a lo que yo pensé? [166]. Se corrió del lugar que le asignaron y afirmó que para ella "las dos maneras de pensar son total y absolutamente legítimas". Y enunció esas dos maneras que los estudiantes expusieron reafirmando "Me parece que las dos acepciones están perfectas."; para después incluir lo que planteó Cristóbal "Y acá, vos pensaste en la vida de cada una de las células con su propio estilo de vida. Este es más individualista, pero también vale." De esa manera, le puso su voz a las tres interpretaciones, avalándolas, y al presentarlas en conjunto habilitó la coexistencia posible de varias interpretaciones para el título del texto que habían leído en clase. Y terminó en [166] concluyendo, “Así que no les voy a decir qué es lo que había pensado." La profesora, autora del texto y de ese título, avaló las interpretaciones que surgieron en el aula diferenciándose de aquello esperado por los alumnos. Tomamos lo que afirman las autoras que citamos antes 
(Espinoza, Casamajor y Pitton, 2009) para sostener cómo esta situación, que se distanciaba de la práctica habitual, podría favorecer la constitución de los estudiantes como lectores más autónomos. Ellas sostienen que:

Cuando la distribución de derechos y obligaciones en relación con la aprobación del significado alcanzado está determinada de una vez y "para siempre" en una sola dirección, disminuyen las posibilidades de los alumnos de formarse como lectores pues dependen siempre de otro con mayor autoridad para validar sus interpretaciones. (Espinoza, Casamajor y Pitton, 2009: 132)

En la siguiente intervención $S$ se ubicó en una situación de par con relación a la posibilidad de dar un significado al título, e hizo una pregunta retórica "¿Por qué voy a legitimar como yo lo pensé?". No sólo la docente/autora tenía el poder de asignar significado, también los alumnos en tanto lectores podían argumentar a favor de pensar en una célula inicial que daba lugar a múltiples células diferentes, o pensar en la vida del individuo y la diversidad de células que lo componían.

Cuando S realizó la segunda pregunta: “ ¿No los convencí pensando en que cada uno lo interpretó bien?'[168], Vanesa pareció remitir al contrato establecido al decir: "Y no" [169]. S repreguntó “¿Por qué no?” [170] y la alumna reforzó la alusión a otras experiencias al decir, "Y alguna trampa tiene que tener..." [171]. Sin embargo, el tono en que Vanesa expresó sus dudas fue cordial y dio lugar a algunas risas y comentarios de otros estudiantes.

Para plantear el hecho de que diferentes opciones de interpretación eran posibles y no era algo extraño, comenté qué había sucedido durante el diseño de la secuencia entre $S$ y yo (profesora e investigadora) en relación con el título de la lectura: "Trabajando entre las dos, yo tuve una interpretación que no era la que ella había pensado, porque justamente el título tiene esa posibilidad de abrir las interpretaciones." [173]. La intención fue mostrar que no era propio de ellos que "no sabían lo que el autor había pensado" sino que en esa interacción entre lector y texto puede surgir cierta interpretación. Finalmente la docente retomó aquello que ya había planteado avalando las interpretaciones al decir en [176]: "Fíjense, tres interpretaciones salieron (...)" enunciando después cada una de las tres versiones que los alumnos habían propuesto de manera tal de ponerlas en su voz y habilitarlas como opciones posibles. Para cerrar en [179] con "Tal cual. Entonces está todo correcto." $Y$ pasar de esa consigna a la siguiente que les pedía recuperar cuáles eran esos estilos de vida.

En este mismo sentido, durante la entrevista realizada al finalizar la secuencia Vanesa refirió a esta situación de enseñanza y recordó la acción de la docente quien a través de sus intervenciones promovió la participación dialógica y habilitó diferentes interpretaciones. 


\begin{tabular}{|l|l|}
\hline Vanesa & $\begin{array}{l}\text { De esta actividad lo que rescato tiene que ver con una forma de pensar. A mí lo } \\
\text { que me pareció interesante, que uno siempre busca que las respuestas... como que } \\
\text { todo tiene un solo origen. Y que en realidad las interpretaciones dependen donde } \\
\text { uno se pare también pueden tener como diferentes panoramas. Y yo de esa } \\
\text { actividad lo que más rescaté fue eso. Porque justamente decís "es cierto, porque } \\
\text { depende dónde vos estás parado podés interpretar esto". Todos decían " ¿Cuál es } \\
\text { la verdad?" Bueno, no hay una verdad absoluta, me acuerdo que dijo S. Lo } \\
\text { importante es dónde uno se para, para poder analizar. }\end{array}$ \\
\hline
\end{tabular}

Vanesa comenzó refiriendo a una forma de pensar y explicó en qué consistía. Mencionó que podían coexistir diversas interpretaciones dado que era posible mirar desde perspectivas diferentes un mismo objeto. Expresó a la vez la necesidad previa de consensuar una interpretación única como parte del contrato acordado y también la ruptura que implicó aceptar que podían coexistir diferentes miradas sobre ciertos objetos. Vanesa refirió a este hecho como algo valioso para ella, dado que le permitió desestructurar su forma de pensar y aceptar que era necesario tener claro desde dónde uno se para al analizar. Otros estudiantes (Abigail, Brenda, Oscar) también refirieron en las entrevistas a la participación y al debate que se generó en el aula en relación con interpretaciones disímiles y recordaban que había sido validada más de una.

Sin embargo, la cuestión de no conocer cuál era la interpretación correcta desde el punto de vista de la docente-autora fue algo incómodo para algunos estudiantes. Durante la entrevista Cristóbal mencionó algo en ese sentido al sostener que no tendría que haber diferencias entre las interpretaciones si se "respetaba la consigna", tal como expresa en el siguiente fragmento de entrevista.

\begin{tabular}{|l|l|}
\hline Cristóbal & $\begin{array}{l}\text { Como acá hablamos de estilos de vida yo lo tomé por ese lado, de la célula (...) } \\
\text { El título podía significar distintas cosas. Yo lo puse de acuerdo a la consigna } \\
\text { según como yo la tomé, como era identificar los tipos de células yo lo tomé para } \\
\text { el lado de la célula individual. Para mí no tendría que haber tanta diferencia en } \\
\text { las interpretaciones si uno respetaba la consigna, el título lo tendríamos que } \\
\text { encarar para ese lado, je, je. }\end{array}$ \\
\hline
\end{tabular}

En realidad, no estuvo previsto que hubiera diferentes interpretaciones del título; pero cuando los alumnos las fueron planteando, la docente motu propio las escuchó e indagó el sentido de cada una de ellas, para finalmente aceptarlas y ponerles la voz. Esa posibilidad que actuó la docente, de correrse de lo instituido y cambiar lo previsto, generó una puesta en aula más dinámica y participativa. De esa manera se generó una condición de enseñanza que favoreció cuestionar el contrato didáctico y constituir un medio que incluyera la participación de los estudiantes como voces autorizadas en una modalidad dialógica. 


\subsubsection{De cómo escribir, leer y hablar acerca de lo que se leyó y escribió promovió explicitar nuevas preguntas}

En este apartado presentamos cómo la situación de escritura permeó en el trabajo posterior con la lectura; cómo a través de marcas en el discurso fue posible vincular las preguntas que formularon Vanesa y Abigail con algunas incertezas que tomaron cuerpo a partir del escrito inicial. La posición reticente de la docente fue relevante para que esas dudas fueran configurando un problema relacionado con aquello a trabajar en la secuencia didáctica.

Durante el plenario la profesora fue consultando a los estudiantes por las respuestas que había acordado en el pequeño grupo. A continuación transcribimos el fragmento 4.6, en el que analizamos la secuencia de interacción desarrollada ante una pregunta de Vanesa en [141]. En la transcripción resaltamos en negrita las referencias a la función celular que realizó Vanesa de manera recurrente, de diferentes formas, a partir de la actividad de escritura.

Fragmento 4.6

Vanesa plantea preguntas acerca de la diferenciación celular Clase 1. Plenario (138-146)

\begin{tabular}{|c|c|c|}
\hline \multicolumn{2}{|c|}{ Turno de habla } & Transcripción plenario \\
\hline 138 & $\mathbf{S}$ & ¿Y otra manera de pensarlo? ¿Yanina, Brenda, Noelia? \\
\hline 139 & Noelia & $\begin{array}{l}\text { Yo lo pensé como Camilo, cada grupo de células tiene una función } \\
\text { determinada: de reproducción, de... }\end{array}$ \\
\hline 140 & $\mathbf{S}$ & $\begin{array}{l}\text { ¿Y una vida qué significa? [Dirigiéndose a Noelia y retomando la } \\
\text { interpretación del título de la lectura] }\end{array}$ \\
\hline 141 & Vanesa & $\begin{array}{l}\text { El tema es de dónde viene esa, esa... Qué tiene esa función especial. Ese } \\
\text { es el tema. ¿Por qué esa célula tiene una función especial dentro de } \\
\text { ese [individuo]? ¿Por qué tiene una vida aparte dentro de la vida? }\end{array}$ \\
\hline 142 & Camilo & $\begin{array}{l}\text { No nos serviría tener todas las mismas células, que estemos formados } \\
\text { todos por una célula igual. Necesitamos células que se encarguen... }\end{array}$ \\
\hline 143 & Vanesa & $\begin{array}{l}\text { No, pero por eso, viene de la célula original que después se empieza a } \\
\text { diferenciar. Acá después explica el proceso de diferenciación celular. } \\
\text { ¿Cómo a partir de esa información, de esa vida, se generan las otras? }\end{array}$ \\
\hline 144 & Abigail & ¿Quién fue antes el huevo o la gallina? je je, \\
\hline 145 & $\mathbf{S}$ & ¿Completaste tu pensamiento Noelia? \\
\hline 146 & Noelia & Sí. Sí. Más o menos tenemos la misma idea. \\
\hline
\end{tabular}


Ante la pregunta que la profesora hizo a Noelia, Vanesa en la línea [141] introdujo su propia pregunta ¿Por qué esa célula tiene una función especial? Su intervención fue puesta en el contexto de lo que venían hablando en la clase, aunque no fuera ésa la cuestión que se estaba trabajando en ese momento. A partir de esta lectura la idea era explicitar lo diverso de las "vidas celulares", y así de ciclos celulares. Cuando estaban hablando de esas vidas diferentes, Vanesa cambió la pregunta y consultó por la causalidad que da lugar a esa diversidad, cómo era posible explicar que un mismo individuo tuviera células con diferentes "vidas" y por lo tanto distintas funciones. Justamente ese por qué fue lo que tuvieron que responder en la consigna de escritura inicial.

Vanesa irrumpió en esa escena, en la que S estaba preguntando a cada alumno cómo habían interpretado el título de la lectura, y refirió a "la célula original que después se empieza a diferenciar [143]. Aunque en el texto leído se mencionaban los procesos de diferenciación celular que Vanesa retomó, no había en él ninguna referencia a una célula original, sólo se describían y comparaban los diferentes tipos celulares. Éste sería otro indicador que nos permitió inferir que Vanesa en realidad estaría pensando en esa célula original a la que hacía mención la consigna de escritura inicial. Era posible que la duda hubiera surgido ante la actividad de escritura, y que la alumna no estuviera segura de la hipótesis que propuso en ese momento para explicar lo que se solicitaba. En esta instancia expresó sus dudas al hacer una pregunta pertinente acerca de cómo sucedía la diferenciación celular.

A continuación, Abigail acotó sobre la causalidad refiriendo a la relación entre causa y efecto con una analogía “¿Quién fue antes el huevo o la gallina?” [144]. S no participó explícitamente de ese intercambio, justamente su manera de intervenir fue dejar que la pregunta fuera consolidándose y retomó en el mismo lugar donde había dejado, repreguntando a Noelia acerca de lo que venía describiendo, si había podido completar aquello que había querido expresar. Esta acción la caracterizamos como una intervención elusiva, en la que $S$ elude dar respuesta en ese momento acerca de la consulta sobre el contenido disciplinar que realiza Vanesa.

La situación de Camilo pareció ser diferente a la de Vanesa, dado que el alumno en [142] planteó que tenemos células distintas porque no serviría tener un único tipo celular, sino que el individuo necesita tener células con diferentes funciones. En la explicación que dio Camilo la función celular dio cuenta de los procesos que dieron lugar a la estructura y esa aseveración no pareció generarle conflicto. Es así que dio vuelta el vínculo anteponiendo la consecuencia (función) como causalidad. Ésta pareció ser una explicación de tipo finalista, en ella la función se constituyó en la razón de las 
características particulares de los organismos y de sus células. Steven Rose (2001) plantea que este tipo de explicación basada en el objetivo suelen parecer muy racionales desde el sentido común. Esa clase de explicación se la denomina telenómica, denominación acuñada por el biólogo evolutivo Ernst Mayr (2006) al plantear que es posible justificar evolutivamente la orientación hacia un objetivo sin la necesidad de invocar un propósito consciente.

Un rato después Vanesa insistió con su pregunta acerca de cuándo ocurría la diferenciación celular; incluimos en el siguiente fragmento [4.7] la interacción suscitada a partir de la reiteración de esa pregunta por parte de la alumna. En esta ocasión la profesora S no eludió la respuesta.

Fragmento 4.7

Vanesa y Abigail continúan con las preguntas acerca de la diferenciación celular Clase 1. Plenario (197-217)

\begin{tabular}{|c|c|c|}
\hline \multicolumn{2}{|c|}{ Turno de habla } & Transcripción plenario \\
\hline 197 & Vanesa & $\begin{array}{l}\text { Profe... ¿le puedo hacer una pregunta? No sé, otra cosa lo responderá. No } \\
\text { me queda claro cuándo es el momento exacto, minuto, segundo...je je, en } \\
\text { que se produce el proceso de la diferenciación celular. Yo digo: bueno, sí, } \\
\text { del cigoto pasa a... Acá lo explica un poco, pero no me queda claro } \\
\text { exactamente cuándo se diferencia. }\end{array}$ \\
\hline 198 & $\mathbf{S}$ & Vos quisieras que yo te diga... \\
\hline 199 & Vanesa & No, no... \\
\hline 200 & $\mathbf{S}$ & Minuto, segundo... \\
\hline 201 & Vanesa & No, pero, no sé si es en el tiempo. El cigoto cuando... \\
\hline 202 & $\mathbf{S}$ & Es un proceso. A medida que empieza la primera división celular, ... \\
\hline 203 & Vanesa & Si.... \\
\hline 204 & $\mathbf{S}$ & $\begin{array}{l}\text { (...) Que se divide dos veces longitudinalmente ahí ya empieza ese } \\
\text { proceso de diferenciación que va a ir dando los distintos tipos celulares. } \\
\text { Desde ahí ya empieza. }\end{array}$ \\
\hline 205 & Vanesa & Ah, desde ahí. \\
\hline 206 & $\mathbf{S}$ & $\begin{array}{l}\text { Sí, sí. Hay animales donde esto es mucho más notorio. En el ser humano } \\
\text { la división es pareja, se hace primero en dos y después cada una de esas } \\
\text { dos, van a dar cuatro que son iguales. Pero, en el caso de los anfibios, por } \\
\text { ejemplo, hace lo mismo pero las de abajo son más grandes y las de arriba } \\
\text { quedan más chiquitas, entonces se diferencian dos polos distintos. Bueno, } \\
\text { ahí es bien manifiesta la diferenciación, ahí ya empieza ese proceso de } \\
\text { diferenciación. Ahí es bien manifiesta la diferenciación lo que pasa que en } \\
\text { el caso humano, los vertebrados... No, los vertebrados no, los mamíferos, } \\
\text { es más sutil, no lo vemos de forma manifiesta, pero ya empieza a haber }\end{array}$ \\
\hline
\end{tabular}




\begin{tabular}{|c|c|l|}
\hline & & $\begin{array}{l}\text { diferencias moleculares que hacen que ya empiece ese proceso de } \\
\text { diferenciación, ¿Por qué, qué es la diferenciación estrictamente? ¿Está } \\
\text { definido acá? }\end{array}$ \\
\hline 207 & Vanesa & Sí, [lee del texto] "cambios en la estructura y en el metabolismo". \\
\hline 216 & Abigail & $\begin{array}{l}\text { Claro, son esos cambios, en la estructura y en el metabolismo. No vemos } \\
\text { de entrada cambios en la estructura, más que las células se van haciendo } \\
\text { cada vez más chiquititas con las divisiones sucesivas, hasta determinado } \\
\text { momento que después empiezan a crecer. Pero a nivel metabólico ya se } \\
\text { están [produciendo], como dice acá [en referencia al texto] cambios } \\
\text { relacionados con la expresión de los genes. Entonces ya hay cambios } \\
\text { en la expresión de los genes. Entonces es un proceso. }\end{array}$ \\
\hline $\begin{array}{l}\text { Profe...Y también enganchado con lo de Vane, porque también le } \\
\text { preguntaba a... Ni bien se forma y empieza la diferenciación celular y por } \\
\text { ejemplo, se producen las células del páncreas, o las nerviosas ésas, -¿ya } \\
\text { dejan de tener información de la célula madre? ¿Ya se diferencian } \\
\text { completamente para la función específica que van a tener? }\end{array}$ \\
\hline 217 & S & $\begin{array}{l}\text { Pero entonces... A ver esperá, porque había otros estilos de vida que } \\
\text { podíamos distinguir y llegamos a esa. ¿Qué otro estilo de vida podemos } \\
\text { distinguir? [Volviendo a la consigna de trabajo con la lectura] }\end{array}$ \\
\hline
\end{tabular}

Al preguntar en [197] Vanesa volvió a referirse a la célula original (cigota) incluida en la consigna de escritura, pero que no se mencionaba en la lectura. Sin embargo, la alumna no hizo referencia a la actividad de escritura, sino que nuevamente vinculó su consulta con lo que estaban trabajando en ese momento. En su intervención señaló el texto que habían leído, y dijo: “Acá lo explica un poco," y agregó que, a pesar de eso, no le quedaba claro el momento en que las células se diferenciaban. La consulta reiterada de Vanesa, aun cuando no estaba prevista, dio lugar a una breve explicación por parte de S en línea [206] en la que precisó cuándo comenzaba el proceso de diferenciación, tal como Vanesa indagó. En esta breve explicación la docente no refirió a un único modelo celular general, sino que comparó la división de las células de un anfibio con cómo se dividían las primeras células al formarse un individuo humano. En estas intervenciones [202], [204], [206], la profesora actuó sobre el contenido disciplinar, en ellas ubicó al proceso de diferenciación celular en el tiempo de vida de un organismo y describió cómo sucedían las primeras divisiones celulares. En estas intervenciones aclaró aspectos del contenido que serían trabajados en la secuencia.

En ese último turno de habla [206] S preguntó “¿Qué es la diferenciación estrictamente? ¿Está definido acá?”, y vinculó la pregunta de la alumna con el texto leído. Así, a través de esa intervención, $S$ invitó a los alumnos a volver al texto y buscar dónde dice y cómo lo dice. Vanesa, quien tal como analizamos en fragmento [4.4] ya había identificado qué 
decía al respecto, leyó en voz alta del texto que la diferenciación celular consistía en "cambios en estructura y metabolismo" [207]. Fue entonces cuando S en [208] describió en qué consistían esos cambios, realizando nuevamente una intervención que actúa sobre el contenido disciplinar, en este caso de tipo aclaratoria.

Por último, en [216] Abigail planteó que "empieza la diferenciación celular y por ejemplo se producen las células del páncreas, o las nerviosas esas," y ejemplificaba así la diferenciación refiriendo a las dos clases de células que se incluyeron en la consigna de la tarea de escritura inicial 1a). Aquí habría un nuevo indicador en el discurso que pareció dar cuenta de que la esa situación de escritura hizo pensar a la alumna en cómo ocurría la diferenciación celular. Abigail expresó la pregunta que venía haciendo de manera recurrente en el pequeño grupo y ahora reiteraba en la revisión con toda la clase: la información genética que tenía esa célula ya diferenciada ¿Era la información original o sólo era parte de esa información? Esas preguntas que enunció25podrían estar representando otra manera de expresar la pregunta incluida en la consigna de la tarea de escritura: "¿Las células del páncreas y las nerviosas de tu cuerpo tienen la misma información genética, o cada tipo celular tiene parte de la información?" Al plantear estas preguntas Abigail pareció mostrar que dudaba acerca de lo que había respondido en el escrito. Tal vez al tener que escribir en esa actividad inicial hubieran surgido dudas acerca de la diversidad celular y fue el contexto de revisión que propuso la tarea de lectura la situación que permitió a Abigail y Vanesa reflexionar acerca de la cuestión y plantear nuevas preguntas. Esto fue posible porque esa segunda actividad prolongó el tiempo didáctico de trabajo con el tema y así amplió la posibilidad de ir consolidando aquello que no se comprendía.

Ante esta pregunta de Abigail, la profesora eludió responder y en cambio retomó la consigna específica acerca de los estilos de vida. Este tipo de acción en la que S pareció no intervenir, dado que no respondió a lo que Abigail planteó y se mostró reticente (Sensevy, 2012), la categorizamos como una intervención elusiva. A través de ellas la docente mantuvo la vigencia de la duda conceptual que la alumna planteaba, en una instancia en la que los alumnos empezaban a pensar en la vida de las células.

A continuación sistematizamos las categorías de intervención que construimos a partir de los datos, y describimos con mayor detalle el rol que tuvieron en pos de constituir el medio didáctico con el que interactuaron.

\footnotetext{
${ }^{25}$ ¿Ya dejan de tener información de la célula madre? ¿Ya se diferencian completamente para la función específica que van a tener?
} 


\subsubsection{Las intervenciones orales de la profesora: categorías elaboradas en este estudio}

En este apartado retomamos las categorías de intervención docente que fuimos describiendo en los apartados previos del capítulo y que fueron recurrentes a lo largo de la secuencia didáctica. Las presentamos durante cada una de las situaciones que analizamos en profundidad, porque consideramos que situarlas en el contexto en el que sucedieron nos permitiría aproximar cómo se vinculan con condiciones didácticas generadas en cada situación de enseñanza. Ahora las retomamos de manera conjunta para profundizar la descripción de cada categoría de intervención, y detenernos en el rol que jugaron en la acción didáctica.

Definimos y retomamos entonces las siguientes categorías de intervención docente:

a. Intervenciones que definen la tarea (por ej. S [77]- apartado 4.3.2.)

b. Intervenciones que actúan sobre quehaceres de lector y/o escritor

- Que vuelven al texto (por ej. en fragmento 4.1)

- Que habilitan diferentes interpretaciones (por ej. en fragmento 4.4)

c. Intervenciones que actúan sobre el contenido disciplinar

- Que aclaran (por ej. en fragmento 4.1)

- Que amplían (por ej. en fragmento 4.7)

- Que eluden (por ej. en fragmento 4.1)

d. Intervenciones que invitan a participar

- Que invitan a participar para expandir (por ej. en fragmento 4.1)

- Que invitan a participar para contrastar (por ej. en fragmento 4.1 y 4.4 )

\subsubsection{Intervenciones que definen la tarea}

En primer lugar retomamos las intervenciones que definen el juego didáctico y establecen o redefinen las pautas que forman parte del contrato. Tal como propone Sensevy (2007) los enunciados del docente tienen un importante valor perlocutivo, en el sentido de que son actos de habla con capacidad de provocar efectos (Austin, 2003), en este caso en las acciones de los alumnos. Durante esta primera clase, hubo tres momentos en los que S intervino definiendo la tarea: al entregar la consigna de escritura inicial (y al recibirla); al dar inicio a la tarea de lectura en pequeños grupos, y al dar comienzo al plenario de lectura. Presentamos las intervenciones de $\mathrm{S}$ que dieron lugar a esas definiciones. 
Tabla 4.1.

Intervenciones que definen la tarea

\begin{tabular}{|c|c|c|}
\hline Intervenciones que definen la tarea & Función & Situación \\
\hline $\begin{array}{l}\text { 1. S: No, no importa, porque en realidad } \\
\text { queremos ver qué es lo que se acuerdan } \\
\text { porque en función de eso, después } \\
\text { seguimos. [Responde a algunos } \\
\text { comentarios de alumnos que plantean si no } \\
\text { importa si no saben responder a las } \\
\text { consignas, al inicio de la actividad de } \\
\text { escritura] }\end{array}$ & $\begin{array}{c}\text { Definir } \\
\text { (sentido de } \\
\text { actividad de escritura) }\end{array}$ & Escritura inicial \\
\hline $\begin{array}{l}\text { 77. S: Esta es la primera lectura ad hoc, creada } \\
\text { por el momento. Van a ir leyendo este } \\
\text { texto. Primero obviamente lo leen de forma } \\
\text { individual. Lo que yo quisiera es que todas } \\
\text { aquellas preguntas que se les cruzan por } \\
\text { la cabeza a medida que lo van leyendo, las } \\
\text { anotan, porque van a ser insumos. Por el } \\
\text { otro lado, vayan viendo cuáles son... } \\
\text { fíjense lo que dice el título: "Una vida con } \\
\text { muchos estilos de vida", entonces fíjense } \\
\text { cuáles son esos estilos de vida que va } \\
\text { proponiendo el título, e identificarlos. Y por } \\
\text { el otro lado, quiero que identifiquen cuáles } \\
\text { son los criterios por los cuales en el título } \\
\text { y en el texto están establecidos esos } \\
\text { estilos de vida. ¿Está claro? }\end{array}$ & $\begin{array}{l}\text { Definir } \\
\text { (orientar } \\
\text { tarea de lectura) }\end{array}$ & $\begin{array}{l}\text { Lectura } \\
\text { en grupo }\end{array}$ \\
\hline $\begin{array}{l}\text { 85. S: Bueno, pero yo quiero que me soplen } \\
\text { ahora cuáles son los estilos de vida y } \\
\text { cuáles son los criterios. ¿Escucharon a } \\
\text { Oscar lo que estaba diciendo? }\end{array}$ & $\begin{array}{c}\text { Definir } \\
\text { (qué retomar } \\
\text { durante el plenario) }\end{array}$ & Plenario lectura \\
\hline
\end{tabular}

En la primera intervención que incluimos $S$ acota el alcance del escrito inicial, a través de esa intervención la docente aclaró que el texto solicitado no tuvo como finalidad la acreditación, sino que la intención era conocer las condiciones de inicio de la secuencia, para conocer la demanda de aprendizaje en términos de Leach y Scott, (2003) y según lo que la profesora expresó: poder seguir con la enseñanza. Esa tarea inicial que la docente configura como parte del medio didáctico, requirió que enunciara algunas reglas de la situación educativa (Rickenman, 2007), para que los alumnos pudieran comprender en qué consistía el juego al que estaban jugando (Sensevy, 2014).

El segundo ejemplo que incluimos en la tabla, refiere a la tarea de lectura Una vida con muchos estilos de vida prevista en el diseño después de la actividad de escritura inicial. A medida que cada estudiante finalizó su escrito, S le entregó la hoja con la lectura; 
cuando todos ya habían finalizado el escrito previo, enunció en qué consistía la tarea de lectura. Esa tarea requería que identificaran los estilos de vida implícitos en el título y los criterios posibles para clasificarlos que ese texto proponía. Pero además en la presentación de la actividad $\mathrm{S}$ le otorgó otro rol a la lectura dado que antepuso la función de ese texto como promotor de nuevas dudas, al decir, "Lo que yo quisiera es que todas aquellas preguntas que se les cruzan por la cabeza a medida que lo van leyendo, las anotan, porque van a ser insumos." Y eso implicó explicitar condiciones poco habituales para la lectura en clase, tal como sería leer para plantear preguntas en vez de leer para responder las preguntas que la docente formulara de antemano.

Por último, en el tercer ejemplo de intervención para definir la tarea al iniciar el plenario, $S$ les propuso a los estudiantes que le soplaran cuáles eran los estilos de vida y los criterios que habían acordado en el pequeño grupo. Eso también implicó una acción de corrimiento, dando a los alumnos el rol de "dictar al docente" aquello que habían trabajado en el grupo; a la vez que autorizó la voz de Oscar al preguntar si escucharon lo que había dicho al iniciar el plenario.

Esas acciones iniciales al distribuir roles en relación al contenido, incidieron en nuevas reconfiguraciones del contrato didáctico que sucedieron durante el plenario y fuimos planteando en este capítulo a medida que describimos y analizamos las intervenciones docentes.

\subsubsection{Intervenciones que actúan sobre quehaceres de lector y/o escritor}

Presentamos ahora un análisis más detallado de este segundo tipo de intervención docente que resultó clave para describir cuáles fueron las condiciones de enseñanza que hicieron posible que el leer, escribir y hablar tuvieran función epistémica.

Un tipo de intervención que realizó la profesora de manera recurrente y que consideramos que actuó sobre el quehacer lector es la que caracterizamos como para volver al texto. Releer y poner la voz a una consigna de trabajo, retomar la bibliografía o una lectura didáctica, leer en clase y compartir aquello escrito por los estudiantes, fue un tipo de intervención que permitió integrar al trabajo en clase esos diferentes tipos de textos y generar un sustrato sobre el que analizar qué y cómo lo dice el escrito. Cuando algunos alumnos le plantearon dudas acerca de lo que estaban leyendo, S los instaba a releer y buscar pistas en el texto.

A continuación en la tabla 4.2 incluimos algunos ejemplos de este tipo de intervención y describimos cómo esta acción sistemática incidió en las condiciones del medio didáctico al inducir a los estudiantes a abordar esos escritos como parte de aquello con lo que debían mediar. 
Tabla 4.2.

Intervenciones que actúan sobre quehaceres de lector y/o escritor: volver al texto

\begin{tabular}{|c|c|c|}
\hline Actúan sobre quehacer lector o escritor & Función & Situación \\
\hline $\begin{array}{l}\text { 9. No, no. Está hablando de la cigota, "se } \\
\text { originan a partir de una primera célula } \\
\text { denominada cigota, esa célula contiene la } \\
\text { información genética que aportaron los } \\
\text { progenitores. ¿Cómo podés explicar que a } \\
\text { partir de esa única célula en algunos } \\
\text { meses, se forme un embrión con varios } \\
\text { millones de células?" [4.1] }\end{array}$ & $\begin{array}{c}\text { Volver al texto } \\
\text { (para revisar significado } \\
\text { concepto específico) }\end{array}$ & Escritura inicial \\
\hline f. Volvé al texto, algo te dice el texto. [4.2] & $\begin{array}{l}\text { Volver al texto } \\
\text { (para responder } \\
\text { preguntas propias) }\end{array}$ & $\begin{array}{c}\text { Lectura en } \\
\text { pequeño grupo }\end{array}$ \\
\hline $\begin{array}{l}\text { 279. S: A ver, ¿Eso está acá? } \\
\text { 280. B: No. Yo no lo tengo } \\
\text { 281. S: ¡¿Cómo no?! [lee el texto] "Algunas } \\
\text { células de la musculatura esquelética, de } \\
\text { la epidermis de la piel, los linfocitos de la } \\
\text { sangre y células del sistema nervioso, al } \\
\text { dividirse dan origen a dos células que } \\
\text { tendrán destinos diferentes. Una de ellas } \\
\text { queda como célula madre, y así crecerá, } \\
\text { copiará su material genético y se dividirá, } \\
\text { y la otra se diferencia como célula } \\
\text { funcional específica y ya no se vuelve a } \\
\text { reproducir." [fragmento no incluido } \\
\text { previamente] }\end{array}$ & $\begin{array}{l}\text { Volver al texto } \\
\text { (para revisar cómo } \\
\text { y qué dice) }\end{array}$ & Plenario lectura \\
\hline
\end{tabular}

En el primer ejemplo $S$ releyó la consigna ante la consulta de un alumno, a quien le respondió que la célula a la que tenía que referir en su escrito no era aquélla que él mencionaba. Esa lectura en voz alta pareció tener como función aclarar cuál era la célula que mencionaba la consigna. $\mathrm{S}$ dijo que esa célula era la cigota, para después leer las frases en las que se la mencionaba, ubicándola en el contexto previo para que no quedaran dudas de cuál era la célula inicial. La relectura del texto que realizó la docente buscando pistas para responder las dudas que le planteaba Camilo es parte de su comportamiento como lectora. A la vez, considerar que se puede volver de otra manera a ese escrito deteniéndose en algunas de las relaciones que propone, es una estrategia que sólo pone en juego aquél que lee con autonomía (Lerner, 2002). En este caso particular la docente volvió al texto para retomar el significado de un término disciplinar, se centró en cómo ese término estaba incluido en la consigna y qué pistas podía aportar ese contexto al alumno que tenía que escribir. 
También durante el trabajo en pequeño grupo, ante una consulta de Abigail, S se mostró reticente y le sugirió volver al texto, argumentando que encontraría algo en relación a lo que ella preguntaba. No respondió cerrando la cuestión, sino que puso a las alumnas del grupo en posición de lectoras, y las instó a releer, ahora con una nueva función: ya no responder preguntas de la docente, sino las propias dudas. A partir de lo que propuso $S$, el pequeño grupo funcionó como un espacio de autonomía lectora, en la que Vanesa, Abigail y Alba leyeron y compartieron lo que decía el texto acerca de aquello que habían consultado.

Acordamos con Lerner (2002) en que restituir la responsabilidad como lectores a los alumnos es un fuerte desafío. Aunque la autora refiere a la escolaridad primaria consideramos que en cualquier nivel de enseñanza esa devolución que otorga a los estudiantes un rol de lector más autónomo, requiere para enfrentarlo establecer ciertas condiciones que den cuenta de una "cuidadosa construcción didáctica, una construcción que permita afrontar las complejas tensiones que se producen en la institución escolar en relación con la autonomía" (Lerner, 2002:15). Es así que la devolución del problema a las estudiantes fue una decisión didáctica que tomó la docente, quien respondió dentro del pequeño grupo muchas otras preguntas referidas a otros temas. Pero ante esta nueva pregunta de Abigail, que estaba relacionada directamente con el contenido disciplinar a trabajar en la secuencia y que por ello demandaba dedicarle tiempo didáctico, decidió sugerirles que volvieran al texto para buscar indicios que les permitieran seguir pensando.

En el último ejemplo de este tipo de intervención incluido en la tabla, $\mathrm{S}$ les dijo a los alumnos si aquello acerca de lo que preguntaban estaba en el texto y para fundamentar que la lectura sí decía algo al respecto, leyó en voz alta un fragmento que seleccionó con ese objetivo. Así mostró un modo de considerar la lectura, al hacer visible el escrito como objeto de reflexión. De manera reiterada ante distintas preguntas de alumnos, la docente les sugirió volver al texto tal como ella volvió para buscar marcas que le permitieran sostener lo dicho. Al preguntar si aquello sobre lo que hablaban estaba en el texto pareció consultarlos para que fueran los alumnos quienes volvieran a leer y cotejaran la duda planteada con lo que decía el texto. Cuando Brenda respondió que no estaba en el texto la referencia a diferenciación celular, $\mathrm{S}$ tomó la voz y releyó el escrito que aportaba datos sobre los distintos destinos de las células al dividirse.

A lo largo de toda la clase ( $\mathrm{y}$ en las otras clases también) $S$ realizó este tipo de intervención en dos sentidos: volvió al texto ella misma para sostener algo que estaba diciendo o para revisar en ese momento qué decía el escrito y cómo lo decía. Pero además en varias instancias lo que hizo fue sugerir a algún alumno que consultaba 
(Camilo, Abigail en los ejemplos seleccionados) que leyera y buscara indicios. Es decir, ella actuó como lectora buscando pistas en el texto e instó a los estudiantes a que también lo hicieran.

Otra intervención de $S$ que también contribuyó a consolidar quehaceres de lector y escritor de los alumnos es aquella que referimos como "que habilita diferentes interpretaciones". En la siguiente tabla presentamos algunos ejemplos de este tipo de intervención para describir cómo actuaron en la constitución del medio didáctico y cuáles fueron las acciones de los alumnos que se sucedieron a partir de esta clase de intervención.

Tabla 4.3.

Intervenciones que actúan sobre quehaceres de lector: habilitan diferentes interpretaciones

\begin{tabular}{|c|c|c|}
\hline Actúan sobre quehacer lector-escritor & Función & Situación \\
\hline $\begin{array}{l}\text { 127. Ojo, no mal ¿eh? Acá no hay nada que esté bien } \\
\text { o que esté mal. Estamos escuchando las } \\
\text { interpretaciones. }\end{array}$ & \multirow{3}{*}{$\begin{array}{c}\text { Habilitar } \\
\text { a los alumnos } \\
\text { como lectores } \\
\text { e intérpretes } \\
\text { de lo que leen }\end{array}$} & \multirow{3}{*}{ Plenario lectura } \\
\hline $\begin{array}{l}\text { 166. ¿Por qué tienen que adherir a lo que yo pensé? } \\
\text { Para mí las dos maneras de pensar me parece } \\
\text { que son total y absolutamente legítimas. O sea a } \\
\text { partir de una vida surge una vida: [de] la cigota } \\
\text { surgen distintos estilos de vida. Y esta otra } \\
\text { [interpretación] también, una vida que se } \\
\text { conforma con distintos estilos de vida. Me parece } \\
\text { que las dos acepciones están perfectas. Y acá, } \\
\text { vos pensaste en la vida de cada una de las } \\
\text { células con su propio estilo de vida. Este es más } \\
\text { individualista, pero también vale. Así que no les } \\
\text { voy a decir qué es lo que había pensado }\end{array}$ & & \\
\hline $\begin{array}{l}\text { 168. Pero lógico, ¿por qué voy a legitimar como yo lo } \\
\text { pensé? ¿No los convencí pensando en que } \\
\text { cada uno lo interpretó bien? }\end{array}$ & & \\
\hline
\end{tabular}

Para habilitar diferentes interpretaciones la docente debió demorar la exposición de su propia versión a fin de no clausurar el intercambio a través de la voz oficial o autorizada (Espinoza et al, 2009). En el primer caso, S expresó la acción que venía promoviendo al decir "estamos escuchando interpretaciones". Esa acción implicó un movimiento topogenético (Sensevy, 2007), la docente se corrió del rol protagónico y fueron los estudiantes quienes interpretaron y explicitaron sus versiones; mientras tanto $\mathrm{S}$ escuchaba, tal como hacían los demás estudiantes. Desde un análisis de la topogénesis ese movimiento cambió la distribución del contenido durante la transacción: ahora era un alumno quien enunciaba su interpretación y adquiría un rol protagónico. 
A la vez, en esta intervención hubo un nuevo encuadre del contrato al expresar que no estaba bien o mal cada interpretación. Ese movimiento permitió establecer una nueva regla del juego: el hecho de que expresar la propia postura en un aula podía tener una función diferente y no sólo ser categorizada desde esa mirada dicotómica (bien o mal) y como tal ser calificada.

Aquí resulta interesante destacar cómo una docente de Ciencias Naturales valida diferentes interpretaciones referidas al uso metafórico de la noción estilos de vida, a diferencia de aquellas intervenciones mencionadas en el apartado previo. En ese caso, volvió al texto para puntualizar un significado unívoco del termino cigota, cerrar, ajustar un concepto disciplinar, que como tal es monosémico y no admite diferentes interpretaciones, tal como sucede con los conceptos específicos de las Ciencias Naturales (Espinoza, 2006).

\subsubsection{Intervenciones que actúan sobre el contenido disciplinar}

La mayoría de las intervenciones docentes que ocurrieron durante las situaciones didácticas analizadas en profundidad tuvieron en cuenta los contenidos disciplinares. Es así que cuando la docente invitó a participar, los alumnos expandieron lo que habían expresado respecto al contenido disciplinar o contrastaron sus perspectivas con las de los compañeros. A la vez cuando referimos a las intervenciones que actuaron sobre los quehaceres de lector y escritor, también fue lo disciplinar aquello que estuvo en juego al volver al texto o al expresar las diferentes interpretaciones del título de la lectura. En esta nueva categoría incluimos otra clase de intervenciones, en las que el foco estuvo puesto en la construcción de conceptos o nociones de la Biología Celular y la docente no los retomó desde lo escrito, sino que fue a través de su discurso oral que intervino. Y así la docente aclaró, amplió o en algunos casos eludió la consulta de algún alumno acerca del contenido disciplinar que se estaba abordando en la clase. A continuación incluimos una tabla con dos fragmentos de registro para ilustrar las funciones que consideramos que adquirió este tipo de intervención al actuar sobre el contenido disciplinar.

Tabla 4.6.

Intervenciones que actúan sobre el contenido disciplinar

\begin{tabular}{|c|c|c|}
\hline \multicolumn{1}{|c|}{ Actúan sobre contenido disciplinar } & Función & Situación \\
\hline 9. S: No, no, está hablando de la cigota & $\begin{array}{c}\text { Ajustar } \\
\text { contenido } \\
\text { disciplinar }\end{array}$ & Escritura inicial \\
$\begin{array}{c}\text { 19. S: } \text { La cigota es la cigota. A partir de que se empieza } \\
\text { a reproducir es el embrión. }\end{array}$ & $\begin{array}{c}\text { (conocer } \\
\text { significado }\end{array}$ & \\
\hline
\end{tabular}




\begin{tabular}{|l|c|c|}
\hline 35. S: Pero ahora ya pasó ese acontecimiento, y ahora \\
es el resultado. & términos \\
específicos) & \\
36. O: Todo lo que suceda a partir de ahí. & \\
37. S: A partir de ahí, claro a partir de la fecundación. & \\
\hline 201. V: (...) El cigoto ¿cuándo [comienza la \\
diferenciación celular]?
\end{tabular}

En el primer ejemplo incluido en la tabla, la docente ajusta el significado del término cigota, ya que tal como describimos con anterioridad fue necesaria esa intervención dado que Camilo parecía no poder ubicar esa célula con precisión. Este tipo de intervención en la que la docente se centra en "ese término" para circunscribirlo y favorecer que el alumno lo pudiera abordar sucedió durante el trabajo en clase con alguna consigna. La profesora volvió de diferentes maneras acotando el alcance del término y ayudando a ubicarlo temporalmente al aclarar de modo tal que el alumno pudiera incorporarlo a su escrito.

El conocimiento de un término implica diferentes grados de aproximación al concepto específico que expresa. Los términos que denotan conceptos específicos no se 
aprenden aislados, como etiquetas, sino que esos términos que forman parte del lenguaje social de las ciencias (Bajtin, 2011), se presentan a través de escritos o del discurso docente, articulados con otros que los sitúan en un contexto. Así, cuando se lee o se escucha una explicación acerca de un tema que involucra una serie de conceptos disciplinares, no se aprende el listado de términos aislados sino a través de las relaciones semánticas que se establecen en el discurso (Portilla y Teberosky, 2010). Es así que el término cigota, tal como mencionamos previamente, era conocido por los estudiantes, pero poder precisar el lapso temporal en que una célula "es cigota" no resultó tan evidente para algunos alumnos. La tarea de escritura los obligó a tener en cuenta el alcance de ese término para poder utilizarlo en su explicación.

En otros casos, como en las intervenciones realizadas en los turnos de habla [202] al [206] incluidas en la tabla precedente, la profesora intervino para ampliar la referencia al contenido disciplinar. No se detuvo en un término preciso sino que presentó ejemplos intentando aportar al conocimiento y la comprensión de una noción compleja que involucraba muchas otras, como era la 'diferenciación celular'. Así se refirió a cuándo y cómo ocurre la diferenciación en los seres vivos, pero no se agotó la referencia en aquello que la profesora amplió, sino que ese concepto fue retomado a partir de otros durante la clase 5, que trataremos en el capítulo próximo.

La diferenciación celular podría ser simplemente una etiqueta que estaba definida en la lectura como "cambios en estructura y función" y eso podría haber clausurado la cuestión. Pero para poder comprender cuándo suceden esos cambios, cómo ocurren y en qué consisten, se requirió trabajar con el lenguaje de manera interpretativa (Sutton y Caamaño, 1997), y no quedarse sólo con esa definición inicial que presentaba el texto. Algunos conceptos disciplinares pueden funcionar como recursos porque son protagonistas imprescindibles para explicar otros sucesos biológicos (Ogborn, Kress, Martins, y Mc Gillcuddy, 1998); y requieren una ampliación del tiempo didáctico para su construcción.

En relación a este último aspecto mencionamos las intervenciones en las que $S$ eludió dar respuesta a algunas preguntas de alumnos. ¿Fue una decisión didáctica demorar la respuesta o no abordar aquello que un alumno le proponía y pasar a otra cosa? Y en ese caso ¿cuándo lo hizo? Aunque no hemos preguntado a la docente acerca de esta situación queremos analizar el contexto en el que surgió la elusión. A continuación presentamos la tabla que recupera algunas de esas intervenciones que actuaron sobre el contenido disciplinar y que categorizamos como elusivas; para que fuera clara la situación de elusión es que incluimos la consulta de alumno que quedó sin resolver. La 
docente en esa intervención elusiva retomó aquello que estaba trabajando antes de la consulta que recibió.

Tabla 4.7.

Intervenciones que eluden

\begin{tabular}{|c|c|c|}
\hline $\begin{array}{c}\text { Eluden responder sobre el contenido disciplinar } \\
\text { 143. Vanesa: No, pero por eso, viene de la célula } \\
\text { original que después se empieza a diferenciar. } \\
\text { Acá después explica el proceso de diferenciación } \\
\text { celular. ¿Cómo a partir de esa información, de } \\
\text { esa vida, se generan las otras? }\end{array}$ & $\begin{array}{c}\text { Eludir } \\
\text { (evita hacer } \\
\text { referencia a otros } \\
\text { temas que se } \\
\text { trabajaran } \\
\text { durante la } \\
\text { secuencia) }\end{array}$ & $\begin{array}{l}\text { Plenario } \\
\text { lectura }\end{array}$ \\
$\begin{array}{l}\text { 144. Abigail: ¿Quién fue antes el huevo o la gallina? } \\
\text { 145. S: ¿Completaste tu pensamento, Noelia? }\end{array}$ & \\
[Retomando plenario] & \\
\cline { 1 - 2 } 216. Abigail: Profe...Y también enganchado con lo de \\
$\begin{array}{l}\text { Vane, porque también le preguntaba a... [Otro u } \\
\text { otra compañera/o]. Ni bien se forma y empieza la } \\
\text { diferenciación celular y por ejemplo se producen } \\
\text { las células del páncreas, o las nerviosas ésas, ¿ya } \\
\text { dejan de tener información de la célula madre? } \\
\text { ¿Ya se diferencian completamente para la } \\
\text { función específica que van a tener? }\end{array}$ & \\
$\begin{array}{l}\text { 217. S: Pero entonces, a ver esperá, porque había otros } \\
\text { estilos de vida que podíamos distinguir y llegamos } \\
\text { a esa. ¿Qué otro estilo de vida podemos } \\
\text { distinguir? [Retomando plenario] }\end{array}$ & \\
\hline
\end{tabular}

Las dos situaciones de elusión que incluimos en la tabla ocurrieron durante el plenario y ambas estuvieron vinculadas con la diferenciación celular, cuestión que tomó relevancia pero no estaba incluida en la consigna de trabajo. Tal como dijimos éste es un concepto complejo que requería avanzar en el trabajo con los contenidos y dedicar tiempo didáctico a su explicación.

En ambos casos las preguntas eludidas apuntaban a conocer un concepto que "empaqueta" muchos otros en su nominación. Para explicar qué es la diferenciación se requería pensar en cómo era que células con igual información genética, como son las de un mismo ser vivo pluricelular, podían realizar funciones diferentes. $Y$ para ello era necesario retomar y relacionar varios conceptos que se iban a desarrollar en la secuencia analizada (como por ejemplo, duplicación de ADN, división celular mitótica, cromosomas y cromátides hermanas, regulación de la expresión genética). Quizás por eso la docente se mostró reticente y eludió responder a esas preguntas en varias ocasiones, tal como las dos transcriptas en la tabla 4.7. 


\subsubsection{Intervenciones que invitan a participar}

Este tipo de intervención fue importante para establecer una modalidad dialógica de enseñanza en la clase (Dysthe, 1996). A partir de la experiencia del primer año de trabajo, intentamos asegurar para esta secuencia que no fueran sólo los alumnos que siempre intervenían ante el requerimiento de la profesora los únicos que participaran, sino que todos los estudiantes se vieran interpelados a hacerlo. Fue por ello que en el diseño de la secuencia incluimos instancias de trabajo que favorecieran que la profesora pudiera generar una modalidad de regulación que diera pie a que los estudiantes intervinieran y participaran. Esos momentos de clase fueron previstos en el diseño y se discutió su alcance y sentido en las instancias previas de trabajo entre la docente y la investigadora.

Las intervenciones docentes que hacian lugar a que todos y cada uno de los alumnos pudieran expresar qué habían pensado se constituyeron en uno de los parámetros del diseño de la secuencia didáctica y durante la implementación fue un aspecto recurrente de la acción docente. Cuando un alumno consultaba dudas al interpretar las consignas de trabajo, a partir de la lectura de la bibliografía o al expresar las respuestas a las actividades, con frecuencia la profesora $S$ hacía extensiva esa consulta a los demás estudiantes.

La participación en clase adquirió una función general tal como que la comunicación no se estableciera de manera lineal sólo entre la docente y algún alumno particular, sino que la información circulara en el aula de manera más radial; pero su rol no quedó relegado a ese único aspecto. En algunos casos $S$ intervino desafiando a los estudiantes a explicitar con mayor precisión algo que habían expresado y así los obligó a utilizar el lenguaje para hablar acerca de lo que pensaban. En esos casos la profesora los instó a participar para expandir la idea que previamente habían expresado de manera general o acotada.

A continuación presentamos algunos ejemplos de esta clase de intervención docente que consideramos que tuvo esa función, y para sostener nuestra interpretación, describimos el contexto de interacción en que sucedieron.

Tabla 4.8.

Intervenciones que invitan a participar para expandir

\begin{tabular}{|c|c|c|}
\hline Que invitan a participar & Función & Situación \\
\hline 27. ¿Qué es lo que estás entendiendo Camilo? [4.1] & \multirow{2}{*}{ Expandir } & Escritura inicial \\
119. ¿Qué habías pensado? (a Camilo) [4. 4] & & Plenario lectura \\
\hline
\end{tabular}


125. ¿Vos qué pensabas? (a Abigail) [4. 4]

Plenario lectura

La intervención de S del turno de habla [27] sucedió después de un intercambio extenso (desde el turno 6 al 26) que transcribimos en el fragmento 4.1 en el apartado 4.3.1. Camilo inició esa secuencia haciendo una consulta acerca de la célula mencionada en la consigna de escritura y que él refiere como "una célula específicamente reproductora". Después de una serie de turnos de habla en los que intervienen otros estudiantes, Camilo pareció no haber entendido acerca de qué célula tenía que escribir. Es $S$ quien "lo obliga" a pronunciarse con la intervención que mencionamos [27] “¿Qué es lo que estás entendiendo Camilo?", el tono de voz de S invitó a Camilo a decir, lo convocó y el alumno efectivamente expandió su idea inicial. Aunque parecía dubitativo, incluyó en su intervención parte de las expresiones de otros estudiantes en los turnos de habla previos [14 a 26]. Así Camilo en [28] enunció: "Eh... No, porque tengo una vaga idea..., como de cigota. Pero pensé que para que se forme esta célula ¿no? que hubo fecundación entre el espermatozoide y el óvulo." Ante el requerimiento de S retomó como aporte lo planteado por otros alumnos para expandir su propia participación y definir el momento en el que se formó la cigota como resultado de la fecundación. Para poder expandir aquello que había enunciado, Camilo tuvo que resolver si la célula cigota se formaba antes o después de la unión entre óvulo y espermatozoide, y así precisar conocimientos disciplinares para responder a la intervención de S.

Las otras dos intervenciones que tomamos como ejemplo sucedieron durante el plenario, en el momento en que los alumnos estaban enunciando las interpretaciones que habían hecho del título de la lectura. Camilo en turno de habla [118] expresó su acuerdo con Abigail diciendo que pensó algo similar a lo que la alumna había propuesto y entonces S lo interpeló pidiéndole que enuncie "qué había pensado". De esa manera el alumno tuvo que ampliar en qué sentido coincidía con su compañera y expresó en [120] y [124] aquello que le pidió S: "Bueno, los estilos de vida... Yo lo hice más simple a los estilos. ¿Se refiere a la diversidad de las células? lo que usted quiso poner.... [...]. No, no tanta explicación... Lo que yo decía es que yo voy más a lo concreto. Para mí los estilos de vida se referían a la diversidad de las células, que haya un grupo de células con ciertas funciones, ciertas características." Esa participación lo llevó a expandir y así refirió a las células individuales con ciertas funciones como aquello que consideraba "estilo de vida".

También Abigail amplió su idea inicial en los turnos siguientes, al decir en [126]: "No, yo a eso lo planteé mal, yo pensé que hacía referencia a tejidos". Para agregar en [128] cómo había pensado la relación entre los diferentes niveles de organización: "Claro y 
bueno si hay diferenciación de células, yo pensé que si hay células nerviosas, células musculares, células epiteliales, necesito varias ¿no? para conformar el tejido, el órgano y así formar al individuo". Abigail expandió aquello que había expresado acerca del significado del título, y para ese "volver a decir" tuvo que hacer más explícitas esas relaciones entre niveles de organización que habían quedado ocultas la primera vez que expresó su interpretación en [115]: "Yo lo que decía era que todos esos diferentes estilos de vida dan origen a eso, la vida al individuo." Esa expansión entonces requirió seguir pensando acerca del contenido y ponerlo en palabras para que se comprendiera qué se quiso decir.

Otro rol que tuvieron las intervenciones que invitaron a participar a los alumnos fue promover que contrastaran la propia interpretación con lo que habían expresado sus pares. ${ }^{26}$ Presentamos algunos ejemplos de intervenciones que tuvieron este rol en la tabla 4.5 y enunciamos en qué sentido está propuesto ese contraste y qué acciones de los estudiantes le sucedieron.

Tabla 4.9.

Intervenciones que invitan a participar para contrastar

\begin{tabular}{|l|l|l|}
\hline \multicolumn{1}{|c|}{ Que invitan a participar } & Función & \multicolumn{1}{|c|}{ Situación } \\
\hline 13. (...) ¿Todos entienden lo mismo? [fragmento 4.1] & & Escritura inicial \\
\cline { 1 - 1 } $\begin{array}{l}\text { 137. ¿Y otra manera de pensarlo? ¿Yanina? ¿Brenda? } \\
\text { ¿Noelia? }\end{array}$ & \multirow{2}{*}{ Contrastar } & Plenario lectura \\
\hline $\begin{array}{ll}\text { 176. Fíjense, tres interpretaciones salieron. El todo... y } \\
\text { para definir a ese todo que tiene distintos estilos de vida. } \\
\text { Después la vida de la cigota que da origen a distintos } \\
\text { estilos de vida. Y cada célula independientemente de } \\
\text { dónde está ubicada o de dónde haya surgido tiene distinto } \\
\text { estilo de vida, tiene vida con su propio estilo, ¿así sería } \\
\text { Cristóbal? [4.5] }\end{array}$ & & Plenario lectura \\
\hline
\end{tabular}

El primer ejemplo que elegimos comienza con la intervención que la docente realiza en el turno de habla [13], era parte de una más extensa en la que la docente indicó a Camilo que leyera la consigna completa de corrido. Para conocer si esa duda de interpretación era compartida por otros alumnos, consultó a la clase si todos entendían lo mismo que Camilo. Así, al invitarlos a participar en esa consulta, dio lugar a que los demás alumnos pudieran plantear otras preguntas en relación a la interpretación, los estudiantes

\footnotetext{
${ }^{26}$ En ocasiones las intervenciones para participar tuvieron ambas funciones, instaron a que los estudiantes expandieran su decir pero también para hacerlo en algunos casos tuvieron que contrastar con otra su propia expresión. La intención no es hacer una separación taxativa entre las funciones que tuvo esta intervención sino analizar qué provocó, qué hicieron los estudiantes a partir de la acción de la docente.
} 
compararon lo que habían entendido de la consigna de escritura con lo que expresó Camilo. Vanesa en el turno siguiente [14] dijo no haber entendido lo mismo que Camilo: "No. O sea yo lo que entendí es: cómo explicar que de ese desarrollo de la célula que es la cigota...” La interrumpió Camilo diciendo en [15]: ‘Claro eso’ y continúa Vanesa en [16] “(...) Se desarrolla el individuo, cómo se producen las otras células. Se forme el embrión, cómo de esa célula..." Vanesa expresó aquello que había entendido de la consigna y lo hizo comparando con la consulta de Camilo, también Brenda y Oscar intervinieron convalidando lo que Vanesa enunció y para ello contrastaron la propia interpretación de la consigna que en ese momento hicieron explícita entre los tres (fragmento 4.1).

Los dos ejemplos siguientes que seleccionamos corresponden a la situación de plenario que se realizó después de la lectura. Vanesa y Abigail plantearon dos interpretaciones diferentes del título de la lectura, la docente las retomó y de esa manera las habilitó y las institucionalizó (Brousseau, 2007), dado que preguntó si había otra manera de pensar qué significado tenía ese título, por lo tanto no sólo les puso la voz sino que autorizó ambas interpretaciones. A partir de esa intervención fue invitando a varias estudiantes a participar, a la vez que las instó a comparar la propia interpretación del título de la lectura con las ya enunciadas, dado que inició su intervención preguntando por "otra manera de pensarlo" y así hizo lugar a una nueva opción que podía surgir al contrastar e intentar cotejar si la propia idea ajustaba en alguna de las dos opciones ya propuestas.

En el turno de habla [176] es S quien puso su voz para las tres interpretaciones que los alumnos finalmente plantearon, las enunció y cerró invitando a Cristóbal (quien propuso la tercera versión del significado del título) a opinar acerca de cómo ella había enunciado la interpretación que él había hecho. En esta situación la participación de Cristóbal al responder en [177], "Sí, exacto" implicó contrastar la propia idea con lo que retomó la profesora. Este tipo de intervención en ocasiones actuó problematizando porque la participación no implicó para los estudiantes sólo intervenir y agregar algo más, sino que los instó a contrastar sus hipótesis, a explicar a otros en qué se parecía o se diferenciaba aquello que habían pensado. $Y$ así seguir amasando esa cuestión difusa que a lo largo de la clase se fue transformando en problema para algunos estudiantes. Tener que comparar las ideas iniciales con otras maneras de pensar acerca de lo mismo dio lugar a un trabajo recursivo alrededor de ellas.

Aunque nos centramos en las intervenciones que realizó la docente, al concebir la acción didáctica como interacción conjunta entre la profesora, los alumnos y el saber (Sensevy, 2007), fue indispensable considerar todos los componentes de esa 
transacción. Por eso al caracterizar las invitaciones a participar para expandir tuvimos en cuenta principalmente la acción efectiva que el alumno realizó a partir de esa intervención. Y ese expandir no fue meramente expresar una opinión sino que implicó poner en la interacción al contenido disciplinar, porque fue alrededor de ese saber que los estudiantes usaron el lenguaje para expandir y hacer entender a otros lo que estaban pensando y comprendiendo (Wells, 2001).

Así también el saber está en juego al contrastar las propias ideas con las de los pares, es acerca de la relación entre las células individuales y el organismo del que forman parte, de la unidad y diversidad celular que los estudiantes hablan en el trabajo en grupo y durante el plenario. Es así que este tipo de intervención incorpora a los estudiantes a la clase, una clase que de esa manera se transforma en dialógica en la que se reconoce la multivocidad (Dysthe, 2000), porque esa invitación a participar no recoge sólo lo que cada alumno quiso decir sino que pone esos dichos en tensión al articularlos entre sí.

\subsection{Las situaciones de escritura desde la perspectiva de los estudiantes}

En este apartado presentamos la perspectiva de estudiantes entrevistados acerca de las situaciones de escritura, tales como las que analizamos en este capítulo. Nos detenemos en los desafíos que surgieron al abordar las tareas de escritura y en algunos de los logros que identificaron al escribir de manera sistemática durante la secuencia didáctica (y el cursado de la asignatura).

En apartados previos mencionamos gestos y comentarios de algunos estudiantes al recibir y entregar las tareas de escritura en esta primera clase de la secuencia. La intención aquí es recoger sus voces en relación con qué les sucedió cuando tuvieron que escribir durante el desarrollo de la secuencia didáctica y cómo lo encararon.

Algunos desafíos que surgieron al abordar la escritura durante la secuencia

\begin{tabular}{|c|c|c|}
\hline Oscar & $\begin{array}{l}\text { El escribir pone a prueba formas de expresión, formas } \\
\text { de explicación. Yo me doy cuenta que cuando me siento a } \\
\text { escribir, soné; desde la muralla que es mi ortografía hasta } \\
\text { la muralla de expresarme gramaticalmente. } \\
\text { Yo me doy cuenta que es importante pero uno es vago. Uno } \\
\text { como alumno es vago y trata de escribir lo menos posible. }\end{array}$ & $\begin{array}{l}\text { Escribir pone a } \\
\text { prueba } \\
\text { Escribir implica } \\
\text { trabajo }\end{array}$ \\
\hline Abigail & $\begin{array}{l}\text { A mí lo que me cuesta, me dificulta mucho es redactar, } \\
\text { armar el texto. Cada vez que tengo que armar una } \\
\text { redacción veo un desafío (...). Por ahí porque no sé si lo } \\
\text { que yo estoy interpretando del libro es correcto y muchas } \\
\text { veces también me faltan palabras; pero eso se soluciona } \\
\text { con la lectura. Y obviamente también (se ríe) no estar en } \\
\text { ridículo, no presentar algo que no sea coherente. }\end{array}$ & $\begin{array}{l}\text { Escribir implica leer, } \\
\text { comprender y } \\
\text { encontrar palabras } \\
\text { para expresar } \\
\text { Escribir es } \\
\text { exponerse }\end{array}$ \\
\hline
\end{tabular}




\begin{tabular}{|c|c|c|}
\hline Camilo & $\begin{array}{l}\text { En mi caso el hecho de armar textos es que primero tengo } \\
\text { que estudiar un poquito, visitar un poco lo que son los libros } \\
\text { para después armar. Porque yo necesito conocer o saber } \\
\text { bien de lo que voy a hablar para después darle mi forma de } \\
\text { expresarme, a mi manera y a mi gusto, como me gusta } \\
\text { expresarlo. Y quizás eso lleva tiempo. No, escribir. Pero el } \\
\text { tema es preparar ese texto, entonces recurro al Curtis (libro } \\
\text { de Biología) y tengo que estar leyendo y comprendiendo ahí } \\
\text { hasta que entienda el tema. Eso me puede llevar toda una } \\
\text { tarde y la escritura no, porque una vez que sé de qué se } \\
\text { trata, que sé las etapas o el proceso de lo que esté } \\
\text { leyendo, ahí ya lo armo como a mí me gusta y con mi } \\
\text { estilo y de la mejor manera trato de expresar el texto. } \\
\text { Porque uno también piensa en no decepcionar al profesor, } \\
\text { uno piensa bueno a ver no podemos hacer cualquier } \\
\text { texto para S. No quiere hacer un texto solo de copiar del } \\
\text { libro, quiere hacer un texto a su manera, pero quiere dejar } \\
\text { asentado que uno entendió y lo explica a su manera. }\end{array}$ & $\begin{array}{l}\text { Escribir implica leer, } \\
\text { comprender, } \\
\text { planificar }\end{array}$ \\
\hline Vanesa & $\begin{array}{l}\text { A veces uno cree que lo tiene comprendido un tema y } \\
\text { cuando lo tenés que trasladar, lo tenés que expresar, } \\
\text { escribirlo [enfatiza], ahí uno se da cuenta que se traba más. } \\
\text { Por lo menos a mí me pasa. A lo mejor si me quiero } \\
\text { expresar, tal vez me exprese mejor oralmente que lo que } \\
\text { escribo. Y lo que me están ayudando estas actividades es } \\
\text { justamente a eso, a poder expresarme en forma escrita. Yo } \\
\text { a veces digo: no se entiende lo que quiero decir. Uno se } \\
\text { puede defender oralmente, pero cuando uno escribe es } \\
\text { como que ahí me doy cuenta que hay un montón de cosas } \\
\text { que no lo manejo como creía que lo manejaba. }\end{array}$ & $\begin{array}{l}\text { Escribir permite } \\
\text { comprender qué se } \\
\text { sabe y qué no }\end{array}$ \\
\hline Noelia & $\begin{array}{l}\text { Aunque a uno por ahí le cuesta armar los textos y por ahí } \\
\text { eso de rehacer y rehacer a veces llega un momento que... } \\
\text { Pero a pesar de eso, me gustó la materia. Sirvió mucho. }\end{array}$ & $\begin{array}{l}\text { Escribir es un } \\
\text { proceso que implica } \\
\text { reescritura }\end{array}$ \\
\hline
\end{tabular}

En estos fragmentos que elegimos surge la noción de que escribir no es simplemente volcar en un papel aquello que se ha pensado. Sino que escribir en situaciones que conllevan desafíos implica reorganizar, transformar lo leído en un texto propio con otro sentido y así podría ser el medio a través del cual se elabora conocimiento (Carlino, 2004). Pero además la escritura presupone un lector, pensar a la escritura como práctica social implica concebirla como un modo de hacer con otros, con los que se conversa a través de la página escrita (Bazerman, 2009).

Al preguntarle acerca de la escritura, Oscar refirió a la ortografía y la gramática como murallas que surgían cuando él intentaba escribir; a la vez mencionó formas de expresar, de explicación, como aquello puesto a prueba durante la escritura. Estas referencias de Oscar nos permiten pensar en un destinatario que debería poder 
interpretar aquello que él expresa de determinada forma. Además para que su texto sea adecuado a la normativa que el contexto de educación superior supone, Oscar siente que debe escalar esas murallas ajustando la ortografía y gramática de su escrito. También Abigail mencionó el desafío que encontraba al armar sus escritos y refirió a un destinatario ante el que no debía quedar en ridículo. Escribir para Abigail y Oscar resultó un reto dado que no era simplemente decir lo que se sabe (Carlino, 2005). Eran conscientes que para producir un texto autónomo que pudiera ser interpretado por ese lector tenían que aportar pistas que guiaran al lector en la comprensión de aquello que querían decir.

En este sentido, al pensar en la docente como lectora de sus escritos Camilo justificó la necesidad de un trabajo previo de elaboración, al afirmar que no puede hacer cualquier cosa para $S$ y quería dejar asentado que había entendido. Aquí emergió el contrato implícito, dado que el hecho de escribir para la docente pareció hacerlo pensar en una mirada evaluativa. Sostuvo que lo difícil sería comprender aquello acerca de lo que debería escribir y no concretamente ponerlo en papel. En esta afirmación parece estar implícita la concepción de que el planeamiento de un escrito sería una etapa previa que no se solapa con el momento de textualizar, vinculando el escribir sólo con esta instancia. Así una vez que ya sabía qué escribir simplemente sería posible hacerlo.

Por su parte, Vanesa diferenció oralidad y escritura y cómo la escritura le permitió darse cuenta que había un montón de cosas que no manejaba como creía. Al poner por fuera aquello que pensaba y poder revisitarlo desde otro lugar pudo analizarlo y concluir cuáles eran sus incertezas. Esa función de revisión y reorganización de las propias ideas puede dar cuenta de su potencialidad epistémica, dado que la escritura, "no sólo nos ayuda a recordar lo pensado y lo dicho: también nos invita a ver lo pensado y lo dicho de una manera diferente" (Olson, 1998:16).

Por último, seleccionamos un fragmento de la entrevista a Noelia porque incluía la noción de que escribir es un proceso recursivo que involucra reescritura. Noelia mencionó que le cuesta armar los textos y en especial "eso de rehacer y rehacer" podríamos completar su frase con es más costoso aún. Esta cita refiere a un desafío implícito que encierra el abordar tareas de escritura. El reto consiste en poder pensar un escrito como texto provisorio que puede ser modificado, reorganizado; que no es un producto acabado, sino que puede dar lugar a volver a pensar esas ideas. Los estudiantes, en tanto escritores nóveles, no suelen ser conscientes de este desafío y generalmente conciben el texto como algo que cristaliza apenas se produce (Gottschalk y Hjortshoj, 2004). En la mención de Noelia estaban implícitas las orientaciones escritas 
que se incluían en las devoluciones y que fueron las que motorizaban ese "rehacer $y$ rehacer".

Por otra parte, durante las entrevistas varios estudiantes vincularon la escritura con la apropiación de lo trabajado durante la secuencia. Seleccionamos fragmentos de entrevistas a dos estudiantes para dar cuenta de cómo expresaron la relación entre las tareas de escritura y sus procesos de aprendizaje.

Algunos logros asociados al escribir durante la secuencia

\begin{tabular}{|c|c|c|}
\hline Oscar & $\begin{array}{l}\text { Vos me preguntas ahora y yo te puedo decir lo que pasa en cada } \\
\text { etapa del ciclo celular, pero no es que lo memoricé. Lo internalicé, lo } \\
\text { digerí, lo mastiqué, y lo tuve que volver a hacer (para una tarea de } \\
\text { escritura). Aparte porque lo integré, siento que lo integré a mis } \\
\text { conocimientos como algo que lo puedo asociar con otras cosas: "Ah, } \\
\text { ésta es una célula que tiene un ciclo celular así y ésta no se divide". } \\
\text { (....) El que nos hagan debatir algo, discutirlo y escribirlo } \\
\text { [enfatizando] yo me doy cuenta que es importante. El tema de } \\
\text { retomar la lectura, digerirla, masticarla, volver a escribir, borrar, } \\
\text { volver a interpretar, reinterpretar lo que uno escribió, para mí es } \\
\text { un ejercicio muy importante, es un ejercicio que no se hace (en } \\
\text { otras materias). }\end{array}$ & $\begin{array}{l}\text { Escribir } \\
\text { para } \\
\text { internalizar } \\
\text { e integrar }\end{array}$ \\
\hline Vanesa & $\begin{array}{l}\text { Escribir me sirve como para poder materializar eso, esa idea que } \\
\text { me viene, que yo creo que la tengo. Lo que yo rescato de estas } \\
\text { actividades es eso, me ayudó un montón a poder expresarme en } \\
\text { forma escrita. Y aparte el tema de tomar esta mirada más } \\
\text { sistémica. El hecho de haber trabajado todo el año con esto de los } \\
\text { textos e integrar y decir no es sólo el sistema circulatorio, sino que es } \\
\text { todo. (...) A mí me da la sensación que cuando uno se para frente a } \\
\text { la vida, la vida no es un recorte pequeño. La vida es un todo. Ver esto } \\
\text { facilita para el resto, para no quedarse con la unidad en sí y poder } \\
\text { tener una mirada más general. Es como cambiar una forma de } \\
\text { aprendizaje, una forma de mirar las cosas también. }\end{array}$ & $\begin{array}{l}\text { Escribir } \\
\text { para } \\
\text { materializar } \\
\text { ideas y } \\
\text { aprender a } \\
\text { pensar de } \\
\text { manera } \\
\text { sistémica }\end{array}$ \\
\hline
\end{tabular}

En el primer fragmento Oscar no sólo refirió a las tareas de escritura sino que mencionó el contexto en el que se escribió durante la secuencia. Así sostuvo que, "que les hagan debatir algo, discutirlo y escribirlo" lo tornaba importante, dado que había tiempo didáctico dedicado a detenerse en ese tema, a profundizar, a intercambiar con otros, y el escribir estaba incluido de manera central en esas acciones. Así la escritura no se percibía como algo por fuera de la enseñanza del contenido, sino que era parte de un trabajo recursivo entre el propio texto, las lecturas requeridas para poder ajustar ese escrito y los intercambios con los pares. Era todo ello lo que ponía en el centro de la escena al contenido disciplinar y el escribir tuvo un rol relevante en ese proceso. En este mismo sentido, Hand y Prain (2012) sostienen que las tareas de escritura que promueven reorganizar ideas alrededor de un tema, de manera tal que para realizarlas los alumnos tienen que establecer conexiones nuevas entre conceptos claves, y para 
ello utilizar diferentes materiales, podrían funcionar como espacios metacognitivos de reflexión acerca del propio aprendizaje.

Por su parte, Vanesa afirmó que al escribir se enfrentaba con aquello que creía saber y por eso sería una oportunidad "para materializar esa idea que me viene y yo creo que la tengo". Darle forma a esa idea le permitiría asirla, concretarla y ajustar aquello que pensaba. La escritura funcionaría para ella como un medio que promovía ese anclaje y revisión del pensamiento. Destacó también que el trabajo con tareas de escritura fuera sistemático y no algo ocasional. Este aspecto fue mencionado por varios alumnos entrevistados como algo clave de la propuesta didáctica. Vanesa consideró que las tareas de escritura le permitieron construir una mirada más sistémica de los seres vivos vinculada con el enfoque relacional sobre los contenidos que se proponía en la asignatura. Es decir, planteó que no sólo aprendió acerca del ciclo celular (o el sistema circulatorio en otra secuencia didáctica) sino que este trabajo le permitió comprender qué había aprendido y cómo había influido en su mirada sobre el mundo. Tal como ella expresó fue como cambiar una forma de aprendizaje, una forma de mirar las cosas. Aun cuando Vanesa relaciona al trabajo con los textos con este aprendizaje, serán ciertas tareas de escritura articuladas con otras múltiples situaciones durante el trabajo con una modalidad dialógica, interactiva aquello que le permitió aprehender esta perspectiva epistemológica imbuida en la propuesta didáctica.

En consonancia con estas reflexiones acerca de lo aprendido, citamos a Hand, Prain y Yore (2001) quienes comparten conclusiones de un estudio de caso en aulas de nivel medio. En ese caso, los estudiantes trabajaron con tareas de escritura realizadas de manera secuenciada y en las que les proponían explicar las propias ideas. Estos autores mencionaron como un aspecto positivo y poderoso que emerge de este estudio que los alumnos pudieron articular con claridad el valor que tuvieron las diferentes tareas de escritura en relación con su propio proceso de aprendizaje. ${ }^{27}$

\subsection{Recapitulación y relación con preguntas de investigación}

En este último ítem del capítulo proponemos un cierre del análisis en profundidad de las situaciones de enseñanza desarrolladas en la primera clase de la secuencia, estableciendo relaciones entre las preguntas y objetivos que nos movilizaron y los principales hallazgos que surgieron de ese análisis.

En los apartados previos documentamos las observaciones que permitieron interpretar cómo la docente constituyó el medio didáctico a través de sus acciones. Desde la

\footnotetext{
27 (...) the students were able to clearly articulate the value of different writing tasks in relation to their own learning, Hand, Prain y Yore (2001: 127)
} 
perspectiva asumida en esta tesis caracterizamos las intervenciones orales de la docente $S$, en consonancia con nuestras preguntas de investigación. Al considerar la acción docente como esencialmente transaccional nos detuvimos en aquello que esas intervenciones provocaron, tal como fuimos recuperando de las secuencias de interacción analizadas puestas en relación con aquellas que sucedieron durante la secuencia completa. Así identificamos y sistematizamos las siguientes clases de intervención:

\begin{tabular}{|c|c|c|}
\hline \multicolumn{2}{|c|}{ Intervención } & Función didáctica \\
\hline \multicolumn{2}{|c|}{ Define la tarea } & Establecer el sentido de las actividades propuestas \\
\hline \multirow{2}{*}{$\begin{array}{c}\text { Actúa } \\
\text { sobre } \\
\text { quehaceres } \\
\text { de escritor } \\
\text { y/o lector }\end{array}$} & $\begin{array}{l}\text { Que vuelve al } \\
\text { texto }\end{array}$ & $\begin{array}{l}\text { Visibilizar lo escrito y proponer reflexionar acerca de lo que } \\
\text { dice y cómo lo dice. }\end{array}$ \\
\hline & $\begin{array}{c}\text { Que habilita } \\
\text { diferentes } \\
\text { interpretaciones }\end{array}$ & $\begin{array}{l}\text { Favorecer la constitución de lectores autónomos al } \\
\text { promover el contraste y la reflexión de diferentes versiones }\end{array}$ \\
\hline \multirow{3}{*}{$\begin{array}{l}\text { Actúa } \\
\text { sobre } \\
\text { contenido } \\
\text { disciplinar }\end{array}$} & Que aclara & Despejar dudas acerca de lo que se está trabajando \\
\hline & Que amplía & Explicar que excede lo planteado en la tarea \\
\hline & Que elude & $\begin{array}{l}\text { Evitar obturar la reflexión y concentrar la reflexión en } \\
\text { ciertas ideas evitando la dispersión }\end{array}$ \\
\hline \multicolumn{2}{|c|}{ Invita a participar } & Al preguntar, interpelar pero sin obturar \\
\hline
\end{tabular}

Al analizar en profundidad las situaciones de enseñanza de esta primera clase, nos detuvimos en particular en las nociones de contrato $y$ medio didáctico para hacer explícita su encarnadura a través de las interacciones analizadas y dar cuenta de la íntima vinculación de la díada. Describimos cómo el contrato didáctico se puso de manifiesto durante la situación de escritura en clase y puso en tensión algo aprendido durante la escolaridad. Escribir para la docente implicó exponerse y mostrar qué se sabía y qué no y eso generó resistencia al medio didáctico por parte de los estudiantes.

Así también durante la situación de plenario el contrato se puso de manifiesto (porque se lo transgredió) cuando se explicitó quién tenía, desde la perspectiva de los alumnos, la palabra autorizada para decidir cuál de las interpretaciones del título de la lectura era la válida. Aceptar esas diferentes versiones que la docente habilitó, sin asumir la posición de validar la suya implicó desajustes en algunas de las reglas conocidas y establecidas por contrato. Tal como mencionamos esta cuestión fue algo valioso para algunos estudiantes, pero resistido por otros. 
Nos pareció importante detenernos en cómo esas tareas que implicaron escribir, leer y hablar dieron lugar a que surgieran preguntas que confirieran sentido a la explicación del proceso de duplicación del ADN que realizaría la docente durante la clase siguiente (clase 2). En este sentido, fue relevante conocer que alrededor de la mitad de los estudiantes (5/9) desconocía que todas las células de un organismo pluricelular poseían la misma información genética. Para poder explicar este hecho era necesario comprender el sentido del proceso de duplicación de ADN en el ciclo de vida de una célula. El desconocer que células del mismo organismo tenían iguales secuencias de ADN seguramente impactó en cómo los estudiantes explicaron que las células cumplían diferentes funciones durante el desarrollo de un individuo en esas primeras producciones escritas. A partir del análisis realizado pudimos conjeturar acerca de cuál era la demanda de aprendizaje (Leach y Scott, 2003), de manera tal de enfocar las tareas subsiguientes en aquellos aspectos que no resultaban evidentes para los estudiantes.

A su vez, a través de las marcas en el discurso de dos alumnas, Vanesa y Abigail, dimos cuenta de cómo la tarea de escritura inicial promovió que esas estudiantes siguieran pensando en el tema, lo relacionaran con el texto didáctico que leyeron en la segunda actividad y así concibieran y delimitaran un problema. Para ello enunciaron de diferentes maneras la cuestión propuesta en la tarea inicial (cómo explicar que un individuo tuviera múltiples células con funciones diferentes). A partir de los aportes de otros compañeros, del texto leído y de las intervenciones docentes esas preguntas fueron configurando un problema relacionado con un concepto disciplinar: diferenciación celular, que tomó cuerpo y hacia el final de la clase pasó a ser el eje de los interrogantes que las alumnas plantearon a la docente.

La secuencia de esas tres instancias de trabajo en el aula durante la clase inicial, (empezar escribiendo en forma individual, leer en pequeño grupo un texto relacionado y discutir en plenario acerca de lo leído), se constituyó en una condición de enseñanza relevante para que Vanesa y Abigail pudieran delimitar ese problema sobre el que seguir pensando. Empezar escribiendo implicó poner en tensión y cuestionar certezas para construir hipótesis propias que después se pusieron a prueba. La articulación entre tareas a partir de esa escritura inicial permitió extender el tiempo didáctico para pensar en la diversidad de células de un organismo, sus funciones y su origen. A la vez que dio lugar a que esas hipótesis fueran recuperadas como implícitas en las preguntas que Vanesa y Abigail formularon de manera recurrente a la docente.

Así también las intervenciones docentes con modalidad dialógica, que invitaron a participar y volver al texto de manera sostenida, actuaron como condiciones didácticas 
relevantes dado que favorecieron la posibilidad de elaborar interrogantes y problematizar aquello que se había expresado inicialmente. Aun cuando hemos descripto aspectos generales relacionados con la acción docente dialógica (Dysthe, 2013), surgieron nuevas preguntas no previstas inicialmente acerca de cuáles fueron las particularidades que el contenido a enseñar y la especificidad disciplinar de la formación de la profesora imprimieron a la acción docente que se desplegó en el aula. Comenzamos en este capítulo a describir la tensión entre lo general y lo particular respecto de la especificidad que puede tener una docente de Biología al trabajar con el leer y escribir para aprender. Así referimos a la precisión y univocidad que, en general, tienen los términos de las Ciencias Naturales y cómo ello incide en las orientaciones y sugerencias que la docente explicitó al volver al texto. En el próximo capítulo tomamos otro aspecto vinculado a lo particular del conocimiento biológico que se trabajó en las situaciones de enseñanza de la secuencia didáctica.

Por último, el análisis de las entrevistas incluido en el apartado 4.5 aportó en el sentido de identificar algunos desafíos y logros relacionados con las situaciones de escritura de toda la secuencia. Escribir no siempre será desafiante, sino que lo será cuando no implique sólo recuperar datos y enunciar algo memorizado, sino que se proponga ir más allá de lo literal. Cuando para responder a esa tarea no alcance con recortar y pegar información, sino que sea una propuesta que invite y empuje a revisar lo conocido, volver a los apuntes, la bibliografía y/o a pensar y organizar aquello con lo que se trabajó durante la clase. $\mathrm{Y}$ por ello esas tareas cuestan, implican rehacer y rehacer, al abordarlas surgen murallas y se ponen a prueba formas de expresión, a la vez que al encararlas se pone en acto que hay un montón de cosas que no manejo como creía que lo manejaba ${ }^{28}$.

Fueron tres los aspectos relacionados con la escritura que retomamos a partir de las voces de los estudiantes y que constituyeron esas tareas en desafiantes, a) percibir a un destinatario lector del texto (Oscar y Abigail); b) concebir al escrito como medio para revisar las propias ideas y no sólo para comunicarlas (Vanesa) y c) admitir al escrito propio como texto provisorio y que como tal puede ser reelaborado (Noelia). Esos aspectos hicieron que abordar las tareas fueran vividas como desafíos para los estudiantes, pero a su vez las significan en relación con los logros. En varias entrevistas hubo menciones acerca de lo positivo del trabajo con escritura para preparar el parcial y aprender acerca del contenido disciplinar. Pero compartimos aquí sólo dos fragmentos porque en ellos Oscar y Vanesa no sólo refirieron al contenido disciplinar específico

\footnotetext{
${ }^{28}$ Las expresiones en cursiva corresponden a: Abigail, Noelia, Oscar y Vanesa.
} 
como otros compañeros, sino que expresaron cómo reflexionaron sobre su propio proceso de aprendizaje.

En el próximo capítulo de resultados presentaremos el análisis en profundidad de situaciones de escritura, lectura y oralidad que se desarrollaron promediando la secuencia, durante las clases 4 y 5 . Para esa presentación incluimos las categorías de intervención que describimos en este capítulo y avanzamos en el análisis de la dualidad entre reticencia y expresión asociada a esas intervenciones. Analizamos además cómo el escribir, leer y hablar sobre lo escrito contribuyó a la transformación del estado de certeza/incerteza con relación al conocimiento en juego. 


\section{CAPÍTULO 5}

\section{Escribir y revisar cooperativamente lo escrito}

Acerca de cómo la interacción con pares aportó al juego didáctico

\section{Introducción}

Presentamos en este capítulo el análisis en profundidad de situaciones de enseñanza desarrolladas en las clases 4 y 5 de la secuencia didáctica. Esas situaciones incluyeron una tarea de escritura individual, así como la tarea de revisión de esas producciones escritas, en pequeño grupo y plenario.

Este análisis tuvo como objetivo profundizar la caracterización de las situaciones de enseñanza desarrolladas en esta clase y así también indagar acerca de las condiciones didácticas que se generaron durante la implementación de esas situaciones y su vínculo con el aprendizaje del ciclo celular. Nos referimos en particular a cómo esas condiciones influyeron en la transformación del estado de certeza/incerteza ${ }^{29}$ (Sensevy, Gruson, Forest, 2015) acerca de ciertas nociones trabajadas durante las situaciones de enseñanza analizadas en este capítulo.

A la vez retomamos las preguntas que enunciamos en relación con las intervenciones docentes: ¿Qué características asumen las intervenciones orales docentes? ¿Qué generan y cómo aportan al aprendizaje? En este capítulo nos interesó analizar la dualidad entre reticencia y expresión (Sensevy, 2014), asociada a esas intervenciones para detenernos en la manera en que se relaciona con la apropiación de contenidos conceptuales, tales como la noción de cromosoma. Para el análisis de las observaciones de clase, tal como hicimos en el capítulo previo, utilizamos la noción de juego didáctico. Así, al analizar las acciones de la docente (por ejemplo las intervenciones orales durante el trabajo de revisión) tuvimos en cuenta las acciones de los alumnos, en tanto coacciones que formaron parte de un juego cooperativo (Sensevy, 2012).

Las situaciones de trabajo con el lenguaje en uso, al leer, escribir y hablar en clases de ciencias permiten poner en práctica términos que remiten a conceptos disciplinares, de manera tal de transformarlos en protagonistas de los sucesos biológicos estudiados (Ogborn, Kress, Martins, y Mc Gillcuddy, 1998). Pero dependiendo del tipo de tarea que se proponga en clase, este lenguaje en uso puede constituirse sólo en un sistema de etiquetas fijas para nombrar elementos y procesos biológicos, o puede ser utilizado de manera interpretativa de forma tal que adquiera sentido ese uso (Sutton y Caamaño, 1997). El modo interpretativo de trabajo con el lenguaje requiere articular nuevos

\footnotetext{
${ }^{29}$ Tal como fue mencionado anteriormente el estado de certeza/incerteza refiere a la relación con el conocimiento en juego.
} 
términos con otros ya conocidos, estableciendo relaciones en diferentes situaciones y contextos, ampliando los significados y poniendo el lenguaje en movimiento. Abordar este tipo de situaciones que proponen un uso del lenguaje disciplinar interpretativo, para el que no es suficiente copiar o repetir literalmente el discurso de la docente o la bibliografía, puede constituir un desafío para algunos estudiantes. Y para poder enfrentar esos desafíos suele ser necesario trasponer resistencias que suponen revisar aquello conocido, modificar la zona de confort que aporta el contrato didáctico ya establecido. En este capítulo mostramos algunos hilos que fueron despuntando como marcas en el discurso de estudiantes. Retomamos esos indicios a fin de realizar algunas conjeturas para poder responder nuestra pregunta acerca de cuáles desafíos y resistencias surgen al trabajar en el aula con situaciones de escritura, lectura y oralidad para aprender el ciclo celular en este contexto.

En las situaciones de enseñanza analizadas en profundidad en este capítulo los estudiantes tuvieron que escribir para establecer vínculos entre diferentes términos específicos y así después hablar acerca de esas relaciones. Al diseñar esas tareas consideramos que podían favorecer la revisión de conceptos ya conocidos al contrastar con los escritos de los pares. En la siguiente tabla sintetizamos las situaciones didácticas e incluimos la organización de la tarea y el vínculo entre leer, escribir y hablar previsto en el diseño.

Tabla 5.A

Secuencia de las situaciones didácticas "escribir y revisar lo escrito".

\begin{tabular}{|c|c|c|l|l|}
\hline Clase & Tarea & Organización & \multicolumn{2}{|c|}{ ¿Qué se hizo? } \\
\hline $\mathbf{4}$ & $\mathbf{6}$ & individual & $\begin{array}{l}\text { Escritura de un texto estableciendo } \\
\text { relaciones entre conceptos disciplinares } \\
\text { (etapas y procesos ciclo celular). }\end{array}$ & $\begin{array}{l}\text { escribir para } \\
\text { relacionar }\end{array}$ \\
\hline $\mathbf{4}$ & $\mathbf{6}$ & plenario & $\begin{array}{l}\text { Comentario oral en plenario acerca de lo } \\
\text { que cada uno escribió. }\end{array}$ & $\begin{array}{l}\text { hablar sobre } \\
\text { lo escrito }\end{array}$ \\
\hline $\mathbf{5}$ & $\mathbf{8}$ & $\begin{array}{l}\text { pequeño } \\
\text { grupo }\end{array}$ & $\begin{array}{l}\text { Revisión de todos los escritos realizados } \\
\text { durante la clase 4. }\end{array}$ & $\begin{array}{l}\text { leer lo escrito } \\
\text { para } \\
\text { contrastar }\end{array}$ \\
\hline $\mathbf{5}$ & $\mathbf{8}$ & plenario & $\begin{array}{l}\text { Comentar y reflexionar sobre lo revisado } \\
\text { en pequeño grupo, en plenario } \\
\text { coordinado por la docente. }\end{array}$ & $\begin{array}{l}\text { hablar sobre } \\
\text { lo leído, para } \\
\text { contrastar }\end{array}$ \\
\hline $\begin{array}{c}\text { Post } \\
\text { clase } \\
\mathbf{5}\end{array}$ & $\mathbf{8}$ & individual & $\begin{array}{l}\text { Reescritura del texto a partir de lo } \\
\text { trabajado en plenario e incluyendo un } \\
\text { nuevo concepto disciplinar (cromatina) } \\
\text { trabajado en clase 5. }\end{array}$ & $\begin{array}{l}\text { escribir a } \\
\text { partir de lo } \\
\text { hablado para } \\
\text { relacionar }\end{array}$ \\
\hline
\end{tabular}


En el apartado 5.1 presentamos la tarea de escritura 6 y analizamos los escritos que produjeron los estudiantes. En el apartado siguiente (5.2) incluimos la consigna de la tarea 8 y el sentido que tuvo esa actividad no prevista en el diseño inicial. En 5.3 nos centramos en el análisis de las interacciones que sucedieron durante el plenario correspondiente a la tarea 8. Finalmente en el apartado 5.4, a través de la información recogida en las entrevistas realizadas, incluimos la perspectiva de los estudiantes y la docente acerca de las situaciones de enseñanza analizadas en este capítulo.

\subsection{Propuesta de escritura en clase y contexto de producción}

En la cuarta clase de la secuencia los estudiantes escribieron un breve texto que entregaron a la docente, en él se les solicitó relacionar una serie de conceptos disciplinares asociados al ciclo celular en el contexto de una célula particular, en este caso una célula epitelial. Dado que la escritura permite concentrar la atención en ciertas ideas y así promover un análisis crítico sobre aquello que se sabe (Carlino, 2005), en ese momento de la secuencia nos interesó proponer una actividad de escritura que permitiera vincular e integrar las etapas de todo el ciclo celular, aun cuando todavía no se habían trabajado en profundidad todas ellas.

Era necesario problematizar aquello que los alumnos consideraban que sabían, ponerlo en cuestión para poder comprender las modificaciones que les ocurrían a las estructuras (los cromosomas, por ejemplo) durante el ciclo celular. Conceptualizar la célula como una estructura estática conlleva pensar en sus propios componentes como inmutables. En este caso la actividad de escritura como parte del medio didáctico, promovió que los estudiantes relacionaran procesos y estructuras de diferente nivel de organización de la materia con las distintas etapas del ciclo celular. Esa propuesta funcionó como una tarea desafiante para algunos estudiantes, como describiremos más adelante.

Comenzamos la descripción presentando la consigna de trabajo, el contexto y las producciones que escribieron los estudiantes a partir de la siguiente consigna:

\section{Actividad 6}

Imagina la vida de una célula epitelial. Refiriéndote a su ciclo celular, escribe un texto relacionando los siguientes conceptos:

Etapa S de interfase - mitosis - cromátidas hermanas - ADN - cromosomas

A través de esta actividad propusimos establecer relaciones entre algunos conceptos trabajados en profundidad durante las clases anteriores (etapa $S$ de interfase, $A D N$, cromátides hermanas) con otros que sólo habían sido abordados de manera más general (mitosis y cromosomas). Estos últimos fueron estudiados durante la formación previa en otras asignaturas y al ser conceptos disciplinares claves no eran desconocidos para los alumnos. Consideramos que era necesario retomarlos en esta instancia para 
profundizar la relación que se podía establecer entre todos ellos ${ }^{30}$ y así comprender el ciclo celular de manera más integral.

De los términos incluidos en la consigna, algunos remiten a etapas del ciclo celular (etapa $S$ de interfase y mitosis), en particular el concepto de mitosis refiere tanto a la etapa del ciclo como a la división celular que sucede en esa etapa. Nuestro propósito era que los estudiantes establecieran una relación temporal y causal entre lo que ocurre en la etapa S de interfase, cuando se duplican las moléculas de ADN, y la mitosis, etapa en la que se separan esas copias y se distribuyen en las células hijas.

Otros de los términos incluidos se vinculan estrechamente entre sí ( $A D N$, cromosoma, cromátides hermanas) y podían ser relacionados con una de las dos etapas del ciclo celular o con ambas. En particular, el término cromosoma es uno de aquellos términos utilizados por los estudiantes a lo largo del aprendizaje de Biología Celular en diferentes materias de nivel secundario y profesorado. En la escolaridad media es habitual que los cromosomas sean concebidos como estructuras estáticas, a pesar de que durante la vida de las células se modifican. Nos interesó detenernos en este concepto, para que los futuros profesores pudieran pensar en cuándo, cómo y por qué cambia un cromosoma a lo largo de las fases del ciclo celular y qué implicancias en la vida de las células y del organismo del que forman parte, tienen esos cambios. Es por ello que en el análisis retomamos cómo los estudiantes incluyeron ese concepto en los escritos y cómo hicieron referencia a él durante el plenario de revisión.

Durante la actividad de escritura estuvieron presentes seis alumnos (del total de nueve que cursaban ese año la asignatura) pero sólo cinco de ellos entregaron el escrito. En la entrevista que realizamos al finalizar la secuencia, Alba explicó que no pudo entregar su escrito porque no sabía cómo relacionar esos términos, intentó escribir y efectivamente lo hizo, pero no le dio ese texto a la docente. A continuación transcribimos los textos que los cinco estudiantes escribieron y entregaron en la clase 4 , en negrita resaltamos los términos que les solicitamos relacionar en la actividad de escritura.

Tabla 5.B

Textos actividad 6

\begin{tabular}{|l|l|}
\hline Oscar & $\begin{array}{l}\text { Al finalizar la etapa S de interfase, la célula epitelial ha logrado duplicar su ADN } \\
\text { quedando formadas dos cromátides hermanas llamadas cromosomas, unidas } \\
\text { por el centrómero. Dicha célula ingresa a la etapa G2, y luego a la etapa de } \\
\text { Mitosis, donde dichos cromosomas se separaran. }\end{array}$ \\
\hline
\end{tabular}

${ }^{30}$ La etapa S de interfase es la etapa del ciclo celular en la que se realiza la duplicación del ADN, proceso biológico con el que los estudiantes trabajaron en profundidad durante la segunda y tercera clase de la secuencia. La duplicación del ADN da lugar a la formación de dos moléculas de ADN por cada molécula original, y estas dos moléculas que forman cada cromosoma constituyen las cromátides hermanas. Estas cromátides de cada cromosoma se mantienen unidas hasta su separación durante mitosis, quedando finalmente cada copia de ADN en células distintas (las células hijas). 


\begin{tabular}{|l|l|}
\hline Cristóbal & $\begin{array}{l}\text { Las células hijas heredan la misma información genética contenida en la célula } \\
\text { progenitora. Transitan por dos etapas la interfase y mitosis y le sigue la fase S, en } \\
\text { la mitosis los ADN hijos están unidos, esos ADN llevan el nombre de cromátides } \\
\text { hermanas, que pasa a llamarse cromosoma después de la separación }\end{array}$ \\
\hline Vanesa & $\begin{array}{l}\text { Las células epiteliales tienen una reproducción celular constante. El ciclo de } \\
\text { reproducción comienza con la duplicación del ADN; el mismo ocurre en la etapa } \\
\text { S de la interfase. Por cada molécula de ADN duplicado, obtengo } 2 \text { cromátides } \\
\text { hermanas. Continuando el proceso ya en la etapa de la mitosis es donde los } \\
\text { cromosomas se empiezan a condensar. }\end{array}$ \\
\hline Brenda & $\begin{array}{l}\text { Una célula epitelial como toda célula somática se reproduce por mitosis. Antes } \\
\text { de la reproducción la célula debe duplicar el ADN y lo hace en la etapa S de } \\
\text { interfase del ciclo celular. Es al finalizar esta etapa cuando el ADN se halla } \\
\text { compactado formando cromosomas con dos cromátidas hermanas. }\end{array}$ \\
\hline Yanina & $\begin{array}{l}\text { En la etapa S de interfase el ADN de una célula epitelial necesita duplicarse para } \\
\text { poder dividirse por mitosis y así dar origen a dos células con la misma información } \\
\text { genética, una vez finalizada la duplicación los cromosomas de la célula epitelial } \\
\text { poseen cromátidas hermanas. }\end{array}$ \\
\hline
\end{tabular}

\subsection{1 ¿Qué dicen los escritos? Análisis de las producciones}

En primer lugar nos detenemos en cómo los estudiantes se refirieron al tema trabajado en profundidad durante las dos clases previas: la duplicación de ADN que sucede en la etapa $S$ de la interfase. En casi todos los textos (4/5) el término ADN estuvo asociado al proceso de duplicación que ocurría en la etapa mencionada y permitía dar cuenta de la formación de cromátides hermanas como podemos ver en la siguiente tabla.

Tabla 5.C

Relación entre etapa $S$ de interfase, ADN y cromátides hermanas

\begin{tabular}{|c|c|}
\hline Oscar & $\begin{array}{l}\text { Al finalizar la etapa } S \text { de interfase, la célula epitelial ha logrado duplicar su ADN } \\
\text { quedando formadas dos cromátides hermanas }(\ldots)\end{array}$ \\
\hline Vanesa & $\begin{array}{l}\text { El ciclo de reproducción comienza con la duplicación del } A D N \text {; el mismo ocurre en } \\
\text { la etapa } S \text { de la interfase. Por cada molécula de } \underline{A D N} \text { duplicado, obtengo } 2 \\
\text { cromátides hermanas. }\end{array}$ \\
\hline Brenda & $\begin{array}{l}\text { (...) la célula debe duplicar el } \underline{A D N} \text { y lo hace en la etapa } S \text { de interfase del ciclo } \\
\text { celular. Es al finalizar esta etapa cuando el ADN se halla compactado formando } \\
\text { cromosomas con dos cromátidas hermanas. }\end{array}$ \\
\hline Yanina & $\begin{array}{l}\text { En la etapa } S \text { de interfase el } \underline{A D N} \text { de una célula epitelial necesita duplicarse }(\ldots) \\
\text { una vez finalizada la duplicación los cromosomas de la célula epitelial poseen } \\
\text { cromátidas hermanas. }\end{array}$ \\
\hline
\end{tabular}

Tal como se observa en los fragmentos transcriptos los cuatro estudiantes asociaron la etapa $S$ de interfase con el proceso de duplicación de $A D N$ que sucede en ese momento del ciclo celular y a la vez vincularon ese proceso con la formación de las cromátidas 
hermanas de cada cromosoma. La relación establecida entre esos tres términos había sido trabajada en las clases previas.

Por su parte, en su texto Cristóbal separó etapa $S$ de interfase y ubicó fase $S$ después de mitosis de manera errónea, tal como se observa en el fragmento transcripto. Si hubiera incluido etapa $S$ de interfase quizás hubiera podido darse cuenta que era una pista para pensar que la etapa $\mathrm{S}$ de interfase ocurría antes de mitosis.

Cristóbal $\quad$ Transitan por dos etapas la interfase y mitosis y le sigue la fase $\mathrm{S}$, en la mitosis los ADN hijos están unidos, esos ADN llevan el nombre de cromátides hermanas, $(\ldots)$

Al realizar este escrito Cristóbal "copió y pegó" de manera textual frases del capítulo del libro indicado como bibliografía con el que se trabajaba también en clase. Los fragmentos de oraciones que el alumno seleccionó para formar parte de su escrito, tenían el mismo orden y los mismos términos en los párrafos originales del material bibliográfico. Sin embargo, al seleccionar eliminó partes del texto original que eran relevantes para conservar el sentido de lo enunciado en esos párrafos.

Como parte del análisis de los escritos, en segundo lugar retomamos la inclusión en el texto del término mitosis que fue utilizado por los estudiantes en dos sentidos: en referencia a la etapa del ciclo celular o al evento que sucede en esa etapa. En las tablas $D$ y $E$ incluimos los textos con ambas acepciones:

Tabla 5.D

Mitosis como etapa del ciclo celular

\begin{tabular}{|l|l|}
\hline Oscar & $\begin{array}{l}\text { "(..) Dicha célula ingresa a la etapa G2, y luego a la etapa de Mitosis, donde } \\
\text { dichos cromosomas se separaran.” }\end{array}$ \\
\hline Cristóbal & $\begin{array}{l}\text { "Las células hijas heredan la misma información genética contenida en la célula } \\
\text { progenitora. Transitan por dos etapas la interfase y mitosis (...)" }\end{array}$ \\
\hline Vanesa & $\begin{array}{l}\text { "(..) Continuando el proceso ya en la etapa de la mitosis es donde los } \\
\text { cromosomas se empiezan a condensar." }\end{array}$ \\
\hline
\end{tabular}

Tabla 5.E

Mitosis como división celular

\begin{tabular}{|l|l|}
\hline Brenda & "Una célula epitelial como toda célula somática se reproduce por mitosis." \\
\hline Yanina & $\begin{array}{l}\text { "(...) para poder dividirse por mitosis y así dar origen a dos células con la misma } \\
\text { información genética (...)" }\end{array}$ \\
\hline
\end{tabular}

En ningún caso hubo dificultades al incluir el término mitosis en los textos, ya sea si referían a la etapa del ciclo o si mencionaban el proceso celular que ocurría en ella. Tanto en las actividades de la primera clase de la secuencia didáctica como en este 
escrito el concepto mitosis fue bien utilizado. A la vez, los alumnos podían ubicar la mitosis como etapa posterior a S, la secuencia temporal de etapas era un dato que en este momento ya tenían claro del ciclo celular. Sin embargo, relacionar de manera causal aquellos acontecimientos que sucedían en etapas diferentes (etapa $\mathrm{S}$ y mitosis en este caso) todavía era un desafío de mayor complejidad.

Un tercer aspecto de los textos que nos interesa retomar aquí fue cómo los alumnos incluyeron el término cromosoma en sus escritos. Las certezas e incertezas acerca de esta noción dieron lugar a un trabajo interactivo durante el plenario de revisión que presentaremos en el apartado 5.3. Transcribimos a continuación fragmentos de los escritos para mostrar cómo se incluyó en ellos el término cromosoma.

\section{Tabla 5.F}

Cromosomas

\begin{tabular}{|l|l|}
\hline Oscar & $\begin{array}{l}\text { "(..) quedando formadas dos cromátides hermanas llamadas cromosomas, } \\
\text { unidas por el centrómero. Dicha célula ingresa a la etapa G2, y luego a la etapa } \\
\text { de Mitosis, donde dichos cromosomas se separaran." }\end{array}$ \\
\hline Cristóbal & $\begin{array}{l}\text { "(..) esos ADN llevan el nombre de cromátides hermanas, que pasa a llamarse } \\
\text { cromosoma después de la separación." }\end{array}$ \\
\hline Vanesa & $\begin{array}{l}\text { "(..) Continuando el proceso ya en la etapa de la mitosis es donde los } \\
\text { cromosomas se empiezan a condensar." }\end{array}$ \\
\hline Brenda & $\begin{array}{l}\text { "(..) Es al finalizar esta etapa cuando el ADN se halla compactado formando } \\
\text { cromosomas con dos cromátidas hermanas. }\end{array}$ \\
\hline Yanina & $\begin{array}{l}\text { "...) una vez finalizada la duplicación los cromosomas de la célula epitelial poseen } \\
\text { cromátidas hermanas." }\end{array}$ \\
\hline
\end{tabular}

Oscar fue el único que mencionó a los cromosomas en ambas etapas del ciclo celular. En la etapa $S$ describió su estructura, al decir que dos cromátides hermanas unidas por el centrómero son llamadas cromosomas, pero aquí quedó la duda si la estructura de dos cromátidas constituía para él un cromosoma o si cada cromátida lo era, tal como se podría interpretar al escribir que en mitosis esos cromosomas se separaran ${ }^{31}$. El trabajo con el texto de Oscar en plenario después de la tarea de revisión, permitió cuestionar la

\footnotetext{
${ }^{31}$ Los cromosomas pueden estar formados por una o dos cromátides dependiendo del momento de la vida celular. El término cromátide remite siempre a cromosoma, es parte de esa unidad de información formada por una molécula de ADN (o dos al duplicarse) y ciertas proteínas estructurales asociadas. Las cromátides hermanas de cada cromosoma se separan durante mitosis, pero no son "los cromosomas" quienes lo hacen en esta división celular. Al separarse y estar en los polos de la célula y reorganizarse los dos núcleos que se forman, es posible referir a cada cromátide (ahora en núcleos y en células distintas cuando se separe el citoplasma) como cromosoma. Como se ve hay una cuestión temporal y contextual que hace que "una cromátide" pueda ser considerada "un cromosoma" o no.
} 
relación entre cromosoma y cromátidas hermanas, y así reflexionar y discutir acerca de cómo cambiaba la estructura de un cromosoma durante el ciclo celular. ${ }^{32}$

El texto escrito por Cristóbal, que fue armado a partir de frases literales del capítulo del libro, refería a cromátides hermanas y cromosoma en la última oración. Esa frase no era correcta porque obvió que cada cromátide pasa a denominarse cromosoma sólo cuando, ya separadas las cromátides hermanas, se encuentran en nuevos núcleos. En el párrafo original la mención a cromátides hermanas estaba distanciada de la de cromosoma por varios renglones que aludían a la mitosis y la formación de nuevas células. Pero en su escrito Cristóbal unió partes de dos oraciones diferentes que estaban separadas en el libro fuente.

Tanto Vanesa como Brenda refirieron en su texto a la compactación (o condensación) de los cromosomas. Esa fue otra condición de los cromosomas, cambiante a lo largo del ciclo celular, que se retomó en el plenario de la clase 5 a partir del trabajo con la revisión de los textos escritos por los estudiantes. Por su parte, el texto de Yanina alude a la formación de las cromátides hermanas como parte de cada cromosoma durante la duplicación, sin hacer ninguna mención a la compactación.

\subsection{Propuesta de revisión cooperativa de lo escrito}

En los textos que los estudiantes escribieron en la clase 4 identificamos algunos problemas, en especial con relación a la noción de cromosoma, por ello propusimos una nueva instancia de trabajo con una actividad de revisión de esos escritos. Durante la actividad de revisión cooperativa que tuvo lugar en la clase 5 , los alumnos leyeron las producciones de todos. Esta tarea se organizó en dos momentos: primero en pequeño grupo, para después compartir en plenario. A partir de ese plenario surgieron dudas que dieron lugar a momentos de explicación docente.

Al inicio de la clase 5, la docente S presentó la actividad de revisión mientras entregaba la consigna escrita a cada estudiante. Transcribimos en el siguiente fragmento su intervención.

\begin{tabular}{|c|l|c|}
\hline & \multicolumn{1}{|c|}{ Transcripción plenario } & Intervención \\
\hline $\mathbf{S}$ & $\begin{array}{l}\text { Con los textos que nos dieron la clase anterior armamos esta } \\
\text { actividad, es una actividad de una actividad. Lo tiene allí cada } \\
\text { cual [en el papel con la consigna escrita]. Ah, les puedo dar uno } \\
\text { a cada uno, estaba "amarrocando" [repartió a cada alumno el } \\
\text { papel con la consigna, previamente había entregado uno por } \\
\text { grupo]. }\end{array}$ & $\begin{array}{c}\text { Definir la } \\
\text { tarea }\end{array}$ \\
\hline
\end{tabular}

32 En el texto de Cristóbal también hay referencia a la relación entre cromátides hermanas y cromosoma, pero tal como dijimos, analizamos su texto en el subapartado siguiente. 


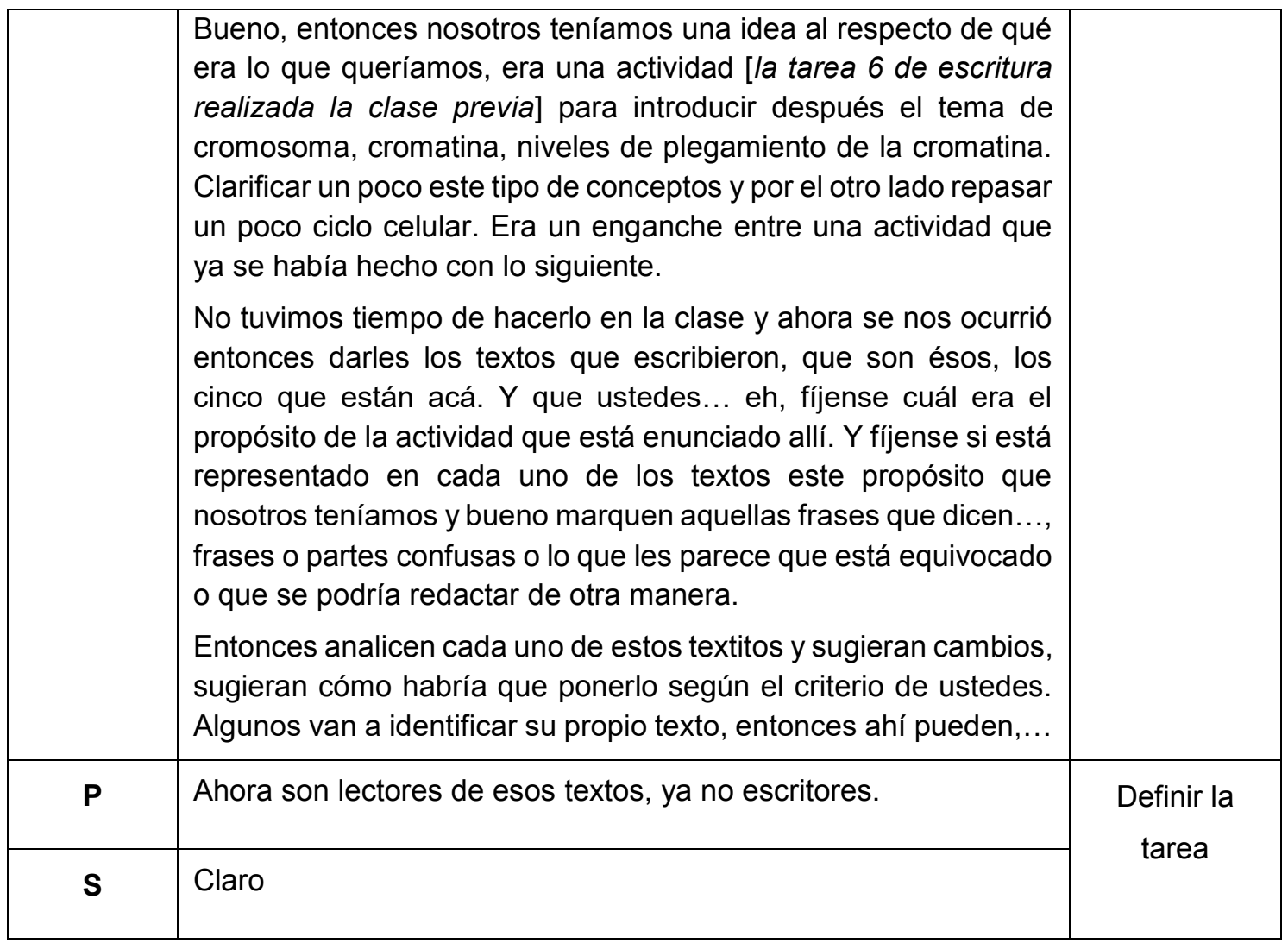

De esta manera, a través de las intervenciones de la docente y la investigadora se definió la tarea a realizar en los pequeños grupos. La consigna entregada en papel incluyó los textos originales que habían escrito los alumnos presentes durante la clase previa, sin identificar a los autores, y se explicitaba en ella el propósito didáctico de esa tarea de escritura. La compartimos a continuación:

\section{Actividad 8}

Los siguientes textos fueron escritos por ustedes durante la clase pasada a partir de la consigna que transcribimos arriba. La actividad tenía como propósito pensar qué relación hay entre los diferentes momentos del ciclo celular, y ubicar a los cromosomas en ese ciclo de vida. Ahora les pedimos que lean los textos de todos y analicen si en cada texto se expresa de manera clara la relación entre:

* Etapa S y Mitosis como etapas del ciclo celular

* ADN, cromosoma y cromátidas hermanas.

Además marquen en el texto si hay frases o partes confusas y si es así, qué sugerencias le harían al compañero autor del texto.

Texto 1: Al finalizar la etapa $S$ de interfase, la célula epitelial ha logrado duplicar su ADN quedando formadas dos cromátides hermanas llamadas cromosomas, unidas por el centrómero. Dicha célula ingresa a la etapa G2, y luego a la etapa de Mitosis, donde dichos cromosomas se separaran.

Texto 2: Las células hijas heredan la misma información genética contenida en la célula progenitora. Transitan por dos etapas la interfase y mitosis y le sigue la fase $\mathrm{S}$, en la mitosis los ADN hijos están unidos, esos ADN llevan el nombre de cromátides hermanas, que pasa a llamarse cromosoma después de la separación

Texto 3: Las células epiteliales tienen una reproducción celular constante. El ciclo de reproducción comienza con la duplicación del ADN; el mismo ocurre en la etapa S de la interfase. 
Por cada molécula de ADN duplicado, obtengo 2 cromátides hermanas. Continuando el proceso ya en la etapa de la mitosis es donde los cromosomas se empiezan a condensar

Texto 4: Una célula epitelial como toda célula somática se reproduce por mitosis. Antes de la reproducción la célula debe duplicar el $A D N$ y lo hace en la etapa $S$ de interfase del ciclo celular. Es al finalizar esta etapa cuando el $A D N$ se halla compactado formando cromosomas con dos cromátidas hermanas.

Texto 5: En la etapa $S$ de interfase el $A D N$ de una célula epitelial necesita duplicarse para poder dividirse por mitosis y así dar origen a dos células con la misma información genética, una vez finalizada la duplicación los cromosomas de la célula epitelial poseen cromátidas hermanas.

En la presentación que realizó S hubo una primera definición del contrato de la actividad (además de aquello que explicitaba la consigna escrita de trabajo), una aclaración acerca de qué acciones implicaría analizar los escritos. Así de manera explícita la docente solicitó que "marquen (...) frases o partes confusas o lo que les parece que está equivocado o que se podría redactar de otra manera". A la vez, les propuso que sugirieran cambios en los escritos según el criterio de cada uno. De esta manera, se les propuso una tarea no habitual: ubicarse como lectores de las producciones de todo el grupo, y que a partir de esa lectura de revisión hicieran sugerencias a los autores de cada texto.

La revisión en pequeño grupo tuvo la intención de que contrastaran su propio escrito con las diferentes producciones obtenidas a partir de una misma propuesta de escritura. Los alumnos cuyos textos estaban incluidos en la actividad, identificaron su escrito y lo corrigieron. Dado lo novedoso de la tarea, durante ese trabajo surgieron dudas acerca de qué se esperaba que hicieran a partir de la lectura de los textos, cuestión que se vio reflejada en las preguntas que formularon. Ante esas consultas la docente $S$ intervino con el propósito de hacer más precisa la definición inicial:

\begin{tabular}{|l|l|l|}
\hline S & $\begin{array}{l}\text { Pueden darse cuenta qué fue lo que escribieron y } \\
\text { qué es lo que debería estar escrito }\end{array}$ & ante consulta de Brenda y Oscar \\
\hline S & Fíjense cómo debería haber sido & ante consulta de Noelia y Cristóbal \\
\hline
\end{tabular}

Dado que en esta tesis analizamos cuáles son las condiciones de enseñanza que podrían potenciar el trabajo con el leer y escribir para aprender nociones biológicas, nos interesó detenernos en cómo se definió esta tarea de lectura. Esas intervenciones, que la docente realizó ante consultas de los estudiantes, aportan a conocer cómo se fue configurando ese contrato didáctico inicial que seguramente influyó en cómo los estudiantes concibieron la tarea a realizar.

Durante el trabajo en pequeño grupo pusimos el grabador en el equipo de Cristóbal y Noelia. El registro de audio fue fragmentario, dado que hablaban en voz muy baja como si evitaran que su intercambio quedara registrado. Posteriormente pusimos el grabador en el grupo de Brenda, Oscar, Camilo y Yanina, pero aquí tampoco lo registrado fue 
relevante para el análisis dado que en ese momento ya habían resuelto cómo corregir los textos y los intercambios registrados fueron sobre aspectos personales y no respecto a la tarea. Fue por ello que seleccionamos para presentar aquí sólo el análisis en profundidad de las interacciones durante la situación de plenario.

\subsection{Interacciones en el aula en torno a la tarea de escritura y lectura. Intervenciones docentes y constitución del medio didáctico}

En este apartado compartimos los resultados del análisis de los intercambios entre la docente y los estudiantes durante situaciones de plenario. En ese análisis incluimos las categorías de intervención descriptas en el capítulo previo de resultados.

En el apartado 5.3.1 presentamos la interacción ocurrida después de la situación de escritura durante la clase 4 , cuando a instancias de la docente los estudiantes comentaron cómo habían relacionado los conceptos incluidos en la consigna de escritura. A su vez, en 5.3.2 presentamos el análisis de las interacciones sucedidas durante el plenario posterior a la tarea de revisión en la quinta clase de la secuencia.

\subsubsection{Comentar acerca de lo escrito}

Tal como anticipamos en la tabla 5.A que resume las situaciones didácticas, durante la clase 4 hubo un momento de escritura individual, seguido de una instancia de plenario en la que la docente invitó a los estudiantes a hablar acerca de lo escrito.

Durante la escritura individual los estudiantes no realizaron consultas en voz alta a la docente, pero sí intercambiaron entre ellos algunos comentarios con relación a las etapas del ciclo y a qué sucedía en ellas. Hubo consultas entre Brenda y Oscar acerca de las etapas, y por otro lado entre Vanesa y Alba, aunque los registros son poco audibles.

En relación con el plenario posterior a la escritura presentamos el siguiente fragmento que incluye intercambios en los que los alumnos refieren a su propio escrito y lo comparan con los textos de sus pares, ese vínculo entre escribir y hablar acerca de lo escrito se reforzó con la tarea desarrollada durante la clase siguiente.

Fragmento 5.1. Comentar lo escrito

Clase 4. Plenario post escritura (373-388)

\begin{tabular}{|c|c|l|c|}
\hline \multicolumn{2}{|c|}{ Turno de habla } & Transcripción plenario & Análisis interacción \\
\hline 373 & S & $\begin{array}{l}\text { Bueno ¿Qué podemos decir? Se quedaron con } \\
\text { la consigna... }\end{array}$ & Invita a participar \\
\hline 374 & Oscar & $\begin{array}{l}\text { A ver. Yo lo que puse... A ver si lo planteé bien: } \\
\text { Que al final de la etapa S de interfase el ADN } \\
\text { se ha duplicado y se formaron dos cromátides } \\
\text { hermanas llamadas cromosomas unidas por el }\end{array}$ & $\begin{array}{c}\text { Hablar sobre lo } \\
\text { escrito }\end{array}$ \\
\hline
\end{tabular}




\begin{tabular}{|c|c|c|c|}
\hline & & $\begin{array}{l}\text { centrómero. Y que luego de pasar por la etapa } \\
\text { G2 van a entrar en la etapa de mitosis en donde } \\
\text { los cromosomas se separan. }\end{array}$ & \\
\hline 375 & Brenda & $\begin{array}{l}\text { Yo puse que las células epiteliales se } \\
\text { reproducían por mitosis y para reproducirse } \\
\text { tienen que duplicar el ADN. Que lo hacen en la } \\
\text { etapa S de interfase y que al comenzar la etapa, } \\
\text { el ADN se encuentra compactado con un } \\
\text { cromosoma con dos cromátides hermanas. }\end{array}$ & $\begin{array}{l}\text { Hablar sobre lo } \\
\text { escrito }\end{array}$ \\
\hline 376 & Yanina & Yo puse algo muy parecido. & $\begin{array}{l}\text { Hablar sobre lo } \\
\quad \text { escrito }\end{array}$ \\
\hline 377 & $\mathbf{s}$ & ¿Por acá? & Invita a participar \\
\hline 378 & Vanesa & $\begin{array}{l}\text { No yo... no puse eso. Yo puse que las células } \\
\text { epiteliales necesitan... o sea que se } \\
\text { reproducen constantemente. Y que el ciclo } \\
\text { celular empieza con la duplicación de ADN que } \\
\text { se produce en la etapa de interfase. Que luego } \\
\text { de la replicación de la molécula de ADN da } \\
\text { como resultado dos cromátides hermanas. Y } \\
\text { ahí, ya ahí eso del cromosoma, ahí yo no } \\
\text { puse... nada más puse que los cromosomas en } \\
\text { la etapa de la mitosis, se pueden... que en la } \\
\text { etapa de la mitosis es cuando se empiezan a } \\
\text { condensar. Como una etapa de condensación. } \\
\text { Pero no puse que era el resultado... que era el } \\
\text { cromosoma... que "las cromátides hermanas } \\
\text { llamadas también cromosomas son las que } \\
\text { ingresan en la mitosis". Eso no puse... Lo puse } \\
\text { más como separado. }\end{array}$ & $\begin{array}{c}\text { Hablar } \\
\text { sobre lo escrito }\end{array}$ \\
\hline 379 & $\mathbf{S}$ & $\begin{array}{l}\text { Bueno ahora al ir armando vamos a ver. ¿Y } \\
\text { Alba? }\end{array}$ & Invita a participar \\
\hline 380 & Alba & $\begin{array}{l}\text { Eh... bueno, yo puse lo de... que necesitan } \\
\text { regenerarse constantemente, que primero se } \\
\text { tiene que duplicar el ADN para entrar a la fase } \\
\mathrm{S} \text { y replicarse y después la última parte no la } \\
\text { tenía bien clara lo de cromosoma y cromátidas } \\
\text { hermanas. O sea lo hablamos antes de } \\
\text { escribirlo, (con Vanesa) pero ja, ja. }\end{array}$ & $\begin{array}{l}\text { Hablar sobre lo } \\
\text { escrito }\end{array}$ \\
\hline 381 & $\mathbf{S}$ & ¿Y Cristóbal? & Invita a participar \\
\hline 382 & $\begin{array}{l}\text { Cristóbal } \\
\qquad(\mathrm{Cr})\end{array}$ & $\begin{array}{l}\text { Yo en esta parte..., estaba viendo la parte de } \\
\text { cromátides. Yo había puesto algo así. Puse: } \\
\text { que desde la culminación de la fase S hasta que } \\
\text { se segregan en la mitosis los ADN hijos } \\
\text { mientras están unidos se llaman cromátides } \\
\text { hermanas que pasan a llamarse después } \\
\text { cromosomas después de la separación. }\end{array}$ & $\begin{array}{l}\text { Hablar sobre lo } \\
\text { escrito }\end{array}$ \\
\hline 383 & $\mathbf{S}$ & ¿Eso fue lo que escribiste o lo que dice el libro? & $\begin{array}{l}\text { Actúa sobre } \\
\text { quehaceres de } \\
\text { escritor }\end{array}$ \\
\hline
\end{tabular}




\begin{tabular}{|c|c|l|c|}
\hline 384 & $\mathrm{Cr}$ & $\begin{array}{l}\text { No. Taché y puse 1, 2, 3, 4... (leyendo y } \\
\text { marcando en el libro) }\end{array}$ & $\begin{array}{c}\text { Hablar sobre lo } \\
\text { escrito }\end{array}$ \\
\hline 385 & $\mathbf{S}$ & ¿Cómo fue eso? & $\begin{array}{c}\text { Actúa sobre } \\
\text { quehaceres de } \\
\text { escritor }\end{array}$ \\
\hline 386 & $\mathrm{Cr}$ & Puse 1...(Apenas audible) & $\begin{array}{c}\text { Hablar sobre lo } \\
\text { escrito }\end{array}$ \\
\hline 387 & $\mathbf{S}$ & ¿Vos lo copiaste de acá? & $\begin{array}{c}\text { Actúa sobre } \\
\text { quehaceres de } \\
\text { escritor }\end{array}$ \\
\hline 388 & $\mathrm{Cr}$ & No, no... & $\begin{array}{c}\text { Hablar sobre lo } \\
\text { escrito }\end{array}$ \\
\hline
\end{tabular}

El plenario comenzó con la invitación de la docente S a participar realizada en [373] a la que respondieron Oscar y Brenda [374 y 375]. Oscar describió las relaciones planteadas en su texto refiriendo a ADN, cromosomas y cromátides. A su vez, Brenda describió su escrito mencionando que en la etapa $S$ el ADN estaba compactado, cuestión errónea que corrigió al iniciar el plenario durante la clase siguiente. En esta instancia la docente no sugirió nada al respecto. Yanina también respondió espontáneamente, planteando que había escrito algo similar, sin embargo en su texto ella no incluyó referencia a compactación.

La docente amplió su invitación a los demás alumnos (Vanesa, Alba y Cristóbal) al decir en [377] ¿Por acá? Fue Vanesa quien respondió afirmando "No, yo... no puse eso." [378] y describió qué había puesto y en qué se diferenciaba su escrito de los textos de Brenda y Oscar al decir, "(...) Y ahí, eso del cromosoma ahí... yo no puse nada más. Puse que los cromosomas en la etapa de la mitosis, se pueden... que en la etapa de la mitosis es cuando se empiezan a condensar." Es decir, Vanesa comentó que su texto incluía a los cromosomas asociados a mitosis y tal como ella mencionó, ésa era una diferencia con lo que Oscar y Brenda habían dicho de sus escritos, en los que habían relacionado cromosoma con cromátides. Vanesa continuó diciendo que en su texto la mitosis fue "Como una etapa de condensación. Pero no puse que era el resultado... que era el cromosoma ... que las "cromátides hermanas llamadas también cromosomas" [en referencia a lo dicho por Oscar] son las que ingresan en la mitosis. Eso no puse." [378]. Es así que ella mencionó en su texto la mitosis pero no estableció relación entre esa etapa y las cromátides. Y confirmó que seguía pensando en ello al decir que incluyó los términos mencionados "como separados".

La docente preguntó directamente a Alba “¿Y vos?” en [379]; Alba, comenzó dudando para después referir "(...) que primero se tiene que duplicar el ADN para entrar a la fase 
S y replicarse..." En esta parte Alba se expresó como si considerara que duplicación de ADN y replicación fueran eventos diferentes. Quizás no se estaba refiriendo a la replicación sino a la reproducción celular pero no parecía tenerlo claro. En la última parte de su intervención afirmó que lo que no tenía claro era "lo de cromosoma y cromátidas hermanas" [380].

Por último, S preguntó a Cristóbal, quien hizo mención a las cromátides y al referir lo que puso, leyó unas frases del capítulo del libro que tenía sobre su mesa. La docente en [383] le preguntó directamente si eso fue lo que escribió, o lo que decía el libro. Cristóbal intentó explicar cómo había armado su texto, al decir en [384] "Taché y puse $1,2,3,4 \ldots$, era probable que estuviera refiriendo al orden que había dado a diferentes frases de la primera parte del capítulo mencionado, tal como se podría interpretar a partir del escrito que efectivamente entregó. Sin embargo, ante la intervención de S en [387], quien le preguntó si lo había copiado del libro, Cristóbal negó haberlo hecho.

Nos interesa mostrar aquí cómo esta tarea planteó un desafío a los estudiantes. A partir de explicitar aquello que reconocían en sus producciones, contrastaron y refirieron si habían escrito algo similar o no. Sin embargo, para Alba y Cristóbal el desafío que proponía la tarea quizás no resultó abordable y por eso no la encararon. Al ser entrevistada Alba mencionó que no entregó su texto, que intentó escribirlo pero no pudo relacionar los conceptos pedidos y finalmente decidió guardarlo. Cristóbal por su parte no encaró la tarea autónomamente sino que copió literalmente el discurso del libro, tal vez porque sintió que no sabía aquello que solicitaba la tarea y entonces realizar un escrito para entregar a la docente implicaba exponerse. En la entrevista final Cristóbal fue el único estudiante que afirmó que no le gustó la situación de enseñanza analizada en este capítulo. Es posible que la tensión generada al sentirse expuesto ante sus pares por haber copiado del libro influyera en su recuerdo. En ambos casos podemos pensar que resistieron enfrentarse con ese medio antagonista que generó la docente y asumir qué no sabían y qué tenían que revisar.

En este grupo Brenda y Oscar eran las principales voces, quienes siempre intervenían, realizaban las tareas en el tiempo solicitado y sabían del tema, desde la perspectiva de sus compañeros. Yanina participaba de ese grupo y en general asentía o sumaba algún comentario a lo que ellos expresaban. Vanesa durante el año en que se implementó esta secuencia fue tomando un rol cada vez más protagónico, con intervenciones en las que exponía su propia posición, a la vez que encontraba lugar para expresar sus dudas. Tanto en el análisis que presentamos en el capítulo previo como en éste, Vanesa reflexionó a partir de una tarea de escritura; en este caso identificó que no había relacionado cromátides hermanas con cromosoma tal como lo habían hecho sus 
compañeros. También Alba, problematizó "lo de cromosoma y cromátides hermanas" [380], al referir que no lo tenía claro. Planteó así una incerteza acerca de ese contenido; sería la escritura y el hablar acerca de lo escrito la situación que permitió hacer consciente esa incerteza.

El rol que las tareas y las intervenciones adquirieron con relación a la evolución entre la certeza /incerteza (Sensevy, 2014) asociadas al conocimiento en juego será uno de los focos que abordaremos en la discusión de los resultados. En las voces de Vanesa y Alba surgieron algunos indicios de que algunas incertezas acerca de la relación entre cromosoma y cromátides se hicieron conscientes (Tiberghien, Cross, Sensevy, 2014). En esta primera instancia enunciaron de manera general aquello que no pusieron en el texto.

\subsubsection{Leer y revisar lo escrito en plenario}

La clase 5 se inició con algunos intercambios breves acerca de los materiales que había enviado la docente por mail; después de ese inicio la profesora definió la tarea mediante la intervención que ya presentamos en el apartado 5.2. El trabajo con la actividad de revisión en pequeño grupo se desarrolló durante la primera media hora de clase y el plenario se extendió durante algo más de una hora.

La tarea de revisión fue una situación desafiante y novedosa para los estudiantes. En parte fue así porque implicó acceder a diferentes versiones escritas realizadas por pares, a partir de una misma consigna de trabajo, y de esa manera pudieron contrastarlas. También resultó un desafío por la manera dialógica (Dysthe, 1996) con la que se trabajaron esos textos durante el plenario con todo el grupo clase. En las entrevistas realizadas al finalizar la secuencia tanto la docente como algunos estudiantes consideraron que el trabajo con esta actividad fue positivo para aprender. Esa calificación la sostuvieron refiriendo a la forma en que se implementó la tarea, cómo las diferentes voces pudieron interpelar y debatir aquello que se estaba discutiendo. En el cierre de este capítulo retomaremos los aportes en este sentido de la docente y de algunos alumnos entrevistados.

Tal como dijimos, para el análisis nos centraremos sólo en las interacciones sucedidas durante el plenario. En esa instancia se revisaron los escritos y a partir de esa acción se problematizaron algunas nociones como cromosoma. Retomamos la noción de juego didáctico, en este caso para describir cómo cambió la forma de interacción de los alumnos con sus producciones a lo largo de la situación de revisión de escritos. ¿Cómo se jugó esa tarea en el aula? ¿Cuál era el contrato que rigió esa actividad que consistió en revisar en clase escritos propios y de los pares? 
Pondremos en foco el rol que tuvo la docente durante ese juego didáctico, y para ello utilizaremos las categorías de intervención que describimos en el capítulo anterior. En la descripción retomaremos las intervenciones para focalizar en el vínculo entre reticencia y expresión. De acuerdo con Sensevy (2012), la docente debe ser reticente para posibilitar que los estudiantes actúen motu proprio; comprender qué aspectos ella mantiene tácitos y acerca de cuáles elige hablar y cómo maneja esa dualidad nos acerca a entender la acción docente (Sensevy, 2014). En este sentido, Sensevy, Gruson y Forest (2015) sostienen que cada práctica de enseñanza pone en acto la relación entre reticencia y expresión, ese vínculo modela tanto los gestos que realiza la docente, como la interpretación de esos gestos por los estudiantes. Estos autores proponen que entre esas nociones se establece una relación dialéctica en la cual, aunque ambos términos son opuestos, se complementan.

Por ello, en consonancia con nuestras preguntas de investigación, analizamos cómo esa dimensión de las intervenciones docentes actuó en relación con las acciones de los estudiantes. Destacamos cómo la docente volvió reiteradamente a los escritos, permitiendo así visibilizar e incluir la reflexión sobre el contenido disciplinar al que aludían, así como la forma en que ese contenido estaba expresado en cada texto. A la vez, abrió la posibilidad de poner en juego diferentes interpretaciones al habilitar el intercambio entre pares y relacionar con cómo otros lectores leían e interpretaban ese mismo escrito. A través de esas intervenciones devolvió a los estudiantes el problema, regulando sin institucionalizar conocimiento disciplinar prematuramente.

Para organizar la presentación del análisis de datos y los resultados diferenciamos episodios dentro del plenario dado que, aun cuando hubo continuidad en las interacciones, surgieron algunas rupturas. El hecho de constituir episodios nos permitió centrar el análisis de cada uno de ellos en algún aspecto que se fue modificando a lo largo del plenario.

\subsubsection{Plenario. Episodio 1}

De cómo comenzó el juego didáctico: revisar para corregir y quitar el error

En este episodio la participación de los estudiantes estuvo centrada en aquello que había que corregir. Algunos alumnos mencionaron al texto 4 como mejor texto y fue su autora (Brenda), quien se opuso a esa elección indicando cómo modificar aquello que consideraba incorrecto, cambiando un término por otro.

Era posible que la representación que los alumnos tuvieran de esta tarea, que nunca habían abordado y que consistía en revisar lo escrito, sólo remitiera a marcar lo incorrecto. En ese caso de acuerdo al contrato didáctico implícito corregir implicaría 
hacer cambios locales para ajustar el texto. Para dar cuenta de estas primeras acciones incluimos a continuación el fragmento 5.2 .

Fragmento 5.2 .

El texto 4 es el mejor

Clase 5. Plenario: episodio 1 (1-24)

\begin{tabular}{|c|c|c|c|}
\hline \multicolumn{2}{|c|}{ Turno de habla } & \multirow{2}{*}{$\begin{array}{c}\text { Transcripción plenario } \\
\text { Bueno. Ya está ¿Podemos empezar? }\end{array}$} & Análisis interacción \\
\hline 1 & $\mathbf{s}$ & & \multirow{5}{*}{ Invita a participar } \\
\hline 2 & Alumnos & Sí & \\
\hline 3 & $\mathbf{S}$ & $\begin{array}{l}\text { Bueno, a ver chicas [dirigiéndose a Alba, } \\
\text { Vanesa y Abigail]. }\end{array}$ & \\
\hline 4 & Vanesa & ¿Nosotras? & \\
\hline 5 & $\mathbf{s}$ & Sí & \\
\hline 6 & Vanesa & $\begin{array}{l}\text { Bueno, analizando los diferentes textos,.. Ah, } \\
\text { ja, ja [se ríe porque fue muy formal su inicio] } \\
\text { Bueno, nosotros en especial creemos que hay } \\
\text { un texto que... ¿Tenemos que decir el que } \\
\text { coincidimos que es el que mejor respeta la } \\
\text { consigna? }\end{array}$ & $\begin{array}{l}\text { Explicita interpretación } \\
\text { consigna. } \\
\text { Ajuste contrato } \\
\text { didáctico. }\end{array}$ \\
\hline 7 & $\mathbf{S}$ & Digan todo lo que quieran & Invita a participar \\
\hline 8 & Vanesa & Es el texto 4 & Enuncia mejor texto \\
\hline 9 & $\mathbf{S}$ & $\begin{array}{l}\text { Que dice: "Una célula epitelial como toda } \\
\text { célula somática se reproduce por mitosis. } \\
\text { Antes de la reproducción la célula debe } \\
\text { duplicar el ADN y lo hace en la etapa S de } \\
\text { interfase del ciclo celular. Es al finalizar esta } \\
\text { etapa cuando el ADN se halla compactado } \\
\text { formando cromosomas con dos cromátidas } \\
\text { hermanas." [Lee el texto } 4 \text { completo] }\end{array}$ & $\begin{array}{c}\text { Actúa sobre } \\
\text { quehaceres } \\
\text { de lector /escritor: } \\
\text { Vuelve al texto }\end{array}$ \\
\hline 10 & Vanesa & $\begin{array}{l}\text { Sí. Por ejemplo, en el texto } 1 \ldots \text { [Intenta } \\
\text { continuar con otro texto] }\end{array}$ & $\begin{array}{l}\text { Intenta contrastar con } \\
\text { texto } 4\end{array}$ \\
\hline 11 & $\mathbf{S}$ & ¿Todos coinciden? & Invita a participar \\
\hline 12 & Brenda & $\begin{array}{l}\text { Ah, no. Hay una parte que está mal [alumna } \\
\text { autora del texto 4] }\end{array}$ & Señala error (corregir) \\
\hline 13 & Alba & La de interfase. & Señala error (corregir) \\
\hline 14 & Oscar & La parte que está compactada. & Señala error (corregir) \\
\hline 15 & Brenda & La de interfase que está compactada & Señala error (corregir) \\
\hline 16 & Vanesa & Ah, bueno. Al finalizar, puede ser & Acepta el error \\
\hline
\end{tabular}




\begin{tabular}{|c|c|l|c|}
\hline 17 & S & ¿Cuándo empieza a compactarse? & $\begin{array}{c}\text { Actúa sobre } \\
\text { contenido disciplinar } \\
\text { para aclarar }\end{array}$ \\
\hline 18 & Brenda & $\begin{array}{l}\text { Borren compactado y pongan duplicado. } \\
\text { Ustedes no lo vieron pero...[se ríe] }\end{array}$ & $\begin{array}{c}\text { Indica cómo corregir } \\
\text { error }\end{array}$ \\
\hline 19 & Cristóbal & $\begin{array}{l}\text { Ah, ¿compactado también es lo mismo que } \\
\text { condensado? }\end{array}$ & \begin{tabular}{c} 
Consulta vocabulario \\
\hline 20
\end{tabular} \\
\hline 21 & Sí & $\begin{array}{c}\text { Actúa sobre } \\
\text { contenido disciplinar } \\
\text { para aclarar }\end{array}$ \\
\hline 22 & Cristóbal & Sí, sería mejor duplicado & $\begin{array}{c}\text { Reitera cómo corregir } \\
\text { error }\end{array}$ \\
\hline 23 & Vanesa & Está bien & Acepta corrección \\
\hline 24 & Brenda & Sí. Cambiamos eso... & $\begin{array}{c}\text { Indica cómo corregir } \\
\text { error }\end{array}$ \\
\hline
\end{tabular}

El plenario comenzó cuando la docente $S$ dio por finalizado el trabajo en pequeños grupos, al decir: "Bueno. Ya está ¿Podemos empezar?” [1]. Para después indicar a Vanesa, Abigail y Alba, que habían trabajado juntas, "A ver chicas" [3], como manera de invitarlas a participar y compartir lo que habían resuelto dentro del grupo y así dar comienzo a la puesta en común.

Vanesa tomó la voz del grupo, retomó lo que solicitaba la consigna y enunció en [6] "Bueno, analizando los diferentes textos...", pero como la manera de expresarse le pareció muy formal, sonrió y continuó diciendo que para ellas "hay un texto que..." se interrumpió y consultó a la docente si efectivamente lo que tenían que hacer era elegir el texto que "mejor respeta la consigna" [6]. Pero S no afirmó que ésa era la tarea sino que les propuso que dijeran todo lo que quisieran con relación a aquello que habían estado trabajando en el grupo. Esa intervención de S en [7] las invitó a participar al dejar en manos de las alumnas decidir qué enunciar de su trabajo, y así aportó a reconfigurar el contrato acerca de cómo hablar sobre los textos.

Como respuesta a esa intervención docente Vanesa propuso que era el texto 4 el que "mejor respetaba la consigna". S intervino en [9] leyendo ese texto en voz alta, así ella volvió al texto para instalar aquello que decía en el plenario actuando sobre quehaceres de lector. Tal como describimos en el capítulo previo esa acción habitual de la docente $S$ al leer los textos para volver sobre ellos una y otra vez, dio lugar a un comportamiento más reflexivo sobre lo escrito, haciéndolo visible como parte del medio didáctico. A la vez, S no acordó con Vanesa ni la contradijo, no anticipó su posición, se 
mostró reticente en cuanto a si el texto 4 era el que "mejor respetaba la consigna", sólo leyó en voz alta el escrito. Pero cuando la alumna en [10] intentó dar por terminada la cuestión y pasar a lo que habían pensado en el grupo con relación al texto $1, S$ intervino otra vez invitando a participar, al consultar a toda la clase diciendo: ¿Todos coinciden?

Aun cuando ese texto tenía una parte errónea, $S$ no se refirió a ello y decidió regular abriendo a la participación de los demás alumnos. Fue ahí cuando Brenda intervino para mostrar su desacuerdo y gestionó la revisión de su propio escrito. Desde el turno [12] al [24] fueron los alumnos quienes propusieron qué cambiar en el texto 4 y cómo hacerlo. En [12] intervino Brenda, autora del escrito, indicando que no coincidía con Vanesa porque "hay una parte que está mal". Alba acordó con ella e indicó que "la parte" sería la de interfase [13]; Oscar a su vez planteó que lo erróneo era "la parte que está compactada". Brenda actuó como mediadora y retomó ambas contribuciones al decir "La de interfase que está compactada". Aquí Brenda tomó una posición relevante como correctora, en este caso de su propio texto, resumió los aportes de sus compañeros e incluyó a ambos en su intervención en [15].

La intervención de S en [17] dio lugar a lo que afirmaba Brenda, aun cuando no lo hizo de manera explícita. Decimos que la habilitó porque la pregunta que $S$ realizó, otorgó sentido a lo que estaban enunciando como incorrecto, y apuntó a que los estudiantes comprendieran por qué era errónea "la parte de interfase que está compactada" ${ }^{33}$. Fue así que S preguntó a los alumnos, “¿Cuándo empieza a compactarse?” para dar pistas acerca del momento del ciclo celular en que ocurría la compactación del material genético y por ello ésta es una intervención que tuvo la intención de actuar sobre el contenido disciplinar. Sin embargo, pareció pasar desapercibida ya que no hubo continuidad ni se dio respuesta a esta intervención de la docente.

Brenda en [18], casi superponiéndose con la intervención previa de la docente indicó cómo corregir el error y mejorar el texto, al decir "Borren compactado y pongan duplicado." Aunque esos dos conceptos refieren a dos atributos independientes del material genético, el cambio que Brenda propuso funcionaba en su texto y era una manera simple y puntual de indicar cómo transformar su escrito en un texto sin errores. Sin embargo, cuando propuso esa modificación Brenda no explicó cuál era el error ni

\footnotetext{
${ }^{33}$ No era adecuado decir que "Es al finalizar esta etapa [etapa $S$ de interfase] cuando el ADN se halla compactado" porque en ese momento el material genético no se encuentra compactado sino laxo, recién al finalizar toda la interfase (formada por las etapas G1, S y G2) es que comienza a compactarse ese material. Además estrictamente, no es el ADN quien se compacta sino la cromatina, que está formada por ADN asociado a unas proteínas denominadas histonas que intervienen en esa compactación. En este momento de la clase aún no habían hecho referencia a cromatina, por ello S no considera incorrecto hablar de ADN compactado, sólo no es correcta su ubicación temporal.
} 
dio razones de cómo el cambio de términos podía enmendar su escrito, tampoco sus compañeros le consultaron en ese sentido. En ese momento Cristóbal en [19] preguntó si eran equivalentes en significado dos términos (compactado y condensado) que suelen vincularse con cambios conformacionales del material genético durante el ciclo celular y la docente le respondió que sí lo eran. $Y$ así se cerró el episodio referido al texto 4 con un par de breves intervenciones de Vanesa quien aceptó las sugerencias de Brenda.

En cuanto al rol que cada actor asumió con relación al saber en juego, es decir analizando la topogénesis en la interacción (Sensevy, 2007), fue Brenda quien asumió una posición topogenética fuerte y así coordinó la corrección de su escrito. Brenda tenía un rol preponderante en la clase, era una muy buena estudiante, asumió el error de su texto y lo enmendó. Sin embargo, no explicó las razones del cambio sugerido. Seguramente ya había pensado cómo hacerlo durante la revisión en el pequeño grupo, de acuerdo a los comentarios que realizó en voz alta sobre su texto durante el trabajo y que quedaron registrados en la grabación. Así como a los que realizó durante la entrevista en relación con lo ocurrido en esta situación y que compartimos al final de este capítulo.

La reticencia estuvo presente en el accionar de $S$ en todo este primer episodio (Sensevy, 2014): su acción fue abrir, ampliar el tiempo didáctico y eso dio lugar a que fueran los alumnos quienes resolvieran cómo corregir ese texto modificando un único término que lo transformaba en "correcto" desde el saber disciplinar. Así la docente se corrió del centro de la escena y pareció asumir un rol topogenético más débil en este episodio (Sensevy, 2012). Sin embargo, esa reticencia no implicó silencio, la docente respondió a Cristóbal cuestiones puntuales de vocabulario e intentó actuar sobre el contenido a través de su pregunta en [17]. A la vez, extendió el tiempo didáctico de trabajo sobre el texto 4 interviniendo para mantener la atención en el escrito.

\subsubsection{Plenario. Episodio 2}

De cómo jugar el juego, revisar implica releer y analizar el propio texto

En este segundo episodio, que es inmediatamente posterior al previo, los alumnos continuaron hablando acerca de los textos desde una mirada binaria caracterizándolos como correctos o incorrectos. A la vez que comenzaron a analizar partes de esos textos y a mencionar no sólo lo que decía el escrito, sino cómo lo decía. En este caso también fue el autor, Oscar esta vez, quien tomó la voz y reflexionó sobre su texto. 
En el fragmento que incluimos a continuación nos detenemos en aquello que dijeron los alumnos sobre los textos y en cómo actuaron las intervenciones de la docente en este segundo episodio para modificar esa percepción binaria.

Fragmento 5. 3.

El texto 1 no está tan mal

Clase 5. Plenario: episodio 2 (25-49)

\begin{tabular}{|c|c|c|c|}
\hline \multicolumn{2}{|c|}{ Turno de habla } & \multirow{2}{*}{$\begin{array}{l}\text { Transcripción plenario } \\
\text { Por ejemplo, y el texto } 1 \text { no me pareció que } \\
\text { estaba tan mal, bah que estuviera mal. Pero lo } \\
\text { que me queda en duda es al finalizar que dice: } \\
\text { "Dicha célula ingresa a la etapa G2, y luego a } \\
\text { la etapa de Mitosis, donde dichos cromosomas } \\
\text { se separan." }\end{array}$} & \multirow{2}{*}{$\begin{array}{l}\text { Análisis interacción } \\
\text { Es correcto, pero... }\end{array}$} \\
\hline 25 & Vanesa & & \\
\hline 26 & Oscar & Se separarán. & \multirow{2}{*}{$\begin{array}{l}\text { Ajusta qué dice el } \\
\text { texto }\end{array}$} \\
\hline 27 & Vanesa & Ah, se separarán & \\
\hline 28 & Oscar & $\begin{array}{l}\text { O sea, dicha célula...Ésta la escribí yo y estaba } \\
\text { autocriticándome totalmente. Porque G } 2 . . . \\
\text { entra a la etapa } \mathrm{G} 2 \text {, yo puse como un bólido, } \\
\text { como un bólido entra y sale; y después... }\end{array}$ & Critica su texto \\
\hline 29 & $\mathbf{s}$ & $\begin{array}{l}\text { Bueno, pero dice "dicha célula ingresa a la } \\
\text { etapa G2 y luego a la etapa de Mitosis" ¿Vos } \\
\text { estás en contra de vos mismo? }\end{array}$ & $\begin{array}{c}\text { Actúa sobre } \\
\text { quehacer de lector } \\
\text { y escritor: } \\
\text { Vuelve al texto }\end{array}$ \\
\hline 30 & Oscar & $\begin{array}{l}\text { No. Es correcto [enfatiza]. Eso lo tiene que } \\
\text { hacer [la célula]. }\end{array}$ & Es correcto, pero... \\
\hline 31 & $\mathbf{S}$ & Ah! [asiente con lo dicho por Oscar] & Acuerda \\
\hline 32 & Oscar & $\begin{array}{l}\text { Pero me da la impresión que tendría que ser un } \\
\text { poco más específico, un poco más... }\end{array}$ & Es correcto, pero... \\
\hline 33 & Yanina & $\begin{array}{l}\text { Para mí es el más correcto, el tuyo. Es el más } \\
\text { completo.[dirigiéndose a Oscar] }\end{array}$ & Mejor texto \\
\hline 34 & Brenda & $\begin{array}{l}\text { Bah, yo por lo que entiendo es el que tiene } \\
\text { todos los datos bien. }\end{array}$ & Mejor texto \\
\hline 35 & Oscar & $\begin{array}{l}\text { No, porque sigue una secuencia lineal, por eso } \\
\text { parece el más correcto. Pero el más correcto } \\
\text { para mí es el } 4 \text {. }\end{array}$ & Es correcto, pero... \\
\hline 36 & $\mathbf{S}$ & Bueno, a ver... & Reticente \\
\hline
\end{tabular}




\begin{tabular}{|c|c|c|c|}
\hline 37 & Camilo & $\begin{array}{l}\text { ¿Es lo mismo decir que ingresa a la etapa, que } \\
\text { comienza la etapa? }\end{array}$ & Consulta vocabulario \\
\hline 38 & $\mathbf{S}$ & Sí & $\begin{array}{l}\text { Actúa sobre el } \\
\text { contenido }\end{array}$ \\
\hline 39 & Oscar & Sí, obvio. & Acuerda \\
\hline 40 & Vanesa & $\begin{array}{l}\text { En realidad, a mí me parece que eso "dicha } \\
\text { célula ingresa" lo hubiese puesto antes. Porque } \\
\text { a mí me parece, yo les decía a las chicas, me } \\
\text { parece que cuando empezó... al finalizar esa } \\
\text { etapa S.... }\end{array}$ & $\begin{array}{l}\text { Vuelve al texto, } \\
\text { analiza y contrasta } \\
\text { forma del escrito }\end{array}$ \\
\hline 41 & Oscar & Pero (inaudible) & \\
\hline 42 & Vanesa & Sí, sí & \\
\hline 43 & Oscar & Está correcto... & \\
\hline 44 & s & $\begin{array}{l}\text { Pero el ciclo celular es una secuencia lineal } \\
\text { (enfatizando). Así lo fuimos dibujando en el } \\
\text { pizarrón, si es por eso... }\end{array}$ & $\begin{array}{l}\text { Actúa sobre el } \\
\text { contenido }\end{array}$ \\
\hline 45 & Oscar & Claro & Acuerda \\
\hline 46 & $\mathbf{S}$ & $\begin{array}{l}\text { [Lee texto 1] "Al finalizar la etapa S de interfase, } \\
\text { la célula epitelial ha logrado duplicar su ADN". } \\
\text { Me salteo la otra parte, [Continúa] "Dicha célula } \\
\text { ingresa a la etapa G2," que viene después de S } \\
\text { "y luego a la etapa de Mitosis." Si es por las } \\
\text { etapas del ciclo... }\end{array}$ & $\begin{array}{l}\text { Actúa sobre } \\
\text { quehaceres de } \\
\text { lector lescritor: } \\
\text { Vuelve al texto }\end{array}$ \\
\hline 47 & Vanesa & Está bien & Acuerda \\
\hline 48 & Oscar & $\begin{array}{l}\text { Está bien. } \mathrm{Y} \text { en mitosis es donde se separan } \\
\text { [los cromosomas]. }\end{array}$ & Acuerda \\
\hline 49 & $\mathbf{S}$ & Bueno & Acuerda \\
\hline
\end{tabular}

Este segundo fragmento del plenario se inició con el comentario que hizo Vanesa sobre otro de los textos de la actividad, el que habíamos ubicado en primer lugar y denominamos texto 1. Vanesa en [25] consideró que no estaba tan mal para después afirmar que no estaba mal. Planteó su duda vinculada a lo que sucedía en la etapa final del ciclo celular (y que se mencionaba en la última frase del texto) en relación con los cromosomas. Era justamente en esa parte del escrito que se planteaba un problema acerca de cuándo una estructura sería considerada un cromosoma. 
Oscar en [28] comentó cuál fue su impresión al releer su texto y afirmó que "estaba autocriticándome totalmente." Y titubeando explicó qué aspecto de su texto no le cerraba cuando refirió a cómo había mencionado la etapa G2 "como un bólido entra y sale". No identificó el problema acerca de cómo estaba utilizando el término cromosoma sino que en esa vuelta al texto, Oscar cuestionó algunos aspectos de forma. Había mencionado una etapa pero sólo dijo que la célula "entra y sale" de la etapa G2, en el escrito no incluyó ninguna referencia acerca de qué sucedía en esa etapa. Es decir, Oscar fue crítico con su texto pero no en aquello que $S$ hubiera querido profundizar.

Aquí consideramos que fueron cruciales las intervenciones de la docente, quien no expresó en ningún momento de la secuencia de interacción que presentamos como fragmento 5.3, cuál era el problema que se les presentaba a los alumnos con ese texto, ni por qué mantuvo la atención en él durante un tiempo extenso. Fue reticente, pero a la vez obligó a los estudiantes a seguir analizando ese escrito. Aquí fue ella quien desde una mirada topogenética asumió una posición relevante con relación al conocimiento en juego, al sostener la interacción alrededor del escrito.

Así en [29] S volvió al texto al releer: "pero dice: dicha célula ingresa a la etapa G2 y luego a la etapa de Mitosis" consultando a Oscar, en tanto autor, si esa frase era parte de lo que criticaba. Oscar respondió que no, que eso "es correcto" pero que "debería haber sido más específico". El estudiante pareció referir que al nombrar una etapa debería haber incluido en su escrito algo particular acerca de lo que sucedía en ella y que no le parecía adecuado sólo mencionarla.

Aquí intervinieron Yanina y Brenda adjetivando el texto, según Yanina era "el más correcto", "el más completo" y Brenda consideró que desde su punto de vista era "el que tiene todos los datos bien." Oscar en [35] se opuso a las afirmaciones de las compañeras y argumentó que su escrito les parecía el mejor "porque sigue una secuencia lineal". De esa manera, dio razones que vinculaban esa percepción de las alumnas a la estructura de su texto que refería en forma secuencial a las etapas S, G2 y mitosis, que se suceden en ese orden; y finalizó su intervención afirmando que "el más correcto para mí es el 4". Cuatro de los alumnos que intervinieron en el plenario (Vanesa, Oscar, Brenda, Yanina) asignaron calificativos de tipo binario a los textos: el mejor texto, está bien, no está mal, tiene todos los datos bien, el más completo, está correcto, el más correcto. Nos preguntamos aquí ¿qué aspectos del contrato didáctico establecido permitirían explicar el consenso acerca del sentido y la forma de desarrollar la actividad? ¿Elegir el mejor texto implicaría contrastar con él a los demás? 
Sin embargo, fueron las intervenciones de $S$ las que reorientaron el sentido de la actividad, estableciendo nuevo contrato e incitando a volver una y otra vez al texto para detenerse en él. En [36] S sólo dijo, “bueno, a ver”, pero no anunció su propia postura, no convalidó lo que Brenda y Yanina afirmaron, tampoco las contradijo, sino que mantuvo la expectativa sobre el texto 1. Permaneció en silencio sobre ciertos aspectos del problema en cuestión al no dilucidar cuál era la dificultad en ese texto 1.

Pero respondió concretamente a la consulta que Camilo realizó en [37], “¿Es lo mismo decir que ingresa a la etapa, que comienza la etapa?". La consulta de Camilo apuntaba a ajustar qué sería válido en el contexto referido, y funcionó como manera de convalidar los sentidos y usos equivalentes que ingresar y comenzar tienen en otros contextos. Fue así que S permaneció reticente acerca de cuál era el problema en el texto en cuestión, pero se expresó cuando las preguntas apuntaban a otros aspectos.

Aquí nos interesa explicitar esa dualidad entre reticencia y expresión. Era necesario que la docente se expresara en aquello que no constituía el nudo conceptual con el que estaba trabajando, para poder mantener la reticencia en cuanto a la relación entre cromátides y cromosoma y que fueran los estudiantes quienes la construyeran de motu proprio (Sensevy, Gruson y Forest, 2015).

En [40] Vanesa volvió a retomar la última parte del texto 1 e intentó explicar aquello con lo que no coincidía, diciendo que ella hubiera mencionado antes "dicha célula ingresa [a la etapa G2]". Oscar intervino pero no parecieron avanzar en el sentido de resolver el problema en cuestión. Fue así que S en [44] buscó explicitar lo ya consensuado, actuando sobre el contenido y para ello expresó un aspecto del ciclo celular sobre el que ya se había trabajado y consideraba que había sido acordado. Así, sostuvo: "Pero el ciclo celular es una secuencia lineal", incluso su afirmación fue enfática en tono y gesto. A la vez, recurrió a elementos del contrato didáctico para sostener su afirmación, al decir "Así lo fuimos dibujando en el pizarrón".

El contrato puede ser visto como un auxiliar del medio didáctico, cuando se alude a él para orientar la indagación de los estudiantes en ese medio (Sensevy, Gruson, Forest, 2015). En este caso, la noción de ciclo celular como secuencia lineal de etapas formaba parte del conocimiento común, ese bagaje que se había expresado tanto en el discurso como en las imágenes que habían utilizado las clases previas para representar al ciclo celular como secuencia lineal de eventos, y que por ello en esta instancia podía ser considerado parte del contrato.

Los textos a revisar, en tanto componentes del medio didáctico, se constituyeron en problemas a resolver por parte de los estudiantes que debían darse cuenta de aquello 
que no sabían y eso requirió que construyeran evidencia que les permitiera, "encontrar su ignorancia, a través de la resistencia del medio" (Sensevy, 2012: 510). Para acotar cuál era el problema en ese momento la docente $S$ en [46] volvió nuevamente al texto, buscando ajustar el acuerdo acerca de lo que expresaba el escrito sobre las etapas del ciclo celular. En esa intervención la docente leyó el texto extrayendo las referencias a la etapa $\mathrm{S}, \mathrm{G}_{2}$ y mitosis y concluyó "si es por las etapas del ciclo..." Vanesa terminó la frase en el turno siguiente diciendo "está bien", y Oscar acordó. La docente cerró esta referencia al orden de las etapas asintiendo, pero sin dar cuenta de cuál era el problema del texto 1.

Ahora bien, la primera relación que establecieron los alumnos con las producciones fue para modificar lo escrito por algo "mejor", de acuerdo a la representación que tenían de la tarea y la interpretación de las orientaciones iniciales dadas por la docente. En este momento del plenario Oscar cuestionó cómo había expresado en su texto las etapas del ciclo celular. La clasificación del texto 1 sólo como correcto/incorrecto comenzó a ser interpelada, tal como surgió a partir de las sucesivas intervenciones de Oscar que describimos en este episodio. Consideramos que la acción reticente de la docente y la decisión de ampliación del tiempo didáctico para trabajar con este texto contribuyeron en ese sentido.

\subsubsection{Plenario. Episodio 3.}

De cómo jugar el juego: revisar implica releer, interpretar y argumentar

En este breve episodio del plenario Abigail presentó una voz disidente acerca de lo que se había acordado con relación al texto 1 y aportó argumentos para sostener la interpretación que realizó a partir de lo implícito en el texto. También mostramos aquí cómo la docente $S$ se mantuvo reticente, pero a la vez habilitó el intercambio al dar lugar a lo expresado por Abigail, sin avalar ni contradecir lo dicho, pero ampliando el tiempo didáctico para permitir que los estudiantes cayeran en la cuenta de cuál era el problema que tenía el texto 1 respecto de la noción de cromosoma. ${ }^{34}$

\footnotetext{
${ }^{34}$ El problema del texto 1 estaba en la última parte de la oración final de ese escrito, que decía "Dicha célula ingresa a la etapa G2, y luego a la etapa de Mitosis donde dichos cromosomas se separaran." Esta última expresión que marcamos en negrita no es correcta porque durante la mitosis no se separan los cromosomas, sino que se separan las cromátides hermanas de cada cromosoma, que son idénticas y se distribuyen en las células hijas. En esa instancia ya cada cromátide constituye un cromosoma, por eso se presta a confusión la noción de "cromosoma" como una estructura cambiante, con dos cromátides o con una cromátide.

Era importante insistir en la relación entre cromátides y cromosoma para comprender que las células que se originan por mitosis (como ocurre con las células del cuerpo) tienen la misma información genética, justamente porque se separan las cromátides hermanas en la división celular que las origina. Además, en el otro tipo de división celular (meiosis) que fue el tema que estudiaron en la secuencia siguiente, ocurre la separación de cromosomas, quedando células hijas con la mitad del número de cromosomas y eso es
} 


\section{Fragmento 5.4}

¿Cuál es el problema del texto 1? Los alumnos hablan acerca de lo que dice

Clase 5. Plenario: episodio 3 (50-58)

\begin{tabular}{|c|c|c|c|}
\hline \multicolumn{2}{|c|}{ Turno de habla } & Transcripción plenario & Análisis interacción \\
\hline 50 & Abigail & $\begin{array}{l}\text { Y en cuanto a los cromosomas ¿ahí ya están } \\
\text { bien compactados? }\end{array}$ & Plantea pregunta \\
\hline 51 & $\mathbf{S}$ & A ver, ¿Qué es lo que querés decir ahí? & $\begin{array}{c}\text { Invita a participar para } \\
\text { expandir }\end{array}$ \\
\hline 52 & Abigail & $\begin{array}{l}\text { Yo creo que en la mitosis [los cromosomas] } \\
\text { recién están bien compactados. Como que en } \\
\text { la G2 se termina de compactar. }\end{array}$ & Da razones \\
\hline 53 & Oscar & Yo no hablé de compactación [autor del texto 1]. & \\
\hline 54 & Brenda & No, no. & \\
\hline 55 & Yanina & Claro, no. No dice. & argumento a partir de lo \\
\hline 56 & Oscar & No dije en ningún momento & \\
\hline 57 & Brenda & Claro, el que habla de compactación es el 4. & \\
\hline 58 & Abigail & $\begin{array}{l}\text { Pero dice, "formados por dos cromátides } \\
\text { hermanas llamadas cromosomas, unidas por el } \\
\text { centrómero." Y cuando están unidos por el } \\
\text { centrómero es cuando más compactados están } \\
\text { [los cromosomas]. }\end{array}$ & $\begin{array}{l}\text { Vuelve al texto } \\
\text { Da razones }\end{array}$ \\
\hline
\end{tabular}

Este fragmento comenzó en [50] cuando Abigail hizo su primera intervención en el plenario y puso la atención en los cromosomas, noción acerca de la que todavía no se había discutido y que era justamente aquello que había que analizar y modificar en el texto 1. Planteó su consulta como pregunta: "Y en cuanto a los cromosomas ¿ahí ya están bien compactados?", en referencia a cómo era el grado de compactación de los cromosomas en las distintas etapas del ciclo celular, en particular en la etapa G2.

En ese momento, en [51] S realizó la única intervención en este fragmento, se dirigió a Abigail y la invitó a participar para expandir lo que había expresado a través de su pregunta, al decir: "A ver, ¿qué querés decir?”. Esta acción docente dio lugar a una serie de intercambios entre los alumnos desde [52] a [58], acerca de cómo estaban referidos los cromosomas en el texto. $S$ habilitó con esa acción a Abigail al solicitarle mayor precisión, quizás intuyó que la alumna podría expresar el problema del texto 1 con relación a los cromosomas.

relevante para entender cómo se forman las células sexuales. Suele ser habitual que los estudiantes confundan ambos tipos de divisiones celulares. 
En [52] Abigail presentó su punto de vista acerca de cuándo los cromosomas estarían bien compactados y en su intervención planteó que esas estructuras se modifican durante las etapas: en mitosis estarán bien compactados, pero en la etapa previa G2 todavía no lo estarían. Ése fue un aspecto interesante que introdujo Abigail, al expresar cómo los cromosomas podían cambiar durante el ciclo celular y así dio lugar a una mirada menos estática acerca de ellos. Esa noción de cómo se iba modificando la estructura de los cromosomas en las diferentes etapas del ciclo celular se puso en discusión durante el plenario y fue en este episodio 3 que se planteó desde la voz de una alumna. Aun cuando para todos los estudiantes estuviera claro que había diferencias en el material genético durante las etapas del ciclo, la noción de cromosoma parecía ser estática, como una foto de una estructura compuesta por dos cromátides (dos palitos en forma de cruz, tal como plantearon oralmente en una de las clases), sólo visible al microscopio durante la división celular.

Oscar, el autor del texto, así como Brenda y Yanina que trabajaron con él en el mismo grupo, en los turnos [53] a [57] sostuvieron que el texto 1 no hablaba de compactación de los cromosomas y eso estrictamente era así. El escrito no refería al grado de condensación de manera explícita. Brenda en [57], expresó que era el texto 4 (su texto) el que mencionaba compactación. Recordemos que en ese texto 4 el término compactado fue aquél que Brenda sugirió cambiar por otro (duplicado) que no aludía a esa misma propiedad sino a otra diferente. $Y$ tal como analizamos en el episodio 1 la docente intentó en ese momento llamarles la atención sobre el punto, al preguntarles ¿Cuándo empieza a compactarse? [17].

En [58] fue Abigail quien volvió al texto, para leer aquello que el escrito decía y se detuvo en la mención al centrómero de los cromosomas asociándolo con el grado de compactación. Esa mención se transformó en parte de su argumento para contrastar con lo que afirmaban sus pares. Pero ese rol que asumió Abigail en este episodio, requirió de la reticencia de $\mathrm{S}$. Hemos seleccionado este breve fragmento que abre y cierra Abigail porque permitió empezar a definir el problema del texto 1 que también se analizará en los siguientes episodios.

Coincidimos con Sensevy (2014) en que se puede fomentar el pasaje desde una incerteza epistémica a una certeza reflexiva y racional a través de juegos argumentativos del lenguaje. En el intercambio que se inició con este episodio algunos alumnos dieron cuenta de la dualidad certeza/incerteza. Abigail comenzó preguntando acerca de la compactación de los cromosomas, pero en sus otras dos intervenciones argumentó acerca de aquellas certezas que asumió (cromosomas compactados en mitosis, presencia del centrómero en el estado de mayor compactación). A través de 
esas tres intervenciones que hizo la alumna quedó de manifiesto el rol topogenético que asumió, fue ella quien preguntó y argumentó respecto del conocimiento que se estaba poniendo en juego. Esa asunción, tal como hemos dicho, requirió como contraparte de la reticencia de la docente, que a su vez asumió una posición topogenética más débil en ese momento (Sensevy, 2010). Esa relación se modificó en el episodio siguiente.

\subsubsection{Plenario. Episodio 4}

De cómo jugar el juego: regular implica reticencia y expresión docente

Analizamos en este episodio 4 cómo se manifestó la dualidad entre reticencia y expresión in situ durante la acción didáctica; al interpretar lo que la docente eligió decir (y por lo tanto mostrar) y aquello que mantuvo tácito (y ocultó) mientras fue descifrando el comportamiento de los estudiantes en este particular proceso semiótico (Sensevy, Gruson y Forest, 2015).

En este momento del plenario la docente retomó el texto 1 dando continuidad al intercambio acerca de los cromosomas y enfocando en aquello que era erróneo en ese escrito. A través de sus intervenciones ofreció pistas para que los alumnos pudieran configurar un problema que no estaban viendo aun. Así reguló la acción de los estudiantes al volver al texto para ajustar las referencias a cromosomas y cromátides y explicitar que iba a centrarse en esa relación y en cómo la presentaba ese texto 1.

Fragmento 5.5

¿Cuál es el problema del texto 1? Acción docente: reticencia y expresión Clase 5. Plenario: episodio 4 (59-79)

\begin{tabular}{|l|c|l|c|}
\hline \multicolumn{2}{|c|}{ Turno de habla } & \multicolumn{1}{|c|}{ Transcripción plenario } & Análisis interacción \\
\hline 59 & S & $\begin{array}{l}\text { A ver, yo leo ahora. Ya quedamos que en } \\
\text { toda la parte de ciclo, la secuencia lineal del } \\
\text { ciclo, todos coincidían. Ahora voy a leer } \\
\text { poniendo énfasis en lo de cromátidas y } \\
\text { cromosoma, "Al finalizar la etapa S de } \\
\text { interfase, la célula epitelial ha logrado } \\
\text { duplicar su ADN quedando formadas dos } \\
\text { cromátides hermanas Ilamadas } \\
\text { cromosomas, unidas por el centrómero. } \\
\text { Dicha célula ingresa a la etapa G2, y luego } \\
\text { a la etapa de Mitosis, donde dichos } \\
\text { cromosomas se separaran." iCoinciden? }\end{array}$ & $\begin{array}{r}\text { Actúa sobre } \\
\text { quehaceres de lector: } \\
\text { Vue al texto }\end{array}$ \\
\hline 60 & Brenda a participar \\
\hline 61 & Vanesa & Sí. & Aí, yo coincido. \\
\hline 62 & Cristóbal & Sí. & Acuerdan lo que dice el texto \\
\hline
\end{tabular}




\begin{tabular}{|c|c|c|c|}
\hline 63 & Brenda & $\begin{array}{l}\text { Después de la explicación de que el } \\
\text { cromosoma es también en estado laxo, sí } \\
\text { [coincido] }\end{array}$ & \\
\hline 64 & Noelia & Claro & \\
\hline 65 & Oscar & Lo que hay es... & \\
\hline 66 & $\mathbf{S}$ & $\begin{array}{l}\text { A ver... [Relee parte del texto] “Dos } \\
\text { cromátides hermanas llamadas } \\
\text { cromosomas”. ¿Las dos cromátides se } \\
\text { llaman cromosomas? }\end{array}$ & $\begin{array}{l}\text { Vuelve al texto } \\
\text { Actúa sobre el contenido }\end{array}$ \\
\hline 67 & Oscar & $\begin{array}{l}\text { No. Cada cromátide hermana es un } \\
\text { cromosoma }\end{array}$ & \multirow{8}{*}{$\begin{array}{c}\text { Actúan } \\
\text { sobre el contenido } \\
\text { para ajustar la relación } \\
\text { entre cromosoma y } \\
\text { cromátidas hermanas }\end{array}$} \\
\hline 68 & S & Cada cromátide llamada cromosoma... & \\
\hline 69 & Vanesa & Claro & \\
\hline 70 & Oscar & Cada cromátide es un cromosoma. & \\
\hline 71 & Vanesa & Ahí está claro. & \\
\hline 72 & $\mathbf{S}$ & Ahí está el tema. Ahí está el tema. & \\
\hline 73 & Brenda & Es cierto. & \\
\hline 74 & Oscar & $\begin{array}{l}\text { Dos cromátides hermanas llamadas } \\
\text { cromosoma cada una. }\end{array}$ & \\
\hline 75 & $\mathbf{S}$ & ¿Un cromosoma cómo está formado? & Actúa sobre el contenido \\
\hline 78 & Brenda & $\begin{array}{l}\text { Un cromosoma puede tener una cromátide } \\
\text { o dos cromátides. }\end{array}$ & $\begin{array}{l}\text { Responde sobre el } \\
\text { contenido }\end{array}$ \\
\hline 79 & $\mathbf{S}$ & $\begin{array}{l}\text { Esto es lo que nos había faltado la vez } \\
\text { pasada. ¿Se acuerdan del esquemita que } \\
\text { había hecho yo la vez pasada? }\end{array}$ & $\begin{array}{l}\text { Actúa sobre el contenido } \\
\text { Retoma y fija contrato }\end{array}$ \\
\hline
\end{tabular}

Este fragmento se inició en [59] con la nueva vuelta de $S$ al texto 1, para releer sólo aquello sobre lo que faltaba consensuar, y así ponerlo en discusión. La docente concentró la atención en esa porción acotada del escrito, de esa manera actuó sobre quehaceres de lector y escritor poniendo en foco qué decía el texto y cómo lo hacía. Finalizó su intervención preguntando a los alumnos si coincidían con lo que enunciaba el texto, así los invitó a participar y tomar posición en relación con lo que había leído. De esa manera, puso en tensión aquello sobre lo que había voces discordantes y promovió la atención de los alumnos en la parte del escrito donde estaba el problema del texto 1 , tal como analizamos en el episodio 3. 
En las líneas [60] a [65] varios estudiantes (Brenda, Vanesa, Cristóbal y Noelia) respondieron a la consulta de S, acordando con lo escrito por Oscar. Esta nueva vuelta al texto hizo visible para la profesora que el problema del texto 1 no era evidente para los estudiantes dado que dijeron coincidir con lo que enunciaba.

La docente en [66] aún se mostró reticente y no anticipó cuál era el error de ese texto, pero cambió de estrategia e invitó a los estudiantes a seguir participando del juego. Así lo hizo, dio nuevas pistas y orientó a través del medio didáctico al releer en esa intervención un fragmento bien acotado del texto: "Dos cromátides hermanas Ilamadas cromosomas" y actuó sobre el contenido al plantear la pregunta concreta "¿Las dos cromátides se llaman cromosomas?" que dio lugar a la respuesta negativa de Oscar en [67], quien a su vez modificó ligeramente la frase al decir: "Cada cromátide hermana es un cromosoma"; pero aun así esa frase no era correcta. La docente pareció releer nuevamente del texto "Cada cromátide llamada cromosoma" agregando el cada al término cromátide, tal como Oscar había enunciado en [67]. En [70] y [74] Oscar volvió a afirmar su frase inicial, al decir "Cada cromátide es un cromosoma" y corregir esa frase en una nueva versión diciendo "Dos cromátides hermanas llamadas cromosoma cada una". Vanesa y Brenda en [69], [71] y [73] acordaron con lo que Oscar finalmente planteó en esa frase.

A pesar de las sucesivas modificaciones de la frase original el problema del texto 1 persistió, pero fue a partir de la precisión que Oscar le dio al vínculo entre cromátide y cromosoma, al decir que cada cromátide es un cromosoma, que la docente pudo entender mejor qué era lo que sucedía con ese texto. $Y$ sería por ello que en [72] $S$ afirmó, "Ahí está el tema". Aun así, se mantuvo reticente en sus intervenciones, y no anticipó qué no la convencía respecto de cómo estaba expresado ese vínculo.

Ante la relación de equivalencia entre cromátide y cromosoma que Oscar enunció, la docente intervino con una pregunta intentando orientar y que los alumnos pudieran darse cuenta de cuál era el problema del texto 1. Así actuó sobre el contenido cuando les preguntó: “ ¿Un cromosoma cómo está formado?”. A esta pregunta respondió Brenda en [78] "Un cromosoma puede tener una cromátide o dos cromátides." Cuestión que iba justo a aquello que era necesario que se aclarara para hacer más preciso y riguroso el vínculo entre cromosoma y cromátides.

Aunque la respuesta que dio Brenda era correcta, S no cerró la cuestión sino que la usó para abrir una secuencia de intervenciones al decir en [79]: "Esto es lo que nos había faltado la vez pasada. ¿Se acuerdan del esquemita que había hecho yo la vez pasada?” mientras iba dibujando en el pizarrón células en diferentes momentos del ciclo celular. 
En estas células fue mostrando cuándo sus cromosomas tenían una cromátide y cuándo dos, tal como Brenda había expresado en su intervención [78].

En este episodio se fue modificando el rol que asumió la docente en relación con el conocimiento respecto a los cromosomas y sus cromátides. A partir de una posición topogenética más débil, tal como describimos en el apartado previo, la docente fue asumiendo una posición topogenética más fuerte al regular e intervenir acotando aquello sobre lo que se discutía en este tramo del plenario (Sensevy, 2010).

Para comprender la acción de S en este episodio transcribimos una cita de Sensevy, Gruson y Forest (2015) en la que refieren al rol docente durante el juego didáctico. Estos autores sostienen que:

La docente no puede realizar los movimientos ganadores (no puede aprender) en lugar de sus alumnos. Todo lo que ella puede hacer es jugar de una manera indirecta, de forma tal de permitir al estudiante, aprender. En este sentido, los alumnos tienen que establecer una relación de primera mano con aquella parte del conocimiento en juego. (Sensevy, Gruson y Forest, 2015:389).

Fue así que $S$ no jugó en lugar de sus alumnos, no tomó la respuesta que Brenda dio en [78] como parte de un nuevo contrato acordado por todos los estudiantes, sino que amplió el tiempo didáctico para que todos pudieran comprender cuál era el problema del texto 1, e incluyó otras maneras de intervenir tal como describiremos en el episodio próximo.

\subsubsection{Plenario. Episodio 5}

De cómo jugar el juego: regular también es explicar para comprender

Este episodio se centró en la explicación docente. De manera implícita la revisión del texto 1 estuvo presente durante esta instancia del plenario, porque fue a partir de esa tarea de revisión que la docente pudo identificar el problema del texto 1 y cuáles eran las relaciones conceptuales que tenía que trabajar en la explicación para poder avanzar en el desarrollo de la secuencia didáctica.

Cuando S representó con esquemas en el pizarrón las modificaciones que sufrían los cromosomas a lo largo del ciclo celular, promovió que los estudiantes volvieran a través de esas representaciones al vínculo entre cromosoma y cromátides. Su intención fue que pudieran reflexionar e intentar comprender cuándo y porqué variaba el número de cromátides de un cromosoma. Para ello retomó la relación entre duplicación de ADN y cromátides hermanas, cuestión que era necesario establecer en ese momento para abordar las incertezas de los estudiantes.

Retomamos ahora con mayor detalle esas intervenciones para analizar cómo a través de la secuencia de dibujos y preguntas la docente fue abordando el problema del texto 
1. La reticencia y la cláusula de motu proprio (que establece que los estudiantes deben aprender por ellos mismos) modelan la semiosis inherente al desarrollo del juego didáctico (Sensevy, Gruson y Forest, 2015). Será en el contexto de la situación de enseñanza donde tanto la reticencia como la expresión de la docente adquieran un significado particular; nos detendremos en ello en la descripción del siguiente fragmento de interacción.

\section{Fragmento 5.6}

¿Cuál es el problema del texto 1? Acción docente: explicar para comprender Clase 5. Plenario: episodio 5 (80 -102)

\begin{tabular}{|c|c|c|c|}
\hline \multicolumn{2}{|c|}{ Turno de habla } & \multirow{2}{*}{$\begin{array}{l}\text { Transcripción plenario } \\
\text { ¿Se acuerdan de esto? Entonces ¿cómo } \\
\text { vamos a tener? Acá teníamos G1, S, G2 } \\
\text { mitosis ¿no? [Mientras dibuja células en } \\
\text { diferentes etapas en el pizarrón]. } \\
\text { Entonces, acá arrancamos con esta célula } \\
\text { y después teníamos dos células ¿Y qué es } \\
\text { lo que habíamos dicho? }\end{array}$} & \multirow{2}{*}{$\begin{array}{l}\text { Análisis interacción } \\
\text { Retoma contrato }\end{array}$} \\
\hline 80 & $\mathbf{s}$ & & \\
\hline 81 & Brenda & Que la célula original ya no estaba & $\begin{array}{l}\text { Responde sobre } \\
\text { contenido disciplinar }\end{array}$ \\
\hline 82 & $\mathbf{s}$ & $\begin{array}{l}\text { Que la célula original ya no está. ¿No? } \\
\text { ¿Estamos claros hasta acá? }\end{array}$ & Invita a participar \\
\hline 83 & Alumnos & Sí & $\begin{array}{l}\text { Responde sobre } \\
\text { contenido disciplinar }\end{array}$ \\
\hline 84 & $\mathbf{s}$ & $\begin{array}{l}\text { Ahora pensemos que cada una de estas } \\
\text { células va a hacer este trayecto para llegar } \\
\text { probablemente acá [Señala las etapas } \\
\text { representadas en el pizarrón]. Si yo tengo } \\
\text { el ADN así acá ¿Qué es lo que va a pasar } \\
\text { en S? }\end{array}$ & Invita a participar \\
\hline 85 & Alumnos & Se duplica & $\begin{array}{l}\text { Responden sobre } \\
\text { contenido disciplinar }\end{array}$ \\
\hline 86 & $\mathbf{s}$ & $\begin{array}{l}\text { En S se duplica [Dibuja en el esquema el } \\
\text { ADN duplicado] Y van a quedar } \\
\text { enganchaditos por el centrómero. ¿Qué es } \\
\text { lo que voy a tener acá? Voy a tener un } \\
\text { cromosoma simple que está formado por } \\
\text { una sola molécula de ADN. ¿Y acá qué es } \\
\text { lo que voy a tener? }\end{array}$ & $\begin{array}{c}\text { Actúa sobre contenido } \\
\text { disciplinar } \\
\text { Institucionaliza } \\
\text { Invita a participar }\end{array}$ \\
\hline 87 & Oscar & Dos & \multirow{2}{*}{$\begin{array}{l}\text { Responden sobre } \\
\text { contenido disciplinar }\end{array}$} \\
\hline 88 & Brenda & Dos & \\
\hline
\end{tabular}




\begin{tabular}{|c|c|c|c|}
\hline 89 & Oscar & Dos cromosomas & \\
\hline 90 & $\mathbf{s}$ & $\begin{array}{l}\text { Un cromosoma duplicado que tiene dos } \\
\text { moléculas de ADN. }\end{array}$ & $\begin{array}{c}\text { Actúa sobre contenido } \\
\text { disciplinar } \\
\text { Institucionaliza }\end{array}$ \\
\hline 91 & Oscar & $\begin{array}{l}\text { Claro, sí. Un cromosoma duplicado. [En } \\
\text { voz baja como para sí mismo] }\end{array}$ & Acuerda \\
\hline 92 & $\mathbf{S}$ & $\begin{array}{l}\text { Cada una de estas moléculas de este } \\
\text { cromosoma duplicado, constituye... ¿Qué } \\
\text { cosa? }\end{array}$ & $\begin{array}{l}\text { Actúa sobre contenido } \\
\text { disciplinar }\end{array}$ \\
\hline 93 & Cristóbal & ¿Cromátides? & \multirow{2}{*}{$\begin{array}{l}\text { Responde sobre } \\
\text { contenido disciplinar }\end{array}$} \\
\hline 94 & Oscar & Las cromátides. Son las cromátides & \\
\hline 95 & $\mathbf{s}$ & $\begin{array}{l}\text { Son las cromátides. Cada cromosoma } \\
\text { duplicado va a tener dos cromátides, cada } \\
\text { cromátide está constituida por una } \\
\text { molécula de ADN. Estoy dejando de lado } \\
\text { las proteínas de esos cromosomas, ¿de } \\
\text { acuerdo? } \\
\text { En G2 ¿Qué va a pasar? Tengo que hacer } \\
\text { otra vez lo mismo [Dibuja la secuencia de } \\
\text { esquemas de células que sigue] } \\
\text { ¿Estamos de acuerdo? }\end{array}$ & $\begin{array}{l}\text { Actúa sobre contenido } \\
\text { disciplinar } \\
\text { Institucionaliza }\end{array}$ \\
\hline 96 & Oscar & Sí, sí. & $\begin{array}{l}\text { Responde sobre } \\
\text { contenido disciplinar }\end{array}$ \\
\hline 97 & $S$ & $\begin{array}{l}\text { ¿Cómo nos damos cuenta que empieza la } \\
\text { mitosis? }\end{array}$ & $\begin{array}{c}\text { Actúa sobre contenido } \\
\text { disciplinar }\end{array}$ \\
\hline 98 & Alumnos & Eh, se empieza a compactar. & $\begin{array}{l}\text { Responde sobre } \\
\text { contenido disciplinar }\end{array}$ \\
\hline 99 & $\mathbf{s}$ & $\begin{array}{l}\text { Esto mismo se empieza a compactar } \\
\text { entonces lo podría hacer una cosa así. } \\
\text { [Dibuja los cromosomas compactándose al } \\
\text { inicio de la división] Los cromosomas } \\
\text { terminan estando más gorditos y más } \\
\text { cortitos. Entonces ahí los veo, al } \\
\text { microscopio ¿Está claro? ¿Sí? }\end{array}$ & $\begin{array}{l}\text { Actúa sobre contenido } \\
\text { disciplinar } \\
\text { Institucionaliza }\end{array}$ \\
\hline 100 & Alumnos & Sí & Acuerda \\
\hline 101 & Abigail & Sí & Acuerda \\
\hline 102 & $\mathbf{S}$ & $\begin{array}{l}\text { Hubo una discusión allí respecto de } \\
\text { cromatina y cromosoma. Lo dejamos en } \\
\text { stand by un ratito. Quería que esto quede }\end{array}$ & Expresa su reticencia \\
\hline
\end{tabular}




\begin{tabular}{|l|l|l|l|}
\hline & $\begin{array}{l}\text { claro. ¿Cómo habría que redactar ese } \\
\text { texto 1? }\end{array}$ & $\begin{array}{c}\text { Actúa sobre quehaceres } \\
\text { de lector y escritor } \\
\text { Vuelve al texto }\end{array}$ \\
\hline
\end{tabular}

La docente comenzó dibujando una secuencia de esquemas de células en las diferentes etapas del ciclo celular y consultó a los estudiantes en [80] si se acordaban que ya los había realizado durante la clase previa. Y en [82] les preguntó “¿Estamos claros hasta acá?", como una manera de invitarlos a participar y consensuar contrato al acordar representaciones.

A continuación señaló el esquema que había dibujado en el pizarrón y que representaba a una célula en la etapa G1 del ciclo celular, y preguntó a todo el grupo clase "Si yo tengo el ADN así acá ¿Qué es lo que va a pasar en [la etapa] S?” [84]. A través de esa pregunta les pidió predecir qué ocurriría en la etapa siguiente con esa célula y los cromosomas que estaban representados en el esquema. Así la docente quiso poner en foco la duplicación de ADN. La intención fue que los alumnos pudieran entender cómo influía ese proceso metabólico en los cambios de la estructura de los cromosomas, cuestión clave para comprender la relación entre cromátides y cromosoma que constituía el problema del texto 1.

Varios alumnos respondieron que ese ADN se duplicaba, la docente asintió y representó entonces el ADN duplicado para agregar en [86]: "En $S$ se duplica, y van a quedar enganchaditos por el centrómero. ¿Qué es lo que voy a tener acá? [Señaló en el esquema la célula que se encontraba en G1, etapa previa a la duplicación]. Y ella misma respondió: "Voy a tener un cromosoma simple que está formado por una sola molécula de ADN, ¿Y acá qué es lo que voy a tener?" [Y señaló la célula representada en la etapa G2, posterior a la duplicación]". A la última pregunta de $\mathrm{S}$, tanto Oscar como Brenda respondieron en [87] y [88] "dos". En [89] Oscar agregó "dos cromosomas".

Fue en ese momento cuando $\mathrm{S}$ dejó de ser reticente e intervino actuando sobre el contenido disciplinar para aclarar en [90], "Un cromosoma duplicado que tiene dos moléculas de $A D N$." Oscar repitió como para sí, "Claro, sí. Un cromosoma duplicado" [91]. En estas intervenciones quedaron nominados los dos estados posibles de los cromosomas de acuerdo a las cromátides que tuvieran: al cromosoma con una cromátide se lo denominó cromosoma simple y cuando tenía dos cromátides hermanas sería un cromosoma duplicado.

Para continuar trabajando con la relación entre cromosoma y cromátides en [92] la docente preguntó a los alumnos, "Cada una de estas moléculas [de ADN] de este cromosoma duplicado, constituye ¿Qué cosa?”. Cristóbal y Oscar respondieron que 
eran las cromátides y en [95] S reiteró lo dicho por los alumnos marcando con énfasis "Son las cromátides"; y después reforzó la relación con la que estaba trabajando al decir: "Cada cromosoma duplicado va a tener dos cromátides, cada cromátide está constituida por una molécula de ADN. Estoy dejando de lado las proteínas de esos cromosomas, ¿de acuerdo?" Al enunciar la relación entre cromosoma, cromátides y ADN, la institucionalizó y actuó sobre el contenido disciplinar al centrar su atención sólo en el ADN como constituyente de los cromosomas.

Hasta ese momento del plenario habían analizado qué ocurría con los cromosomas de la célula modelizada en la etapa $S$, en esa misma intervención la docente invitó a los alumnos a predecir qué ocurriría con cromosomas, cromátides y ADN en la etapa siguiente, al decir: “En G2 ¿Qué va a pasar?”, para después preguntarles en [97] “ ¿Cómo nos damos cuenta que empieza la mitosis?”. Así recorrió con los estudiantes todas las etapas del ciclo celular y les hizo pensar cuáles eran las transformaciones que les ocurrían a los cromosomas en cada una de esas etapas, para poder profundizar el vínculo conceptual entre cromosoma y cromátides.

Con esta última intervención que mencionamos, la docente comenzó a trabajar los niveles de compactación del material genético y cómo ese hecho influía en la visibilidad de los cromosomas en tanto estructuras discretas, al observar células al microscopio. Algunos alumnos respondieron afirmando que el inicio de la compactación del material genético indicaría el comienzo de la mitosis. En consonancia, señalando en el dibujo del pizarrón la docente afirmó en [99]: "Esto mismo se empieza a compactar, entonces podría hacer una cosa así [lo dibujó en el pizarrón más compactado]. Los cromosomas terminan estando más gorditos y más cortitos. Entonces ahí los veo al microscopio ¿Está claro? ¿Sí?”. En esta intervención, en la que también actúa sobre el contenido, $S$ expresó cuál era el momento del ciclo celular en el que los cromosomas eran visibles al microscopio óptico y por qué eso era así.

En una intervención apenas posterior, la docente dijo, "Hubo una discusión allí respecto de cromatina y cromosoma. Lo dejamos en stand by un ratito. Quería que esto quede claro." [102] Así dio cuenta de aquello que expresamente dejó para después y explicitó cuál era su intención en ese momento del plenario cuando decidió dejar de ser reticente e intervenir con nueva información. De esta secuencia de interacción se evidenció que $S$ tuvo en mente las dificultades que habían surgido con el texto 1 dado que centró sus intervenciones en ellas. No perdió de vista cuál era la tarea que estaban realizando, ni cuál había sido el sentido de su intervención porque a continuación en la misma intervención preguntó a la clase, “¿Cómo habría que redactar ese texto 1?” 
Hasta aquí presentamos el análisis de la interacción transcripta en el fragmento 5.6, ahora comentaremos algunas cuestiones que nos parecieron relevantes y que corresponden a los turnos de habla posteriores: [103] a [190].

Cuando la docente decidió retomar la revisión del texto 1 la investigadora $(P)$ supuso que todavía quedaban algunas dudas con relación a la noción de cromosoma. Por ello, planteó una pregunta a los alumnos, pero previamente consultó en voz alta a la profesora si podía hacerla. La docente estuvo de acuerdo y la investigadora preguntó a los estudiantes: “¿Cuántos cromosomas hay representados en cada etapa? En la etapa S cuántos cromosomas había ahí en el dibujo que hizo S". [105]. Se suele considerar que las imágenes, como las utilizadas en clases de Biología, son más sencillas de comprender que otros lenguajes y que sería posible interpretarlas de manera uniforme. Por ello, podrían contribuir a la comprensión de aquello expresado mediante el lenguaje verbal (Pérez Echeverría, Postigo, López Manjón y Marín, 2009). En este caso, a partir de algunos comentarios de los alumnos, parecía que las imágenes no habían funcionado así y fue por esa razón que se decidió intervenir y solicitar que explicitaran qué habían interpretado.

A partir de la pregunta de la investigadora, durante cinco minutos se desarrolló un intenso intercambio acerca de la progresión de los dibujos. Casi todos los estudiantes intervinieron expresando si en las células dibujadas en el pizarrón había sólo un cromosoma, en cuál había dos; cuándo los cromosomas eran simples y cuándo duplicados y a qué atribuían los diferentes colores que había utilizado la docente al representar los cromosomas. En esa secuencia de interacción que correspondió a los turnos de habla [106] a [190], la docente también fue haciendo nuevas preguntas a los estudiantes mientras dibujaba e invitó a participar a aquellos alumnos que espontáneamente no intervenían. Por ejemplo, en [165], preguntó: ¿Yanina y Camilo? En [176]: ¿Todos opinan lo mismo?; en [178]: ¿Alba?

Además de los esquemas que dibujó en el pizarrón, en dos intervenciones la docente apeló a otros recursos para sostener aquello que estaba afirmando. Esos recursos también incluían imágenes. En [180], la docente expresó en referencia al libro que utilizaban como bibliografía: “¿Qué es lo que dice De Robertis?”. Realizó una pregunta retórica, dado que no esperó respuesta sino que en la misma intervención fue señalando en el libro cómo se representaban los cromosomas en las distintas instancias del ciclo celular, al decir: 


\begin{tabular}{|l|l|}
\hline $\begin{array}{l}\text { (señalándola en G2). Acá tengo un cromosoma duplicado con las cromátides } \\
\text { condensadas (ahora señalando una célula al inicio de mitosis). Acá tengo las } \\
\text { cromátides separadas que después se van a pasar a llamar cromosoma individual } \\
\text { (señalando las células hijas al finalizar mitosis). }\end{array}$ \\
\hline
\end{tabular}

En su explicación también utilizó imágenes de un power point que había enviado por mail a los estudiantes y que ellos tenían en la netbook para trabajar en clase. A medida que mostraba las imágenes en [184] S fue diciendo:

\begin{tabular}{|l|l|l|}
\hline 184 & $\mathbf{S}$ & $\begin{array}{l}\text { Yo lo que quería mostrarles acá en una fotografía de tejido. En todas aquellas } \\
\text { células donde no ven los cromosomas, donde se ven teñidas, pero no se ven los } \\
\text { cromosomas de forma individual. Acá, esto (va mostrando las imágenes del ppt } \\
\text { que había mandado con la netbook), acá los cromosomas se ven como palitos, } \\
\text { pero en estas otras se ve una manchita (va mostrando las imágenes en la net } \\
\text { acercándola a los grupos). Los cromosomas están, pero no se van a ver. No se } \\
\text { los ve pero estar, están. En estas otras se ven los cromosomas. }\end{array}$ \\
\hline
\end{tabular}

En este episodio la docente se corrió de la posición reticente que hemos descripto en episodios previos y expresó (al dibujar y hablar manteniendo implícita la referencia al texto) la relación entre cromosomas y cromátides a lo largo del ciclo celular. Esa acción promovió pensar en los cromosomas como estructuras más dinámicas, ubicarlos en diferentes etapas del ciclo de vida de las células y predecir si estarían formados por una o dos cromátides. A la vez, reforzó esa noción al vincular expresamente imagen y expresión verbal al nominar y representar en el pizarrón, mostrar en el libro y en la netbook diferentes representaciones que aludían a la noción de cromosoma.

Aun cuando las imágenes pueden ser en apariencia más realistas que otras representaciones y por ello se les asigna mayor simplicidad a la hora de analizar, interpretar y comprenderlas (Pérez Echeverría et al, 2009), en esta situación no resultaron auto explicativas. Se requirió de un trabajo con sucesivas intervenciones docentes que entrelazaran los dibujos y el lenguaje verbal para que esas imágenes tuvieran un rol importante en la comprensión del vínculo entre cromosoma y cromátides. En este mismo sentido, Roni y Borches (2013) analizaron lo ocurrido durante una secuencia didáctica diseñada para la enseñanza de la síntesis de proteínas en educación secundaria. En ese caso, la interpretación de imágenes fue un soporte que funcionó para que los alumnos pudieran anclar la información compleja que exponía la bibliografía. Pero para que ello ocurriera fueron relevantes los momentos de interacción entre docente y alumnos contrastando interpretaciones acerca de qué decían esas imágenes y cómo se vinculaban con los textos.

En la última intervención que transcribimos [184] S utilizó una imagen de un corte de tejido con diferentes células que estaban en distintas etapas del ciclo celular. Por eso 
en algunas de esas células los cromosomas estaban más condensados y se los podía individualizar como estructuras discretas, pero en otras sólo se observaba una mancha oscura. Esas fotografías con imágenes de células observadas con microscopio se complementaron con los dibujos de células en el pizarrón y con los esquemas del libro. Cada una de esas imágenes fue leída y contribuyó para poder interpretar y modelizar aquello que decía el texto. Esa integración entre imágenes y escrito que la docente promovió se constituyó en un quehacer de lector relevante para abordar textos de Biología desde una mirada disciplinar.

\subsubsection{Plenario. Episodio 6}

De cómo jugar el juego: regular implica institucionalizar y reescribir

Este extenso episodio 6 también giró alrededor de la noción de cromosoma y en este caso se trabajó en particular con el nivel de compactación. Este episodio incluye la presentación por parte de la docente de la noción de cromatina, que consideró necesario explicar en este momento del plenario para favorecer la comprensión de los cambios en la condensación del material genético durante el ciclo celular.

El primer tramo de este episodio abarcó los turnos de habla [191] a [227] que registramos en el fragmento 5.7 , transcripto a continuación. Durante ese intercambio la docente retomó el texto 1 para no sólo poner en foco los conceptos teóricos involucrados (la diferencia entre cromosoma duplicado y simple al referirse a dos estadios de los cromosomas), sino también revisar cómo incluirlos en el escrito.

Con posterioridad a esa interacción la docente explicó la noción de cromatina y sus niveles de plegamiento, cuestión que derivó a partir de los interrogantes que surgieron durante la revisión del texto analizada en este episodio y que correspondieron al registro de turno de habla [228] a [355], que referimos de manera más general.

\section{Fragmento 5.7}

Se resuelve el problema del texto 1

Clase 5. Plenario. Episodio 5, parte 1 (191-227)

\begin{tabular}{|l|c|l|c|}
\hline \multicolumn{2}{|l|}{ Turno de habla } & \multicolumn{1}{|c|}{ Transcripción plenario } & Análisis interacción \\
\hline 191 & $\mathbf{S}$ & $\begin{array}{l}\text { (...) Bueno volviendo entonces al texto. Se duplicó } \\
\text { el ADN quedando dos cromátidas hermanas. Y } \\
\text { ¿cómo cambiaríamos esto? [en el texto 1] porque } \\
\text { en ese momento son cromátides hermanas } \\
\text { formando parte de un cromosoma duplicado }\end{array}$ & $\begin{array}{c}\text { Actúa sobre } \\
\text { quehaceres de } \\
\text { lector y escritor } \\
\text { Vuelve al texto }\end{array}$ \\
\hline 192 & Oscar & $\begin{array}{l}\text { Dos cromátidas hermanas unidas por un } \\
\text { centrómero llamado cromosoma duplicado. }\end{array}$ & Vuelven al texto \\
\hline
\end{tabular}




\begin{tabular}{|c|c|c|c|}
\hline 193 & $\mathbf{s}$ & Ahí está. O constituyendo un cromosoma & \multirow[t]{7}{*}{$\begin{array}{l}\text { para pensar cómo } \\
\text { reescribirlo }\end{array}$} \\
\hline 194 & Oscar & $\begin{array}{l}\text { O constituyendo un cromosoma duplicado. Ahí } \\
\text { estaría mucho más claro. }\end{array}$ & \\
\hline 195 & $\mathbf{S}$ & $\begin{array}{l}\text { Exactamente. ¿Se entiende? Y después, luego a } \\
\text { la etapa de mitosis donde... }\end{array}$ & \\
\hline 196 & Oscar & $\begin{array}{l}\text { Dicho cromosoma duplicado, los cromosomas se } \\
\text { separarán. Noo. }\end{array}$ & \\
\hline 197 & $\mathbf{S}$ & Pero ¿qué es lo que se separa? & \\
\hline 198 & Alumnos & Las cromátides & \\
\hline 199 & $\mathbf{s}$ & Las cromátides hermanas & \\
\hline 200 & Oscar & $\begin{array}{l}\text { Las cromátides se separan. Por esto dice De } \\
\text { Robertis "llamados cromosoma" [en referencia al } \\
\text { capítulo del libro cuyo uso del término } \\
\text { cromosoma lo había confundido] Para él [para De } \\
\text { Robertis] ahí después ya con tranquilidad puede } \\
\text { llamarlo cromosoma porque cuesta...tiene } \\
\text { dificultad para definir en este período el concepto. }\end{array}$ & $\begin{array}{l}\text { Certeza derivada de } \\
\text { incertezas previas }\end{array}$ \\
\hline 201 & Alumno & ¿Cómo? & \\
\hline 202 & $\mathbf{S}$ & ¿A ver? & Invita a participar \\
\hline 203 & Oscar & $\begin{array}{l}\text { Porque hay algo que se arrastra desde hace } \\
\text { mucho tiempo. El concepto de que cuando está } \\
\text { laxo como cromatina, no es cromosoma. } \\
\text { Entonces uno asocia el concepto de cromosoma } \\
\text { y eso crea confusión. Y además a mí me genera } \\
\text { confusión el texto de De Robertis, que dice que } \\
\text { cuando se separan son cromosomas. Además a } \\
\text { mí se me crea la confusión que surge del texto. } \\
\text { Y lo que le decía a Vanesa, entonces el tema es } \\
\text { que hay que adecuar la oración, porque en } \\
\text { realidad yo lo que interpreté es: cromátides } \\
\text { hermanas que forman un cromosoma duplicado. } \\
\text { Lo que no quiere decir que yo diga: hay dos } \\
\text { cromosomas. Hay 'un cromosoma duplicado' es } \\
\text { la mejor definición que encontramos: cromosoma } \\
\text { duplicado. Que luego en mitosis esas cromátides } \\
\text { hermanas se separan y van a formar cada una un } \\
\text { cromosoma. }\end{array}$ & \multirow[t]{2}{*}{$\begin{array}{l}\text { Certeza derivada de } \\
\text { incertezas previas }\end{array}$} \\
\hline 204 & Vanesa & Un cromosoma... & \\
\hline 205 & $\mathbf{s}$ & [un cromosoma] Simple & $\begin{array}{l}\text { Actúa sobre el } \\
\text { contenido }\end{array}$ \\
\hline
\end{tabular}




\begin{tabular}{|c|c|c|c|}
\hline 206 & Oscar & Simple. Claro & \multirow{2}{*}{ Acuerdan } \\
\hline 207 & Brenda & Sin duplicar & \\
\hline \multicolumn{4}{|c|}{ [208-221 Los alumnos comentan sobre los colores de las tizas que utilizó S al dibujar ] } \\
\hline 222 & Vanesa & Le puedo decir algo profe... & Consulta \\
\hline 223 & $\mathbf{S}$ & Dale & Invita a participar \\
\hline 224 & Vanesa & $\begin{array}{l}\text { A mí sinceramente me trajo mucha confusión } \\
\text { esto. Pero previo [se refiere a que en otras } \\
\text { situaciones de enseñanza ya había tenido } \\
\text { dificultades con el concepto cromosoma]. Yo } \\
\text { siempre le decía a ella [dirigiéndose a Abigai]. Yo } \\
\text { no entiendo si ¿es siempre un cromosoma? ¿No } \\
\text { te decía a vos? }\end{array}$ & \multirow{3}{*}{$\begin{array}{l}\text { Incertezas } \\
\text { conscientes }\end{array}$} \\
\hline 225 & Abigail & Sí. & \\
\hline 226 & Vanesa & $\begin{array}{l}\text { Cómo puede ser, a lo mejor lo llaman con } \\
\text { diferentes nombres. Pero ¿por qué de entrada no } \\
\text { dicen todo es cromosoma? y vamos a llamar así } \\
\text { porque... }\end{array}$ & \\
\hline 227 & $\mathbf{S}$ & $\begin{array}{l}\text { Bueno entonces no lo vamos a retrasar más. } \\
\text { Vamos a hablar de: la cromatina [enfatizando] }\end{array}$ & $\begin{array}{l}\text { Actúa sobre el } \\
\text { contenido }\end{array}$ \\
\hline
\end{tabular}

Este episodio comienza cuando la docente volvió al texto 1 con su intervención en [191] en la que afirmó lo que ya habían acordado, "Se duplicó el ADN quedando dos cromátidas hermanas"; se ubicó en una posición más central en la interacción desde un análisis topogenético, al decir: "Y ¿cómo cambiaríamos esto?" "Esto" en su frase correspondería a lo que continuaba en el texto 1 y que había dado lugar al intercambio que describimos en el episodio 4. En esa intervención les propuso a todos los alumnos que cambiaran esa parte del texto y enunció que "en ese momento son cromátides hermanas formando parte de un cromosoma duplicado", cuestión que habían acordado durante la explicación previa y que ya formaba parte del nuevo contrato didáctico.

Fue Oscar, el autor del texto, quien expresó otras formas posibles de establecer ese vínculo al decir: "Dos cromátidas hermanas unidas por un centrómero llamado cromosoma duplicado" [192], y "O constituyendo un cromosoma duplicado. Ahí estaría mucho más claro" [194]. Y así fue reelaborando de manera oral su texto ajustando aquello que expresaba.

S habilitó esta última opción en [195] al afirmar, "Exactamente. ¿Se entiende?” y fue leyendo el texto de Oscar. Con el decir de la docente se superpuso la voz de Oscar 
quien completó la frase referida a su texto y dijo en [196], "Dicho cromosoma duplicado, los cromosomas se separarán. Nooo..." Oscar intentó incluir la noción de cromosoma duplicado y precisar si iba en singular o plural, pero al decirlo en voz alta pareció darse cuenta que algo no estaba bien en esa reconstrucción del texto. En su frase omitió la relación entre cromátides hermanas y cromosoma, fue por eso que $S$ intervino actuando sobre el contenido para que Oscar aclarase ¿qué es lo que se separa? [197]. Varios alumnos respondieron que eran las cromátides quienes se separaban en la división celular mitótica y no los cromosomas. La docente repitió la respuesta de los alumnos avalándola y también Oscar intervino en [200] afirmando que se separaban las cromátides.

Oscar vinculó su confusión previa y el problema que surgió en el texto 1 con cómo estaban referidos los cromosomas por el autor del libro disciplinar (De Robertis) en el capítulo correspondiente al tema. En esa misma intervención Oscar agregó "Por esto dice De Robertis "llamados cromosomas"; para él ahí, después ya con tranquilidad puede llamarlo cromosoma porque cuesta, tiene dificultad para definir en este período, el concepto." En [202] S intervino diciendo, ¿A ver? y así lo invitó a participar para expandir la relación que había expresado.

En [203] Oscar hizo una extensa intervención en la que explicitó que se concebía a los cromosomas como una estructura que existía sólo cuando era visible al microscopio óptico, es decir cuando no estaba laxo. Y por ello planteó: “(...) porque hay algo que se arrastra desde hace mucho tiempo, el concepto de que cuando está laxo como cromatina no es cromosoma." Así consideró en esta intervención que el uso acotado del término cromosoma, referido tan sólo a un momento de la vida de las células (la división celular), le creó una confusión que "arrastra hace mucho tiempo".

En esta intervención Oscar reflexionó en voz alta acerca de las razones de su confusión (tal como él consideraba al problema de los cromosomas en el texto 1) y aludió a una segunda razón que le permitiría explicar las dificultades que hubo al revisar ese escrito. El alumno afirmó, "Y además a mí me genera confusión el texto de De Robertis que dice que cuando se separan son cromosomas. Además a mí se me crea la confusión que surge del texto." De esta manera, relacionó su escrito con la lectura que había recomendado la docente del capítulo de ese libro. En él el autor refiere a la separación de las cromátides hermanas que formaban parte de un mismo cromosoma. "(...) cada célula hija recibe una sola cromátida, que pasa a llamarse cromosoma después de la separación." (De Robertis, Hib, 2004: 299) 
En esa misma intervención [203] Oscar expresó que "el tema es que hay que adecuar la oración", al volver a su propio escrito para reformularlo. Y algo esencial para que pudiera reescribirlo era comprender cómo podía ser interpretado por un lector. La explicación previa de la docente pareció ser de utilidad para esa reformulación, dado que Oscar incluyó en su nueva versión el concepto cromosoma duplicado que S había introducido unos minutos antes. Así reflexionó en voz alta, "Y lo que le decía a Vanesa, entonces el tema es que hay que adecuar la oración porque en realidad yo lo que interpreté es: cromátides hermanas que forman un cromosoma duplicado. Lo que no quiere decir que yo diga: hay dos cromosomas. Hay 'un cromosoma duplicado es la mejor definición que encontramos: cromosoma duplicado. Que luego en mitosis esas cromátides hermanas se separan y van a formar cada una un cromosoma”.

De este modo, el estudiante integró lo trabajado durante la clase con la tarea de escritura previa y reflexionó acerca de por qué surgieron dificultades al tener que utilizar el concepto cromosoma en su escrito para relatar aquello que ocurría en las diferentes etapas del ciclo celular. A partir de la etapa S "Hay 'un cromosoma duplicado" cuestión que Oscar hizo suya porque consideró "que es la mejor definición que encontramos." Para después decir que era en otra etapa (mitosis) cuando "esas cromátides hermanas se separan y van a formar cada una un cromosoma."

Resulta interesante cómo ese texto 1 puso en tensión la noción de cromosoma y dio lugar a tener que pensar en esas estructuras de manera más dinámica (con una cromátide/ con dos cromátides y en estado laxo/ más condensado). Cómo el hecho de tener que relacionar los cromosomas con dos de las etapas del ciclo celular promovió pensar en qué les ocurría durante todo el ciclo, y eso implicó problematizar la noción de cromosoma e interpelarla. La tarea de escritura y revisión propuesta y el desarrollo de esa tarea de manera colaborativa, así como la regulación de la docente promovieron que esa actividad tuviera una función epistémica para algunos estudiantes (Bazerman, 2009).

Vanesa pareció quedar pensando en lo que Oscar enunció y reiteró: un cromosoma en [204], la docente agregó simple, Oscar acordó con esa acotación y Brenda en [207] aclaró sin duplicar. La docente volvió al esquema que había hecho en el pizarrón y puso esos términos en relación con los dibujos y señalándolos preguntó qué era lo que iba a haber en uno de los esquemas. Oscar en [214] enunció " $Y$ en ése [en referencia a uno de los esquemas que representaba cromosomas en un momento del ciclo celular] va a tener duplicadas las cadenas de $A D N$, dos cromátides hermanas, cromosoma duplicado." En ese mismo sentido, Vanesa intervino en [224] planteando también su confusión en relación con el momento del ciclo celular en que era posible referir a 
cromosomas y expresó: "Yo no entiendo si es siempre un cromosoma." Así pareció preguntar si era acertado hablar de cromosomas a lo largo de toda la vida celular (sería el siempre que ella enunció), o sólo cuando esos cromosomas se compactan y son visibles al microscopio óptico (tal como venía haciéndolo). Vanesa continuó planteando que "a lo mejor lo llaman con diferentes nombres." Pero dado que eso causaba confusión, propuso que, si así fuera, explicitaran cuáles eran las convenciones "todo es cromosoma y vamos a llamar así porque..."

Oscar y Vanesa dan cuenta, a través de sus intervenciones en esta instancia de plenario, de las certezas e incertezas respecto a los cromosomas. Ser consciente de cuáles son las certezas y cuáles las incertezas respecto a una noción hace posible cuestionar aquello que se conoce, revisarlo y así favorece la construcción de nuevo conocimiento (Tiberghien, Cross y Sensevy, 2014). Para entender qué sucede en un aula es necesario comprender la evolución temporal de aquello que se comunica y en ese sentido es posible utilizar la noción de continuidad, entendida como las múltiples relaciones entre diferentes partes de tareas o actividades, así como de los discursos asociados (Hamza y Wickman, 2013). Es por ello que resulta pertinente incluir aquí en el análisis de este episodio el momento en el que la docente decidió trabajar con la noción de cromatina, dado que esa intervención adquirió otro sentido a la luz de la interacción previa durante este plenario.

Aun cuando estaba previsto trabajar durante esta clase o la siguiente con esta noción, la interacción que se suscitó durante este episodio del plenario pareció influir en la decisión docente de explicar qué era la cromatina y qué relación tenía con la noción de cromosoma. En [227] la docente interviene actuando sobre el contenido disciplinar, al decir: Bueno, entonces no lo vamos a retrasar más. Vamos a hablar de la cromatina. Así la docente marcó que había otro concepto que era necesario reformular para abordar esa confusión.

De esta manera dio comienzo la instancia de explicación docente que abarcó los turnos de habla [228] a [355] y se centró en la presentación del concepto de cromatina y los grados de compactación o plegamiento que vinculan esta noción con cromosoma.

La docente comenzó definiendo qué era la cromatina y cuál iba a ser la relación entre cromatina y cromosoma con la que trabajarían, al decir en [232]: "La cromatina es la composición química de los cromosomas. O sea la cromatina es lo que constituye a los cromosomas. Es el ADN más las proteínas." Esa intervención que actuó sobre el contenido disciplinar sintetizó la relación entre cromatina y cromosomas, así como 
entre cromatina y ADN. A lo largo de este extenso segundo momento del episodio 6 la docente profundizó los vínculos que estableció en esta intervención.

A través de una serie de intervenciones más extensas que las que había realizado hasta el momento en el plenario, $S$ vinculó la noción de cromatina, que no había sido abordada previamente, con varias cuestiones que surgieron a partir de la tarea de revisión. De esa manera, actuó sobre el contenido disciplinar al afirmar que la relación entre cromatina y cromosoma no era temporal, no estaba dada por el momento del ciclo celular en que se encontraba la célula. $Y$ en esa aclaración incluyó los conceptos cromosoma simple y duplicado para marcar diferentes estadios estructurales de los cromosomas durante el ciclo celular con el vocabulario que había trabajado en la explicación previa. A la vez, refirió qué era visible al microscopio óptico al observar células en diferentes momentos del ciclo celular. Para ejemplificar esto último utilizó imágenes del power point que había enviado. Así como en el episodio 5 aquí también las imágenes tuvieron un rol preponderante. Esas imágenes fueron utilizadas por la docente como formas de modelizar aquello que estaba presentando a través del lenguaje verbal.

En las diferentes intervenciones $S$ dio razones acerca de por qué resultaba visible la cromatina al observar células al microscopio. Así como refirió a los grados de compactación de la cromatina durante el ciclo celular, al decir en sus intervenciones: "está más compacta" [253]; "está menos compactada” [255]; "menos plegada (...) más plegada" [257]. Al mismo tiempo, intentó vincular esa noción con una representación visual, al relacionar su nivel de plegamiento con cómo se visualiza esa cromatina ("veo un masacote (...) son manchones "[253]; "es más clarito" [255]; "la parte más oscura (...) uno lo ve como una mancha así oscura" [257]). Estas intervenciones contribuyeron a que los estudiantes pudieran leer esas imágenes y modelizar los cambios estructurales de los cromosomas durante el ciclo celular. Tal como dijimos en el episodio anterior, la trama entre lenguaje verbal e imagen es pertinente en la comprensión de nociones en Biología (Massarini, 2008).

Después de estas intervenciones, Brenda concluyó que "Entonces siempre hay cromatina y siempre hay cromosomas" [258]. La docente acordó con ella al decir "Exactamente, el grado de plegamiento es lo que los diferencia” [259], para después sugerir que retomaran el power point que había enviado así liquidaban a la cromatina. La liquidación de la cromatina incluyó presentarla a través de diversas imágenes, como las del power point, dibujos en el pizarrón así como gestos con las manos que acompañaron al lenguaje verbal para explicar cómo una fibra de cromatina se plegaba sobre sí misma. S introdujo a través de esta presentación nuevo vocabulario específico 
que no había sido trabajado en la actividad de escritura (histonas, nucleosoma, solenoide, bucle). Para finalmente referir a la relación entre el nivel de plegamiento y la expresión de los genes al presentar la eucromatina y la heterocromatina. Esa secuencia de interacción correspondió a los turnos de habla [261] a [355] que no incluiremos aquí dado que no incidieron en la reelaboración de los textos que corresponden a la actividad de revisión que estamos analizando.

\subsubsection{Plenario. Episodio 7}

De cómo jugar el juego también implica modificar forma del texto y no sólo contenido

Este episodio correspondió a la última parte del plenario en la que se revisaron los escritos pendientes. En esa instancia se trabajó con los textos de Cristóbal (2) y Vanesa $(3)^{35}$ y posteriormente con el escrito de Yanina (5). Nos centraremos aquí en la revisión del texto 5, constituido por una única oración extensa que dejaba algunos implícitos. Aunque era un escrito que no tenía errores conceptuales dio lugar a dudas en la interpretación de lo que enunciaba.

Nos interesó detenernos en la secuencia de interacción que se desarrolló durante la revisión de este texto porque no estuvo centrada en la discusión de nociones disciplinares, como ocurrió en los episodios previos. La revisión de este texto se aproximó más a un trabajo de edición centrado en el lector, durante ella la docente y los alumnos se ocuparon de quehaceres de lectores y escritores (Lerner, 2001; 2009). Así, hablaron de la pertinencia en el uso de ciertos términos ajenos al discurso disciplinar, discutieron el formato de oración única y extensa que presentaba el escrito y propusieron modificaciones que podían favorecer la interpretación de aquello que se quería decir en él. A continuación incluimos la interacción que se desarrolló durante esa tarea de revisión, transcripta en el fragmento 5.8.

Fragmento 5.8

Revisión del texto 5

Clase 5. Plenario. Episodio 7 (401-424)

\begin{tabular}{|c|c|c|c|}
\hline \multicolumn{2}{|c|}{ Turno de habla } & \multicolumn{1}{|c|}{ Transcripción plenario } & Análisis interacción \\
\hline 401 & S & $\begin{array}{l}\text { (..) ¿Y en el 5? Dice: "En la etapa S de } \\
\text { interfase el ADN de una célula epitelial } \\
\text { necesita duplicarse..." }\end{array}$ & $\begin{array}{c}\text { Actúa sobre quehaceres } \\
\text { de lector y escritor } \\
\text { Vuelve al texto }\end{array}$ \\
\hline
\end{tabular}

\footnotetext{
${ }^{35}$ La revisión de los textos 2 y 3 correspondió a los turnos de habla [356] a [400]. Oscar y Vanesa intervinieron refiriendo a la confusión en el orden de etapas del ciclo celular que presentaba el texto 2 , Cristóbal autor de ese texto no intervino. Con respecto al texto 3, escrito por Vanesa, fue ella como autora quien sugirió cuáles eran los errores y cómo modificarlos. En este caso también hubo algunos intercambios referidos a cómo podía ser interpretada una frase del texto en los que intervinieron Brenda, Oscar, la docente y la investigadora, además de Vanesa.
} 


\begin{tabular}{|c|c|c|c|}
\hline 402 & Vanesa & Bueno, ése necesita... & $\begin{array}{l}\text { Vuelve al texto para } \\
\text { comentar como lectora }\end{array}$ \\
\hline 403 & $\mathbf{s}$ & Ése necesita... & $\begin{array}{l}\text { Actúa sobre quehaceres } \\
\text { de lector y escritor }\end{array}$ \\
\hline 404 & Oscar & $\begin{array}{l}\text { Es como los hijos de De Robertis. (En } \\
\text { referencia al uso de } A D N \text { y cromosomas } \\
\text { hijos que hacía el autor del capítulo de la } \\
\text { bibliografía y que ya habían mencionado } \\
\text { como algo confuso) }\end{array}$ & $\begin{array}{l}\text { Vuelve al texto } \\
\text { Relaciona con bibliografía }\end{array}$ \\
\hline 405 & $\mathbf{S}$ & Je, je & \\
\hline 406 & Vanesa & Claro & Acuerda \\
\hline 407 & $\mathbf{S}$ & $\begin{array}{l}\text { "para poder dividirse por mitosis y así dar } \\
\text { origen a dos células con la misma } \\
\text { información genética, una vez finalizada } \\
\text { la duplicación los cromosomas de la } \\
\text { célula epitelial poseen cromátidas } \\
\text { hermanas." Acá lo que no se entiende... } \\
\text { A mí me pasó, no sé si a ustedes. A } \\
\text { ustedes ¿Hay algo que les haga ruido? }\end{array}$ & $\begin{array}{l}\text { Actúa sobre quehaceres } \\
\text { de lector } \\
\text { Vuelve al texto } \\
\text { Reticencia } \\
\text { Invita a participar }\end{array}$ \\
\hline 408 & Vanesa & Sí & $\begin{array}{l}\text { Vuelve al texto para } \\
\text { comentar como lectora }\end{array}$ \\
\hline 409 & $\mathbf{S}$ & ¿Qué cosa? & Reticencia \\
\hline 410 & Vanesa & Bueno. Por ahí cómo está redactado & $\begin{array}{l}\text { Vuelve al texto para } \\
\text { comentar como lectora }\end{array}$ \\
\hline 411 & $\mathbf{S}$ & ¿En qué aspectos? & Reticencia \\
\hline 412 & Vanesa & $\begin{array}{l}\text { Cuando dice "En la etapa } S \text { de interfase } \\
\text { el ADN de una célula epitelial necesita } \\
\text { duplicarse para poder dividirse por } \\
\text { mitosis..." Es que es tan larga la... que } \\
\text { no se si primero decir que las células por } \\
\text { medio de la mitosis se dividen, o sea } \\
\text { empezar no sé, al revés. }\end{array}$ & $\begin{array}{l}\text { Actúa sobre quehacer } \\
\text { lector y escritor } \\
\text { Vuelve al texto para } \\
\text { comentar como lectora }\end{array}$ \\
\hline 413 & $\mathbf{S}$ & $\begin{array}{l}\text { O sea ¿lo que finaliza es la duplicación } \\
\text { del ADN o la duplicación de la célula? A } \\
\text { mí, "los cromosomas de la célula epitelial } \\
\text { poseen cromátides hermanas". No sé... }\end{array}$ & $\begin{array}{l}\text { Actúa sobre quehaceres } \\
\text { de lector y escritor } \\
\text { Vuelve al texto }\end{array}$ \\
\hline 414 & Oscar & $\begin{array}{l}\text { Una vez finalizada...Ah, la frase final } \\
\text { usted dice. (La lee) "una vez finalizada la } \\
\text { duplicación los cromosomas de la célula } \\
\text { epitelial poseen cromátidas hermanas." } \\
\text { Eh... }\end{array}$ & $\begin{array}{l}\text { Vuelve al texto para } \\
\text { comentar como lector }\end{array}$ \\
\hline 415 & Yanina & A mí esa parte ... (inaudible) & $\begin{array}{l}\text { Vuelve al texto para } \\
\text { comentar como escritora }\end{array}$ \\
\hline
\end{tabular}




\begin{tabular}{|c|c|c|c|}
\hline 416 & $S$ & $\begin{array}{l}\text { ¿La duplicación de qué cosa genera las } \\
\text { cromátides hermanas? }\end{array}$ & $\begin{array}{c}\text { Actúa sobre el contenido } \\
\text { disciplinar }\end{array}$ \\
\hline 417 & Oscar & Del ADN & \multirow{2}{*}{$\begin{array}{l}\text { Responde sobre contenido } \\
\text { disciplinar }\end{array}$} \\
\hline 418 & Alumno & ADN & \\
\hline 419 & $P$ & $\begin{array}{l}\text { Por ahí justo antes habló de mitosis, por } \\
\text { eso queda pegado a mitosis... }\end{array}$ & Vuelve al texto \\
\hline 420 & s & $\begin{array}{l}\text { Por eso queda... ¿Se dan cuenta de lo } \\
\text { que estoy diciendo? Como que en el } \\
\text { medio habla de mitosis. Empezó } \\
\text { hablando de la duplicación de ADN y } \\
\text { después se mete en Mitosis y dice las } \\
\text { dos células ¿se entiende? En el medio } \\
\text { está mitosis. } \\
\text { Por eso cuando retoma tiene que haber } \\
\text { algún tipo de conector o un punto y } \\
\text { volver a retomar lo del principio para } \\
\text { continuar con las cromátides hermanas, } \\
\text { ¿Se dan cuenta lo que voy diciendo? }\end{array}$ & $\begin{array}{c}\text { Actúa sobre quehaceres } \\
\text { de lector y escritor } \\
\text { Vuelve al texto }\end{array}$ \\
\hline 421 & Vanesa & Sí & \multirow{2}{*}{$\begin{array}{l}\text { Responde sobre contenido } \\
\text { disciplinar }\end{array}$} \\
\hline 422 & $\mathrm{Al}$ & Sí & \\
\hline 423 & Oscar & $\begin{array}{l}\text { Sí, sí. El De Robertis lleva algo de eso } \\
\text { cuando uno lo lee, porque va y viene, va } \\
\text { y viene. Entonces uno tiene que ubicarse } \\
\text { y a mí lo que me costó cuando hice la } \\
\text { frase, dije agarro y lo hago lineal. }\end{array}$ & $\begin{array}{l}\text { Actúa sobre quehaceres } \\
\text { de lector y escritor }\end{array}$ \\
\hline 424 & S & $\begin{array}{l}\text { No. Pero en lo que hace a las etapas } \\
\text { está bien. Fijate que las va poniendo (a } \\
\text { las etapas) lineal. }\end{array}$ & $\begin{array}{l}\text { Actúa sobre quehaceres } \\
\text { de lector y escritor }\end{array}$ \\
\hline
\end{tabular}

La docente comenzó leyendo en [401] para volver al texto y tenerlo presente. Se detuvo ante el comentario de Vanesa [402] que pareció cuestionar la inclusión del término "necesita" para referirse a una molécula como el ADN. Oscar en [404] compara ese uso, que parece más propio de seres vivos que de moléculas inertes, con el uso de "los hijos" al referir a cromosomas en el capítulo del libro de De Robertis. Esos comentarios que la docente avaló, remitían a cómo algunos términos presentes en el texto no les parecían compatibles con el discurso científico.

En [407] S volvió al texto nuevamente para completar la lectura, y agregó que "Acá lo que no se entiende..." pero se interrumpió, y no anticipó qué era lo que consideraba que no se entendía. En su intervención se puso en evidencia que decidió mantenerse reticente para no anunciar su propia postura acerca del texto. De esa manera, dio lugar a que los estudiantes pudieran plantear su propia interpretación como lectores. A través de esa acción sobre los quehaceres de lector, la docente evitó un cierre temprano del 
trabajo sobre el texto, para no obturar la expresión de los estudiantes (Espinoza, Casamajor y Pitton, 2009).

En esa misma intervención, $\mathrm{S}$ los invitó a participar, al decir: "A mí me pasó, no sé si a ustedes. A ustedes ¿Hay algo que les haga ruido?”. Fue Vanesa quien respondió que le hacía ruido cómo estaba redactado el texto, y la docente, sin anticipar su acuerdo, le pidió que fuera más precisa en los aspectos a los que refería. Vanesa en [412] leyó parte del texto para comentar que la oración era tan larga que la confundía, y por ello propuso que se podría "empezar al revés". Aquí ella sugirió qué podría cambiar del texto si fuera la autora, a partir de su experiencia como lectora.

En [413] la docente volvió en tercera instancia al texto, y mencionó la duda que tuvo como lectora “¿lo que finaliza es la duplicación del ADN o la duplicación de la célula?”, esa duda surgió porque el texto comenzaba con la referencia a la duplicación del ADN, pero después mencionaba la formación de dos células a través de la división celular. Y en la última parte del escrito volvía a incluir la duplicación pero sin explicitar "quién" se duplicaba. La mención inicial a ese proceso quedaba muy alejada en el texto, por ello hubiera sido necesario reponerla en esta última frase para evitar ambigüedades en la interpretación.

Oscar leyó en voz alta la parte del texto a la que refería la docente y pareció intentar comprender cuál era el problema. También la autora del texto, Yanina, intervino en este momento pero no fue audible su voz. La docente para orientar la relectura, preguntó a todos: “¿La duplicación de qué cosa genera las cromátides hermanas?'[416]; varios alumnos respondieron que lo que se duplicaba era el ADN.

Al comenzar su intervención en [420] parecía que S iba a compartir cuál había sido su interpretación, al decir: "Por eso queda..." Pero no lo hizo, se mantuvo reticente y consultó con los estudiantes si habían entendido aquello que estaba queriendo mostrar. Era posible que hubiera cierta perplejidad en este momento del plenario acerca de cuál era el problema que tenía este texto 5 . Un escrito que, a diferencia de los anteriores, no presentaba ningún error conceptual sino sólo tenía algunos problemas de cohesión. La docente continuó aclarando porqué ella consideraba que era necesario articular las dos veces que en el texto se mencionaba el término duplicación. Así indicó que "En el medio está mitosis"; en referencia a que se incorpora mitosis entre las dos menciones a duplicación. ${ }^{36}$ Y sugirió que una manera de mejorar la cohesión de ese texto era que

\footnotetext{
${ }^{36}$ El problema que subyace a estas intervenciones se vincula con los términos: duplicar, dividir. Cuando las células se dividen, se podría decir que duplican su número. Sin embargo, dado que el material que hay en ellas se reparte no se suele utilizar esta manera de referir al evento de división. El término duplicar se utiliza para referir a la copia del $A D N$, que es un evento previo a la división celular. En este texto queda
} 
cuando al volver a referir a duplicación, "tiene que haber algún tipo de conector o un punto y volver a retomar lo del principio para continuar con las cromátides hermanas." En esta intervención la docente actuó sobre quehaceres de lector y escritor, sugiriendo cuestiones de forma que a su parecer harían más claro ese escrito para ella como lectora.

En ese mismo sentido, Oscar en [423] se refirió al autor del capítulo del libro que utilizaban y lo relacionó con el requerimiento de $S$ para que en el escrito se dieran más pistas al lector. Oscar mencionó que De Robertis "va y viene, va y viene", y que ello lo obligó como lector a "ubicarse". Y afirmó que fue por eso que tomó una decisión como escritor "lo hago lineal", probablemente para que sus lectores no tuvieran esa dificultad que él manifestó experimentar.

La reticencia inicial de la docente favoreció que surgieran aportes como el de Vanesa que se ubicó como lectora, en consonancia con el rol que asumió $S$ durante esta revisión. Esas intervenciones explicitaron qué cuestiones de la estructura del texto les dificultaba la comprensión y aportaron sugerencias para reelaborarlo.

\subsection{La situación de enseñanza desde la perspectiva de estudiantes y docente}

En este apartado presentamos en primer término voces de estudiantes con relación a la situación de enseñanza analizada en este capítulo, para después compartir la perspectiva de la docente $\mathrm{S}$. Nuestro propósito fue sumar otra fuente de manera tal de enriquecer y reajustar la interpretación de los datos, y así triangular la información obtenida a partir de nuestra fuente principal, es decir: los registros de observación de clases.

\subsection{1. ¿Qué dijeron los estudiantes?}

En las entrevistas realizadas a los estudiantes con posterioridad a la implementación de la secuencia, les mostramos las consignas de todas las actividades impresas, de manera tal que fuera más sencillo rememorar cada situación. Les preguntamos si hubo alguna actividad que recordaran en particular y consideraran que les había servido para aprender, para después consultarlos por algunas situaciones específicas, como sucedió con esta actividad 8.

A partir de la lectura de las respuestas seleccionamos dos aspectos recurrentes. El primero de ellos remitió al rol que adquirió la tarea desde la perspectiva de los estudiantes. Es decir, para qué les sirvió esa situación de enseñanza. En este sentido,

el término duplicación muy cercano a la división celular y a la mención de las dos células resultantes. Es por ello que la docente considera necesario explicitar "qué cosa se duplica". 
varios alumnos refirieron que la tarea les aportó en la revisión del propio conocimiento así como algunos consideraron además que lo propuesto fue un aporte a su formación para la práctica docente. El segundo aspecto que seleccionamos se asocia con el cómo de la tarea y fue mencionado por varios alumnos al referir al lugar que ocupó la interacción entre pares en esta situación de enseñanza en particular.

En la tabla siguiente compartimos fragmentos de entrevistas que refieren específicamente a esta situación de enseñanza (actividad 8), y en la columna de la derecha indicamos los aspectos que puntualizamos y que fueron mencionados en los textos. Con posterioridad establecemos algunas relaciones entre esas voces y el análisis realizado a partir de las observaciones de clase.

\begin{tabular}{|c|c|c|}
\hline Estudiante & Fragmento de entrevista (actividad 8$)^{37}$ & Análisis ${ }^{38}$ \\
\hline Alba & $\begin{array}{l}\text { Al corregir esto yo me di cuenta que lo estaba } \\
\text { haciendo mal, yo entendía mal las diferencias. Bah, } \\
\text { confundía las etapas de la interfase. }\end{array}$ & $\begin{array}{l}\text { Revisión del } \\
\text { conocimiento }\end{array}$ \\
\hline Noelia & $\begin{array}{l}\text { (...) Sí, me gustó porque vio que por ahí en el frente lo } \\
\text { dice el profesor y uno no lo entiende, pero por ahí lo } \\
\text { dice un compañero con otras palabras más } \\
\text { sencillas y por ahí uno lo termina de entender. Eso } \\
\text { es lo que me gusta de la puesta así en común. }\end{array}$ & $\begin{array}{l}\text { Revisión del } \\
\text { conocimiento } \\
\text { Interacción entre } \\
\text { pares }\end{array}$ \\
\hline Brenda & $\begin{array}{l}\text { Yo decía: "Noo, cómo escribí esto! Puse que es al } \\
\text { finalizar esta etapa cuando el ADN se encuentra } \\
\text { compactado formando cromosomas con dos } \\
\text { cromátides hermanas al finalizar la interfase. Esta la } \\
\text { hicimos antes de empezar con este tema si mal no } \\
\text { recuerdo. Y yo dije "Ay, no, qué puse!" y después } \\
\text { bueno la corregí. } \\
\text { Sí, a mí me gustó porque aparte fue más amena la } \\
\text { clase al trabajar así, al intercambiar opiniones, } \\
\text { información, la clase se pasa más rápido. Lo que yo } \\
\text { pensaba de una manera y a otro le parecía otra. A } \\
\text { mí me gustó pero yo estaba con Oscar, uno veía un } \\
\text { texto y otro veía otro. A mí me parece que sirve. }\end{array}$ & $\begin{array}{l}\text { Revisión del } \\
\text { conocimiento } \\
\text { Interacción entre } \\
\text { pares }\end{array}$ \\
\hline Yanina & $\begin{array}{l}\text { Esta me gustó porque uno como profesor está bueno } \\
\text { que tenga la posibilidad de encontrarse con algo y } \\
\text { ver: "esto está bien, esto está mal" o sea de } \\
\text { corregirlo. Capaz que todavía no tenemos los }\end{array}$ & $\begin{array}{l}\text { Rol docente } \\
\text { Revisión del } \\
\text { conocimiento }\end{array}$ \\
\hline
\end{tabular}

\footnotetext{
${ }^{37}$ Las negritas destacan algunas frases del discurso de los estudiantes que nos parecieron relevantes para el análisis realizado.

${ }^{38}$ Los aspectos indicados están ubicados en cada casillero en el orden en que fueron mencionados en el discurso de cada alumno.
} 


\begin{tabular}{|c|c|c|}
\hline & $\begin{array}{l}\text { conceptos todos así para decir: "esto está bien, esto } \\
\text { está mal." Pero te ayuda. } \\
\text { Porque a ver (si digo) "A mí me parece que esto está } \\
\text { bien". Lo consulto con mi compañero y dice: "No, mirá } \\
\text { a mí me parece que está mal, por esta oración." (Y digo } \\
\text { entonces) "Ah, mirá, sabés que tenés razón." Ayuda. }\end{array}$ & $\begin{array}{l}\text { Interacción entre } \\
\text { pares }\end{array}$ \\
\hline Oscar & $\begin{array}{l}\text { Hay varias razones, una primero que es la de aprender } \\
\text { a evaluar. Yo creo que estamos a dos años de } \\
\text { terminar la carrera y no aprendimos, no tuvimos algo } \\
\text { que nos diga cómo evaluar. Nos hablaron de } \\
\text { evaluación en espacio de la práctica, en pedagogía, } \\
\text { bueno, pero no aprendimos a evaluar. } \\
\text { Yo creo que esto nos sirve para evaluar objetivamente. } \\
\text { Tratar de ser objetivo y evaluar. Para evaluar uno tiene } \\
\text { que criticarse primero, tiene que haber una autocrítica. } \\
\text { Entonces volver a leer en este ejercicio donde cada } \\
\text { uno, vergonzosamente o no, reconocía su texto y decía } \\
\text { "Ah! y lo están leyendo todos" Es como que uno logra } \\
\text { hacer una autocrítica. } \\
\text { Y el leer el texto de otro, sin caer en la pavada, es } \\
\text { importante creo...porque tener al otro... A mí me pasó } \\
\text { con Brenda, que dijo "éste es el mío!" (Cuando } \\
\text { reconoció su texto en la consigna de la actividad). Lo } \\
\text { leímos todos, la miramos y ella se puso colorada y dice } \\
\text { "bueno no, no..." "Pará, pará, vamos a evaluarlo! Que } \\
\text { hay muchas cosas que decís que son correctas y por } \\
\text { ahí otra es una pavada." Se animaron todos los que } \\
\text { estábamos ahí (en el pequeño grupo) a decir cuál era } \\
\text { el texto de cada uno. Estaba el de Yanina, el de } \\
\text { Brenda, el mío. } \\
\text { Me pareció muy productivo en cuanto a poder discutir, } \\
\text { porque empezamos a tener otra mirada. Cuando uno } \\
\text { está en un examen, lo hace individualmente y no sabe } \\
\text { lo que está poniendo el compañero; uno está } \\
\text { concentrado en pensar. Cuando uno hace un trabajo } \\
\text { en conjunto las ideas se tiran, uno escribe y el que } \\
\text { escribe en general es el que aporta más ideas y no es } \\
\text { muy parejo. Acá me pareció muy homogéneo el poder } \\
\text { discutir la frase, decir algo concreto cada uno, la visión } \\
\text { que tenía. Yo empecé a leer y dije "Ups!" Acá ya } \\
\text { saltaba a la vista mi inconveniente para entender el } \\
\text { tema de un cromosoma, dos cromosomas. Claro, ahí } \\
\text { saltó. Lo planteé porque yo lo leí en el De Robertis y } \\
\text { me quedó la duda, porque no me terminó de cerrar la } \\
\text { frase, no me terminó de cerrar. }\end{array}$ & $\begin{array}{l}\text { Revisión del } \\
\text { conocimiento y cómo } \\
\text { escribir }\end{array}$ \\
\hline Vanesa & $\begin{array}{l}\text { Estuvo bueno porque nosotros nos pusimos en la } \\
\text { postura de corregir, sin saber de quién era (el texto) y } \\
\text { fue interesante porque nos colocó en la situación de } \\
\text { observar y poder identificar qué es lo que estaría mal }\end{array}$ & $\begin{array}{l}\text { Revisión del } \\
\text { conocimiento y cómo } \\
\text { escribir }\end{array}$ \\
\hline
\end{tabular}




\begin{tabular}{|c|c|c|}
\hline & $\begin{array}{l}\text { en la redacción o no, como para poder colocarnos } \\
\text { de los dos lados. No es que uno corrige solamente } \\
\text { para marcar un error, sino para construir, eso me } \\
\text { pareció interesante. (...) hubo bastante participación, } \\
\text { fue bastante interactivo. Se fue armando un debate y } \\
\text { ahí saltó el tema de los cromosomas duplicados o no. } \\
\text { Me acuerdo que a mí me quedó claro eso. }\end{array}$ & $\begin{array}{l}\text { Interacción entre } \\
\text { pares }\end{array}$ \\
\hline Cristóbal & $\begin{array}{l}\text { A mí este tipo de actividad es la que menos me } \\
\text { gusta, pero es cuestión de gusto nomás. En realidad } \\
\text { (piensa), no sé por qué no me gustó. } \\
\text { Pero no es que no me gusta leer los textos de otro. Me } \\
\text { ayuda, porque hay muchos textos de estos que los } \\
\text { pude solucionar, entonces al leer textos de otro, como } \\
\text { dije en otra materia: me inspiro, je. Pero no sé por qué } \\
\text { no me gustó analizar tanto el tema, sería porque } \\
\text { todavía no aprendía bien el tema como para corregir a } \\
\text { mis compañeros. Porque todavía no sabía los } \\
\text { conceptos como para corregir. } \\
\text { (...) En esta materia yo tuve que corregir los textos de } \\
\text { mis compañeros, ya cumplo el lugar del profesor } \\
\text { con mis compañeros. Tengo que involucrarme más } \\
\text { como profesor. Y eso está bueno. }\end{array}$ & $\begin{array}{l}\text { Revisión del } \\
\text { conocimiento }\end{array}$ \\
\hline
\end{tabular}

Al pensar en la tarea propuesta Alba dijo que al revisar esos textos pudo darse cuenta que confundía las etapas de interfase. A su vez, Noelia mencionó que el hecho de que diferentes compañeros intervinieran y dijeran aquello que planteaba la profesora con otras palabras, le dio nuevas posibilidades para comprender. En ambos casos hicieron referencia a cómo esa tarea les permitió revisar su propio conocimiento.

Brenda centró la primera parte de su comentario en qué le sucedió al leer su propio escrito en esta nueva situación, en la que su texto fue objeto de revisión por toda la clase. Esa referencia de Brenda a la parte errónea, que detectó durante el trabajo en pequeño grupo (y que también mencionó Oscar), nos permitiría entender la razón de su enfática intervención durante el episodio 1, cuando indicó a sus compañeros cómo corregir el escrito del que era autora. Además de esa situación vinculada con la revisión de su propio conocimiento, ella reconoció como un aspecto positivo, la interacción entre pares durante el trabajo en pequeño grupo y plenario, al considerar que "Lo que yo pensaba de una manera y a otro le parecía otra (...) A mí me parece que sirve."Y así dar cuenta de cómo esa interacción permitió confrontar diferentes posturas.

Por su parte, Yanina también mencionó la interacción entre pares como aquello que le permitió conocer una postura diferente de la propia, que quizás no había tenido en cuenta, tal como recreó de manera dialogada. A la vez, al pensar en la situación de 
corrección que proponía la consigna de la actividad, señaló el aporte que tenía esa tarea para la constitución del rol docente.

En ese mismo sentido, Oscar refirió al propósito de la situación de enseñanza como un aporte al aprendizaje del rol docente. En particular, asoció esa situación con el aprender a evaluar cuando mencionó que al revisar los textos era necesario ser autocrítico, y que leer críticamente su propio texto les permitió posicionarse en otro lugar, al decir que "empezamos a tener otra mirada".

Vanesa valoró la posibilidad de ponerse de los dos lados, haciendo referencia a la posición del escritor y del lector/corrector de ese texto. Esta posición no quedaba reducida a marcar un error, sino que implicaba construir, quizás dando a entender que el propósito de ese lector era dar sugerencias acerca de cómo reelaborar el texto. Tanto Vanesa, al decir: "ahí saltó el tema de los cromosomas duplicados o no", como Oscar al referir a la revisión de su texto diciendo: "Acá ya saltaba a la vista mi inconveniente para entender el tema de un cromosoma, dos cromosomas", pusieron en el centro de la escena la noción de cromosomas que se trabajó y profundizó durante esta tarea, tal como describimos en varios de los episodios presentados en el apartado previo.

Por su parte, Cristóbal refirió que la actividad no fue de su gusto. Ante la repregunta acerca de si la causa era que no le gustaba leer textos de sus compañeros, respondió que no era así, que interactuar con escritos de pares lo ayudó. Y mientras fue pensando, iba diciendo que quizás la razón era que "todavía no sabía los conceptos como para corregir." Parece surgir de sus dichos cierta tensión. Tensión entre revisar para cuestionar lo que se sabe (el propio conocimiento) o saber (el propio conocimiento acabado) para poder revisar y cuestionar el saber del otro. Esa tarea de corregir los textos de pares, que pudo ser desafiante pareció generar resistencia en Cristóbal quien afirmó que "no me gustó analizar tanto el tema", aunque no sabía las razones de ello. La extensión del tiempo didáctico que menciona el estudiante en su afirmación sólo fue referida por él en asociación con esta tarea. Otros alumnos hicieron referencia al tiempo didáctico extenso con relación a otras situaciones de las secuencias del año previo, y relacionaron ese hecho (mucho tiempo dedicado) con malestar y ausencia de sentido. Ante esta misma tarea Cristóbal valoró la relación que estableció con la práctica docente al decir que "cumplo el lugar del profesor con mis compañeros", y afirmar que "eso está bueno" como también lo hicieron Yanina y Oscar.

Tal como propuso Cristóbal, para poder decir algo del escrito de otro se requiere conocer del tema, contrastar con aquello que se sabe acerca de él; pero a la vez revisarlo permite mirar con otros ojos el propio y quizás cuestionarlo. Nuestro propósito inicial de esta 
actividad de revisión fue cuestionar ciertas nociones, ponerlas en discusión y reformularlas como forma de aprender y aprehenderlas. El escrito de los pares funcionó aquí como parte de ese medio antagonista (Brousseau, 2007; Sensevy, 2010) que provocó resistencia. Esa resistencia que se manifestó en algunos dichos y gestos y obligó a los estudiantes a enfrentar otras formas diferentes de resolver una tarea, cuestionando la propia. Ese fue el propósito inicial que tenía esta tarea para nosotras, no había sido nuestra intención recrear la función del docente como revisor o corrector. Sin embargo, en este contexto ese nuevo propósito emergió de la situación de enseñanza desde la perspectiva de varios estudiantes y de la docente y por ello fue asumido como genuino.

\subsection{2. ¿Qué dijo la docente S?}

Compartimos a continuación fragmentos de la entrevista realizada a la profesora unos meses después de finalizar la implementación de la secuencia. Los dichos que transcribimos fueron enunciados cuando le consultamos concretamente sobre la actividad 8.

\begin{tabular}{|c|l|c|}
\hline Docente & \multicolumn{1}{|c|}{ Fragmento de entrevista (actividad 8) (39 $^{39}$} & Análisis \\
\hline $\mathbf{S}$ & $\begin{array}{l}\text { Esta actividad me parece valiosa en la formación docente, } \\
\text { porque los pone a ellos como lectores, por un lado, y por el } \\
\text { otro lado como correctores. Pero más que nada para ver que } \\
\text { podés escribir lo mismo de otra manera, otro tiene otra manera } \\
\text { de expresar lo mismo. }\end{array}$ & Rol docente \\
$\begin{array}{l}\text { Me parece que también es una de las actividades que los } \\
\text { hicieron animarse, porque viste que cuando ellos escriben } \\
\text { textos y uno se los devuelve y qué se yo... hay como una cosa } \\
\text { muy íntima entre cada uno de ellos y el docente. Y en realidad } \\
\text { esto crea como... la fantasía, el imaginario que Brenda siempre } \\
\text { debe escribir textos brillantes. Y seguramente que Oscar } \\
\text { también. Y no necesariamente es así. Entonces, esto es como } \\
\text { poner en juego, ponerlos a todos en juego. Je je Es como } \\
\text { jugar a... ¿cómo es ese juego de la verdad? ja ja, y decir “Ahh yo } \\
\text { no lo escribí tan mal, no lo escribí mal ¿y Brenda? Ah, pero } \\
\text { Brenda se equivocó en esto." Entonces me parece que es una } \\
\text { cuestión también de nivelación en las expectativas, en el } \\
\text { imaginario que todos tienen de que el otro es mejor que yo. } \\
\text { (...) Yo creo que a partir de una actividad de este tipo quizás los } \\
\text { personajes se ubican mejor en la realidad, digamos. Es lo que yo } \\
\text { sentí en ese momento. }\end{array}$ \\
\hline
\end{tabular}

${ }^{39}$ Las negritas destacan algunas partes del discurso de la docente que nos parecieron relevantes para el análisis. 
En primer lugar la docente destaca el rol de la tarea en el contexto de formación docente inicial, y menciona dos razones. En principio dice que, "los pone a ellos como lectores, por un lado, y por el otro lado como correctores", esa doble perspectiva, que también mencionó Vanesa, sobre un objeto (texto) profundizó la función de la corrección. Posicionarse como lector de un texto implicó intentar entender lo que propuso quien escribió, qué quiso transmitir y así se enriquece el rol de quien revisa un texto. La otra razón que dio la profesora fue en el sentido de admitir diferentes maneras de decir y así considerar que un otro puede tener otra perspectiva. Eso requirió abrir la mirada sobre ese objeto que se observaba. Esa relación entre docente y texto fue el primer aspecto que la profesora mencionó al referir a la actividad.

El segundo ítem que la docente destacó en su respuesta se vinculó con la interacción entre pares, y ella la recuerda como horizontal, tal como también destacó Oscar al hablar de una actuación homogénea, muy pareja, según sus palabras. La profesora mencionó cómo las transacciones que se realizaron durante el plenario permitieron "ponerlos a todos en juego" y quizás romper con estereotipos fijados, tal como hemos mencionado al analizar los primeros episodios.

Fue en este sentido que resultó notable cómo la acción de la profesora durante esta tarea no aparece visible en el discurso de los estudiantes, y en su propio decir. Esa manera de percibir el lugar que ocupó la docente durante la situación de enseñanza podemos vincularla con el interjuego entre reticencia y expresión que hemos descripto en los episodios previos. Así, la interacción con los pares adquirió un rol central tanto para algunos estudiantes como para la docente. Las voces de los compañeros parecieron emerger en las entrevistas como promotoras de reflexión y aprendizaje. Sin embargo, el hacerse invisible de la docente requirió acción. Fue a través de las intervenciones que hemos analizado en los episodios previos, que la docente $S$ habilitó la voz de los estudiantes y esa interacción entre pares se hizo palpable durante el plenario. Estableciendo así la dialogicidad, al interactuar diferentes voces que no se yuxtaponen sino que dialogan, con el sentido de enriquecer un mismo objeto de conocimiento (Dysthe, 1996, 2011).

\subsection{Recapitulación y relación con preguntas de investigación}

En este capítulo de resultados profundizamos en la caracterización de las situaciones de enseñanza desarrolladas en las clases 4 y 5 de la secuencia, de manera tal de aportar a nuestro problema acerca de cómo se desarrolla una secuencia didáctica que integre escribir, leer y hablar para aprender contenidos biológicos en una asignatura del Profesorado de Biología. 
Fue en ese sentido que retomamos el objetivo de identificar condiciones didácticas que favorecieran ese aprendizaje; aquí con el propósito de poner en relación esas condiciones con la modificación del estado de certeza/incerteza acerca de la noción de cromosoma. Nos preguntamos entonces ¿cuáles condiciones didácticas favorecieron el surgimiento de incertezas epistémicas? Esas incertezas que dieron lugar a que los estudiantes pudieran revisar aquello que para muchos era ya conocido, tal como ocurrió con la noción de cromosoma a lo largo del plenario.

En las características de la tarea propuesta se subsumen condiciones didácticas que fueron relevantes en este caso. Las situaciones de escritura, lectura de esos escritos e intercambios orales acerca de ellos permitieron abordar de manera recursiva el contenido disciplinar. En parte, porque hicieron posible tener en cuenta en simultáneo varias escrituras, a la vez que para varios alumnos una de ellas era de su autoría. De esa manera, los estudiantes pudieron ponerlas en relación y contrastarlas, cuestionarlas, ver en qué concordaban o no y, con base en ello, no sólo decidir acciones para mejorar un escrito sino, más sustantivamente, transformar la comprensión acerca de ciertos conocimientos disciplinares (como los cromosomas) y sobre cómo los distintos usos del lenguaje los materializan. Pero a la vez, esta característica de la propuesta (volver sobre los textos, el propio y de los compañeros) adquirió un sentido particular en este contexto de formación docente inicial. Al ser entrevistados, varios estudiantes (Yanina, Oscar y Cristóbal) y la docente $S$ vincularon la situación de revisión con una instancia de corrección asociada a la práctica docente de evaluación. Y como tal fue valorada.

Fue así que la tarea propuesta en este contexto y la manera de organizarla (con una situación individual, otra en pequeño grupo y plenario) favorecieron que hubiera diversas instancias en las que los estudiantes volvieran sobre lo hecho, para revisarlo y contrastarlo con lo que un par expresaba por escrito y también oralmente. Es decir, la tarea generó condiciones didácticas que promovieron la revisión del conocimiento y así aportó sustrato para aprender. Pero ese aporte implicó el amasado de varios componentes durante el desarrollo de las situaciones en el aula. Esos componentes que se amalgamaron como condiciones de enseñanza fueron no sólo las consignas de trabajo propuestas, sino también cómo se trabajó en el aula durante la implementación de estas situaciones y el sentido que adquirió para los estudiantes revisar los escritos de los compañeros en este contexto particular, de aproximación a su futuro rol como docentes.

En relación con ese cómo se trabajó, la mayoría de los alumnos entrevistados destacaron el lugar que ocupó la interacción con los pares durante esta tarea. Algunos 
estudiantes representaron mediante diálogos simulados cómo a partir de ese trabajo conjunto surgió un punto de vista diferente, que les permitió reflexionar acerca de sus certezas, cuestionarlas y en algunos casos transformarlas en incertezas. Esas incertezas emergieron como epistémicas durante el desarrollo del plenario y tomaron forma en algunas de las preguntas enunciadas por los estudiantes acerca de los cromosomas y sus cambios durante el ciclo celular. Desde el punto de vista de los estudiantes esa interacción dio lugar a la revisión del propio conocimiento y promovió que se enriqueciera. Así también coincidimos desde la observación con lo expuesto por algunos de los entrevistados en que la interacción alrededor de esa tarea dio lugar a una modalidad dialógica de trabajo, donde los roles se hicieron más homogéneos (en términos de Oscar) y ello permitió ponerlos a todos en juego tal como sostuvo la docente S.

En este sentido, fueron relevantes las intervenciones de la docente, que en consonancia con nuestra pregunta de investigación analizamos en profundidad también en este capítulo. En particular aquí nos centramos en qué ocurrió durante la interacción didáctica a partir de la tensión entre reticencia y expresión, en tanto componente de esas intervenciones docentes. $Y$ así quisimos dar cuenta de qué se generó y cómo se vinculó con el aprendizaje de la noción de cromosoma, trabajada durante las situaciones de enseñanza abordadas en este capítulo. El análisis de los registros de clase dio cuenta de cambios en la relación de los alumnos con el contenido disciplinar durante el plenario. Esa transformación se vinculó con el trabajo recursivo de revisión mediado por las intervenciones de la docente.

En un comienzo, la revisión se centró en modificar términos aislados, es decir, en el ajuste de significados locales del texto tal como mostramos en los episodios 1 y 2 del plenario. En estos episodios se recreó el contrato inicial que subyacía a las intervenciones de los estudiantes: seleccionar el mejor texto, corregir para mejorar el escrito pero sin reflexionar acerca de por qué era erróneo. A lo largo del desarrollo de la situación los estudiantes comenzaron a discutir la pertinencia del uso de ciertas expresiones, a la vez que establecieron conexiones más integradas entre los conceptos y la manera de expresarlos en las producciones escritas, tal como ocurrió en los episodios 3 y 4 . Eso implicó cambiar la mirada (como dijo Oscar al ser entrevistado), y poder colocarse de los dos lados (según la voz de Vanesa), es decir no posicionarse sólo como corrector sino pensar en el escrito tanto desde la posición de lector como de escritor. Asumir ese cambio de mirada fue un desafío para los estudiantes y fue en el sentido de asumirse como autores y poder separarse del escrito a revisar. 
Aun cuando durante este trabajo la docente orientó la interacción entre los estudiantes, fue reticente en relación con el conocimiento. Sus intervenciones promovieron la participación, poniéndolos en juego y así fue cómo la interacción entre pares adquirió un papel relevante, tal como varios estudiantes y la profesora destacaron en las entrevistas. En el episodio 5, la docente dejó de ser reticente e intervino para expresar aquello que había sido problematizado a partir del texto 1: cómo cambiaba durante el ciclo celular la relación entre cromosomas y duplicación, al referir a la presencia de una o dos cromátides. Durante el episodio 6, intervino para colaborar en el ajuste del texto 1 incorporando lo que había sido explicado y realizó nuevas intervenciones para abordar ahora la relación entre cromosomas y compactación. Finalmente se revisaron los demás textos, tal como registramos en el episodio 7. Al pensar en la noción de cromosoma de manera más dinámica para establecer nuevas relaciones conceptuales, el conocimiento acerca de ellos a lo largo del plenario se transformó y profundizó.

Durante los episodios que recapitulamos en vez de sólo corregir, mediante sus intervenciones la docente abrió el juego a la participación de los estudiantes. Al preguntarles, manteniéndose reticente, los invitó a participar y les devolvió el problema al orientar la interacción y discusión en torno a los escritos que estaban revisando. De este modo, la regulación de la docente a través de intervenciones orales instauró la necesidad de volver al texto, dándole visibilidad y poniendo en tensión el contenido y la forma de escribir acerca de ese contenido. Así actuó sobre los quehaceres lectores y escritores, y los textos escritos por los estudiantes se transformaron en un soporte sobre el que se pudo reflexionar. A la vez que explicitaron relaciones con otros contextos de referencia para los conceptos tratados (bibliografía y otras situaciones didácticas previas).

Nos referimos hasta aquí a condiciones didácticas e intervenciones docentes que durante el desarrollo de las situaciones analizadas fueron estableciendo un diálogo didáctico. Ese diálogo requirió un interjuego de reticencia y expresión docente para que los alumnos produjeran ciertas estrategias ganadoras e interactuaran con el saber (Sensevy, Gruson y Forest, 2015). Eso implicó que confrontaran con un medio antagonista que resultó desafiante para algunos estudiantes que resistieron a esas primeras interacciones (Fregona y Báguena, 2011).

En este sentido fue que el medio constituido por la situación de escritura confrontó a los estudiantes. Identificamos algunos gestos como indicios de resistencia a interactuar con ese medio que constituía la situación de escritura individual. Uno de ellos fue la acción de Alba de conservar su escrito y actuar como si lo hubiera entregado en el plenario posterior en el que se comentó acerca de lo escrito. Un segundo gesto de 
resistencia fue la copia de frases de la bibliografía como estrategia de textualización que puso en práctica Cristóbal durante la situación de escritura. Y después negarlo durante la situación en la que comentaron lo escrito, pero además recordar durante la entrevista que la situación de enseñanza no le gustó.

Para reelaborar teóricamente y cerrar este análisis retomamos algunos conceptos que Sensevy (2012) propone para dar cuenta de la acción didáctica conjunta. Nos interesa retomarlos dado que ponen en foco lo colaborativo de esa acción y por ello nos permitirían iluminar algunas otras aristas de lo sucedido durante las situaciones de enseñanza analizadas en este capítulo.

En primer lugar, consideramos la atención conjunta (joint attention) que refiere a cuando se comparte la atención sobre los mismos objetos al mismo tiempo. En la situación analizada, todos los estudiantes realizaban en clase la misma tarea. $Y$ en especial, durante el plenario la docente fue regulando esa atención conjunta al ir enfocando en un recorte del objeto de estudio, por ejemplo en cómo el texto enunciaba la relación entre cromosomas y cromátides. Esa atención generó a la vez una potencialidad conjunta (joint affordance), que se puso de manifiesto cuando los estudiantes expresaban cuáles eran las acciones que podían realizar para ajustar las relaciones en las que estaban trabajando en algunos episodios del plenario. El tercer concepto que propone Sensevy en relación con la acción didáctica, sería el sustrato común (common ground), una noción que remite a los significados compartidos por los estudiantes y que forman parte del contexto de referencia para esa acción didáctica. Podemos pensar aquí en el sustrato común vinculado a las nociones disciplinares compartidas que dieron sentido a los intercambios e incluso a las confusiones y dificultades que hubo con relación a cómo se concebían los cromosomas. Pero también el contexto de formación inicial puede haber modulado el rol que le otorgaron algunos entrevistados a la tarea de revisión, vinculándola con la función del docente como corrector/evaluador. Estos tres conceptos en realidad forman un sistema en el que interactúan (Sensevy, 2012), de manera tal que ese contexto común permitió que los diferentes estudiantes enfocaran su atención durante el trabajo en los mismos objetos, y que pudieran darse cuenta de sus posibilidades de actuar sobre ellos. 


\section{CAPÍTULO 6}

\section{Conclusiones generales}

Esta tesis tuvo como principal propósito conocer qué sucedía durante el desarrollo de una secuencia didáctica que integraba escribir, leer y hablar a la enseñanza de un contenido de biología celular. Y por ello para este estudio diseñamos e implementamos de manera colaborativa con la docente a cargo del curso una secuencia de enseñanza.

En las páginas previas hemos presentado los resultados del análisis que realizamos y el propósito, en esta última parte de la tesis, es retomar algunos aspectos que delinearon la mirada sobre el objeto de análisis y sistematizar los principales hallazgos de este trabajo de investigación en relación con las preguntas iniciales que planteamos. A partir de ese vínculo, mencionaremos algunas tensiones que surgieron durante el proceso investigativo, propondremos posibles contribuciones y esbozaremos algunas nuevas preguntas.

\subsection{Acerca de las prácticas de enseñanza como prácticas sociales, cooperativas}

Nuestro interés estuvo puesto en las prácticas de enseñanza que se desarrollan en escenarios singulares enmarcados por el contexto, en ellos interactúa diversidad de elementos que las constituyen en prácticas sociales de alto nivel de complejidad (Edelstein y Coria, 1995). Esta perspectiva compleja considera las múltiples dimensiones del aula, el carácter particular y diverso de las situaciones que se presentan, los conflictos de intereses entre los participantes, el establecimiento de interacciones regladas y no regladas, la riqueza y variedad de comportamientos, todos ellos como aspectos que caracterizan el hecho educativo (García, 1988). Desde esta mirada la construcción del contexto, del escenario en que se desarrollan esas prácticas, cobra especial relevancia.

Para analizar las prácticas desde la complejidad resulta necesario utilizar registros diferentes a los tradicionales, es en este sentido que Edelstein (2002) enfatiza sobre la necesidad de despegarse del atravesamiento evaluativo que suele condicionar la mirada del investigador y no le permite observar otros elementos del objeto. Si se mirara la práctica con una lente ajustada en categorías prefijadas no sería posible dar cuenta de los procesos sociales que se materializan. Al respecto la autora plantea que:

Y es la historia no documentada, justamente la que se trata de reconstruir a la luz de este enfoque y que sienta sus raíces en la recuperación de "lo cotidiano" como categoría central, teórica y empírica aquello que aparece como obvio, fragmentario, recurrente, contradictorio, divergente, con efecto de sentido para los actores sociales (Edelstein, 2002:186) 
Ese cotidiano sucedido en un aula de formación docente fue aquello que intentamos poner en foco en esta tesis, conocer e interpretar los eventos que sucedieron durante la implementación. Y para ello resultó pertinente reconocernos como sujetos no neutrales, para estar atentas y "... suspender tanto juicios totalizantes como visiones unilaterales" (Edelstein, 2002:185). Y así desmontar el aparato de enjuiciamiento tan enraizado en nuestra matriz, que apenas nos descuidamos se explicita, aún sin ser conscientes de ello. Por su parte, Rockwell (1987) sostiene que la mirada del observador está impregnada por una forma de ver y categorizar lo que sucede en el aula fuertemente influida por lo normativo-valorativo. Es por ello que resulta necesario ser conscientes de esta impronta que han dejado los años de escolarización en los investigadores en tanto sujetos sociales.

Nuestra intención aquí fue conocer y comprender lo que se desarrollaba durante las prácticas de enseñanza ( $\mathrm{y}$ en particular en situaciones que integraban prácticas de escritura, lectura y oralidad), en vez de catalogar esa práctica o analizarla a partir de aquello que no era. Fue una decisión explícita no comparar lo ocurrido con lo que podría haber sucedido. Intentamos posicionarnos desde una actitud de apertura, y para ello no observamos las clases con un eje ya delineado, sino intentamos ir y sorprendernos.

Esta decisión se enmarcó en el trabajo colaborativo con la docente $\mathrm{S}$ que, tal como dijimos previamente, implicó una decisión no sólo metodológica sino que está basada en nuestra postura epistemológica con relación a cómo concebimos la acción docente. En este sentido, fue que profesora e investigadora acordamos y sostuvimos propósitos comunes, tanto durante el diseño de la secuencia didáctica como en su implementación, acerca de cómo conceptualizar las prácticas de enseñanza (Morales, Sensevy y Forest, 2017). Este posicionamiento resulta consecuente con la perspectiva de la ingeniería cooperativa (Sensevy, Forest, Quilio y Morales, 2013). Y a la vez podemos asociarlo a la investigación colaborativa, para referir a cómo se concibe el trabajo conjunto entre docentes e investigadores. En este sentido, compartimos lo que expresan Dumrauf, Mengascini y Cordero (2017) respecto de la experiencia colaborativa que llevaron a cabo un equipo de investigadoras de la universidad Nacional de La Plata y docentes de una institución pública de la provincia de Buenos Aires,

Nuestros caminos de trabajo colaborativo pretendieron aportar a la superación de uno de los problemas más importantes que se plantea actualmente la investigación en educación en Ciencias Naturales: la disociación entre el conocimiento que se genera en el campo de investigación y el que se utiliza en el aula. El trabajo colaborativo se presenta como alternativa para superar dicho obstáculo. Al ser los y las docentes co-responsables del proceso de innovación e investigación se genera una redefinición de sentidos, roles, interacciones, problemáticas y usos de la investigación que rompe con los moldes y las jerarquías propios de los estudios producidos exclusivamente en la academia. Por otra parte, constituye una estrategia para abordar la complejidad de los problemas 
educativos, las dificultades de las instituciones para desarrollar proyectos pedagógicos fructiferos, así como el descreimiento sobre la posibilidad de transformar positivamente las prácticas docentes. (Dumrauf, Cordero y Mengascini, 2017:58)

También aquí nos interesó aportar a superar la disociación entre investigación y práctica de enseñanza y para ello trabajamos de manera conjunta con la docente S.

\subsection{Acerca de la recapitulación de resultados.}

Retomando algunos de los hilos que emergieron

En los dos últimos capítulos de resultados presentamos recapitulaciones parciales, relacionando lo analizado en cada uno de ellos con las preguntas de investigación y el problema inicial. La intención en este apartado no es reiterar esas conclusiones sino vincularlas con el marco del proceso global de investigación, de eso trata la recapitulación y nueva trama que aquí presentamos, tejida a partir de hilos que emergieron en los capítulos previos.

La secuencia diseñada e implementada se constituyó en un dispositivo didáctico que resultó del trabajo de investigación desarrollado. Eso no implica que propongamos aislarla del medio y que consideremos que fue la secuencia la que, puesta en aula, generó ciertas condiciones y tuvo función epistémica. Sin embargo, a partir del análisis realizado podemos plantear que ciertas características de ese dispositivo didáctico promovieron que los estudiantes escribieran, leyeran y hablaran y así aprendieran acerca del ciclo celular. Retomamos ahora nuestros objetivos y preguntas iniciales para ponerlos en relación.

Uno de nuestros primeros objetivos fue caracterizar las situaciones de escritura, lectura y oralidad que constituyeron la secuencia didáctica. Nos interesó describir y analizar esas situaciones implementadas en el aula como una manera de dar cuenta de aquello que provocó la propuesta en ese escenario.

Fue así que en el capítulo tres de esta tesis describimos lo sucedido al interior de cada clase, como así también contrastamos entre sí todas las situaciones de escritura, de lectura y de diálogo. Eso permitió dar cuenta de la diversidad de situaciones, así como el contexto en que cada una se había desarrollado. Aun cuando las propuestas de lectura y escritura no siempre se realizaron en el aula, de diferentes maneras ocuparon tiempo didáctico durante las clases, por lo tanto estuvieron integradas a la enseñanza del ciclo celular. En ese sentido, nos interesó mostrar cómo se habían articulado entre sí las situaciones en clase y entre clases, dando lugar a un trabajo sistemático con el leer y escribir a lo largo de toda la secuencia didáctica.

En los capítulos cuatro y cinco analizamos en profundidad lo sucedido durante una serie articulada de situaciones que se iniciaba con una tarea de escritura, continuaba con una 
lectura y concluía con diálogo plenario, y que fueron desarrolladas en dos momentos de la secuencia didáctica (al iniciar y al promediar). Y en ambos pudimos caracterizar con mayor detalle esas situaciones de enseñanza vinculándolas con aquello que sucedió durante el trabajo.

A la vez, en esta tesis nos preguntamos acerca de las características que asumían las intervenciones docentes durante estas situaciones de enseñanza y quisimos comprender aquello que generaron con relación al conocimiento en juego. Para ello en el capítulo tres referimos a las modalidades de intervención (oral y escrita) acordadas con la docente durante el diseño de la secuencia y el propósito inicial de esas intervenciones. En el capítulo cuatro describimos y categorizamos las intervenciones orales analizando la interacción que sucedía desde la perspectiva de la acción didáctica conjunta (Sensevy, 2007, 2012). Fue así que, al pensarlas como parte de una secuencia de interacción, las situamos en relación con la acción complementaria de los estudiantes, para posteriormente sistematizar cada tipo de intervención. Así referimos a las intervenciones que definen la tarea, que actúan sobre quehaceres de lectores y/o escritores, que actúan sobre contenidos disciplinares y que invitan a participar. En el capítulo cinco retomamos esos tipos de intervenciones enfocando en la dualidad entre reticencia y expresión que se ponía de manifiesto a través de ellas.

Para que la lectura y la escritura sean incorporadas como práctica de estudio y adquieran función epistémica para los estudiantes, se requiere generar ciertas condiciones didácticas. En este sentido, nos preguntamos en esta tesis cuáles eran las condiciones de enseñanza que presentaron potencialidad epistémica, y para recapitular aquello que ya hemos dicho y poder responder esta pregunta, queremos entretejer aquí las situaciones e intervenciones a las que referimos en los párrafos previos. En particular, nos centraremos en dos condiciones globales que surgen de lo presentado en los capítulos anteriores, que retomamos y entrelazamos aquí. Ellas son:

- las características de la tarea propuesta

- la modalidad dialógica de la interacción

En relación con la primera condición, las características de la tarea propuesta, tal como dijimos al presentar los referentes teóricos no todas las situaciones de escritura (o lectura) promueven aprendizaje. Esa tarea debía tener sentido para los estudiantes y para ello era necesario que estuviera integrada con aquello que se trabajó durante la clase, que para realizarla no alcanzara con leer y/o escribir para recortar y pegar información, sino que fuera una propuesta que invitara a volver a los apuntes, la guía de 
trabajo, la bibliografía, a pensar y organizar lo ya abordado. Las consignas deberían promover el trabajo recursivo sobre los contenidos, favorecer la integración al establecer vínculos entre lo que la docente explicó en clase y lo que se había trabajado previamente. $Y$ transformarse así en un instrumento dinámico y organizador del trabajo en el aula.

Aun cuando al elaborar la secuencia nos propusimos diseñar situaciones que tuvieran esas características, fue a partir del análisis de las observaciones de clase y de aquello que dijeron estudiantes y docente durante las entrevistas que pudimos abordar qué sucedió durante esas situaciones y proponer así algunos argumentos que nos permitieran mostrar cuáles características de esas situaciones de enseñanza adquirieron funciones relevantes en relación con el proceso de aprendizaje en tanto constituyentes del medio didáctico con el que interactuaron los estudiantes. A continuación puntualizamos aquellas características que asumieron las situaciones:

- desafiantes y diversas

- articuladas y recursivas

- trabajadas de manera sistemática

Tal como propusimos al analizar la situación de escritura de la primera clase de la secuencia, en el capítulo cuatro de esta tesis, algunas situaciones plantearon desafíos. En él mostramos cómo la tarea de escritura inicial aportó a problematizar la relación entre información genética y función para las células de un mismo organismo. Y cómo a partir de marcas en el discurso de algunos estudiantes esa tarea movilizó y promovió que surgieran preguntas en pos de conocer y comprender qué era la diferenciación celular para así establecer relaciones entre lo ya conocido y lo novedoso (apartado 4.3.2). Durante las entrevistas varios alumnos refirieron a los desafíos que se les presentaron al abordar las diferentes tareas de escritura (apartado 4.4). De acuerdo a diversas investigaciones, esa clase de tareas para las que resulta necesario combinar información nueva con aquello previo, podría tener potencial epistémico (Bazerman, 2009).

A la vez, resulta pertinente referir a que las situaciones fueron diversas. La condición de desafiante la asociamos a la diversidad dado que no todas las situaciones se constituyeron en desafíos para todos los alumnos. Fueron diversas en un sentido descriptivo relacionado con su organización y la función respecto del contenido conceptual que cada situación adquirió, tal como surgió del análisis que presentamos en el capítulo tres (apartados 3.3; 3,4 y 3.5). $\mathrm{Y}$ en otro sentido caracterizamos las 
situaciones como diversas a partir de aquello que los estudiantes expresaron al ser entrevistados, al dar relevancia a diferentes situaciones en relación con su aprendizaje. El segundo par de características que destacamos es articuladas y recursivas. Al analizar las situaciones en la secuencia hicimos hincapié en cómo cada una de ellas se vinculaba directamente a otras. En algunos casos porque una tarea daba sustento a aquello que se discutía en la siguiente, como sucedió con las actividades 1 y 3 (analizadas en el capítulo cuatro). En otros porque se retomaba la tarea previa de manera explícita y como parte de la nueva, como sucedió con las actividades 6 y 8 (analizadas en el capítulo cinco). En este caso además la nueva tarea de revisión de lo escrito promovió un trabajo recursivo sobre los textos (propios y de pares). Dando lugar a un proceso de ajuste de la noción de cromosoma a través de instancias sucesivas de vuelta al texto e intercambio con pares modulado por las intervenciones docentes.

Por último, destacamos el trabajo sistemático con actividades durante toda la secuencia como una condición didáctica que hizo posible aprender el ciclo celular. Tal como referimos en los apartados 3.7 y 4.4, varios alumnos entrevistados manifestaron cómo el trabajo con actividades a lo largo de toda la secuencia influyó en su proceso de aprendizaje. En este mismo sentido resulta lo expresado en distintos trabajos de investigación (Bazerman et al, 2005; Bazerman, 2009; Hand y Prain, 2012; Tynjälä, Mason y Kirsti, 2001) acerca de cómo la continuidad del trabajo con tareas de escritura realizada por períodos extensos tuvo incidencia en el aprendizaje de estudiantes en distintos contextos.

Un aspecto particular que queremos retomar aquí es cómo algunos estudiantes relacionaron el trabajo con estas tareas durante su formación, con el rol profesional docente. Al presentar la perspectiva de los estudiantes sobre la propuesta de trabajo algunas alumnas remitieron al trabajo sistemático con actividades y en particular con ciertas tareas de escritura como una característica valiosa en tanto modelo para la propia práctica docente (presentado en capítulo tres). A la vez, al referir a la situación de revisión de textos propios y de pares, tanto la docente $S$ como varios estudiantes valoraron esa situación de enseñanza en tanto había sido una tarea potente para aprender cuestiones propias del rol docente (tal como presentamos en el capítulo cinco).

Esas características particulares que hemos mencionado adquirieron relevancia asociadas a cómo efectivamente se desarrollaron las situaciones durante las clases y ello estuvo íntimamente vinculado con la segunda condición que destacamos, la modalidad dialógica de la interacción. En esta recapitulación nos vamos a centrar en dos pilares que sostuvieron esa modalidad. Estos son: 
- las intervenciones de la docente

- la interacción entre pares

En primer lugar retomamos los hallazgos vinculados con cómo, desde la intervención, la docente $S$ construyó la dialogicidad en el aula. En el capítulo cuatro documentamos cómo las intervenciones docentes, por ejemplo aquéllas que invitaban a participar a los estudiantes, dieron lugar a que se estableciera un diálogo alrededor de la interpretación del título de la lectura "Una vida, muchos estilos de vida" realizada en esa primera clase. A través de sus intervenciones, la docente $S$ habilitó las diferentes opciones que los estudiantes propusieron acerca de la interpretación de ese título. Esa instancia de prestar su voz para enunciar cada una de ellas, sugerir que contrastaran y pensaran en las diferentes opciones fue una instancia relevante en esa primera clase para establecer la modalidad de diálogo para el trabajo durante la secuencia. A la vez, para ello fue pertinente la reticencia que asumió la docente decidiendo, en ese momento, dejar de lado su propia interpretación como manera de dar lugar y jerarquizar todas las voces, dado que todas ellas planteaban opciones posibles.

En esa misma situación tal como dijimos la docente promovió la interacción entre pares al solicitarles que contrastaran la propia interpretación con aquella que iban enunciando los compañeros. En este sentido, Dysthe (2013) propone que:

Cuando los alumnos construyen nuevos significados reaccionando a lo que dicen los demás también se activa un conjunto de otras voces. Lo que han oído, leído o visto antes incide en su respuesta y, dado que las experiencias de cada alumno son únicas, su expresión deviene "irrepetible". Esta es una de las razones por las que la enseñanza basada en el diálogo es interesante para el docente. (Dysthe, 2013:59)

Sin embargo, concluye la autora, para que en el contexto educativo el potencial plurivocal se pueda aprovechar en pos de la construcción de conocimiento requiere de una reflexión y esfuerzo especial por parte del docente. Dado que resulta un desafío, además de dar lugar a esas voces diversas, tiene que cerciorarse que queden claras las diferencias que existen entre ellas. $\mathrm{Y}$ asumir que los desacuerdos podrían aportar a mejorar la comprensión de aquello que se discute.

En este sentido, Bakhtin (1981) refiere a la palabra autorizada como aquella que demanda que se la acepte tal cual e implica una relación jerárquica. En las instituciones escolares, que son básicamente jerárquicas, la palabra docente suele asumir esta condición. A la vez, propuso la palabra intrínsecamente convincente, como aquella que llega desde fuera pero que nos confronta al encontrarse con nuestros pensamientos. Esa palabra es puesta a prueba a través del diálogo, la adoptamos y la podemos usar de nuevas formas, en esa instancia se convierte en productiva (Dysthe, 2013). En las situaciones analizadas en esta tesis podemos reconocer cómo a través de la 
confrontación de voces de pares, mediada por las intervenciones de la docente $\mathrm{S}$ a través de la regulación de la reticencia y la expresión se fue modificando el discurso acerca de la diferenciación celular (en el capítulo cuatro) y la noción de cromosoma (capítulo cinco). En este sentido, la palabra de la docente jugó un rol relevante como parte de esta modalidad dialógica, tal como sostiene Dysthe, (2013):

En el contexto de la enseñanza, la confianza de los alumnos por la autoridad académica del profesor (la palabra autorizada) es un requisito para la verificación crítica de múltiples voces y, con ello, una condición para que los alumnos puedan desarrollar su palabra intrínsecamente convincente, ya se trate de conocimientos, valores u opiniones personales sobre una obra de arte o sobre la temática de la asignatura. (Dysthe, 2013:63)

La manera en que la docente intervino fue central para que la interacción entre pares se constituyera en una condición naturalizada en este aula y pasara a formar parte del contrato didáctico; tal como se desprende de los episodios analizados en el capítulo cinco y las voces de estudiantes entrevistados, que recogimos en ese mismo capítulo.

A la vez, queremos detenernos aquí en cómo se construyó esa modalidad dialógica en este contexto particular de las clases de Biología celular en un aula de nivel superior de enseñanza. Esa dialogicidad no implicó negar la univocidad de los términos científicos, pero sí permitió abrir interpretaciones a través de las voces de los estudiantes para favorecer la comprensión. Nos parece interesante resaltar aquí este aspecto particular de la enseñanza de la disciplina en este nivel, cómo durante el trabajo en pequeño grupo y plenario la docente fue abriendo esa univocidad, modificando el contrato y actuando en la constitución del medio didáctico con el que los estudiantes se enfrentaron. Ese proceso lo actuó a través de sus intervenciones que dieron cuenta de la relación dinámica entre reticencia y expresión docente.

El aporte al conocimiento vinculado con las condiciones de enseñanza que referimos hasta aquí se puso en evidencia a través de marcas en el discurso que dieron cuenta de cómo determinadas certezas se cuestionaron y pasaron a constituirse en incertezas epistémicas. Como por ejemplo los reajustes sucesivos durante diferentes episodios del plenario, acerca de la noción de cromosoma, tal como presentamos en el capítulo cinco.

Por último en esta tesis también nos propusimos conocer algunos desafíos, resistencias y logros que surgieron durante el desarrollo de las situaciones de escritura, lectura y oralidad. Hemos referido ya a los desafíos que plantearon algunas de las tareas de la secuencia, íntimamente asociados a sus características. A la vez al abordar algunas de esas situaciones hubo estudiantes que resistieron ante esa interacción con el medio didáctico, tal como propusimos en los capítulos cuatro y cinco en referencia a las situaciones de escritura individual. A la vez, en ambos capítulos y en la recapitulación precedente ya hemos referido a logros vinculados con el trabajo 
durante la secuencia. Estos tres aspectos están imbricados en los hilos que retomamos vinculando las características de las situaciones, las intervenciones y la interacción entre pares.

\subsection{Acerca de tensiones, aportes y nuevas preguntas}

Mencionamos ahora algunas de las tensiones que surgieron durante el proceso de investigación realizado para esta tesis.

En primer lugar, la tensión entre la información relevada y la necesidad de ajustar el foco de análisis. Esa gran cantidad de información en cuanto a volumen y diversidad estuvo dada por condiciones particulares del mismo proceso investigativo que implicó la intervención didáctica. Diseñamos y pusimos en aula tres secuencias de enseñanza, cuyas clases presenciamos, audiograbamos y en parte transcribimos. Recogimos todos los materiales utilizados (consignas de trabajo, bibliografía, videos, otras imágenes entregadas), así como las sucesivas versiones de las producciones escritas, incluyendo las evaluaciones parciales que realizaron los estudiantes. A la vez, grabamos las sesiones de trabajo realizadas con la docente durante las etapas de diseño y guardamos los borradores de los planes de clase que realizamos de manera conjunta en sus sucesivas versiones. Como así también las entrevistas realizadas a la docente y los estudiantes al finalizar la secuencia que efectivamente fue analizada para esta tesis.

Pero el trabajo de seleccionar y jerarquizar esa multiplicidad de información de manera tal de transformar parte de ella en datos pasibles de ser abordados, resultó en un arduo y extenso proceso que llevó varios años. En el capítulo dos presentamos algunos de sus hitos, así como las decisiones metodológicas que tomamos con el objetivo de ajustar el foco de análisis.

En segundo lugar mencionamos la tensión entre la perspectiva asumida de investigación colaborativa y los presupuestos que surgieron, en principio sin ser consciente de ellos. Esto implicó reflexionar acerca de lo difícil que es sostener una postura investigativa en un trabajo cooperativo, y que para hacerlo resulta necesario estar pendiente de no desplegar el aparato de enjuiciamiento al intentar explicar por qué no había sucedido algo similar a las predicciones previas durante el trabajo en aula con algunas de las situaciones de enseñanza diseñadas.

Por ejemplo, al trabajar con la actividad 8 (que fue analizada en detalle en el capítulo cinco), resultó inesperada la posición binaria inicial que asumieron los estudiantes como correctores en interacción con el medio. Durante el análisis tuvimos que despojarnos de esa mirada para comprender el rol del contrato didáctico en esas acciones, tal como presentamos en el análisis del episodio 1 (apartado 5.3.2.1). 
Ahora queremos reflexionar acerca de los posibles aportes de esta tesis y para ello compartimos algunos puntos en relación con la investigación centrada en prácticas de enseñanza.

- El estudio que realizamos podría aportar evidencias acerca de cómo el trabajo sostenido y regulado con ciertas prácticas de escritura y lectura generó condiciones que promovieron aprender contenidos disciplinares específicos. El análisis de cómo las situaciones didácticas y las intervenciones docentes generaron determinadas condiciones de enseñanza que fueron potentes en relación con el conocimiento en juego, podría ser un insumo para pensar cómo integrar esas prácticas a la enseñanza en el contexto de disciplinas específicas.

- En particular, este trabajo estuvo centrado en el nivel superior de enseñanza, un ámbito en que enseñar integrando tareas que involucren escribir y leer durante las clases (y no sólo en las evaluaciones) no suele ser la modalidad hegemónica de enseñanza. En este espacio hay pocos trabajos que se centren en la interacción sucedida durante las clases alrededor de esas prácticas, consideramos que esta indagación puede aportar acerca de cómo y para qué incluir prácticas de escritura y lectura para enseñar en este nivel. Así como plantear sugerencias respecto a las condiciones que podrían favorecer que efectivamente esas prácticas se transformen en epistémicas.

- Por otro lado, nos referimos aquí a la enseñanza de un contenido disciplinar abstracto de la Biología asociado a vocabulario específico e unívoco. Sin embargo, el hecho de promover la interacción en el aula a través de ciertas situaciones de enseñanza mediadas por intervenciones docentes permitió poner en discusión los conceptos disciplinares con los que se trabajaba. Y movilizar certezas, como ocurrió con la noción de cromosomas, para constituir incertezas epistémicas que permitieran enriquecer el conocimiento acerca de ellos. Las situaciones de enseñanza, así como las intervenciones de la docente tuvieron un rol relevante en este sentido. Es por ello que consideramos que el trabajo en los diferentes episodios descriptos podría aportar a comprender algunos indicios acerca de cómo esas nociones se ponen en movimiento durante la enseñanza de contenidos de biología celular.

- Por último, consideramos que la información que aporta esta tesis podría brindar algunos ejemplos para reflexionar acerca de cómo impacta la formación docente inicial disciplinar en la constitución del rol profesional. Esta tesis no se propuso trabajar en ese sentido, pero emergieron algunas puntas acerca de 
cómo el contexto particular de formación inicial se constituyó en un escenario potente para que los futuros docentes reflexionaran y reconocieran modelos acerca de cómo concebían su propia práctica.

Para finalizar, esbozamos algunas nuevas preguntas y asoman como nuevas puntas para seguir indagando. Nos preguntamos si ¿las categorías de intervención que construimos en íntima asociación con los datos relevados, podrían ser fructíferas para pensar otros casos? ¿Y en esos casos qué particularidades adquiriría por ejemplo "actuar sobre quehaceres de lector y/o escritor"? ¿Esas particularidades están asociadas al trabajo específico que actúa un docente disciplinar?

Otro tipo de preguntas que surgen y nos planteamos tienen que ver con profundizar la comprensión acerca de la acción docente. Una cuestión central relacionada con lo abordado aquí es ¿Cómo la docente sostuvo la tensión entre reticencia y expresión? En este sentido, hubiera sido interesante analizar clases de las diferentes secuencias que diseñamos, para así contrastar diferentes momentos y analizar sus sentidos cuando la dualidad reticencia/ expresión se puso de manifiesto. $Y$ poder pensar en el proceso completo de trabajo y el contexto de cada implementación.

A la vez también nos preguntamos, en este espacio de formación docente inicial, acerca de los estudiantes en tanto futuros profesores, y así nos interesa ahondar en ¿Cómo se aprende la dialogicidad? El hecho de haber atravesado por propuestas de enseñanza de modalidad dialógica ¿alcanza para hacerla visible? ¿Permearon esos modelos y experiencias? ¿Logran los estudiantes recuperar esa modalidad en el ejercicio profesional? Creemos que hubiera sido necesario trabajar con instancias de doble conceptualización (Lerner, Stella y Torres, 2009) para que ello fuera objeto de reflexión y enseñanza. Estas son algunas nuevas puntas de hilos que es posible desmadejar y que dejamos tendidas aquí.

El trabajo desarrollado para esta tesis implicó mucho tiempo y esfuerzo, con épocas luminosas y otras oscurecidas por diferentes causas; algunas propias de las crisis derivadas de la tarea y otras vinculadas con el devenir de la propia historia personal. Para cerrar este trabajo finalmente recogemos la punta del ovillo que, como el hilo de Ariadna, nos llevó a través del laberinto al que los habíamos invitado a ingresar con la promesa de disfrutar la travesía. Un recorrido que nos ha desvelado, pero que al salir de ese laberinto, nos permite reconocer un conocimiento didáctico situado alrededor de una experiencia innovadora que llevaron adelante estudiantes de una carrera de formación docente y una profesora comprometida con mejorar su práctica y orientar a 
sus estudiantes en su proceso de aprendizaje a través de integrar escribir y leer para aprender. 
ANEXO 


\section{Secuencia didáctica Ciclo Celular.}

\section{Clase 1}

\section{Actividades de escritura inicial}

\section{Actividad 1}

Nuestro cuerpo está formado por células con estructura y funciones diversas: células nerviosas, epiteliales, sanguíneas, musculares, etc. Todas esas células tienen información genética.

a) Las células beta del páncreas producen la proteína insulina, una hormona que interviene en la regulación del nivel de glucosa sanguínea. Las células nerviosas no producen esta proteína, pero producen otras. ¿Cómo podrías explicar que las células del páncreas sí produzcan insulina y las nerviosas no lo hagan? ¿Las células del páncreas y las nerviosas de tu cuerpo tienen la misma información genética, o cada tipo celular tiene parte de la información?

b) Todos los organismos de reproducción sexual se originan a partir de una primera célula denominada cigota, esa célula contiene la información genética que aportaron los progenitores. ¿Cómo podés explicar que a partir de esa única célula, en algunos meses, se forme un embrión con varios millones de células? Menciona qué sucesos consideras que deben ocurrir para formar un individuo pluricelular, por ejemplo un bebé humano.

\section{Actividad 2}

Cuando nos referimos al concepto "información genética" suelen surgir varios términos asociados. Les pedimos que escriban una o dos oraciones en las que relacionen los siguientes conceptos: ADN, genes, cromosomas e información genética. Úsenlos de manera explícita y en el orden que prefieran 


\section{Clase 1. Actividad 3}

\section{LECTURA: UNA VIDA CON MUCHOS ESTILOS DE VIDA}

¿Te pusiste a pensar que el cuerpo humano, como el de cualquier organismo pluricelular, es una comunidad de células con estructuras y funciones algo diferentes que se auto organizan en un patrón corporal determinado? Los humanos estamos formados por una sociedad celular donde conviven entre 50 y 100 billones de células distribuidas en unos 200 tipos celulares diferentes, así es que conviven en nosotros más de 200 estilos de vida diferentes. A pesar de estas diferencias, nuestras células presentan muchos aspectos comunes y por eso toda esta diversidad de tipos celulares se puede ordenar o clasificar teniendo en cuenta algunos criterios consensuados. Por ejemplo, cuando identificamos tejidos, un criterio posible es clasificar los tipos celulares según las funciones que cumplen. Otro criterio para clasificar a las células podría ser la periodicidad con que se reproducen.

Este es un aspecto interesante, pues para que adquiramos la forma que tenemos y además podamos mantenerla en el tiempo, la reproducción o la no reproducción de las células es un asunto de vital importancia. Como dice Steven Rose en su libro Trayectorias de Vida (2001), el organismo es tanto el tejedor como el tejido. En este sentido, la auto organización y auto reparación son propiedades esenciales que dan forma y funcionalidad al organismo, desde que fuimos un cigoto se fueron desplegando secuencias de eventos que desembocaron en el desarrollo de un cuerpo con una gran diversidad celular. Precisamente esta variedad proviene del proceso de diferenciación celular, que implica numerosos cambios en la estructura y el metabolismo. Estos cambios, relacionados con la expresión de los genes, permiten que esas células cumplan funciones diferentes en los tejidos que conforman a los órganos. Además, esta diversidad celular requiere que todas ellas convivan en democrática armonía para mantener el cuerpo saludable.

Si nos referimos al período de tiempo que demora una célula en reproducirse podemos considerar que hay variedad de tiempos. Las células embrionarias se reproducen velozmente, en alrededor de 24 horas a partir de una célula se forman dos, y cada una de ellas desencadena rápidamente los sucesos necesarios para volver a dividirse, esto lleva al acelerado crecimiento del embrión. Pero a medida que las células se van diferenciando durante la organogénesis y adquieren sus características definitivas, su ciclo de vida se hace más lento y dura más tiempo. No sólo en un embrión hay células de vida corta que rápidamente se dividen y dan origen a dos células iguales que reiteran el ciclo, sino que varios tipos de células de un organismo adulto también pasan por una serie consecutiva de etapas que llevan a la reproducción. Es decir, transitan por el ciclo celular de manera continua, sin detenerse. Por ejemplo, las células basales del epitelio de la piel y de las superficies internas de los conductos del cuerpo (vasos sanguíneos, tubo digestivo, conductos urinarios, etc.) se regeneran constantemente. Los glóbulos rojos no tienen núcleo y viven aproximadamente 6 meses, por lo tanto debe haber una reposición continua para sostener el abastecimiento de oxígeno para la respiración celular. Esto requiere que las células precursoras de las células sanguíneas, que se encuentran en la médula ósea, se reproduzcan permanentemente en ciclos celulares consecutivos. Se estima que se producen 2,5 millones de nuevos glóbulos rojos por segundo.

De esta manera, la reproducción de las células somáticas permite el crecimiento de cada uno de los órganos y así el crecimiento del organismo pluricelular, como también la reproducción celular hace posible la reposición o reemplazo de células que van muriendo, o la reparación de tejidos luego de algún daño. En el cuerpo humano adulto se supone que ocurren unas 25 millones de divisiones por segundo, todo esto a su tiempo y armoniosamente en un contexto de salud física. Se requiere de un control preciso de la reproducción celular para determinar el tamaño y la forma de cada órgano, no puede ser indefinida esa división. Algunas células deben dejar de reproducirse para estabilizar el tamaño y el diseño estructural y funcional del órgano y consecuentemente del organismo como un todo. Por ejemplo, el desarrollo del cerebro implica la reproducción de millones de células por hora, las 24 horas durante casi toda la gestación. Sin embargo, el cerebro no crece como una masa amorfa. Está altamente organizado, con regiones funcional y estructuralmente especializadas donde las neuronas están organizadas según un patrón particular. Las neuronas, una vez que completaron su diferenciación y ocuparon su lugar definitivo, ya no se reproducen. 
Pero para llegar a un cerebro adulto de kilo y medio con cien mil millones de neuronas y un billón de células de la glía, no sólo hubo reproducción celular diferencial, sino también muerte celular programada (apoptosis) de aquellas neuronas que no establecieron las conexiones correctas. El cerebro de un adulto no tiene más neuronas que el de un bebé, sino que cambia el tamaño de estas células, la cantidad de sinapsis que establecen, la mielinización y aumenta la cantidad de células de la glía. La muerte celular programada es de vital importancia para el desarrollo y el diseño final de los órganos y su funcionamiento apropiado, esto sucede en la muerte por apoptosis de la membrana interdigital entre los dedos de un embrión humano para el diseño final de las manos.

Algunas células de la musculatura esquelética, de la epidermis de la piel, los linfocitos de la sangre y células del sistema nervioso, al dividirse dan origen a dos células que tendrán destinos diferentes. Una de ellas queda como célula madre, y así crecerá, copiará su material genético y se dividirá, y la otra se diferencia como célula funcional específica y ya no se vuelve a reproducir. Las células madres dan origen a dos tipos de células, una se parece a la progenitora y la otra no. Otros tipos de células normalmente no se reproducen y quedan "detenidas" en una etapa de su vida, pero cierto estímulo adecuado las induce a reproducirse. En el hígado adulto, los hepatocitos cumplen con su función diferenciada y no se reproducen, pero si el órgano sufre un daño importante y pierde a muchas de sus células, las restantes se desdiferencian y se reproducen hasta que el órgano alcanza el tamaño original. En ese momento se detiene la división celular. Los linfocitos son otra clase de células que no se reproducen siempre, sino sólo cuando interactúan con el antígeno correcto, en ese momento se activa la reproducción. También los fibroblastos del tejido conjuntivo comienzan a dividirse sólo cuando nos lastimamos la piel, y a su vez estimulan a las células epiteliales para repararla correctamente.

Entonces, las relaciones tanto espaciales como químicas que se establecen dentro de esta compleja sociedad celular, que son los organismos pluricelulares, determinan junto con las características genéticas el tamaño y la forma del organismo. 


\section{Clase 3. Duplicación de ADN}

\section{Actividad 4}

Las siguientes frases refieren a eventos que suceden durante el proceso de replicación de ADN que se desarrolla en una célula.

A. Les pedimos que ordenen cronológicamente esos sucesos colocando números al lado de cada frase.

a. La hebra retrasada se sintetiza de manera discontinua, formándose los fragmentos de Okazaki.

b. Las enzimas Helicasas van abriendo la burbuja de replicación a partir del sitio ORI, hacia ambos lados.

c. A partir de cada molécula de ADN se sintetizan dos moléculas de ADN que quedan unidas por la zona del centrómero.

d. Una enzima ADN Polimerasa va completando con desoxiribonucleótidos los sectores donde se encontraban los primers. Lo realiza a partir del extremo 3'.

e. Las Topoisomerasas cortan las hebras de ADN que giran liberando la tensión acumulada en los extremos de cada horquilla de replicación.

f. Las enzimas ADN Polimerasas avanzan "leyendo" desde el extremo 3'al 5' de la cadena de ADN.

g. La enzima Primasa sintetiza a partir del ORI un pequeño ARN complementario a cada hebra de ADN.

h. La ADN Polimerasa va uniendo cada nucleótido nuevo desde el extremo 5' al extremo 3' del último que había ubicado en la cadena en formación.

i. La cadena adelantada se sintetiza de manera directa y continua.

j. A medida que las Helicasas separan las hebras del ADN, la enzima Primasa sintetiza un nuevo primer en la cadena complementaria a la directa.

k. Se reconoce un sitio ORI que nunca fue abierto para replicación.

I. Una enzima separa los primers de los fragmento de Okazaki.

m. Los fragmentos de Okazaki son unidos por acción de la enzima Ligasa.

n. Se fusionan las diferentes burbujas que se replicaron en una misma molécula de ADN.

o. La enzima ADN Polimerasa une un desoxiribonucleótido al extremo 3'del primer o cebador.

p. Se forman cromosomas con dos cromátides hermanas.

q. Se forman dos complejos conformados por las enzimas Helicasa, Primasa y dos ADN Polimerasas. Cada complejo está sujeto por un anillo proteico.

r. Se completa la síntesis de ADN de una burbuja de replicación.

B. Ahora les pedimos que relacionen los esquemas 17.6 y 17.9 del capítulo 17 del libro de De Robertis con los eventos del listado previo, ¿cuáles frases podrían corresponder a cada uno?

\section{Actividad 5}

Escriban un texto que describa lo que sucede durante el proceso de duplicación de ADN. Para ello pueden utilizar como base las frases de la actividad 4, adaptándolas ahora al texto que redacten y agregando los términos o conectores necesarios para que el escrito resulte claro. Si quieren pueden incorporar nuevas oraciones o extender algunas de las que se presentan en la actividad.

Además piensen y ubiquen esa descripción en un contexto determinado, es decir, elijan como protagonista un tipo de célula humana particular. Según cuál consideren incluyan en su texto alguna referencia al momento de la vida de ese ser humano del que forma parte la célula que se encuentra duplicando su ADN. La intención es obtener un texto final que pueda ser de utilidad para estudiar el proceso de replicación al momento del parcial. 


\section{Clase 4. Actividad 6}

\section{Actividad 6}

Imagina la vida de una célula epitelial. Refiriéndote a su ciclo celular, escribe un texto relacionando los siguientes conceptos:

Etapa $S$ de interfase - mitosis - cromátidas hermanas - $A D N$ - cromosomas

\section{Clase 5. Actividad 8}

\section{Actividad 8}

Los siguientes textos fueron escritos por ustedes durante la clase pasada a partir de la consigna que transcribimos arriba. La actividad tenía como propósito pensar qué relación hay entre los diferentes momentos del ciclo celular, y ubicar a los cromosomas en ese ciclo de vida. Ahora les pedimos que lean los textos de todos y analicen si en cada texto se expresa de manera clara la relación entre:

* Etapa S y Mitosis como etapas del ciclo celular

* ADN, cromosoma y cromátidas hermanas.

Además marquen en el texto si hay frases o partes confusas y si es así, qué sugerencias le harían al compañero autor del texto.

Texto 1: Al finalizar la etapa $S$ de interfase, la célula epitelial ha logrado duplicar su ADN quedando formadas dos cromátides hermanas llamadas cromosomas, unidas por el centrómero. Dicha célula ingresa a la etapa G2, y luego a la etapa de Mitosis, donde dichos cromosomas se separaran.

Texto 2: Las células hijas heredan la misma información genética contenida en la célula progenitora. Transitan por dos etapas la interfase y mitosis y le sigue la fase $\mathrm{S}$, en la mitosis los ADN hijos están unidos, esos ADN llevan el nombre de cromátides hermanas, que pasa a llamarse cromosoma después de la separación

Texto 3: Las células epiteliales tienen una reproducción celular constante. El ciclo de reproducción comienza con la duplicación del ADN; el mismo ocurre en la etapa $\mathrm{S}$ de la interfase. Por cada molécula de ADN duplicado, obtengo 2 cromátides hermanas. Continuando el proceso ya en la etapa de la mitosis es donde los cromosomas se empiezan a condensar

Texto 4: Una célula epitelial como toda célula somática se reproduce por mitosis. Antes de la reproducción la célula debe duplicar el ADN y lo hace en la etapa S de interfase del ciclo celular. Es al finalizar esta etapa cuando el ADN se halla compactado formando cromosomas con dos cromátidas hermanas.

Texto 5: En la etapa $S$ de interfase el ADN de una célula epitelial necesita duplicarse para poder dividirse por mitosis y así dar origen a dos células con la misma información genética, una vez finalizada la duplicación los cromosomas de la célula epitelial poseen cromátidas hermanas. Etapa $S$ de interfase - mitosis - cromátidas hermanas - ADN cromosomas 


\section{Actividad 7. Mitosis}

(Entregada al finalizar la clase 4 como tarea entre clases para exponer durante la clase 5)

Para trabajar con el proceso de división celular mitosis, les pedimos que cada 2 o 3 alumnos realicen dos diapositivas de un power point referidas a la fase asignada (si consideran que aporta mayor claridad pueden agregar alguna más). Consideren que la célula que van a representar es $2 n=4$.

Las diapositivas deben tener imagen y texto. La imagen puede ser uno o más esquemas, fotos o dibujos, en esa imagen tiene que estar representado lo que sucede en esa etapa con los cromosomas. El texto solicitado debería describir los principales acontecimientos que ocurren en esa etapa en relación a los cromosomas, los husos mitóticos, los centríolos, la membrana nuclear. Recuerden que los "actores principales" del proceso son los cromosomas.

Pueden trabajar con diferentes fuentes de datos, como el capítulo 18 del libro Biología Celular de De Robertis, otros libros que ustedes tengan (por ejemplo Biología de Curtis que presenta fotos y esquemas, además de tener una animación). También pueden usar materiales de la web (enciclopedias, videos de you tube, u otros) y buscar en internet utilizando Google imágenes (citen las páginas si toman imágenes). La próxima clase comentaremos acerca de las fuentes.

Les pedimos que envíen por mail el ppt a la casilla de biología celular: bioceluymol@gmail.com y a todos los compañeros del curso, de manera que la próxima clase todos puedan tener las diapositivas de toda la división celular en su netbook. 


\section{Clase 6. Mitosis}

ACTIVIDAD 9. Las moscas de la especie Drosophila melanogaster tienen células diploides con 6 cromosomas. Imagine una célula somática de una mosca de esa especie que está realizando Mitosis, dibuje un esquema que represente esa célula en Metafase y otro de la célula en Anafase. Señale en el dibujo un par de cromosomas homólogos y un par de cromátidas hermanas.

ACTIVIDAD 10. Compare los resultados obtenidos entre la mitosis de una levadura (hongo unicelular) y las células de la hoja de una planta. ¿En qué caso se puede decir que se obtuvieron descendientes? Explique su respuesta.

ACTIVIDAD 11. El complemento cromosómico de los chimpancés es $2 n=48$. Suponga una célula somática del chimpancé y complete las casillas en blanco de la siguiente tabla:

\begin{tabular}{|c|c|c|c|c|}
\hline $\begin{array}{c}\text { Fase del ciclo } \\
\text { celular }\end{array}$ & $\begin{array}{c}\text { Cantidad de } \\
\text { cromosomas }\end{array}$ & $\begin{array}{c}\text { Cantidad ADN } \\
\text { (pg.) }\end{array}$ & $\begin{array}{c}\text { Cantidad de } \\
\text { cromátidas por } \\
\text { cromosoma }\end{array}$ & $\begin{array}{c}\text { Cantidad de } \\
\text { moléculas de } \\
\text { ADN por } \\
\text { cromosoma }\end{array}$ \\
\hline G1 & & $100 \mathrm{pg}$ & & \\
\hline G2 & & & & \\
\hline $\begin{array}{c}\text { Telofase (en } \\
\text { cada polo) }\end{array}$ & & & & \\
\hline
\end{tabular}

ACTIVIDAD 12. Considere un organismo pluricelular, por ejemplo una planta cuya raíz está creciendo. Al respecto redacte un texto que contenga y relacione los siguientes términos: cromatina, duplicación del $A D N$, cromátidas hermanas, mitosis, enzimas. 


\section{Clase 7. Actividades preparación parcial ${ }^{40}$}

ACTIVIDAD 13. Los siguientes esquemas representan diferentes células en plena división celular. Observe cada uno de ellos y diga: cuáles de ellos corresponden al proceso de MITOSIS, en qué fase de la división celular se encuentra y cuál es el complemento cromosómico ( $n$ o 2n) de la célula original (la que inició la división). Recuerde que la Mitosis se puede llevar a cabo tanto en células de organismos diploides como haploides.

a



d

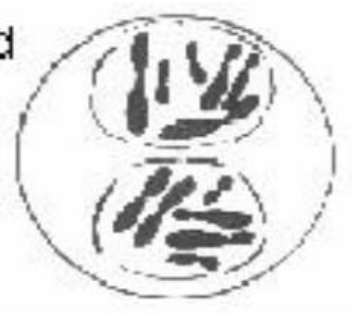

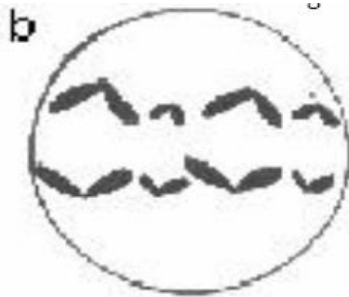

$\epsilon$

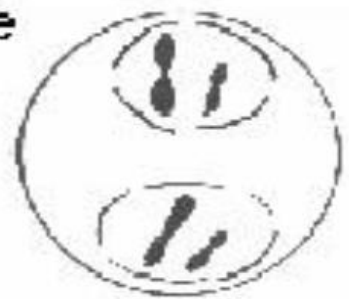

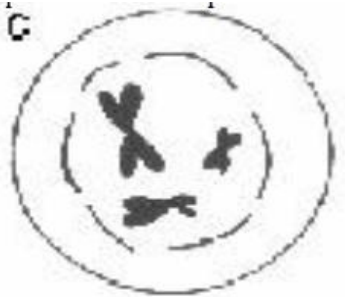

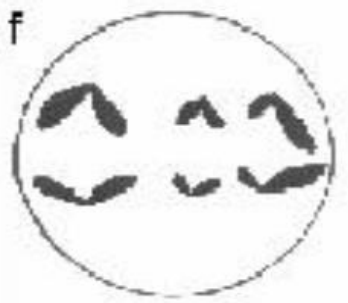

ACTIVIDAD 14. Observe los siguientes esquemas:

a) Para cada caso mencione si la célula representada se trata de una célula haploide o diploide.

b) Elija una célula haploide y otra diploide. Mediante esquemas represente la mitosis de cada una de ellas.
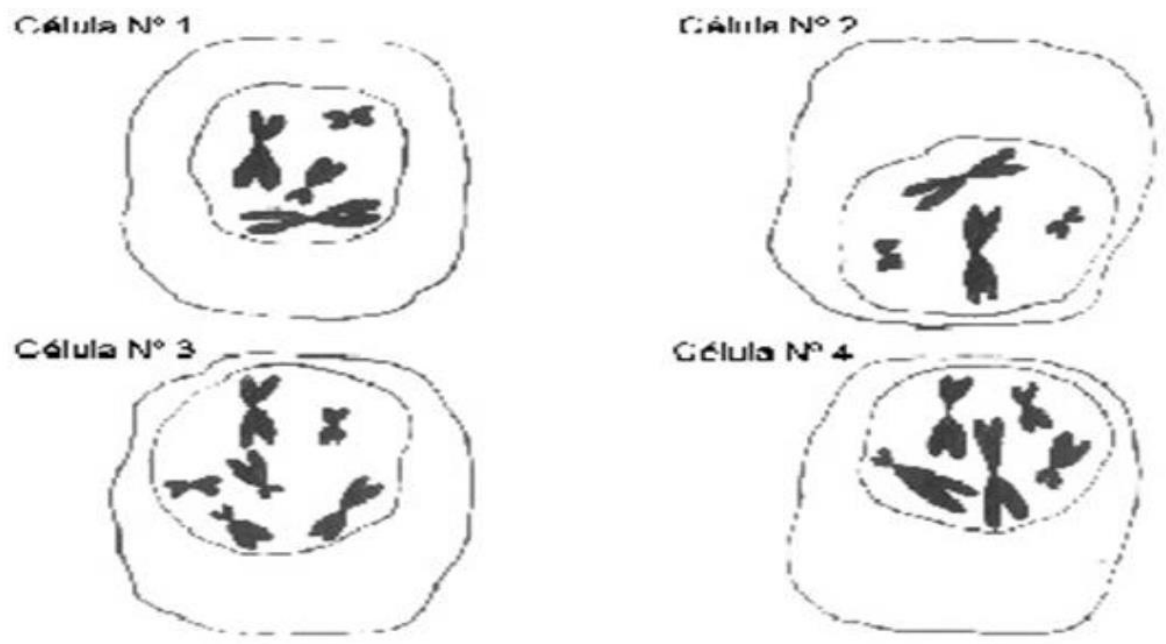

ACTIVIDAD 15. Las siguientes son fotografías de células vegetales en diferentes fases de la división celular Mitosis. Identifique a que fase correspondería cada foto, indicando qué dato tiene en cuenta para ubicar la foto en esa etapa.

40 Las imágenes que forman parte de las actividades 13, 14 y 15 son parte del libro Acerca de genes, organismos y células (2006), escrito por De Micheli A,; Donato, A.; Iglesia, P. y Otero, P. Material de la cátedra De Micheli de Biología de la sede Regional Norte del CBC. UBA 

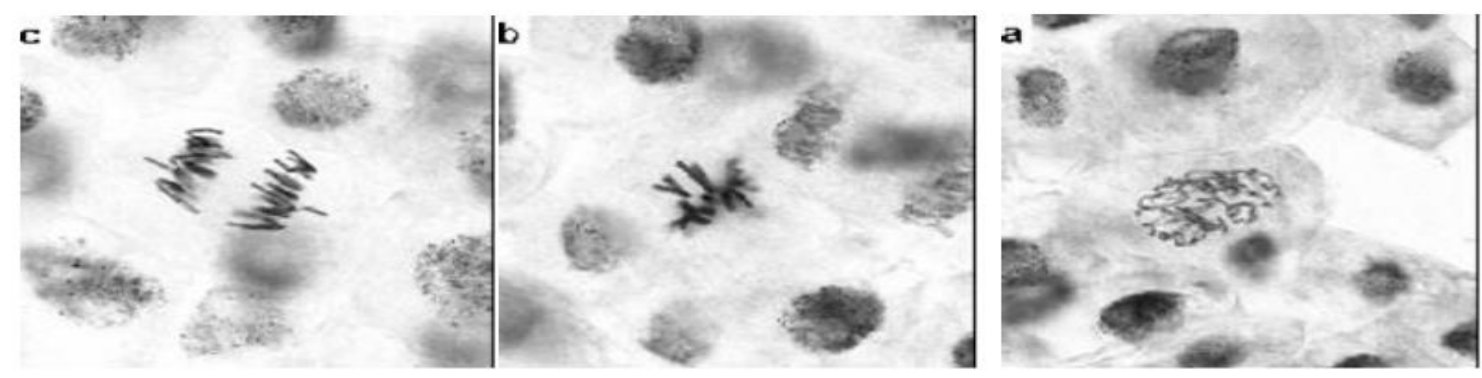

ACTIVIDAD 16. En la mayoría de los seres vivos de reproducción sexual tanto el macho como la hembra tienen células diploides, pero existen algunas especies en las que el macho es haploide. Esto sucede en algunos insectos, como por ejemplo las hormigas de la especie Myrmecia pilosula la hembra tiene 2 cromosomas y el macho uno solo. La primera célula (cigota) de una hormiga hembra es $2 n=2$. Esa cigota recién formada pasa por las etapas de interfase e inicia su división celular dando lugar a las dos primeras células de la hormiguita que a través de ciclos celulares cortos sucesivos formarán un embrión.

a. Dibuja el ciclo celular de una cigota hembra de hormiga y de cada una de las células hijas, representando todas las fases por las que pasan las células involucradas. Incluyan en el dibujo los cromosomas, representando los cambios que les suceden en los diferentes momentos del ciclo.

b. Indica en cada fase dibujada:

Nombre de la fase

Número de moléculas de ADN por cromosoma

Número total de moléculas de ADN

Tipo de cromosoma (simple/duplicado)

Número de cromátides por cromosoma

Número total de cromosomas (en la célula o en cada polo según corresponda)

c. ¿Cómo crece el macho haploide?

ACTIVIDAD 17. En la actividad 13 referida al crecimiento de un embrión de hormiga ustedes mencionaron los diferentes momentos del ciclo celular. En relación a este ciclo,

1. ¿Cuál es la fase o etapa del ciclo celular que se desencadena a partir de la formación del FPS (SPF o factor promotor de la síntesis)? Describan cómo sucede la formación de ese complejo y cómo actúa de manera tal que se desencadena la fase que mencionaron.

2. ¿Cuál es la fase que se desencadena a partir de la formación del FPM (MPF o factor promotor de la mitosis)? Describan cómo sucede la formación de ese complejo y cómo actúa para dar lugar a la consecuencia que mencionaron.

ACTIVIDAD 18. Indique si las frases son verdaderas o falsas. Justifique su respuesta.

a. La hormona insulina no se sintetiza en las células epiteliales porque estas células no tienen la información genética que codifica la síntesis de esta proteína.

b. Las células hepáticas no producen insulina porque el "gen que informa para" su síntesis está en una porción de heterocromatina en estas células.

c. La diferenciación celular en un organismo pluricelular implica la presencia de células que tienen la misma información genética, pero que pueden cumplir funciones diferentes.

d. Las células diferenciadas (por ejemplo las neuronas y los glóbulos blancos) pueden cumplir funciones diferentes porque tienen distintos genes.

e. Las células diferenciadas (por ejemplo las neuronas y los glóbulos blancos) pueden cumplir funciones diferentes porque producen distintas proteínas.

f. El gen de la insulina en las células beta del páncreas se encuentra en zona eucromatina.

g. Todas las células de un organismo pluricelular producen las mismas enzimas para llevar a cabo su metabolismo común. Por ejemplo para degradar glucosa realizan el proceso de glucólisis mediado por las mismas proteínas.

h. Todas las células de un organismo pluricelular expresan algunos genes que codifican para las enzimas responsables de los procesos metabólicos generales y esos genes se encuentran siempre en porciones de heterocromatina. 


\section{Guía de orientación para lectura - Capítulo 18: La Mitosis. Control del ciclo celular}

Recomendaciones generales: Tengan en cuenta el título de cada apartado, esas frases son buenos orientadores sobre lo que se desarrolla bajo ese título. Diferenciamos partes del capítulo en función de lo que interesa en esta materia, destacaremos algunos aspectos de cada parte:

\section{A) Primera parte: Ciclo celular}

Los primeros apartados $(18.1,18.2,18.3$ y 18.4$)$ retoman el ciclo celular completo que ya había sido presentado en el capítulo anterior. Se mencionan características generales de las etapas, en particular de la Interfase y cada uno de los períodos que la constituyen (G1, S y G2).

En esos apartados se mencionan algunos datos interesantes en relación a:

- Las diferencias en el ciclo celular de las células que se dividen y aquellas que no lo hacen. Este aspecto es retomado para el período G1.

- Cómo se demostró que la duplicación de ADN sólo ocurre en un período particular del ciclo y la relación entre ese período (S) y los cambios en la cantidad de ADN de una célula. Esos cambios en la cantidad de ADN se representan en el esquema de la figura 18.1 que fue descripto en clase y representado en el pizarrón.

\section{B) Segunda parte: Mitosis}

- El apartado 18.5 presenta una descripción general de la mitosis. Recomendamos leerlo para pensar esta división celular en el contexto del ciclo celular, además en él se presentan algunas de las estructuras claves que después se pondrán en acción como también se mencionan las etapas de la mitosis. En el curso hemos tomado la profase como una única etapa, De Robertis menciona además una etapa intermedia entre profase y metafase, la prometafase y la incluye en la figura 18.3 esquema. Mitosis es un proceso continuo que dividimos en etapas y las caracterizamos para comprenderlo mejor. También se menciona la división del citoplasma o citocinesis. ¿En qué etapa comienza la citocinesis? Recomendamos analizar la figura 18-3 ¿Cuántos cromosomas tiene esta célula? ¿Es una célula diploide o haploide? ¿Por qué?

- En los apartados 18.6 y 18.7 se describe la Profase, una etapa en la que suceden muchos eventos. Les sugerimos que consideren en especial lo que les sucede a los cromosomas, la función del huso mitótico, los cambios en la estructura del núcleo.

- A continuación, se presentan las demás etapas Metafase, Anafase y Telofase además de la citocinesis en los apartados 18.8, 18.9, 18.10, 18.11. No acordamos con el título del apartado 18.9 que dice Durante la anafase los cromosomas hijos se dirigen a los polos de la célula. El término cromosoma hijo resulta confuso, podemos cambiarlo por Durante la anafase las cromátides se dirigen hacia los polos de la célula, es decir en esta etapa se separan las cromátides hermanas que posteriormente pasaran aser cromosomas simples.

- Posteriormente se presenta información referida a los centríolos, los cinetocoros y la organización de los husos mitóticos a partir de los microtúbulos y su rol durante la división celular. Esta información complementa la que ya hemos resaltado pero primero es necesario comprender qué sucede con el material genético durante el ciclo celular, es decir qué ocurre con los cromosomas tal como hemos resaltado en las sugerencias anteriores.

\section{C) Tercera parte: Control del ciclo celular}

Es muy importante tener claro el funcionamiento general y habitual de los ciclos de vida de las células para poder pensar después las consecuencias que pueden desencadenarse cuando "algo se aparta del funcionamiento normal".

- En las células existen mecanismos que controlan el desarrollo de las sucesivas etapas del ciclo celular. Esto se realiza regulando la velocidad a la que se suceden las diferentes etapas y controlando el inicio y la finalización de cada una de ellas. Para trabajar con estos aspectos recomendamos leer detenidamente los apartados 18.22, 18.23, 18.24, 18.25 y 18.26 , 
- Sugerimos trabajar en detalle con la figura 18.10 en la que se representan las etapas del ciclo celular y las moléculas que participan en su regulación. Es importante identificar las diferentes moléculas y poner atención en cómo se comportan a lo largo del ciclo. Es decir, si varía o se mantiene constante la concentración de cada una de las proteínas reguladoras durante el desarrollo del ciclo celular. También la figura 18.11 es importante, porque representa de otra manera las interacciones entre las moléculas reguladoras. Les sugerimos que pongan en relación estos dos esquemas con la información que se presenta en los apartados anteriormente mencionados.

- Sobre el comportamiento del Factor Promotor de la Síntesis (SPF o FPS) es importante considerar cómo se relaciona su formación con la activación de diferentes enzimas y otros aspectos claves del proceso de replicación de ADN. Es decir, ¿Cómo el SPF promueven la síntesis o duplicación de ADN?

- En relación al mecanismo que desencadena la Mitosis que se describe el apartado 18-26 les pedimos que intenten identificar cómo "los protagonistas" (las diferentes proteínas reguladoras) interactúan y cuáles son las diversas consecuencias que resultan de esa interacción. Recomendamos hacer un esquema que les permita representar la cascada de eventos que desencadenan la división de la célula, es decir la mitosis y aquellos sucesos que conducen al desarrollo y finalización de la división celular. Incluir aquí la acción del Factor Promotor de Mitosis (MPF o FPM).

- Tener en cuenta que así como se activan los genes que posibilitan la síntesis de las ciclinas, también se desactivan para que no se vuelva a repetir la síntesis del ADN o la Mitosis.

- En los apartados 18.27 y 18.28 se menciona cómo la acción de ciertas sustancias inductoras influye en la velocidad del ciclo y por lo tanto de la división celular. ¿En qué circunstancias se considera que una célula se encuentra en la fase G0? ¿Por qué se utiliza la división celular que se desencadena a partir de la célula huevo o cigota como ejemplo "diametralmente opuesto" al caso anterior?

- En el apartado 18.28 se mencionan diferentes sustancias inductoras y su forma de actuar. Aun cuando no importa cómo se denominan las diferentes sustancias que inducen la proliferación celular, es interesante tener en cuenta la diversidad de maneras de inducción. Por ejemplo, cómo los mecanismos intrínsecos que dan lugar a las divisiones repetitivas a partir de la célula huevo dependen de componentes ya presentes en esa célula. A diferencia de aquellos mecanismos que se desencadenan a partir de la presencia de sustancias inductoras externas que provienen de células vecinas 0 distantes. Así la lectura de los diferentes casos puede aportar a pensar cómo sucede la regulación en función del tipo celular.

- Finalmente el apartado 18.29 presenta cómo una proteína reguladora la P53 actúa en las células ante la presencia de $A D N$ dañado. Esta acción es relevante dado que la alteración del gen P53 (denominado gen supresor de tumores) está vinculada con ciertos tipos de cáncer.

D) Cuarta parte: Cuando el control se descontrola.

Relación control ciclo celular con cáncer, 18.30, 18.31, 18.32

- Les recomendamos prestar atención a las dos clases de genes que controlan el ciclo celular, los protooncogenes y los genes supresores de tumores. Detenerse en el rol que ejercen a través de las proteínas que se producen a partir de ellos. Al comprender la función que cumplen es posible comprender también qué consecuencias trae la alteración de cada uno de ellos.

- Es importante la noción que sintetiza el título del apartado 18.30: muchos tipos de cánceres se producen por acumulación de alteraciones genéticas. Les sugerimos tener en cuenta que el proceso que transforma células normales en células cancerosas no ocurre en una sola generación celular sino que implica sucesivas mutaciones ocurridas durante varios ciclos celulares que se acumulan en ciertas células. 
- Recomendamos detenerse en la relación entre protooncogenes y oncogenes, (presentada en el apartado 18.31) para considerar ¿Qué información codifican estos genes? Y así pensar porqué la alteración de estos genes trae consecuencias en el ciclo celular y desencadena la proliferación desmedida de las células. No es necesario conocer los nombres de los protooncogenes o de las proteínas que resultan de su expresión, pero recomendamos leer el listado que se presenta en el apartado para pensar qué tienen de particular las proteínas codificadas por estos genes.

- En relación a los genes supresores de tumores, se menciona en el apartado 18.32 como ejemplo el caso del gen que codifica la proteína P53. La ocurrencia de mutaciones en este gen que den como resultado que la P53 esté ausente en una célula permite explicar la aparición de tumores. ¿Por qué? ¿Cómo se relacionan estos dos eventos: ausencia de P53 y aparición de tumores?

- Para limitar el alcance de los temas de este capítulo, tener en cuenta lo dado en clase. 


\section{REFERENCIAS BIBLIOGRÁFICAS}

Adúriz Bravo, A. (2011) Concepto de modelo científico: una mirada epistemológica de su evolución. En Galagovsky, L. (coord.). Didáctica de las ciencias naturales: El caso de los modelos científicos, 141-161. Buenos Aires: Lugar Editorial.

Aisenberg, B. (2005). La lectura en la enseñanza de la historia: las consignas del docente y el trabajo intelectual de los alumnos. Lectura y Vida, 26(3), 22-21.

Aisenberg, B. (2010): Enseñar Historia en la lectura compartida. Relaciones entre consignas, contenidos y aprendizaje. En: Siede (coord.) (2010): Ciencias Sociales en la escuela. Criterios y propuestas para la enseñanza. Aique, Buenos Aires.

Aisenberg, B. (2012): Usos de la escritura en la enseñanza de la Historia. En el Volumen 16 de la Revista Clío \& Asociados, publicación conjunta de la Universidad Nacional del Litoral y de la Universidad Nacional de La Plata. pp 99- 113.

Aisenberg, B. (2014): Nuevas aproximaciones a las relaciones entre lectura y aprendizaje escolar de la Historia. E-book de las XV Jornadas Nacionales y IV Internacionales de Enseñanza de la Historia. A.P.E.H.U.N. y Facultad de Humanidades y Ciencias de la Universidad Nacional del Litoral. Santa Fe, 17 al 19-09-2014. Disponible en: http://www.fhuc.unl.edu.ar/materiales_congresos/CD_ensenanza_historia_2014/index.html

Aisenberg, B. y Lerner, D. (2008). Escribir para aprender historia. Lectura y Vida, 29(3), 24-43.

Aisenberg, B.; Lerner, D.; Bavaresco, P.; Benchimol, K.; Larramendy, A. y Olguín, A. (2009): Diferentes explicaciones para un hecho histórico. La enseñanza a través de la lectura. En Reseñas de enseñanza de la historia $\mathrm{N}^{\circ}$ 7, Octubre de 2009. A.P.E.H.U.N. (pp. 93-129)

Ametller Lleal, J.; Leach, J. y Scott, P. (2009). Hacia un modelo de conexión entre la teoría y la práctica en el aula para el diseño y la evaluación de la enseñanza de las ciencias. Enseñanza de las Ciencias, Número Extra VIII Congreso Internacional sobre Investigación en Didáctica de las Ciencias, Barcelona. Págs. 2803-2808. Disponible en: https://ddd.uab.cat/pub/edlc/edlc_a2009nEXTRA/edlc_a2009nExtrap2803.pdf

Anderberg, E.; Svensson, L; Alvegard, C; y Johansson, T. (2008) The epistemological role of language use in learning: A phenomenographic intentional - expressive approach. Educational Research Review, 3, 14-29

Applebee, A. (1984). Writing and reasoning. Review of Educational Research, 54, 577-596.

Arnoux, E., Alvarado, M., Balmayor, E., Di Stefano, M., Pereira, C. y Silvestri, A. (1996). El aprendizaje de la escritura en el ciclo superior. En Arnoux, E. (Comp.), Adquisición de la escritura. Rosario, Santa Fe: Centro de Estudios de Adquisición del Lenguaje, Facultad de Humanidades y Artes, Universidad Nacional de Rosario, Editorial Juglaría.

Arnoux, E., Silvestri, A. y Nogueira, R. (2002). La construcción de representaciones enunciativas: el reconocimiento de voces en la comprensión de textos polifónicos. Revista Signos, 35(51-52), 129-148.

Artemeva, N. y Feedman, A. (2008). Rhetorical Genre Studies and Beyond. Winnipeg (Canadá): Inkshed Publications.

Artigue, M. (1990). Ingénierie didactique. Recherches en Didactique des Mathématiques, 9(3), 283-307.

Austin, J. (2003) Cómo hacer cosas con palabras: palabras y acciones. $2^{\circ}$ edición. Buenos Aires, Paidós

Bachelard, G. (2004) La formación del espíritu científico. Contribución a un psicoanálisis del conocimiento objetivo. México: Siglo XXI

Bajtín, M. (1952/53) El problema de los géneros discursivos. En Bajtín, M. (2011), Estética de la creación verbal. Buenos Aires: Siglo XXI.

Bakhtin, M. (1981) Discourse in the Novel. I Holquist, M. The Dialogic Imagination; Four Essays by M.M Bakhtin (red and overs). C. Emerson y M. Holquist. Austin TX. University of Texas Press 
Bazerman, C. (1988). Shaping written knowledge. The genre and activity of the experimental article in science. Madison, WI: University of Wisconsin Press.

Bazerman, C. (2009). Genre and cognitive development: Beyond writing to learn. En Bazerman, Ch; Bonini, A. y Figueiredo, D. Genre in a Changing World. Perspectives on Writing. Fort Collins, Colorado.

Bazerman, C. (2010). The Informed Writer: Using Sources in the Disciplines. Forth Collins, CO: The WAC Clearinghouse.

Bazerman, C. y Prior, P. (2004). What writing does and how it does it. An introduction to analyzing texts and textual practices. New Jersey: Lawrence Erlbaum Associates

Bazerman, C., Little, J., Bethel, L., Chavkin, T., Fouquette, D. y Garufis, J. (2005). Reference Guide to Writing Across the Curriculum. West Lafayette, Indiana: Parlor Press.

Bazerman, C., Little, J., Bethel, L., Chavkin, T., Fouquette, D. y Garufis, J. (2016) Escribir a través del Currículum: una guía de referencia / Charles Bazerman [et al.]; editado por Federico Navarro. Córdoba: Universidad Nacional de Córdoba, 2016. Libro digital, PDF. Disponible en: https://www.researchgate.net/profile/Federico_Navarro/publication/309322270_Edicion_y_tradu ccion_de_Escribir_a_traves_del_Curriculum_Üna_guia_de_referencia/links $/ 580 \mathrm{a} 024 \mathrm{~b} 08 \mathrm{a} e 3 \mathrm{a} 0$ 4d624f67f/Edicion-y-traduccion-de-Escribir-a-traves-del-Curriculum-Una-guia-de-referencia.pdf

Bogel, F. y Hjortshoj, K. (1984). Composition Theory and the Curriculum. En F. B. y. K.Gottschalk (Eds.), Teaching Prose. A Guide for Writing Instructors (pp. 1-19). NewYork: Norton.

Brousseau, G. (2007). Iniciación al estudio de la teoría de las situaciones didácticas. Buenos Aires: Libros del Zorzal.

Brousseau, G. y Warfield, V. (1999). El caso Gaël: El estudio de un niño con dificultades matemáticas. The Journal of Mathematical Behavior. Vol. 18, nro.1.

Carlino, P. (2005). Escribir, leer y aprender en la universidad: una introducción a la alfabetización académica. Buenos Aires: Fondo de Cultura Económica de Argentina.

Carlino, P. (2008). Reading and writing in the Social Sciences in Argentine universities. En Bazerman, C. (Ed.), Traditions of Writing Research: Trends and Trajectories. New York: Taylor and Francis.

Carlino, P. (2013). Alfabetización académica diez años después. Revista mexicana de investigación educativa, 57(abril-junio).

Carlino, P. y Estienne, V. (2004). ¿Pueden los universitarios leer solos? Un estudio exploratorio. Ponencia presentada en las Memorias de las XI Jornadas de Investigación en Psicología, Facultad de Psicología de la Universidad de Buenos Aires, Buenos Aires.

Carlino, P., Iglesia, P. y Laxalt, I. (2012) Leer y escribir en las asignaturas en la formación de profesores secundarios: Qué dicen los docentes que se hace. En Lectura, escritura y aprendizaje disciplinar UNESCO Rio Cuarto. A.Vázquez, M.Novo, I.Jakob, L. Pelizza (comp.) págs 675-693. http://www.unrc.edu.ar/unrc/digtal/libro_jornadas_unesco_unrc_2010.pdf

Carlino, P., Iglesia, P. y Laxalt, I. (2013) Concepciones y prácticas declaradas de profesores terciarios en torno al leer y escribir en las asignaturas. Revista de Docencia Universitaria, 11 (1) 105-135. Disponible en: https://www.aacademica.org/paula.carlino/215

Carlino, P., Iglesia, P., Bottinelli, L., Cartolari, M., Laxalt, I. y Marucco, M. (2013). Leer y escribir para aprender en las diversas carreras y asignaturas de los IFD que forman a profesores de enseñanza media: concepciones y prácticas declaradas de los formadores de docentes. Buenos Aires: Ministerio de Educación de la Nación.

Cartolari, M. (2014) ¿Qué motiva a los alumnos a participar o no en la construcción conjunta de significados sobre lo leído y lo escrito? El punto de vista de estudiantes de un profesorado en Historia. Ponencia presentada e incluida en la Publicación Anual $n^{\circ} 2$ del Centro Cultural de la Cooperación Floreal Gorini de la Ciudad de Buenos Aires: II Encuentro hacia una pedagogía emancipatoria en Nuestra América, 29 y 30 de septiembre de 2014. Disponible en: http://pedagogiaemancipatoria.wordpress.com/

Cartolari, M. (2015) Leer y escribir en asignaturas disciplinares de la formación docente en Historia. Usos y sentidos de la lectura y la escritura desde el punto de vista de los alumnos de 
los profesores. Tesis doctoral presentada y aprobada en el Programa Inter-Institucional de Doctorado en Educación de las Universidades Nacionales de Lanús, San Martín y Tres de Febrero -1a ed. Ciudad Autónoma de Buenos Aires: Cartolari, M. M y GICEOLEM, 2015. Edición electrónica. Disponible en: https://sites.google.com/site/integrantesgiceolem/manuela-cartolari

Cartolari, M. y Molina, M. E. (2015) Modos de leer y escribir en Historia: perspectivas de alumnos y profesores de la formación docente inicial, REDU Revista de Docencia Universitaria, Vol. 13 (3), pp.235-263, Dic. 2015. http://polipapers.upv.es/index.php/REDU/article/view/5428

Carter, M.; Miller, C. y Penrose, A. (1998) Effective Composition Instruction: What Does the Research Show? Center for Communication in Science, Technology and Management, Publication Series, №3, April, North Carolina State University.

Castedo, M. (1995). Construcción de lectores y escritores. Lectura y Vida, 16(3), 5-25.

Castedo, M. (2007a). Notas sobre la didáctica de la lectura y la escritura en la formación continua de docentes. Lectura y Vida, 28(2), 6-18.

Castedo, M. (2007b). Revisión de textos en situación didáctica de intercambio entre pares. Archivos de Ciencia de la Educación, Nro. 1, 255-256.

Cavagnetto, A. R. (2010). Interventions in K 12 Science Contexts Argument to Foster Scientific Literacy: A Review of Argument. Review of Educational Research, (80), 33657.

Chanock, K. (2001). From Mystery to Mastery. Ponencia presentada para las Actas de la Conferencia Australiana sobre Lenguaje y Habilidades Académicas Changing identities, Universidad de Wollongong, New South Wales.

Chanock, K. (2004). Introducing Students to the Culture of Enquiry in an Arts Degree. Milperra: Herdsa.

De Micheli, A. e Iglesia, P. (2009) La escritura en aulas de Biología del CBC en el marco de una innovación curricular. Avances y perspectivas de un proceso de investigación-acción. En Anuario 2008 IICE Instituto de Investigaciones en Ciencias de la Educación. Editorial de la Facultad de Filosofía y Letras, UBA. Buenos Aires.

De Micheli A. e Iglesia P. (2012) Writing to Learn Biology in the Framework of a Didactic-Curricular Change in the First Year Program at an Argentine University. En Christopher Thaiss, Gerd Bräuer, Paula Carlino, Lisa Ganobcsik-Williams \& Aparna Sinha (Eds), Writing Programs Worldwide: Profiles of Academic Writing in Many Places. Anderson, South Carolina: Parlor Press and Fort Collins, Colorado: The WAC Clearinghouse. 2012. Capítulo accesible en: http://wac.colostate.edu/books/wpww/chapter3.pdf.

De Micheli, A. e Iglesia, P. (2017). Escribir para aprender biología en el marco de un cambio didáctico - curricular en el primer año de una universidad argentina. Versión traducida y actualizada del capítulo del libro editado por Chris Thaiss, Gerd Bräuer, Paula Carlino, Lisa Ganobcsik-Williams \& Aparna Sinha (Eds.), Writing Programs Worldwide: Profiles of Academic Writing in Many Places, Disponible en: http://writingprogramsworldwide.ucdavis.edu/wpcontent/uploads/2014/12/De-Micheli-e-Iglesia-ARGENTINA-Escribir-para-aprenderbiolog\%C3\%ADa-CON-ADENDAS.pdf

De Micheli, A.; Donato, A.; Goveto, L.; Iglesia P. y Otero, P. Acerca de organismos, células, genes y poblaciones. Ediciones Villoldo Yanele, Buenos Aires, 2006.

De Robertis, E. e Hib, J. (2004). La replicación del ADN. Capítulo 17 en De Robertis, E, y Hib, J. Fundamentos de Biología Celular y Molecular. Buenos Aires. El Ateneo.

De Robertis, E. e Hib, J. (2004).La mitosis. Capítulo 18 en De Robertis, E, y Hib, J. Fundamentos de Biología Celular y Molecular. Buenos Aires. El Ateneo.

Di Benedetto, S. y Carlino, P. (2007). Correcciones a exámenes escritos en la universidad: cómo son y para qué sirven a los alumnos. Ponencia presentada y publicada en las Memorias de las XIV Jornadas de Investigación en Psicología y Tercer encuentro de investigadores en Psicología del Mercosur La investigación en Psicología, su relación con la práctica profesional y la enseñanza, Facultad de Psicología de la Universidad de Buenos Aires.

Diment, E. y Carlino, P. (2011) Ayudas pedagógicas y recursos para escribir en los primeros años universitarios, En Actas de las Jornadas La lectura y la escritura en la formación académica, 
docente y profesional. Equipo PRODEAC por la Universidad Nacional de General Sarmiento y Universidad Tecnológica Nacional (Pacheco) 9 y 10 de junio de 2011. Disponible en:

http://www.ungs.edu.ar/prodeac/wp-content/uploads/2012/03/Laco-L.-Natale-L.-y-\%C3\%81vilaM.-2012.-La-lectura-y-la-escritura-en-la-formaci\%C3\%B3n- acad\%C3\%A9mica-docente-yprofesional.pdf

Di Stefano, M. y Pereira, C. (2004). La enseñanza de la lectura y escritura en el nivel superior: procesos, prácticas y representaciones sociales. En Carlino, P. (Coord.), Leer y escribir en la universidad. Textos en Contexto $N^{\circ} 6$ (pp. 23-39). Buenos Aires: Lectura y Vida / International Reading Association.

Dumrauf, A. G, Mengascini, A. y Cordero, S. (2017), Urdimbres y tramas de un triple proceso de trabajo conjunto. Capítulo 2 en Tramas entre escuela y universidad. Formación docente, innovación e investigación colaborativa, coord. Por Dumrauf, A, y Cordero, S. La Plata. Editorial Universidad Nacional de La Plata.

Dumrauf, A.G., Cordero, S. y Colinvaux, D. (2003). Construyendo puentes y fronteras: caracterización del género discursivo en una clase universitaria de física. Revista Brasileira de Pesquisa em Educação em Ciências. Vol. 3, 1, pp. 55-67. www.fcep.unep.br/abrapec/revista.htm.

Dumrauf, A.G. y Cordero, S. (2004). "¿Qué cosa es el calor?" Construyendo estructuras sobre inestabilidades en una clase de física. Revista Electrónica de Enseñanza de las Ciencias. Vol. 3, $\mathrm{n}^{\circ} 2$. www.saum.uvigo.es/reec.

Dysthe, O. (1996). The Multivoiced Classroom: Interactions of Writing and Classroom Discourse. Written Communication, 13(3), 385-425.

Dysthe, O. (2000). Giving them the tools they need to succeed: A high school theacher's use of writing and talking to learn in a literature class. Actas de la Biennial Conference of EARLI SIG Writing 2000. Universidad de Verona, Italia, 6 al 9 de septiembre de 2000.

Dysthe, O. (2012). Multivoiced Classrooms in Higher Education Academic Writing. En Castelló, M. y Donahue, C. (eds.), University Writing: selves and Texts in Academic Societies. Estados Unidos: Emerald.

Dysthe, O; Bernhardt, N.; y Esbjorn, L. (2013) Enseñanza basada en el diálogo: El museo de arte como espacio de aprendizaje. Skoletjenesten en colaboración con editorial Fagbokforlaget Vigmostad y Bjorke AS/Noruega. Copenhague, Dinamarca.

Edelstein, G. (2011) Formar y formarse en la enseñanza. Buenos Aires. Paidós.

Elbow, P. (2004) Writing First! Putting Writing before Reading is an Effective Approach to Teaching and Learning. Educational Leadership. Vol.62. Número 2: págs 9-13.

Emig, J. (1977). Writing as a mode of learning. College Composition and Communication, 28, $12-$ 28.

Espinoza, A, (2006) La especificidad de las situaciones de lectura en "Naturales". Revista Lectura y vida. Buenos Aires.

Espinoza, A., Casamajor, A. y Pitton, E. (2009). Enseñar a leer textos de ciencias. Buenos Aires: Paidós.

Espinoza, A., Casamajor, A., Pitton, E. y Aziz, C. (2012) Escribir para aprender Ciencias Naturales, cuando los alumnos le dictan al docente. Actas III Jornadas de Enseñanza e Investigación Educativa en el campo de las Ciencias Exactas y Naturales. Facultad de Humanidades y Ciencias de la Educación. Universidad Nacional de La Plata. http://jornadasceyn.fahce.unlp.edu.ar/iii-2012

Ezcurra, A. M. (2011). Igualdad en Educación Superior: un desafío mundial. Los Polvorines: Universidad Nacional de General Sarmiento.

Fernández, G. y Carlino, P. (2006). ¿En qué se diferencian leer y escribir para la escuela media y la universidad? La perspectiva de ingresantes universitarios de las humanidades. Ponencia presentada en el Primer Congreso Nacional Leer, escribir y hablar hoy, 30 de septiembre al 01 de octubre de 2006, Tandil, Buenos Aires. 
Fernández, G. y Carlino, P. (2010) ¿en qué se diferencian las prácticas de lectura y escritura de la universidad y de la escuela secundaria? Perspectivas de alumnos y profesores en Ciencias Humanas y Veterinarias. Lectura y Vida, 31(3), 6-19.

Fernández, G. y Carlino, P. (2008). Leer y escribir en ciencias humanas y veterinarias: el punto de vista de docentes y alumnos. Ponencia presentada en el $22^{\circ}$ Congreso Mundial de Lectura. Lectoescritura en un mundo diverso, San José, Costa Rica.

Fernández, G., Izuzquiza, M. V. y Laxalt, I. (2004). El docente universitario frente al desafío de enseñar a leer. En Carlino, P. (Coord.), Leer y escribir en la universidad. Textos en Contexto № 6. Buenos Aires: Lectura y Vida / International Reading Association.

Fregona, D. y Orús Báguena, P. (2011). La noción de medio en la teoría de las situaciones didácticas; una herramienta para analizar decisiones en las clases de matemática. Buenos Aires. Libros del Zorzal.

García Romano, L.; Padilla, C. y Valeiras, N. (2012) Representaciones sobre la lectura y la escritura en estudiantes de Biología y Profesorado en Ciencias Biológicas. Memorias de las IX Jornadas Nacionales y IV Congreso Internacional de Enseñanza de la Biología. ADBiA, Asociación de Docentes de Biología, Córdoba

García Romano, L.; Valeiras, N. y Masullo M. (2013) Escribir en el inicio de la universidad: El caso de las carreras de Ciencias Biológicas y Profesorado en Ciencias Biológicas. Memorias IX Congreso internacional sobre investigación en didáctica de las ciencias. Girona 9 al 13 septiembre 2013. https://ddd.uab.cat/pub/edlc/edlc_a2013nExtra/edlc_a2013nExtrap1489.pdf

García Romano, Padilla y Valeiras, N. (2016). ¿Cómo conciben estudiantes y docentes de biología el rol del lenguaje en las prácticas científicas? Ciencia, Docencia y Tecnología. Vol 27, N52. Universidad Nacional de Entre Ríos. Concepción del Uruguay. Entre Ríos. Argentina. (319342)

Giordan, A, y De Vecchi, G. (1997) Los orígenes del saber. De las concepciones personales a los conceptos científicos. Sevilla. Díada.

Gottschalk, K. y Hjortshoj, K. (2004). The Elements of Teaching Writing. Boston: Bedford/St.Martin's.

Haas, C. (1994). Learning to read biology: One student's rhetorical development in college. Written Communication, 11(1), 43-84.

Hamza, K. y Wickman, P. (2013) Supporting Students' Progression in Science: Continuity Between the Particular, the Contingent, and the General. Sci Ed 97:113-138, 2013.

Hand, B. y Prain, V. (2002). Teachers implementing writing-to-learn strategies in junior secondary science: a case study. Wiley Periodicals, Inc. SciEd 86: 737-755- InterScience.

Hand, B. y Prain, V. (2012) Writing as a Learning Tool in Science: Lessons Learnt and Future Agendas. Capítulo 88. En Second International Handbook of Science Education, Springer International Handbooks of Education 24, Springer Science. Business Media B. V.

Hand, B. ; Prain, V. y Yore, L. (2001) Sequential writing tasks influence on science learning. En Writing as a learning tool. Integrating theory and practice, Tynjälä, P.; Mason, L. y Kirsti L. The Netherlands, 2001, Kluwer Academia Publishers

Hand, B. ; Hohenshell, L. y Prain, V. (2006) Examining the effect of multiple writing tasks on Year 10 biology students understandings of cell and molecular biology concepts. Instructional Science (2007) 35: 343-373. Springer.

Iglesia, P. (2014) Propuestas y alternativas para integrar la escritura (y la lectura) en asignaturas de los primeros años de la universidad. En Giménez, G; Luque, D y Orellana, M. (2014) Leer y Escribir en la Universidad Nacional de Córdoba. Reflexiones, Experiencias y Voces. UNC. Secretaría de Asuntos Académicos. Córdoba. Disponible en: https://ansenuza.unc.edu.ar/comunidades/handle/11086.1/875

Iglesia, P; De Micheli, A; Donato, A y Otero P. (2005) Análisis de producciones escritas de alumnos ingresantes a la universidad. En Enseñanza de las Ciencias VII Congreso Internacional sobre Investigación en Didáctica de las Ciencias. CD ROM. Granada. España. ISSN 0212-4521 
Iglesia, P. y De Micheli, A. (2008). La incorporación de la escritura a la enseñanza de Biología en primer año de la Universidad. Obstáculos y estrategias. Primeras Jornadas Latinoamericanas de Lectura y Escritura Críticas de la cátedra UNESCO. Tucumán: Universidad Nacional de Tucumán.

Iglesia, P. y De Micheli, A. (2009). Leer textos de biología en el primer año de la universidad: ¿es un saber construido o una práctica a enseñar? Enseñanza de las Ciencias, Número Extra VIII Congreso Internacional sobre Investigación en Didáctica de las Ciencias, Barcelona, 817-820.

Iglesia P. y De Micheli, A. (2011) Writing to Learn Biology at First Year Courses. Ponencia presentada en Writing Research Across Borders II Internacional Conference. George Mason University, Washington DC, 17-20 Febrero 2011. Disponible en: http://www.writing.ucsb.edu/wrconf11

Iglesia, P. y De Micheli; A; Donato, A y Otero, P. (2005) Análisis de producciones escritas de alumnos ingresantes a la universidad. En Enseñanza de las Ciencias VII Congreso Internacional sobre Investigación en Didáctica de las Ciencias. CD ROM. Granada. España. ISSN 0212-4521.

Izquierdo, M (2005) Hacia una teoría de los contenidos escolares. Enseñanza de las ciencias 200523 (1). 111-122. Barcelona.

Izquierdo, M. y Sanmartí, N. (2000) Enseñar a leer y escribir textos de Ciencias Naturales. En Jorba, J., Gómez, I. y Prat, A. Hablar y escribir para aprender. Uso de la lengua en situaciones de enseñanza-aprendizaje desde las áreas curriculares. Barcelona. ICE UAB. Síntesis.

Ivanič, R. (1998). Writing and Identity: The discoursal construction of identity in academic writing. Amsterdam: John Benjamins.

Jakob, I.; Bono, A.; Vélez, G.; Boatto, Y.; Luján, S. y Rainero, D. (2014) Leer, escribir y aprender: Tareas y espacios áulicos compartidos en el primer año universitario. Departamento de Cs. de la Educación, Facultad de Cs. Humanas, UNRC. Revista Contextos de Educación Año 14 - № 16. Disponible en: www.hum.unrc.edu.ar/publicaciones/contextos

Jiménez Aleixandre, M. P. (2003) Comunicación y lenguaje en las clases de ciencias en Jiménez Aleixandre, M. P. (coord) Caamaño A.; Oñorbe, A.; Pedrinaci, E. y de Pro, A. Enseñar ciencias en la escuela secundaria. Barcelona. Grao.

Jiménez Aleixandre, P. y Díaz de Bustamante, J. (2003) Discurso de aula y argumentación en la clase de ciencias: cuestiones teóricas y metodológicas. Enseñanza de la Ciencias, 21 (3), 359370 .

Jimenez Aleixandre, M.P. y Erduran, S. (2007). Argumentation in science education: An overview. En Erduran, S. y Jiménez Aleixandre, M.P. (eds.) Argumentation in Science Education: Perspectives from classroom based research (pp. 328-367). Dordrecht, Netherlands: Springer.

Joffredo-Le Brun,S. ; Morellato, M. ; Sensevy, G y Quilio, S. Cooperative engineering as a joint action. EERJ. European Educational Reserch 2018, Vol. 17(1) 187-208

http://journals.sagepub.com/doi/10.1177/1474904117690006

Kelly, G. y Bazerman, C. (2003). How Students Argue Scientific Claims: A RhetoricalSemantic Analysis. Applied Linguistics, 24(1), 28-55, Oxford Univ. Press.

Kelly, G., Bazerman, C., Skukauskaite, A. y Prothero, W. (2010). Rhetorical features of student science writing in introductory university oceanography. En Bazerman et al. (eds.), Traditions of Writing Research (pp. 265-282). New York: Routledge.

Kelly, G.; Mc Donald, S. y Wickman, Per Olof, (2012) Science Learning and Epistemology. Capítulo 20. En Second International Handbook of Science Education, Springer International Handbooks of Education 24, Springer Science. Business Media B. V.

Langer, J. y Applebee, A. (1987). How Writing Shapes Thinking: A Study of Teaching and Learning. Urbana (Illinois): National Council of Teachers of English.

Lave, J. y Wenger E. (1991). Situated Learning, Legitimate Peripheral Participation, Cambridge: Cambridge University Press.

Lea, M. y Street, B. (1998). Student writing in Higher Education: an academic literacies approach. Studies in Higher Education, 23(2), 157-172. 
Leach, J., y Scott, P. (2002). Designing and evaluating science teaching sequences: An approach drawing upon the concept of learning demand and a social constructivist perspective on learning. Studies in Science Education, 38, 115-142.

Leach, J., Hind, A., Lewis, J., y Scott, P. (2006). Designing research evidence-informed teaching interventions. In R. Millar, J. Leach, J. Osborne, \& M. Ratcliffe (Eds.), Improving subject teaching: Lessons from research in science education (pp. 60-78). London: Routledge Falmer,

Leach, J.; Amettller, J. y Scott, P. (2009). The relationship of theory and practice in designing, implementing and evaluating teaching sequences: learning from examples that don't work.

Education el didactique, volúmen 3 - №2 - Junio 2009. Disponible en: http://educationdidactique.revues.org/497

Lemke, J. (1997) Aprender a hablar ciencia. Lenguaje, aprendizaje y valores. Barcelona. Paidós. Lerner, D. (1996). La enseñanza y el aprendizaje escolar. Alegato contra una falsa oposición. En Castorina, J.A., Ferreiro, E., Kohl de Oliveira, M. y Lerner, D. (Coords.), Piaget-Vigotsky: Contribuciones para replantear el debate. Buenos Aires: Paidós.

Lerner, D. (2001). Leer y escribir en la escuela: lo real, lo posible y lo necesario. México: Fondo de Cultura Económica.

Lerner, D. (2002). La autonomía del lector. Un análisis didáctico. Lectura y Vida, 23(3), 6-19.

Lerner, D., Stella P, y Torres M. (2009) Formación docente en lectura y escritura. Recorridos didácticos. Paidos. Buenos Aires

Lerner, D.; Aisenberg, B. y Espinoza, A. (2009). La lectura en Ciencias Sociales y en Ciencias Naturales: objeto de enseñanza y herramienta de aprendizaje. En: J. A. Castorina y V. Orce (coords.) (2009): Anuario del Instituto de Investigaciones en Ciencias de la Educación 2008. Editorial de la Facultad de Filosofía y Letras de la Universidad de Buenos Aires.

Lerner, D.; Larramendy, A. y Benchimol, K. (2012) Tensiones de la escritura en el contexto escolar. Análisis desde una investigación sobre la enseñanza y el aprendizaje de contenidos históricos. En Lectura, escritura y aprendizaje disciplinar e-book UNESCO Rio Cuarto. Alicia Vázquez, María del Carmen Novo, Ivone Jakob, Luisa Pelizza (comp.) págs 41- 84. Disponible en: http://www.unrc.edu.ar/unrc/digtal/libro_jornadas_unesco_unrc_2010.pdf

Lewontin, R. (2001) El sueño del genoma humano y otras ilusiones. Buenos Aires. Paidós.

Lewontin, R., Rose, S. y Kamin, L.J. (1987). No está en los genes. Crítica del racismo biológico. Barcelona. Crítica.

Lijnse, P. (2000) Didactics of science: the forgotten dimension in science education research? En R. Millar, J. Leach and J. Osborne (eds.) Improving Science Education: The Contribution of Research (Buckingham: Open University Press), 308-326.

Lillis, T. (1999). Whose 'Common Sense'? Essayist literacy and the institutional practice of mystery. En Jones, C., Turner, J. y Street, B. (Eds.), Students writing in the university. Cultural an epistemological issues (pp. 127-148). Amsterdam: John Benjamins.

Lucarelli, E. (2009) Teoría y práctica en la universidad. La innovación en las aulas. Buenos Aires. Miño y Dávila.

Massarini, A, (2008) Las imágenes en la enseñanza de las ciencias naturales. Capítulo 4 en Augotwsky, G.; Massarini A. y Tabakman, S. Enseñar a mirar imágenes en la escuela. Buenos Aires. Editorial Tinta Fresca.

Massarini, A. y Schneck, A. (2015) Ciencia entre todxs. Tecnociencia en contexto social: una propuesta de enseñanza. Buenos Aires. Paidós.

Maturana, H. y Varela, F. (1984). El árbol del conocimiento. Las bases biológicas del entendimiento humano. Santiago de Chile. Editorial Universitaria.

Maxwell, J. A. (2005). Qualitative Research Design: An interactive approach. London: Sage.

Maxwell, J. y Miller, B. (2008). Categorizing and connecting strategies in qualitative data analysis. En Leavy, P. y Hesse-Biber, S. (Eds.), Handbook of emergent methods (pp. 85-106). New York: Guilford Press 
Mayr, E. (2005) Así es la biología. Madrid, Debate.

Mayr, E. (2006) La autonomía de la biología. En ¿Por qué es única la biología? Consideraciones sobre la autonomía de una disciplina científica (pp. 36-58). Buenos Aires. Katz Editores.

Meyer, F. (1979) Situación epistemológica de la Biología. En Meyer,F. Papert. S. Nowinski, C. y Piaget, J. Buenos Aires. Paidós.

Molina, M E (2014). Argumentar y escribir para aprender Biología en la universidad: revisión de antecedentes y perspectivas de alumnos. Polifonías. Revista de Educación, (IV) 97-119.

Molina, M. E. (2015) Argumentar por escrito para aprender en dos disciplinas universitarias: alcance de las condiciones didácticas y las condiciones docentes. Tesis de doctorado en Humanidades (área Letras). Facultad de Filosofía y Letras. Universidad Nacional de Tucumán.

Molina, M. E., y Carlino, P. (2013). Escribir y argumentar para aprender: las potencialidades epistémicas de las prácticas de argumentación escrita. Revista Texturas, 13(1). 85

Molina, M. E., y Padilla, C. (2013). Argumentar en dos disciplinas universitarias: una aproximación toulminiana a la argumentación académica en Letras y Biología. Revista Logos, 23(1), 65-82.

Morales, G.; Sensevy, G y Forest, D. (2017) About cooperative engineering: theory and emblematic examples. Educational Action Research, 25:1, 128-139, Disponible en: http://dx.doi.org/10.1080/09650792.2016.1154885

Morin, E. (1990) Introducción al pensamiento complejo. Barcelona. Gedisa.

Morin, E. (2001). Los siete saberes necesarios para la educación del futuro. Buenos Aires. Nueva Visión.

Mortimer, E., y Scott, P. (2003). Making meaning in secondary science classrooms. Buckingham, UK: Open University Press.

Nelson, N. (2001). Writing to learn: One Theory, Two Rationales. En Tynjälä, P., Mason, L. y Lonka, K. (Eds.), Writing as a Learning Tool: Integrating Theory and Practice. Dordrecht, Boston \& London: Kluwer Academic Publishers.

Newell, G. (1984). Learning from writing in two content areas: A case study/protocol analysis. Research in the Teaching of English, 18, 265-287

Olson, D. (1998). El mundo sobre el papel. Barcelona. Gedisa.

Ogborn J., Kress, G., Martins, I. y Mc Gillcuddy, K. (1998) Formas de explicar. La enseñanza de las ciencias en secundaria. Madrid. Santillana.

Ong, W. (1982). Orality and literacy. Nueva York: Methuen.

Osborne, J. (2010). Arguing to Learn in Science: The Role of Collaborative. Critical Discourse Science, 23(10), 463-466.

Osborne, J., Erduran, S. y Simon, S. (2004a). Enhancing the quality of argument in school science. Journal of Research in Science Teaching 41(10), 994-1020.

Osborne, J., Erduran, S. y Simon, S. (2004b). Ideas, evidence and argument in science. London: Nuffield Foundation.

Padilla, C. (2004). La comprensión de textos académicos en estudiantes universitarios: el caso de la dimensión polémica, RASAL (Revista de la Sociedad Argentina de Lingüística), no 2, 45 66.

Padilla, C. (2008). ¿Enseñar a argumentar e la universidad? ¿Por qué y para qué? Primeras Jornadas Latinoamericanas de Lectura y Escritura Críticas de la cátedra UNESCO. Tucumán: Universidad Nacional de Tucumán,

Padilla, C. (2012). Escritura y argumentación académica: trayectorias estudiantiles, factores docentes y contextuales. Magis, 5(10), 31-57.

Padilla, C., Avila, A. y Lopez, E. (2007). ¿Cómo preparamos a los estudiantes universitarios para abordar textos académicos? Lectura y escritura: caminos para la construcción del mundo. Editorial Científica Universitaria de la UNC. Cátedra UNESCO, Catamarca. 
Pereira, C. y Di Stefano, M. (2003). La enseñanza de la argumentación en el nivel superior. Propuestas y experiencias de trabajo en los niveles de grado y de posgrado. En García Negroni, M.M. (Coord.), Actas del Congreso Internacional de Argumentación. Buenos Aires: Universidad Nacional de Buenos Aires.

Pérez Echeverría, M.; Postigo, Y; López Manjón. A. y Marín C. (2009). Aprender con imágenes e información gráfica. Capítulo VIII en Pozo, J.I. Psicología del aprendizaje universitario: La formación de competencias. Madrid: Ediciones Morata. Disponible en: https://books.google.com.mx/books?id=v5lyAgAAQBAJ\&printsec=frontcover\&hl=es\#v=onepage $\& q \& \mathrm{f}=\mathrm{false}$

Peters, J. (1987) La reflexión, un concepto clave en la educación del profesor, en Revista de Educación, $\mathrm{N}^{\circ} 282$. MEC. Madrid.

Porlán, R.; Martín del Pozo, R. ; Martín, J. y Rivero, A. (2001) La relación teoría-práctica en la formación permanente del profesorado. Informe de una investigación. Sevilla. Díada Editora.

Portilla, C. y Teberosky, A. (2010) Aprender vocabulario por medio de la producción de textos y la generación de tablas de doble entrada. Una experiencia en preescolar. Lectura y Vida. Revista latinoamericana de lectura. Año XXXI- Número 1- Marzo 2010. Buenos Aires.

Prain, V. y Hand, B. (1999). Students perceptions of writing for learning in secondary school science. Science Education, 83, 151-62.

Prior, P. y Bilbro, R. (2012). Academic enculturation: Developing literate practices and disciplinary identities. En Castelló, M. y Donahue, C. (Eds.), University writing: Selves and texts in Academic Societies (pp. 20-31). Bingley: Emerald.

Rickenmann, R. (2006). Metodologías clínicas de investigación en didácticas y formación del profesorado: un estudio de los dispositivos de formación en alternancia. Actas del Congreso Internacional de investigación, educación y formación docente, Universidad de Antioquia, Medellín, Colombia, 30 de agosto al 2 de septiembre 2006.

Rickenmann, R. (2007). Investigación y formación docente: Dispositivos de formación y elementos para la construcción de una identidad profesional. EccoS revista científica, juliodiciembre, vol 9 número 002. Centro Universitario Nove de Julho. Pp 435-463. Sao Paulo Brasil.

Rivarosa, A.; De Longhi , A. y Astudillo C. (2011) Dilemas sobre el cambio de teorías: la secuenciación didáctica en una noción de alfabetización científica. Revista Electrónica de Enseñanza de las Ciencias. Vol № $10, N^{\circ} 2,368-393$

Roni, C. y Borches, E. (2013) Enseñar a leer imágenes para aprender Biología. En Cuarto Encuentro de Innovadores Críticos. Las prácticas reflexivas en la enseñanza de las ciencias Biológicas.Caminos innovadores para la inclusión con calidad. Organizado por ADBia (Asociación de Docentes de Biología de Argentina). 21 al 23 de noviembre 2013. Buenos Aires.

Roni, C.; Alfie, L. y Borches, E. (2012) Entramar lectura, escritura y animaciones de you tube, una secuencia didáctica sobre síntesis de proteínas. Actas III Jornadas de Enseñanza e Investigación Educativa en el campo de las Ciencias Exactas y Naturales. Facultad de Humanidades y Ciencias de la Educación. Universidad Nacional de La Plata. http://jornadasceyn.fahce.unlp.edu.ar/iii-2012

Rose, Steven (2001) Trayectorias de vida- Biología, libertad y determinismo. Ediciones Granica. Barcelona.

Russell, D. (1990). Writing Across the Curriculum in Historical Perspective: Toward a Social Interpretation. College English, 52: 52-73.

Russell, D. (1994). American origins of the writing-across-the-curriculum movement. En Bazerman, C., and Russell, D., Eds. (pp. 3-22). Landmark essays in writing across the curriculum. Davis, CA: Hermagoras Press.

Russell, D. (2013). Contradictions regarding teaching and writing (or writing o learn) in the disciplines: What we have learned in the USA. Revista de Docencia Universitaria, 11(1), 161-181.

Russell, D., Lea, M., Parker, J., Street, B., y Donahue, T. (2009). Exploring notions of genre in 'academic literacies' and 'writing across the curriculum': approaches across countries and 
contexts. En Bazerman, C., Bonini, A. y Figueiredo, D. (Eds.), Genre in a Changing World. Perspectives on Writing. (pp. 459-491). Colorado: WAC Clearinghouse/Parlor Press

Ruthven, K.; Laborde, C.; Leach, J. y Tiberghein, A. (2009). Design Tools in Didactical Research: Instrumenting the epistemological and cognitive aspects of the design of teaching sequences. Educational Researcher, Vol.38, № 5. pp 329-342

Sanmartí, N. (2005) La unidad didáctica en el paradigma constructivista. En: Couso, D.; Badillo, E.; Preafán, G. y Adúriz Bravo, A. Capítulo 1. Unidades de Ciencias y Matemáticas. Bogotá. Editorial Magisterio.

Sensevy, G. (2007) Categorías para describir la acción didáctica. Capítulo traducido con autorización de los autores tomado del libro Sensevy, G. y Mercer, A. (2007). Agir ensemble: láction didactique conjointe du professeuret des éleves. Rennes:PUR. Traducción de Juan Duque y revisión de Renée Rickenmann.

Sensevy, G. (2009). Outline in a Joint Action Theory in Didactics. En Proceedings of CERME 6, January 28th-February 1st 2009, Lyon, France. www.inrp.fr/editions/cerme6

Sensevy. (2012) About the Joint Action Theory in Didactics. Zeitschrift für Erziehungswissenschaft Volumen 15, Issue 3, págs. 503-516. Disponible en: http://python.espebretagne.fr/sensevy/ZFE\%20Sensevy\%202012\%20JATD.pdf

Sensevy, G. (2014) Characterizing teaching effectiveness in the Joint Action. Theory in Didactics: an exploratory study in primary school, Journal of Curriculum Studies, 46:5, 577-610. Disponible en: http://dx.doi.org/10.1080/00220272.2014.931466

Sensevy, G., Tiberghien, A., Santini, J., Laube, S.,\& Griggs, P. (2008). An epistemological approach to modeling: Cases studies and implications for science teaching. Science Education, 92(3), 424-446

Sensevy, G., Forest, D., Quilio, S. y Morales, G. (2013). Cooperative engineering as a specific design-based research. ZDM. The International Journal on Mathematics Education. Vol 45 - 13. 1031-1043. Diciembre 2013. Disponible en: http://blog.espe-

bretagne.fr/sensevy/ZDM\%20Sensevy\%20et\%20al\%202013\%20Cooperative\%20Engineering.p $\underline{\mathrm{df}}$

Sensevy, G.; Gruson, B. y Forest, D. (2015) On the Nature of the Semiotic Structure of the Didactic Action: The Joint Action Theory in Didactics Within a Comparative. Interchange (2015) 46:387-412. Disponible en:

https://www.researchgate.net/publication/284067783_On_the_Nature_of_the_Semiotic_Structur e_of_the_Didactic_Action_The_Joint_Action_Theory_in_Didactics_Within_a_Comparative_App roach

Sirvent, M.T. (2008) Educación de adultos: investigación, participación, desafíos y contradicciones. Buenos Aires. Miño y Dávila.

Sirvent, M.T. (2010) Relaciones de teoría y metodología en investigación educativa. Controversias y Concurrencias Latinoamericanas. №3. Año 2. Octubre 2010.

Sirvent, M.; Monteverde, A.; Clerici, C.; Peruzzo, L.; Agulló, M. (2016). Algunas reflexiones acerca del proceso de formación en investigación de estudiantes de grado y posgrado. $V$ Encuentro Latinoamericano de Metodología de las Ciencias Sociales, 16 al 18 de noviembre de 2016, Mendoza, Argentina. Métodos, metodologías y nuevas epistemologías en las ciencias sociales: desafíos para el conocimiento profundo de Nuestra América. EN: Actas (2016). Ensenada: Universidad Nacional de La Plata. Facultad de Humanidades y Ciencias de la Educación. Centro Interdisciplinario de Metodología de las Ciencias Sociales. Disponible en: http://www.memoria.fahce.unlp.edu.ar/trab_eventos/ev.8588/ev.8588.pdf

Solé, I y Castells, N. (2004) Aprender mediante la lectura y la escritura. ¿Existen diferencias en función del dominio disciplinar? Lectura y Vida. Año $25 \mathrm{~N}^{\circ}$ 4, 6-17

Street, B. (1995). Social literacies: Critical approaches to literacy in development, ethnography and education. London: Longman.

Sutton, C. (2003). Los profesores de ciencias como profesores de lengua. Revista Enseñanza de las Ciencias, 21 (1), 21-25. 
Sutton, C. y Caamaño, A. (1997) Ideas sobre la ciencia e ideas sobre el lenguaje. Alambique № 12. Grao. Barcelona.

The Design-Based Research Collective (2003) Design-Based Research: An Emerging Paradigm for Educational Inquiry. Educational Researcher, Vol $N^{\circ} 1$, pp. 5-8. Disponible en: http://www.designbasedresearch.org/reppubs/DBRC2003.pdf

Tiberghien, A.; Cross, D. y Sensevy, G. (2014) The Evolution of Classroom Physics Knowledge in Relation to Certainty and Uncertainty. Journal of Research in science teaching.

Tiberghien, A. (2016). How does knowledge live in a classroom? In ESERA 2013 Book of Selected Papers. (pp. 11-27). Dordrecht: Springer. Disponible en: http://www.springer.com/us/book/9783319200736

Thaiss, C. y Porter, T. (2010). The State of WAC/WID in 2010: Methods and Results of the U.S. Survey of the International WAC/WID Mapping Project. College Composition and Communication, 61(3), 534-570.

Torres, M. (2008) Leer para aprender historia: el lugar del texto en la reconstrucción de un contenido. Lectura y vida. Revista Latinoamericana de Lectura (Buenos Aires), año 29, núm 4, 20-29

Torres, M. y Larramendy, A. (2010): Ler e escrever para aprender História en: Projeto Revista de Educação: escrita, Vol. 10, N 12, 2010, Porto Alegre, Brasil. ISSN 1516-6910

Tynjälä, P.; Mason, L. y Kirsti L., (2001), Writing as a learning tool: an introduction, en Writing as a learning tool. Integrating theory and practice, The Netherlands, 2001, Kluwer Academia Publishers.

Vasilachis, I. (2007) La investigación cualitativa. Capítulo 1 en Estrategias de investigación cualitativa. Vasilachis de Gialdino, (coord.). Buenos Aires. Gedisa.

Vázquez, A. y Miras, M. (2004). Cómo se representan estudiantes universitarios las tareas de escritura. Ponencia publicada en las Actas Electrónicas de la Reunión Internacional Mente y Cultura: Cambios representacionales en el aprendizaje, organizada por el Centro Regional Universitario Bariloche de la Universidad Nacional del Comahue y por la Facultad de Psicología de la Universidad Autónoma de Madrid, 11-13 de febrero, Bariloche.

Vázquez, A., Jakob, I., Pelizza, L. y Rosales, P. (2003). Enseñar a escribir en la universidad. Análisis de los cambios en las estrategias de producción de textos. Ponencia presentada y publicada en las Memorias de las X Jornadas de Investigación en Psicología, Tomo I, pp. 322325. Facultad de Psicología de la Universidad de Buenos Aires, 14-15 de agosto, Buenos Aires.

Vázquez, A.; Rosales, P.; Jakob, I. y Astudillo, M. (2005). Enseñar y aprender a escribir en la universidad, en Memorias de las XII Jornadas de Investigación. Primer Encuentro de Investigadores en Psicología del MERCOSUR, Tomo I, Buenos Aires, 2005, Universidad de Buenos Aires.

Vázquez, A, y Jakob, I. (2007) La escritura y el aprendizaje en el aula universitaria: componentes cognitivos y didácticos. Innovación Educativa, núm., 7 (36), 2007, pp. 21-35

Vázquez, A.; Jakob, I.; Pelizza, L. y Rosales, P. (2009) Enseñar y aprender en la universidad: saberes, concepciones y prácticas de escritura en contextos académicos. Innovación Educativa, vol. 9, núm. 49, octubre-diciembre, 2009, pp. 19-35. Instituto Politécnico Nacional- Distrito Federal, México. Disponible en: http://www.redalyc.org/articulo.oa?id=179414968004

Wellington, J, y Osborne J. (2001) Language and Literacy on Science Education. Open University Press. Buckingham Philadelphia. Oxford.

Wells, G. (2001). Dialogic Inquiry: Towards a Sociocultural Practice and Theory of Education. New York: Cambridge University Press.

Wickman, P.O. y Ostman, L. (2002) Learning as discourse change: a sociocultural mechanism. Wiley Periodicals, Inc Sci Ed 85: 1-23,2002. 
